\title{
Landscape Sub(Vert.)Urbanity
}

a model for integrating gardens, as an architectural device, into higher density housing to encourage New Zealanders to live in the inner city 
Landscape Sub(Vert.)Urbanity

a model for integrating gardens, as an architectural device, into higher density housing to encourage New Zealanders
to live in the inner city

Annabel Fraser A 220 point thesissubmitted to the School of Architecture, Victoria for the degree of Masters of Architecture [Professional]

Victoria University of Wellington 
Acknowledgements

Thank you firstly to Kerstin Thompson, my continually inspirational and insightful supervisor, this project would

On a whole other scale, my greatest appreciation must go to the people of my life - my friends, family, lecturers and ever humorous (cum helpful) peers - who over the with learning, laughter and love:

I am ever grateful. Thank you. 
Landscape Sub(Vert.)Urbanity

a model for integrating gardens, as an architectural device, into higher density housing to encourage New Zealanders to live in the inner city

Landscape:

1. (noun) all the visible

features of an

area of land, often
considered in terms

considered in terms
of their aesthetic

appeal.

2. (verb) to improve the

1. (prefix) situated

under or beneath.

2. (verb) replace or be
replaced; substitute.

Vert:

1. (adjective) a dark

bright green.

2. (abbreviation)

Urbanity:

(noun) the quality or

(noun) the quality or
state of being urban
Urban:

1. of, pertaining to or designating a city or town.

2. living in a city.

3. characteristic of or accustomed to

Subvert:

1. (verb) to overthrow (something established or
existing). Sub(vert)urbanity:

1. (adjective) inhabiting, or being in a suburb or the suburbs of a city or

2. (adjective) characteristic of a
suburb or suburbs. 

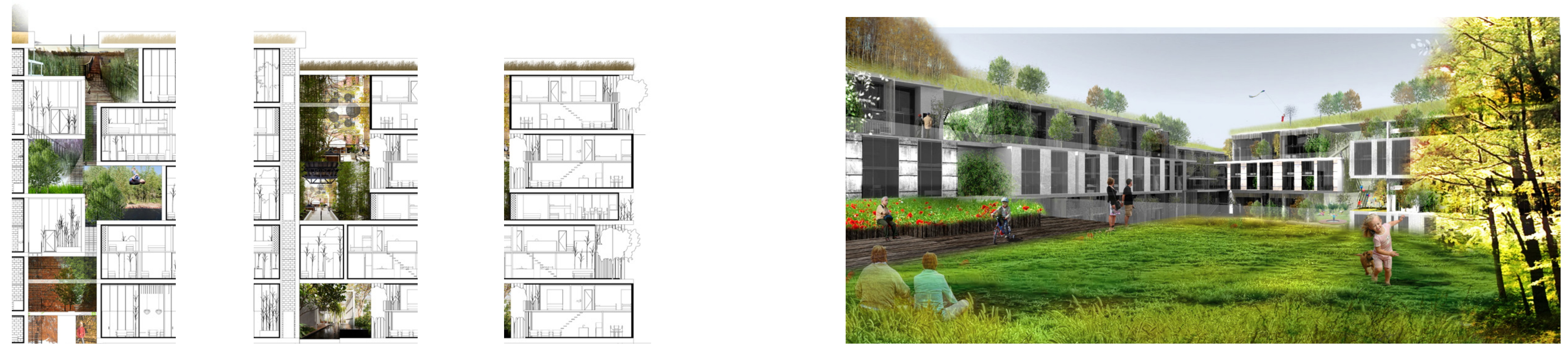


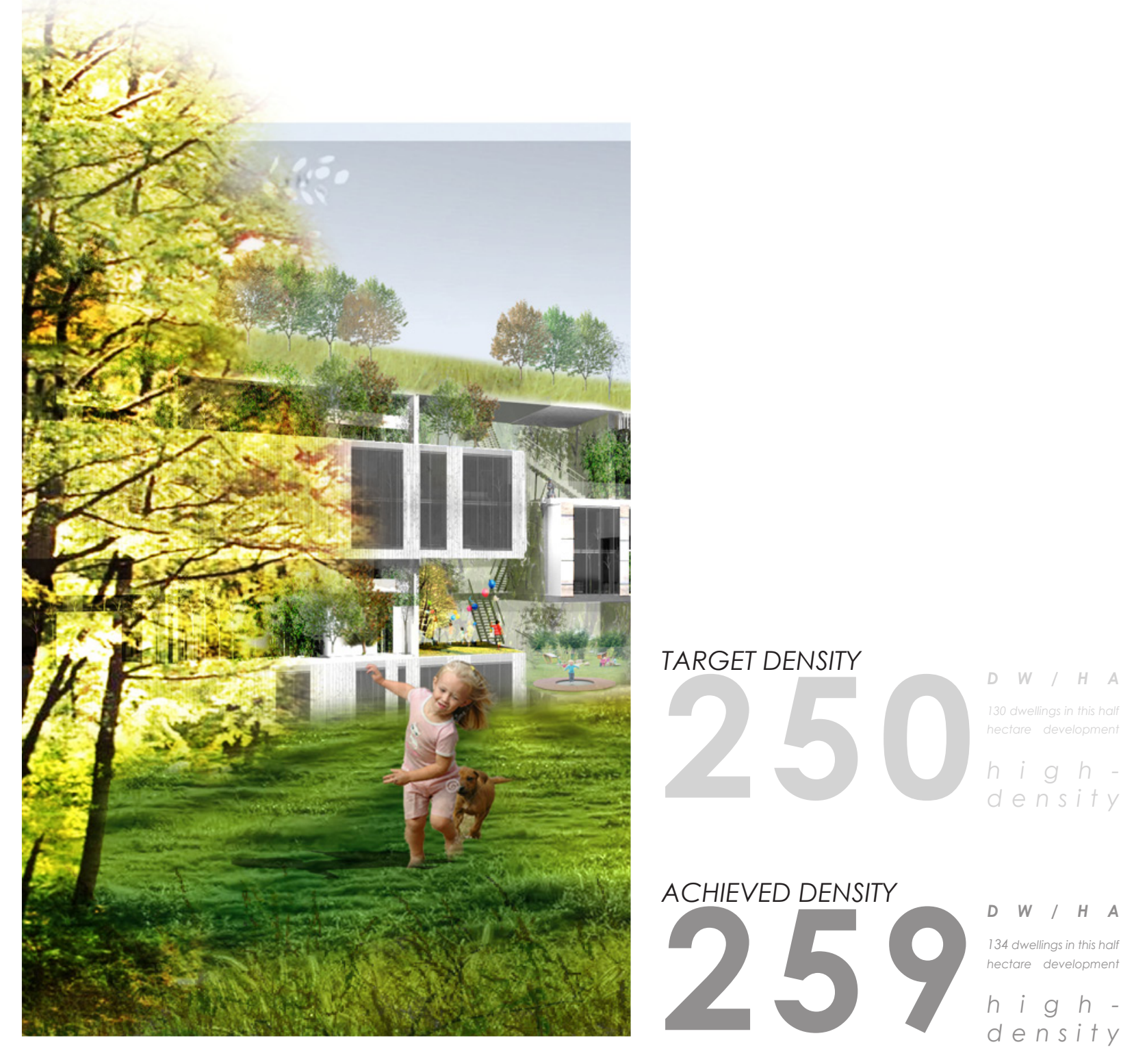

Abstract

ew Zealanders continue to resist higher density housing as a way of living. The detached house in the suburbs remains the preferred housing choice for most.

This proposal addresses the key attributes required for higher density living adoption as identified by the Centre for Housing Research Aotearoa New Zealand (2011). Furthermore, this central Wellington proposal includes additional design features that increase the desirability of this type of housing to the suburban market.
Combined, these and other drivers create a new typology of higher density housing in which vertical and other garden types bring a verdant living option to inner city Wellington.

Key considerations include creating high levels of amenity: gardens, solar access and privacy to produce a vertical neighbourhood that balances collective and private amenity.

The proposal provides three housing typologies (maisonettes, terraces, park 


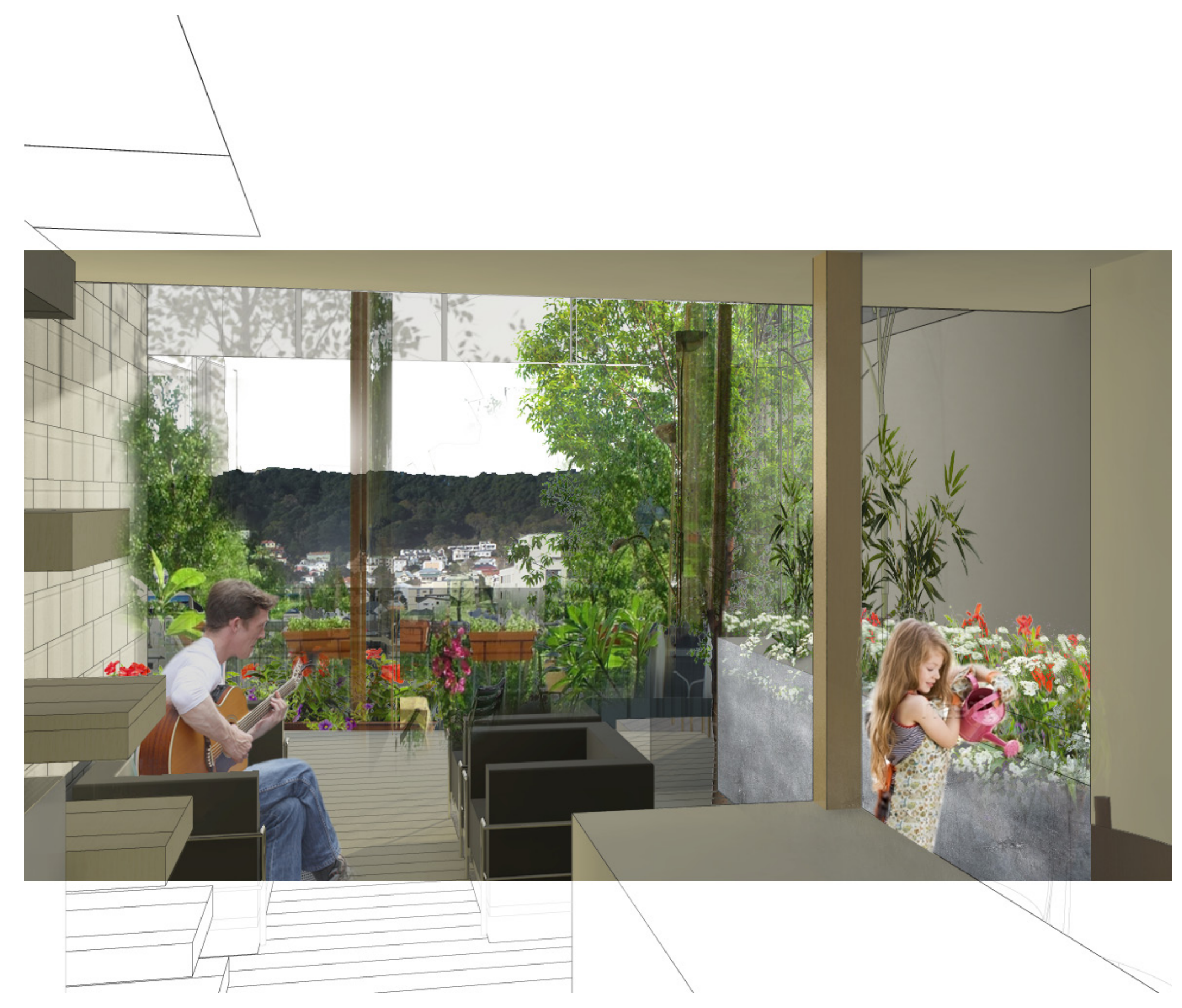

houses) to accommodate household diversity to target various stages of the family cycle.

This inner city proposal also demonstrates how public amenity access can be used to offset the (perceived) loss of amenity when moving from the suburbs. By drawing from the public amenityrich city, the need for private amenities is minimised. Furthermore, just as the surrounding city contributes amenity to these dwellings, this proposal illustrates that this kind of development can in turn contribute back to the city. 


\section{Directory of Content}

\begin{tabular}{|c|c|c|c|}
\hline SEARCHING FOR A QUESTION & 17 & RESEARCHING AN ANSWER & 21 \\
\hline Introduction & 19 & Design Test Three & 93 \\
\hline 0.1 Methodology & 27 & 3.0 Case Study: 8 House & 95 \\
\hline 0.2 Site Selection & 35 & 3.1 Common Green Network & 101 \\
\hline 0.3 Icon in Architecture & 43 & 3. 1 A Design Test Three A (3(A)) & 103 \\
\hline 0.4 Case Study: Chews Lane & 45 & 3.2 Case Study: Jeanne Hachette & 109 \\
\hline Design Test One & 51 & 3.3 Case Study: Mondrian Apartments & s 115 \\
\hline 1.0 Case Study: Porter House & 53 & 3.4 Design Test Three $B(3(B))$ Review & 121 \\
\hline 1.1 Design Test One Review & 59 & Design Test Four & 27 \\
\hline Design Test Two & 71 & 4.0 Landscape Taxonomy & 129 \\
\hline 2.0 Case Study: Sanctum Apartments & 73 & 4.1 Design Test Four Review & \\
\hline 2.1 Design Test Two Review & 79 & & \\
\hline 2.2 Question Identified & 89 & & \\
\hline
\end{tabular}
Final design test PRESENTATION
Design Test Five
5.0 Design Test Five Review
5.1 Final Design Presentation
5.2 Linking Landscapes
5.3 Landscape Typologies
5.4 Unit Typologies
5.5 Vision For Living

3

149

151

155

187
RESEARCH POSITION
6.0 Further Research Directions
7.0 Typological Ties
8.0 Conclusion

Selected Bibliography

Figure Reference List

Appendix 


\section{Paokl 1}

SEARCHING FOR A QUESTION What orchitecture can solve: 


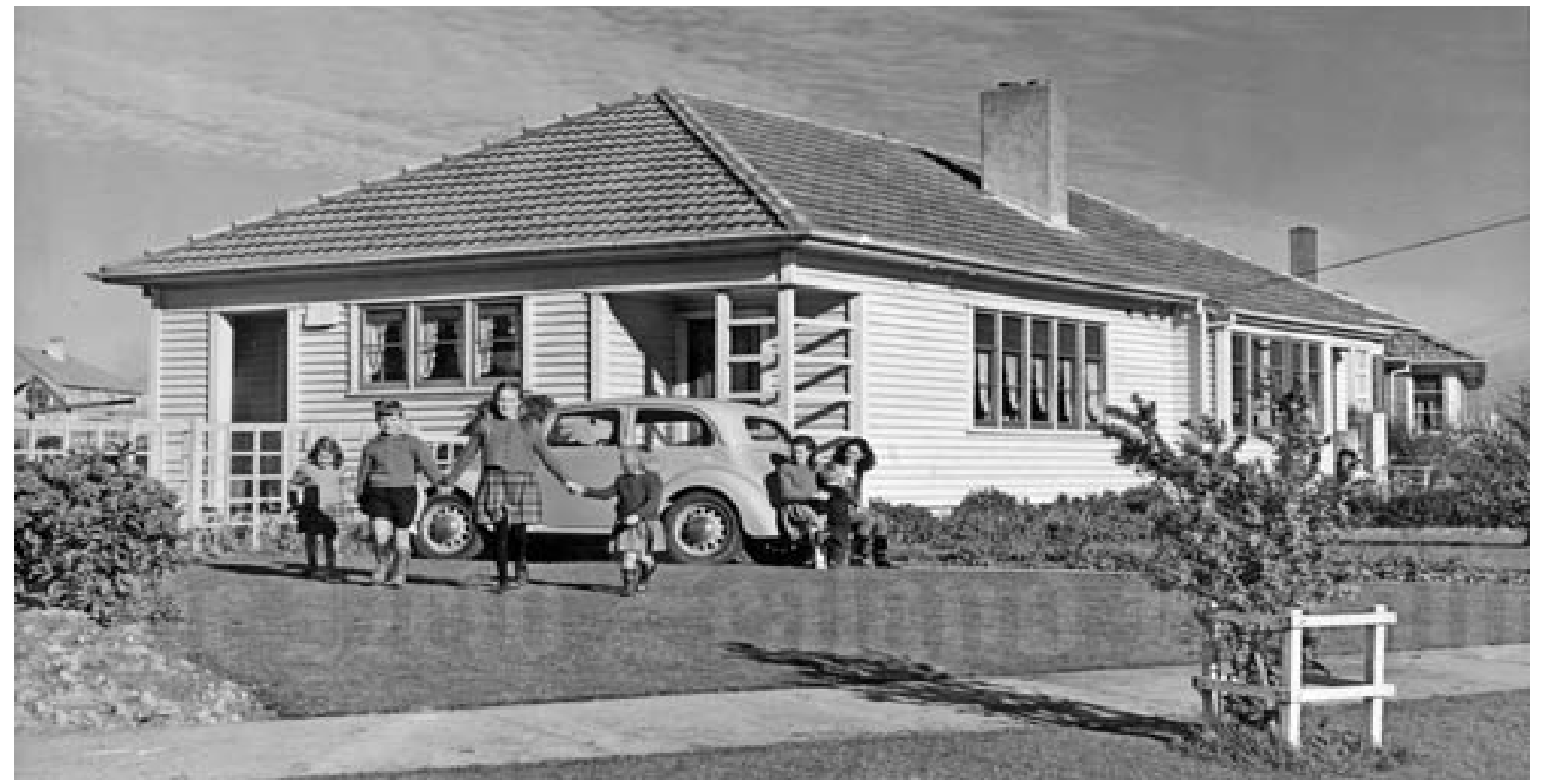

Single detached houses are the preferred housing type of New Zealanders. This preference is rooted in the 'kiwi quarter acre dream'; part of a complex home ownership, child rearing and cultural condition present in New Zealand (CHRANZ, 2011, p. 3). This has led to a continued resistance to higher density housing as an alternative to suburban living. This results in the sprawl of New Zealand cities, causing problematic and inefficient use of land and municipality resources, un-walkable neighbourhoods and disjointed localities (Lindstrom \& Bartling, p. 5).

Higher density cities are capable of countering these problems but can only do so if the resistance to them is answered. It is a common 'kiwi' perception that it is not possible to raise a family in an urban environment. However, through the considered design of structures and andscape, architecture can begin to address this perception.

By designing high density buildings with integrated landscape elements this proposal seeks to illustrate that it is possible to create suburban like desirability in urban situations. This is achieved by balancing the public, common and private amenities of inner city living against the private amenity afforded by the suburbs. 
Primary Literature Reference: Improving the Design, Quality and Affordability of Residential Intensification in New Zealand (CHRANZ, 2011)

"New Zealanders have a long standing

on individual sections." (CHRANZ P. it
Originally this research focussed on confronting the design quality of many higher density developments. The remnants of this are visible in the challenging density target that seeks to recognise New Zealand's developer driven market, and aims to give the scheme an element of plausibility.

A target density of 250 dwellings/hectare
(DW/HA) was established based upon international definitions of high density and remained a fix variable in every design test (Mozas \& Fernández, p. 6). In comparison to New Zealand, where over 50 DW/HA gross neighbourhood is defined as high density (Auckland Regional Growth Forum, 2003), this target seeks to prove the design through an extreme scenario.

\section{Domain attributes that require addressing}

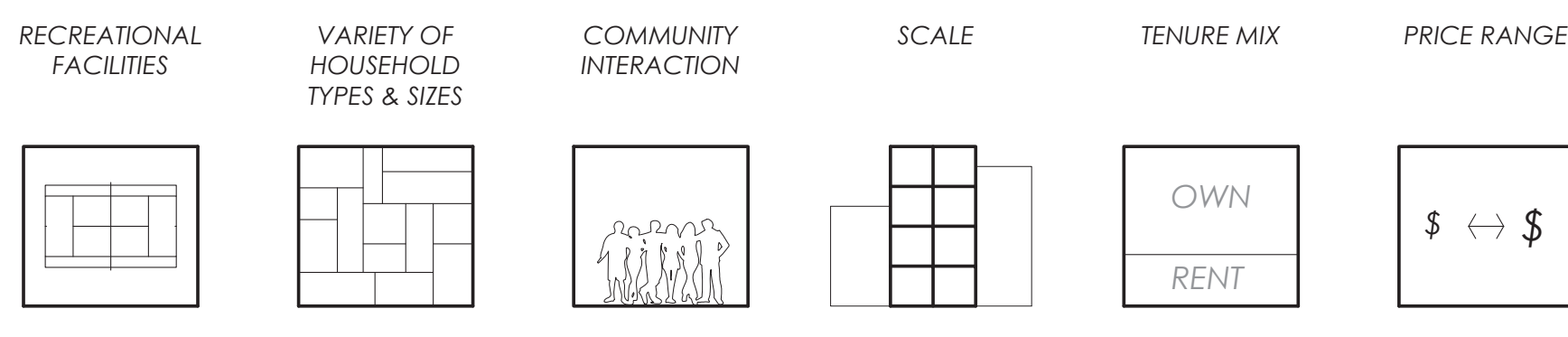

Complex / Exterior attributes that require addressing

EASILY

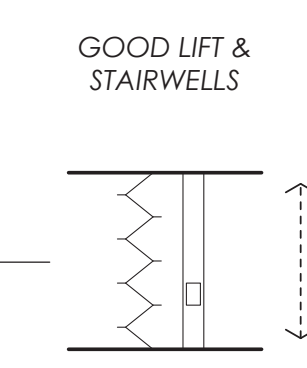

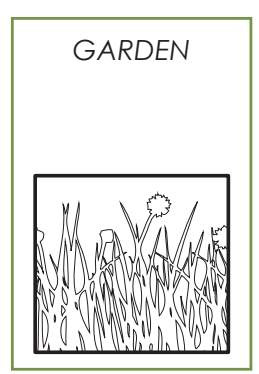

VISUAL
APPEAL

SECURITY
AND SAEETY

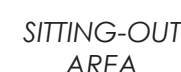

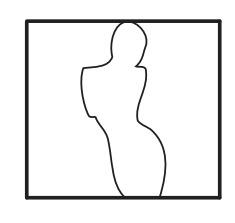

Figure 0.0 .02

need to be

addressed.

Adapted from

Table One:
Desirable Attributes

Desirable Attibutified by
Ident

Medium Density

Housing Residents
Domain attributes that require addressing

1. Recreational facilities,

including parks
2. Scale: Conceivable

CHRANZ Domain Definition:

"Encompasses the

day-to-day social

relations are formed

and regular or lower

order transactions

take place. This
corresponds broadly

corresponds broac

neighbourhood

and may include

elements of the

medium density

(p. 1 )

ingers? number of households in the development

3. Community interaction: Networks and strength of ties/Ethnic diversity nationalities

4. Varied household types and sizes

5. A price range

6. Tenure mixes
Complex/Exterior attributes that require addressing

1. Good stairwell and lift spaces in apartments

2. Safe access roads/ Easily accessible

3. Appropriate trees and gardens in places

4. Visual appeal

5. Security and safety

6. A sitting-out ared 
Sanctuary attributes that require addressing
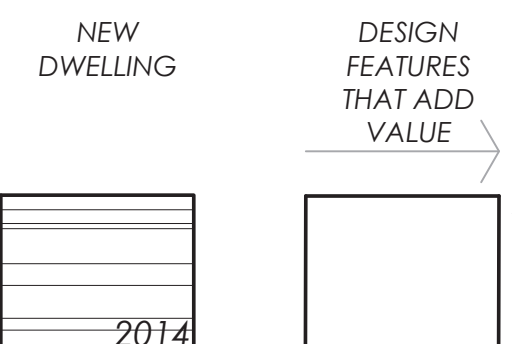

QUALITY
MATERIALS

FIAURES AND
FITINGS

$\stackrel{\text { LOW }}{\text { MAINTENANCE }}$
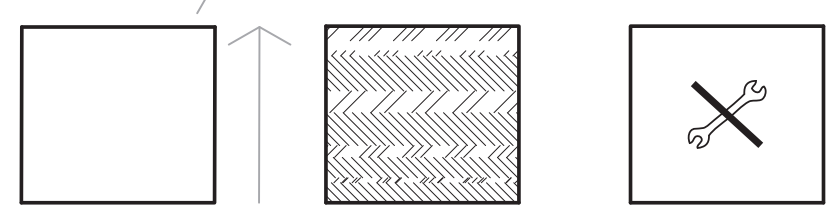

RATIO OF
BATHROOMS
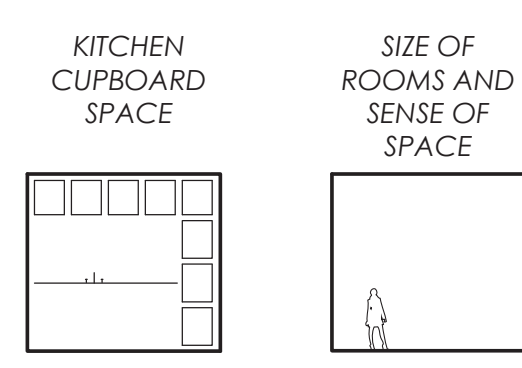

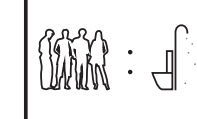
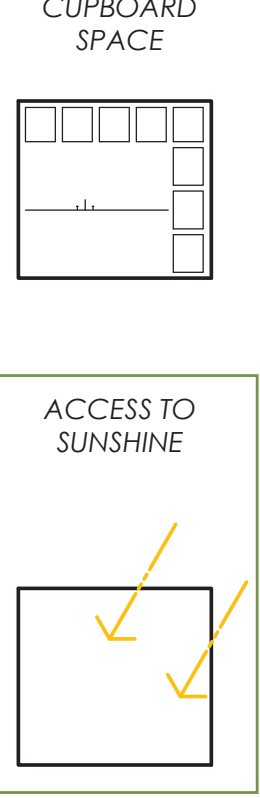

WELL
INSULATED
AND WARM
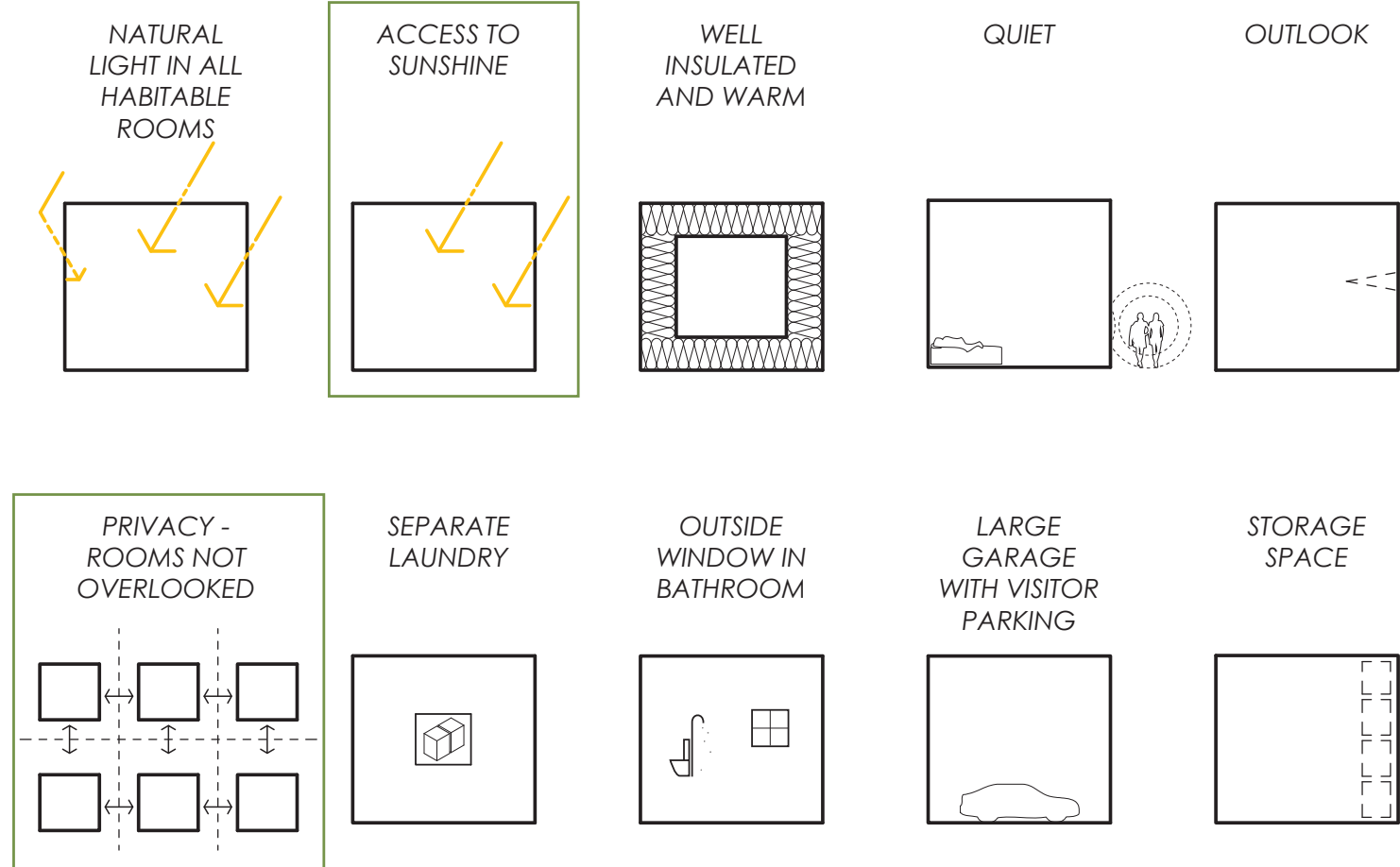

OUTSIDE

LARGE
GARAGE

GAREE
WITH VISTO
PARKING

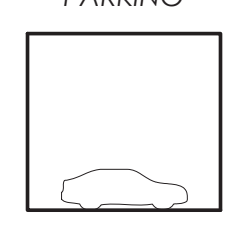

STORAGE

d) $\boxplus$

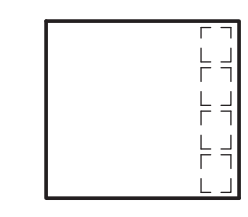

In 2011 the Centre for Housing Research Aotearoa New Zealand (CHRANZ) produced a report outlining 29 key attributes that need to be addressed before New Zealanders consider adopting medium or higher density housing solutions (CHRANZ, 2011, p.

VI). These attributes, illustrated on the opposite page, have been used a primary and defining parameters to

Figure 0.0.03 Attributes that need to be Adapted from Adapted from
Table One: Desirable Attributes Identified by Mousing Residents drive design tests (Figure 0.0.02 - Figure 0.0.03). Of these, three were prioritised after design test two to structure and drive design-research decision making: garden, sunlight and privacy.

Furthermore, six additional design considerations were identified as worthy of address in the design proposal, aiming to give the scheme an uncommon CHinition:

"Refers to the

dwelling, and may

the relationship

of the dwelling to

the complex and

the immediate

(p. i)

\section{Sanctuary attributes that require addressing}

1. A new dwelling

10. Well insulated and warm

Design features that add 11. Quie value

3. Quality fixtures and

fitting

4. Low maintenance

5. Ratio of bathrooms

6. Kitchen and bathroom cupboard space

7. Size of rooms and a sense of space

8. Natural light in all habitable areas

9. Access to sunshine
12. Nice outlook

3. Privacy, rooms not overlooked

14. Separate Laundry

5. Outside window in bathroom

6. Large garage with visite parking spaces

17. Storage space 
"Home buyers want sections for children,

a spacious 3-4 bedroom

\section{0}

Target density established from A\&T's

as

as 'high density' (p. o)
Additional Design Attributes

1. Civic contribution

2. Liveable

3. Relationship to street

4. Iconic

5. Kiwi

6. Flexible generosity: civic contribution, liveable, relationship to street, iconic, kiwi and flexible (Figure 0.0.04). Together with the 29 CHRANZ attributes, iterative designs tests are developed to provide gardens, other amenities and housing choice to families living at high densities.

Additionally, this proposal draws upon and critiques applicable design research within the discipline using New Zealand and international built examples as case studies. These are introduced throughout the thesis as they arise between design tests. They also relate to the final part of this exegesis where this research is contextualised with further reflections and ties are made to similar existing models.
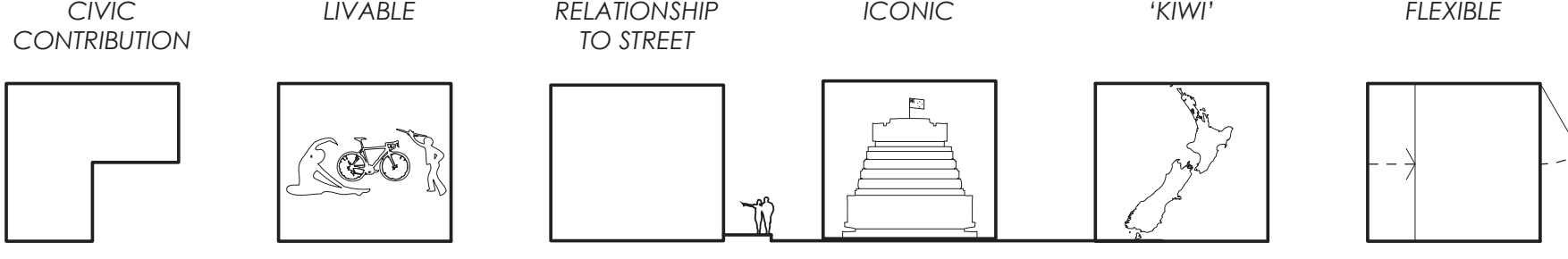

Primarily this research aims to be propositional about the merits of city living in order to suggest an alternative to encourage suburbanites into living in the inner city. 
0.1 Methodology

This thesis employs a process of designled research in which multiple generated design solutions are tested against a framework, then reworked and resolved

to develop a comprehensive design solution (Downton, 2003). This process was followed consistently throughout with each iteration accompanied by a reflection on its value.

Extending over three design phases and one presented in respective 'parts' (Figure 0.1 .01 - Figure 0.1.03). The design phase encompass five iterative design tests an jix case studies, all used to cross critique. which further develop solutions and contextualise the research within current knowledge of the discipline.
Literature is a fundamental driver of these design iterations, both written and built. Prior to commencing this research, the primary text by CHRANZ, "Improving the Design, Quality and Affordability of Medium Density Housing in New Zealand' was examined to deduce the aforementioned 29 key design checks.

The CHRANZ text, in combination with the $250 \mathrm{DW} / \mathrm{HA}$ density target and site conditions, established a framework for the design process. This framework was adapted when problems with initial design tests were identified during phase one, leading to a review of both the design and testing framework. Framework revisions were considered against New Zealand and international case study reflections to gain an understanding of 


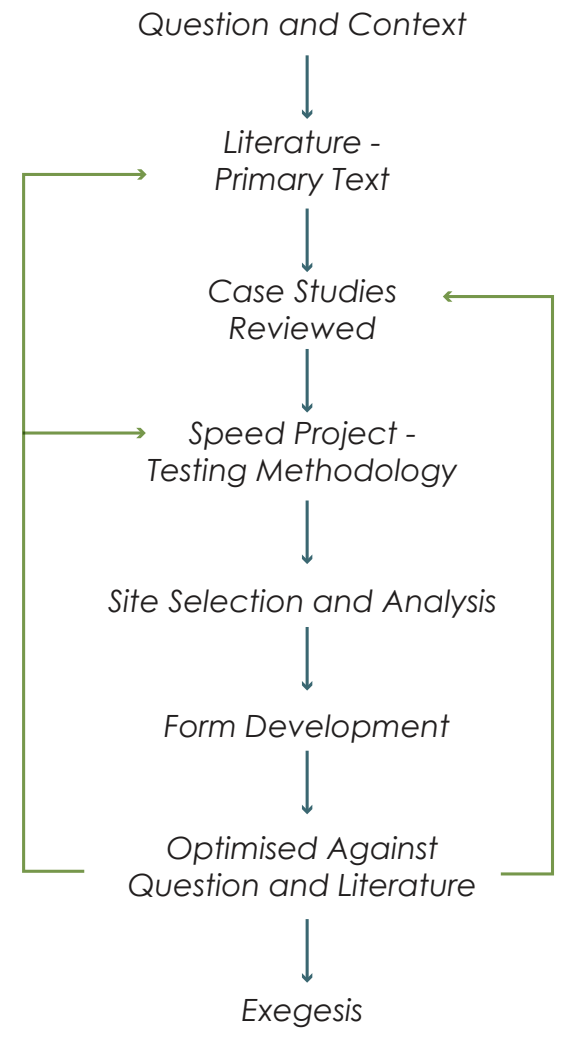

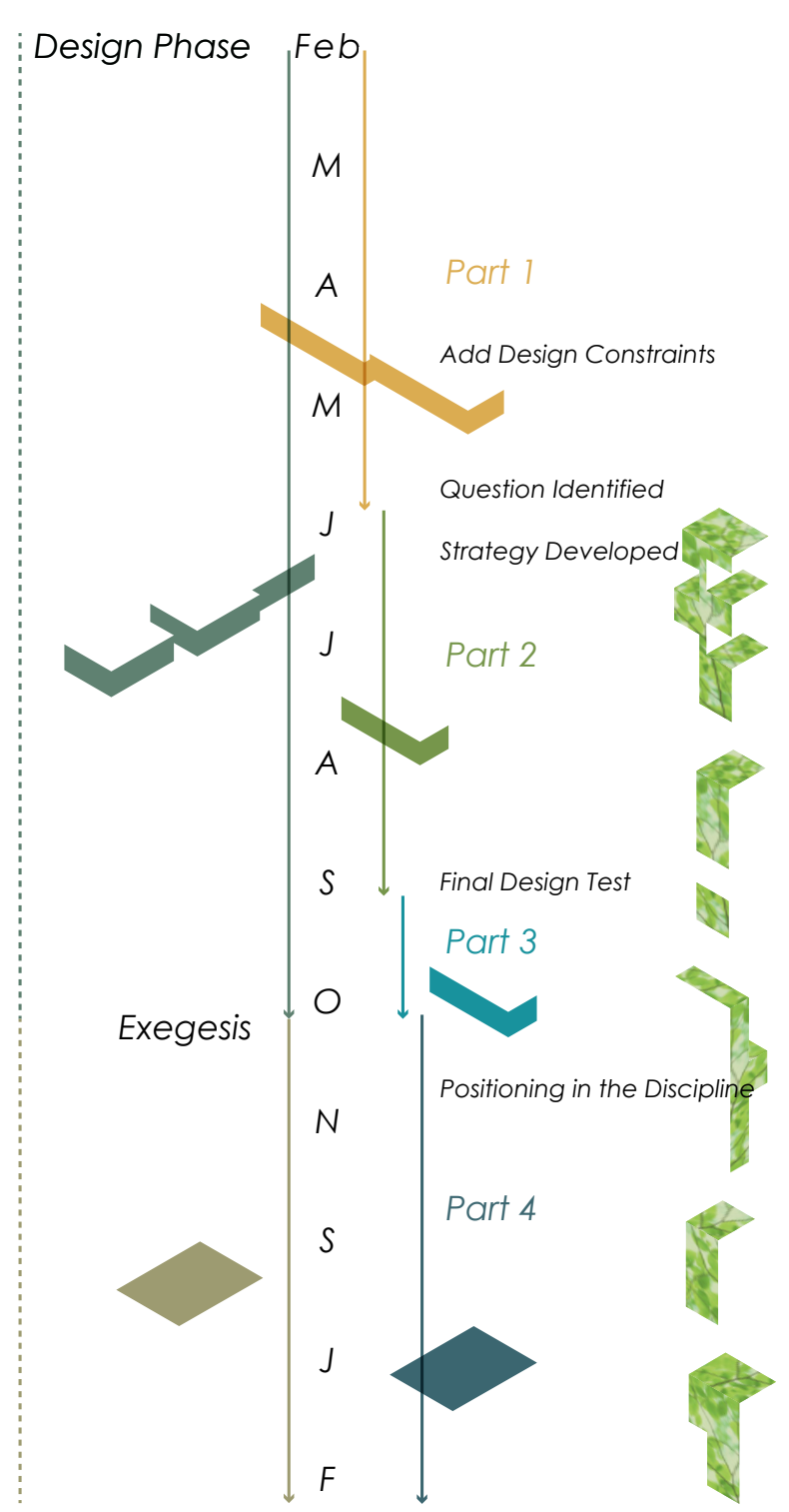

Figure 0.1.01

Original

Methodology,
as expected at

beginning of thesis

$\longleftarrow$

Figure 0.1.02

Methodology

developed over

$\longleftarrow$

Figure 0.1.03 Thesis time line summary practice solutions. As a result additional design constraints were added, namely six further attributes and three amenity priorities, resulting in the development of a robust framework to design within.

Phase one was catalysed by a 'speed project' in which the 250 DW/HA density and 29 key attributes were first grappled with; although on a different centra Wellington site (Figure 0.1.04 - Figure 0.1.09)

In phase two further design tests were used to developed strategies and solutions within the framework. This led into phase three, the final design phase, which is primarily the presentation of the design's final evolution.

The final phase (phase four) is a reflection on this work within the wider discipline where conclusions on the work's discoveries and relevance are drawn.

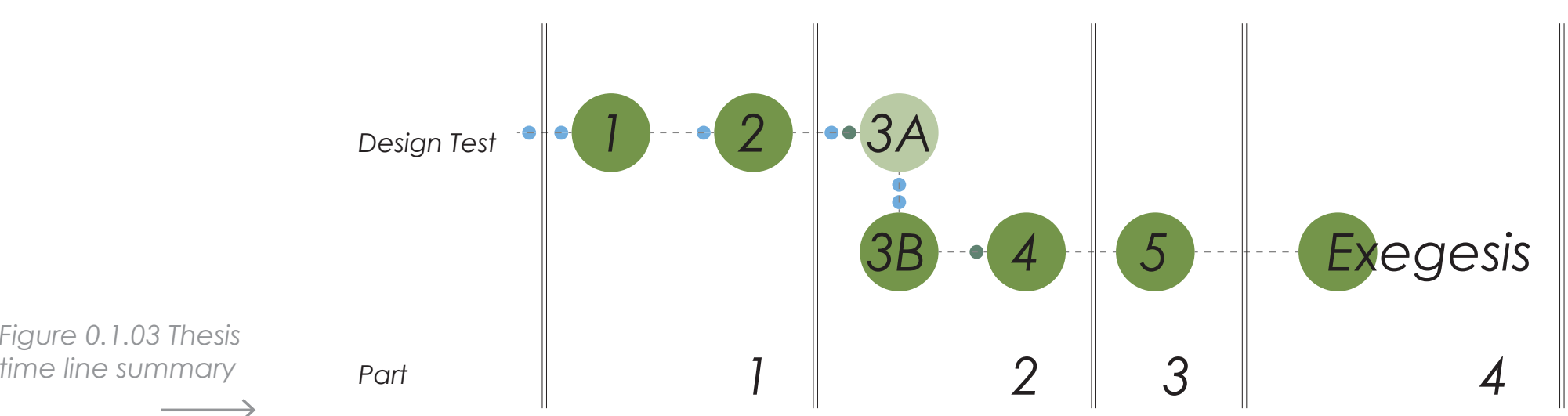




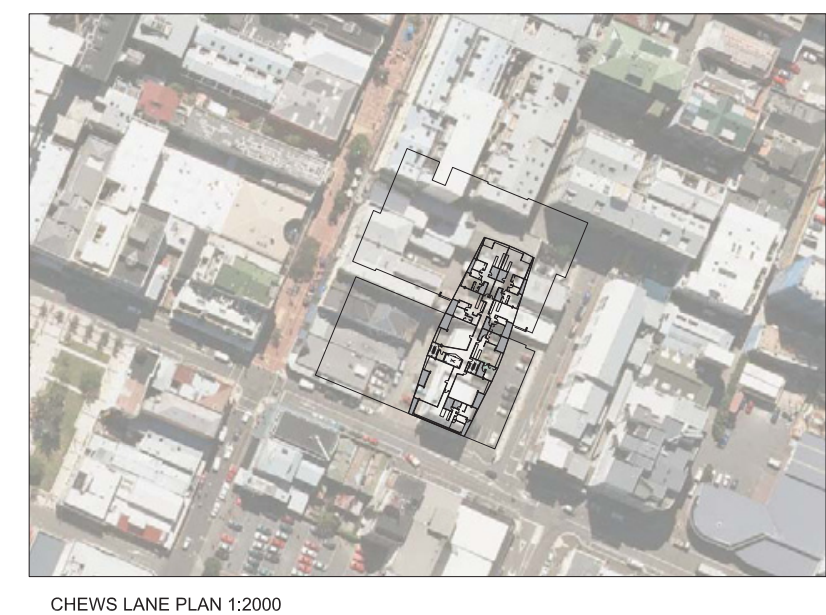

40

Figure 0.1.04 Early

over test site to ge

an indication of
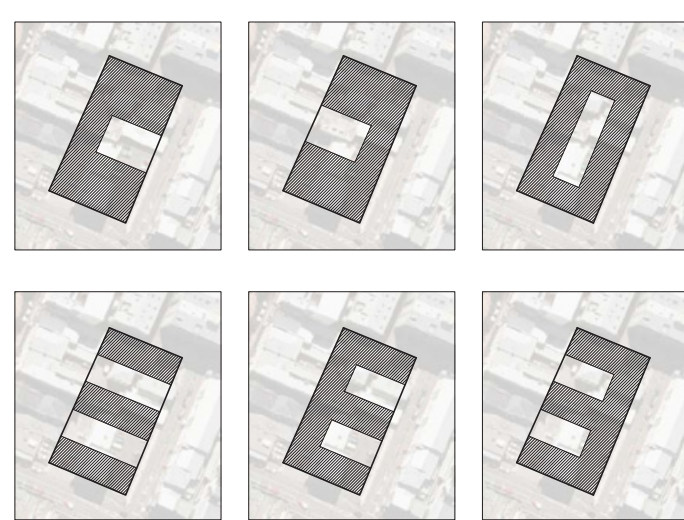

$x+\%$ t

Yl 2 and

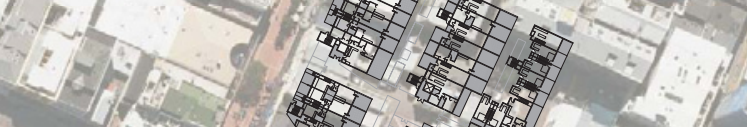

min $2 x^{2}$

-

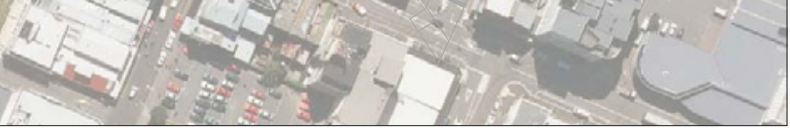

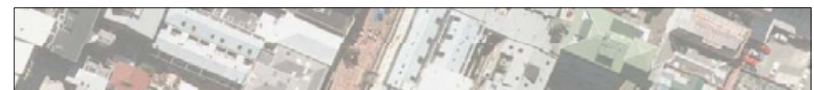
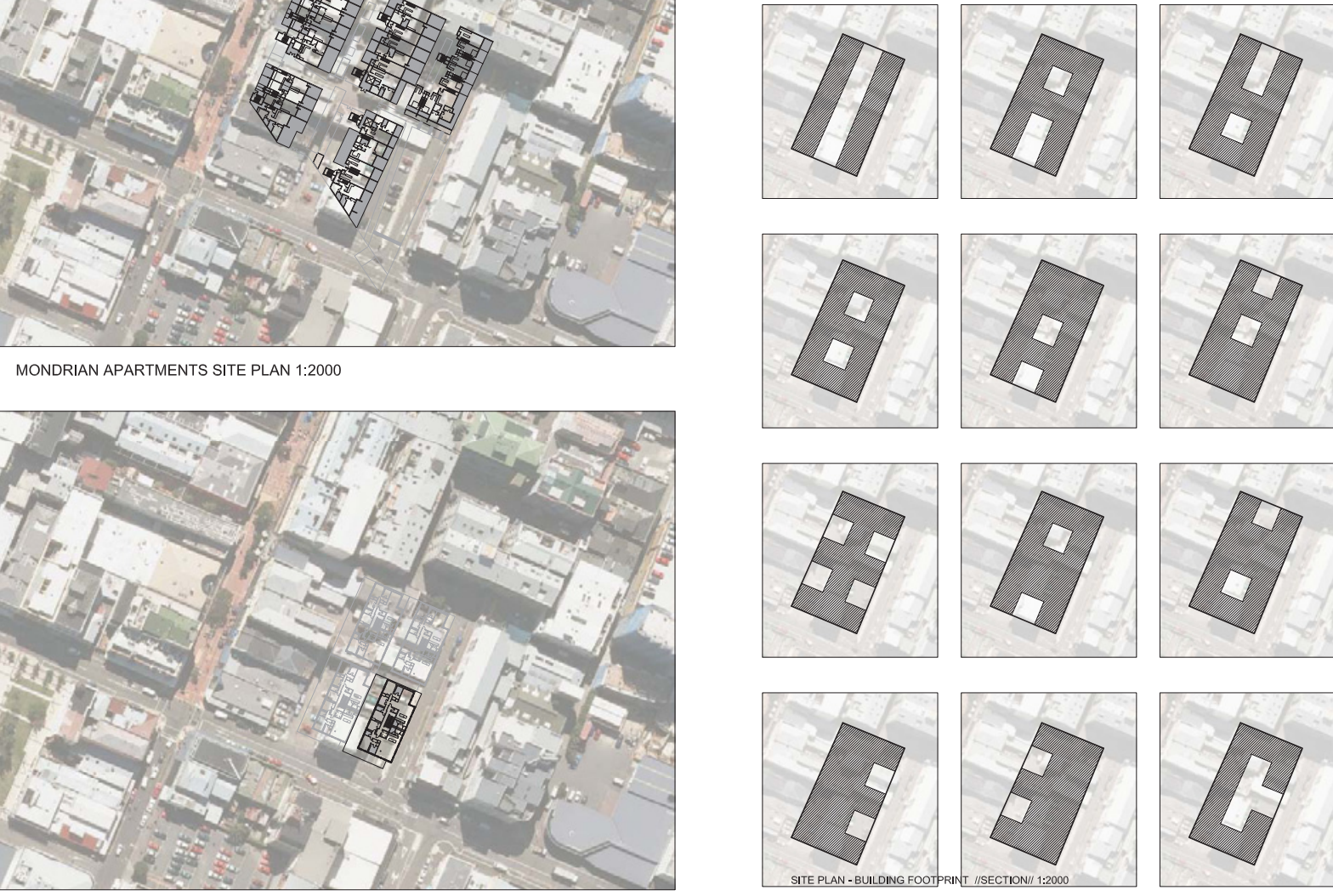

(4)

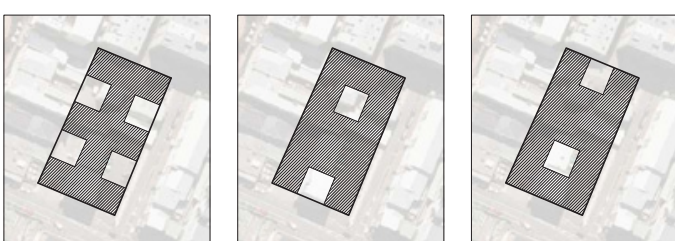

Figure 0.1.05 Test

on site Each

'Zone' is $10 \times 12 \mathrm{~m}$.
Each experiment
is optimised to
solve one CHRANZ
disincentive

Zone' is 10x12m.
Each experiment
is optimised to
solve one CHRANZ
disincentive

disincenti

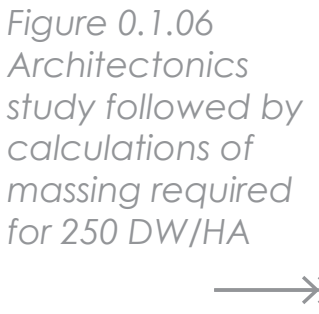

Figure 0.1.07 Floor

plate footprint over

site with proposed

and associated

apartment types
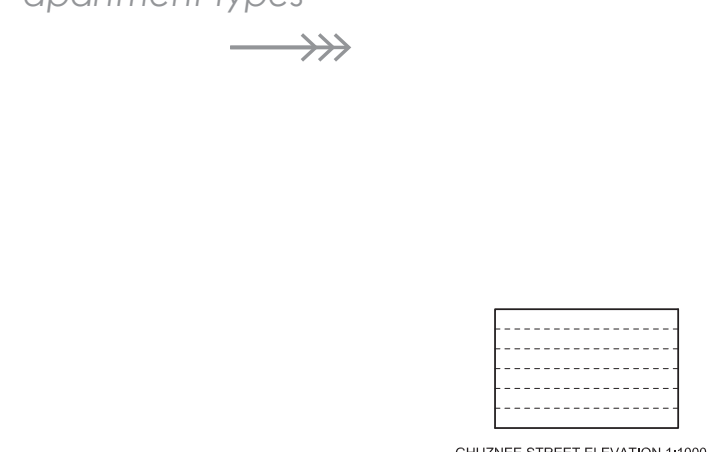

Figure 0.1.08 Selected design

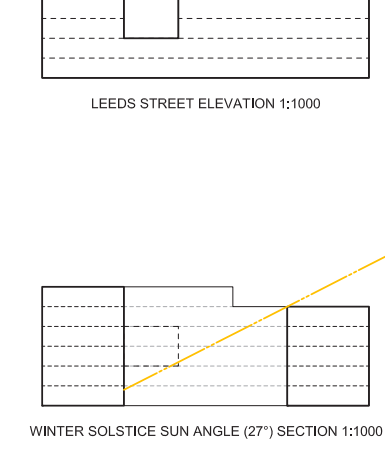

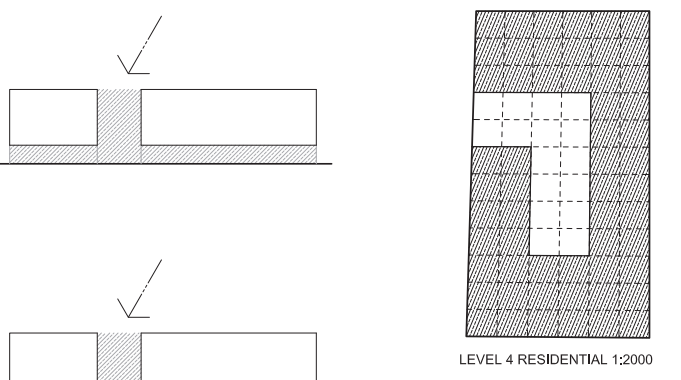
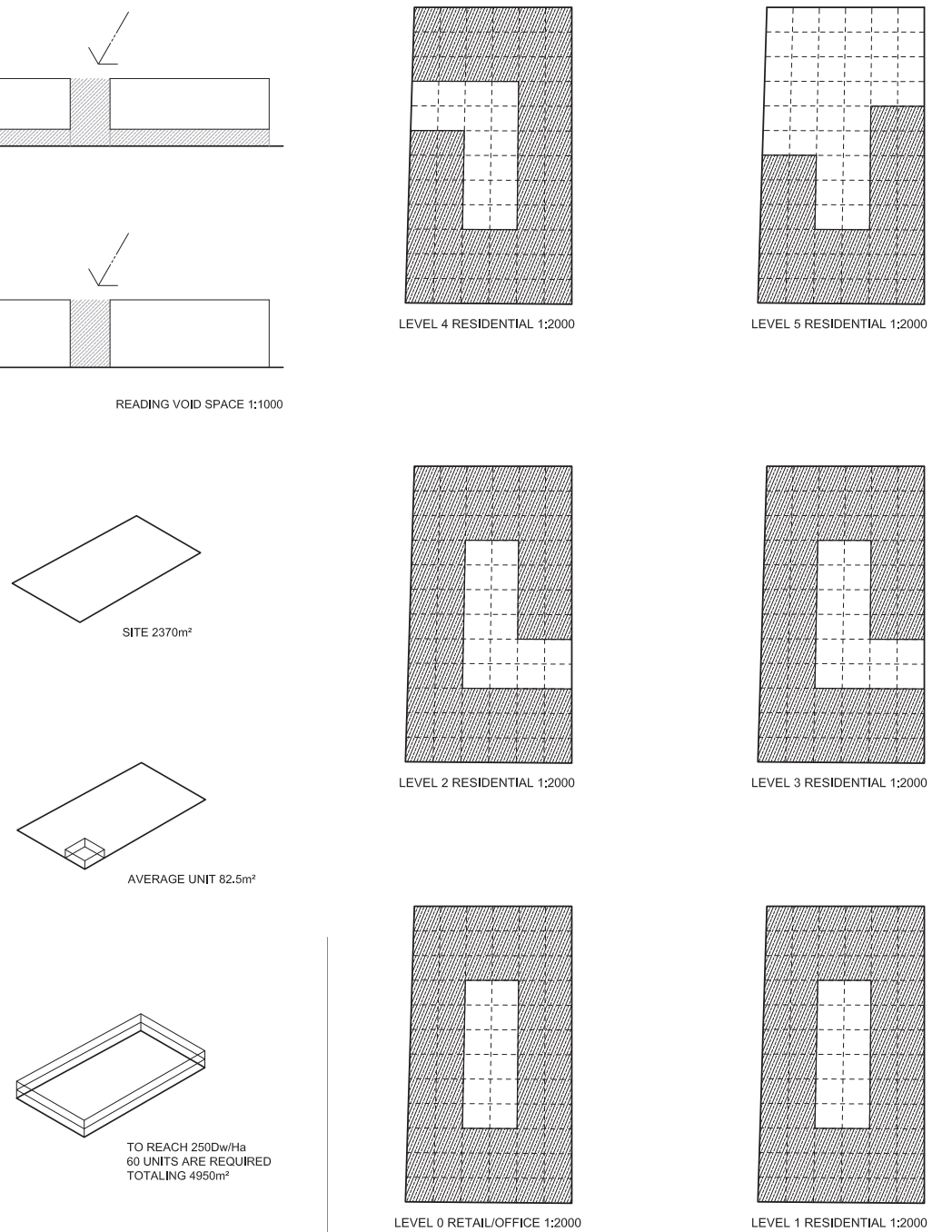

1

舟

DEMOGRAPHIC APARTENT TYPES

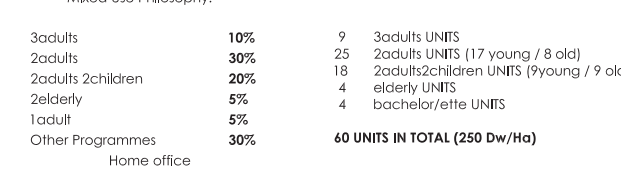

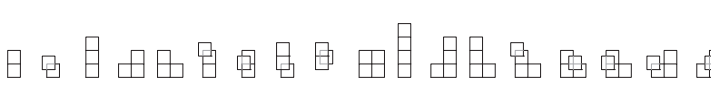




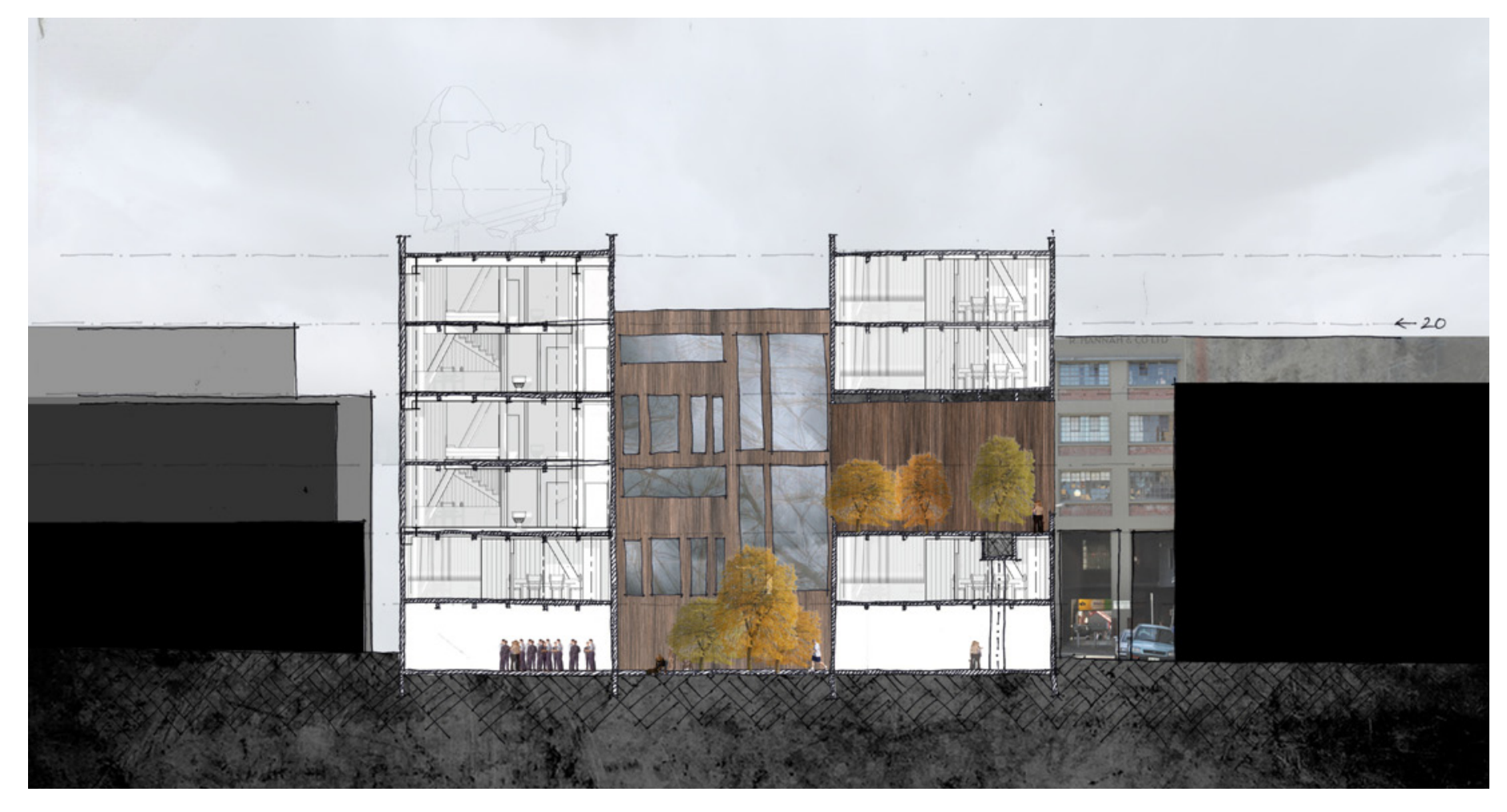


Complex trade-offs, including social economic, life-stage and geographic considerations, are assessed by New Zealanders when selecting a dwelling (CHRANZ, p. 39). Local amenities affect the value of each consideration. higher density housing choosing reduced private amenities (as compared to the typical suburban dwelling), balanced ggainst access to larger common and public amenities, is a significant factor (p. 39)

These concepts of alternative amenity access were applied at an urban scale during the site selection process. For this, Richard Roger's London study 'Towards an Urban Renaissance' (Urban Task Force, 1999) formed the basis of selection. Rogers cites the maximum ideal distances to amenities that people accept as convenient for use (Figure 0.2041. These distances were critiqued and adapted for the New Zealand condition and generation. Sharing a similar housing culture (CHRANZ, p. III. although in a differenttechnological age, some maximum distances were adjusted (e.g. post office doubled to $1000 \mathrm{~m}$ ) and an additional ' $200 \mathrm{~m}$ to public transport' parameter was introduced.

Every Wellington amenity was mapped modelled and overlaid by category to find an amenity-rich site (Figure 0.2.01, Figure 0.2.03 - Figure 0.2091. Some amenities were identified as transferable and capable of introduction into a 


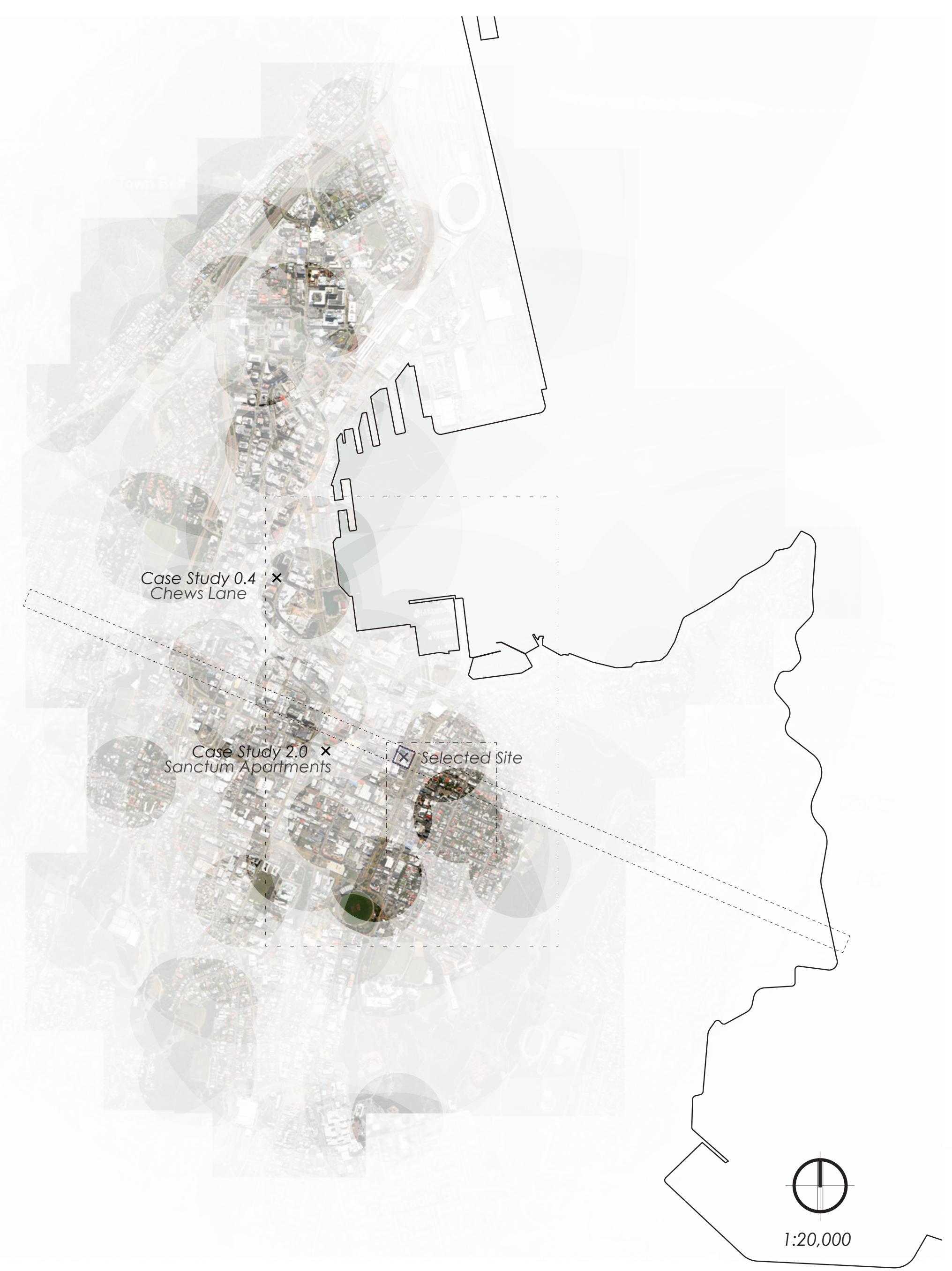

Figure 0.2.02 Panorama from site identifying significant

endscapts

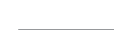

Figure 0.2.01 A

map produce

adapted Rogers

R. Towards an

amenity distances

over Wellington

developer might

do, establish the

ideal site. The

clearer the area

in this map, the

more amenities
the site has access

to. The selected

to. The selected
site has two

missing amenities;

a crèche and a

green. These are
to be incorporated

to be incorporated
into the project

into the project

give something

back to the city

as well as invite

people onto the

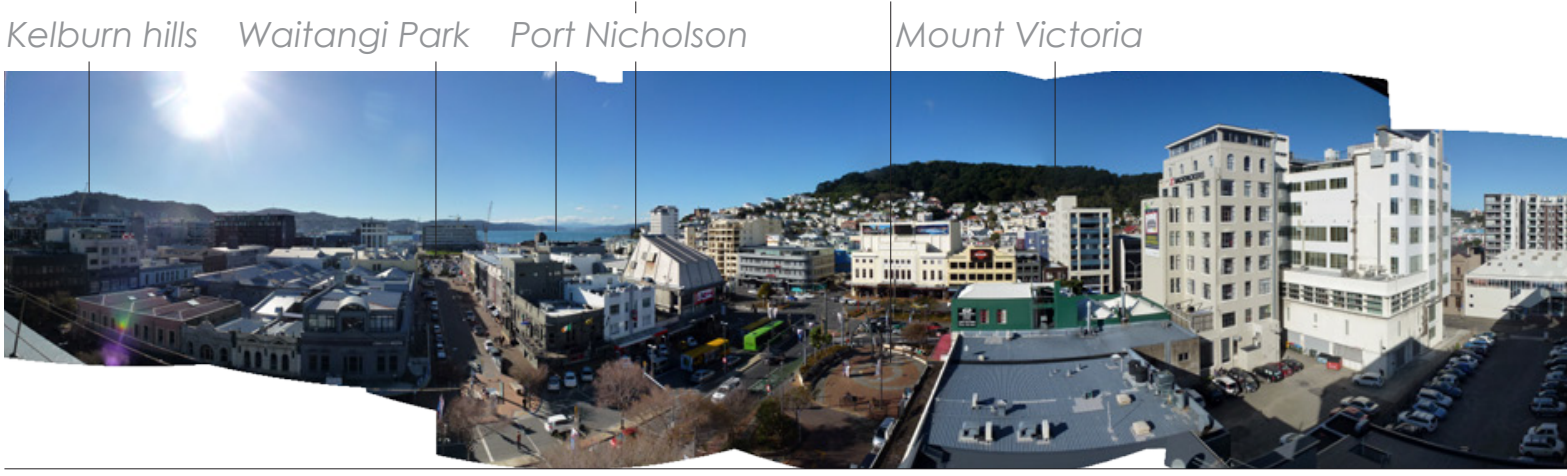

housing scheme's brief: green, crèche shop and pub. The non-transferable amenities were prioritised to guide site selection this would apply for studies of other cities (Figure 0.2.08).

The selected site of $5170 \mathrm{~m}^{2}$, on Cambridge Terrace between Courtenay Place and Alpha Street, was found to be missing a crèche and green both of which were brought into the project brief (Figure 0.2.09)

This site is on the cusp of an area of high density residential development with views and amenity access out to the Mount Victoria green belt, "high city' and Port Nicholson (Figure 0.2.02 Figure 0.2.10). It is also on the threshold of the western course grained high rise residential part of the city, and the eastern fine grained residential area of Mount Victoria so, like the programme, the form too can serve as a mediator between these two states. For these reasons this site is well suited to a propositional design.

The benefit of Wellington's amenity study means the scheme can also offer something valuable back to the public realm - the two identified missing amenities: a crèche and green. This recognises that higher density housing has the potential in itself to be an amenity to the city, bringing in people and providing opportunities for supplementary programmes to activate the area. 


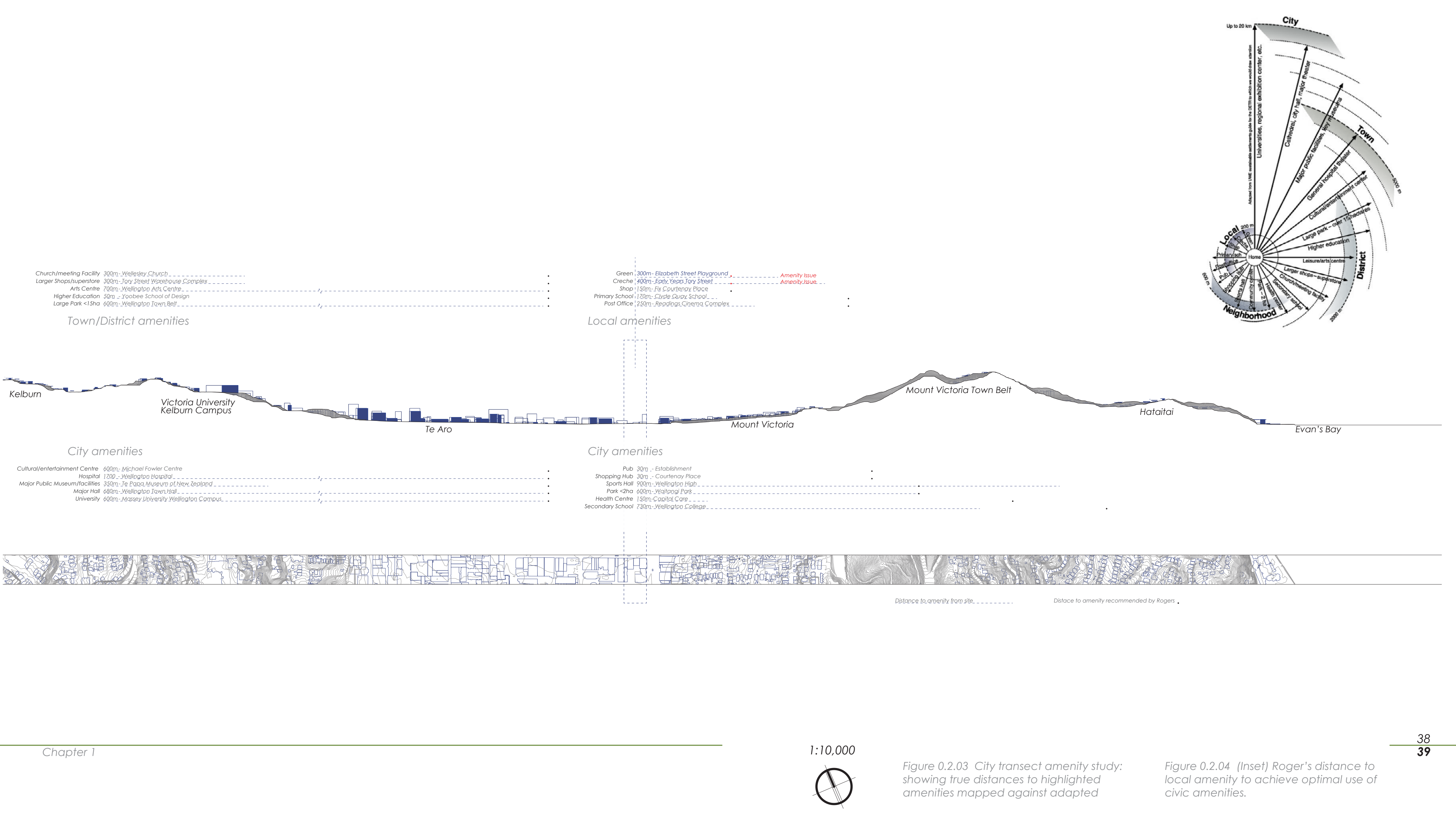



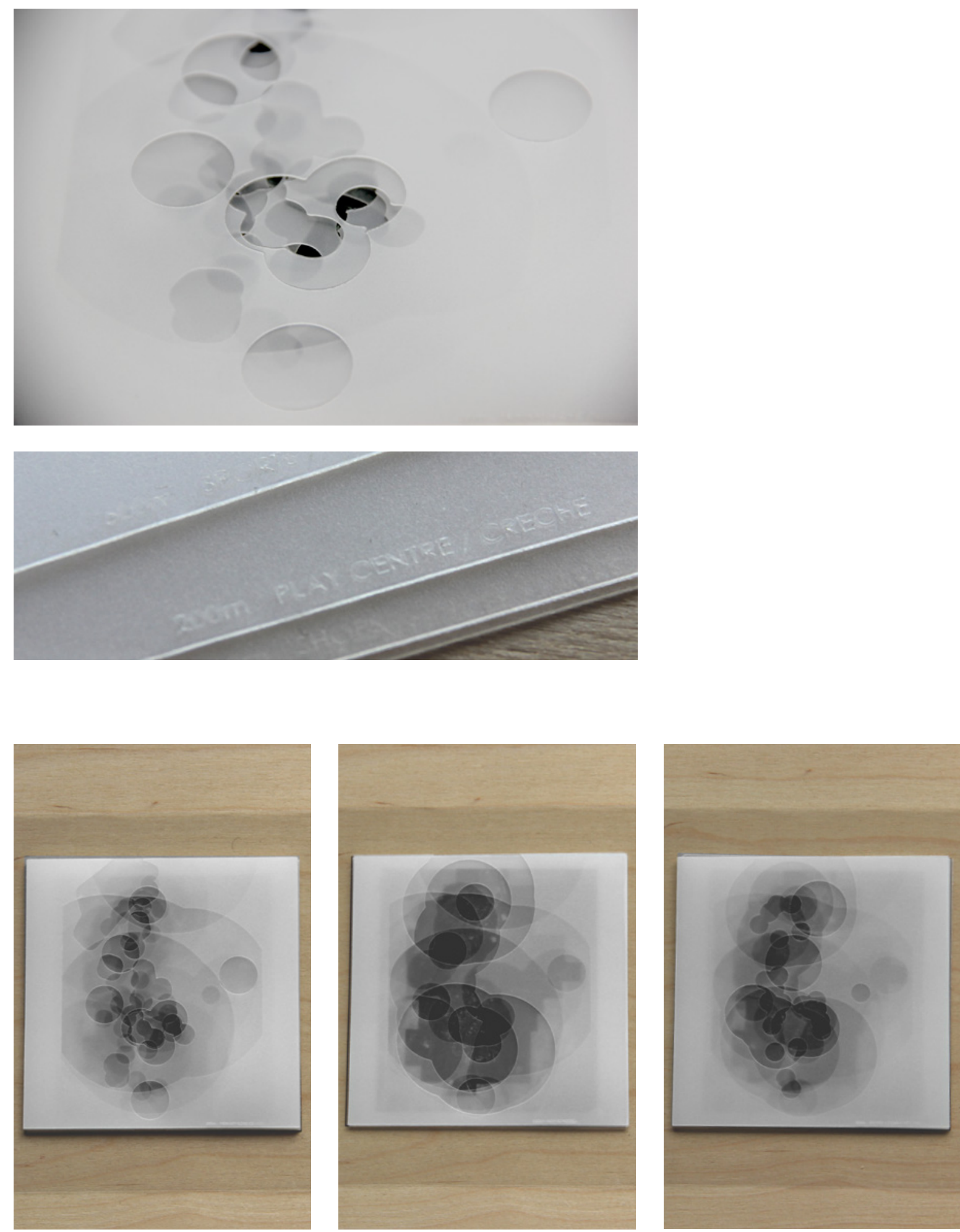

Figure 0.2 .05 Sit
model close up

showing layering of

amenities

$\longleftarrow$

Figure 0.2.10 Loca

amenifies and

fabric highlighted.

entral business

district and Mount

Victoria shaded

Figure 0.2.06

Detail call outs of

amenily layers

Figure 0.2.07 Site

amenities overlaid.

Clear = amenity

Figure 0.2.08

Site model with

'transferable'

amenifies

removed: green,
crèche, shop, pub

世

Figure 0.2.09

Site model with

crèche and green

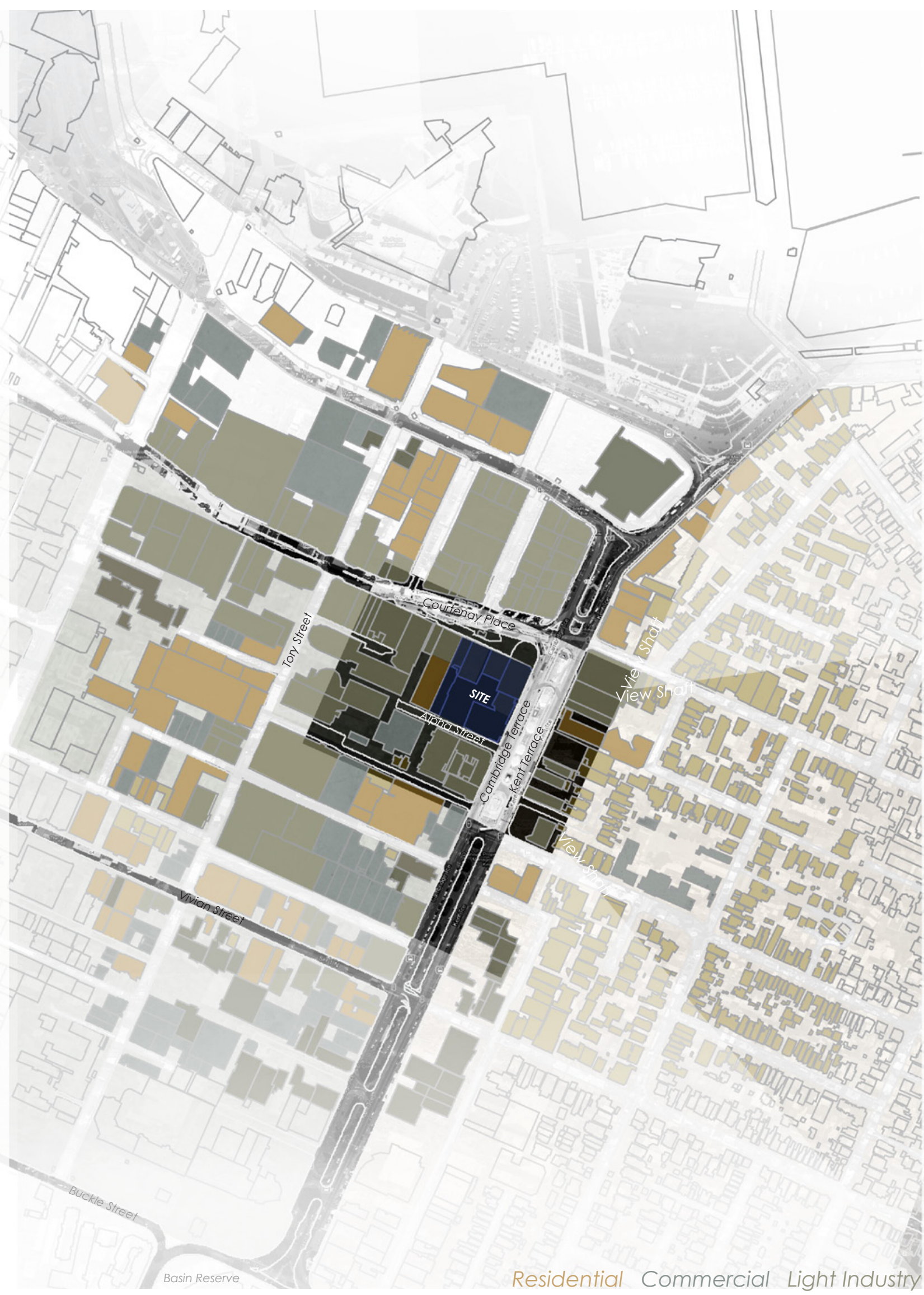




\subsection{Icon in Architecture}

The framework used for assessing a scheme's icon-value was introduced following an interview with Sam Kebbell.

In combination with ideas relating to the Bilbao effect, value, and desirability, a framework was developed defining four categories of building: good-weird good-normal, bad-normal and badweird (Jencks, p. 5).

Good-weir

(Iconic)

Good-normal

Bad-norma

Bad-weird

(Iniconic)

Usp$$
\text { Unspect }
$$

unual, in one significant or multiple

apealing architecture

Architecture that is well designed for its

users and context, and not unusual

Architecture that is poorly designed for its

users and/or its context, and not unusual

Architecture that is bad; doing something

unusual without success
A direct relationship between icon 7) desirability exists (Jencks, p. suburbanites to inner-city living, it is helpful if this propositional design is iconic or 'good-weird' under the is icolicication. Although these classifications are somewhat subjective and only used in this case to assess external appearance they are useful in valuating case studies and design tests.

\section{g. SHoP Porter} House, Jeanne House e.g. Mondrian partments

e.q. Sanctum Apartments

e.g. Chews Lane (residential tower) 


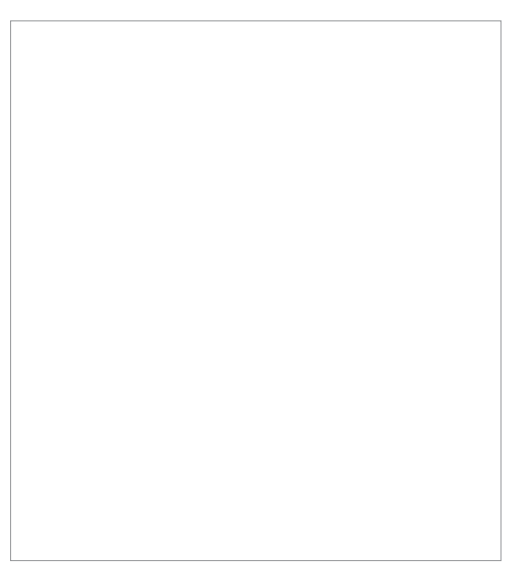

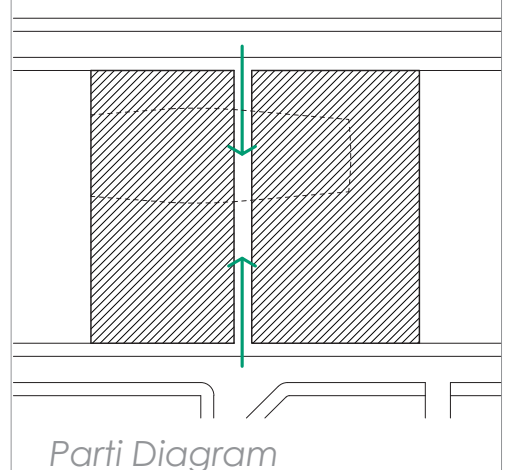

Parti Diagram

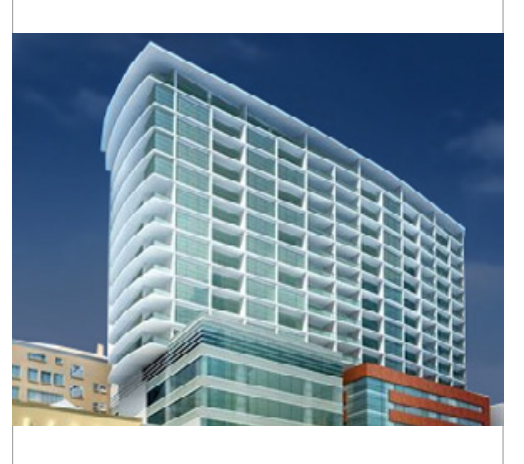

Perspective
Chews Lane balances civic contribution lactivating the existing lane with shops and offices) with common and private amenities (including gardens, balconies and views) to produce a popular high density Wellington scheme. Reaching 840 DW/HA over the residential tower's footprint, it is $210 \mathrm{DW} / \mathrm{HA}$ over the whole development's area.

This scheme includes a common garden on the northern podium's roof. Although the garden has much potential to add to the residents' lifestyles if integrated well, its dwarfed size and difficult access renders it unoccupied.

The visually dominating bridging residential tower illustrates an attempt at iconic architecture, but is unsuccessful due to its clunky proportions and heavy articulation (bad weird) (Figure 0.4.02). However, despite this, the scheme remains desirable for its superior access to most amenities. 
Apartments -single storey (typically single aspect)

Recessed balconies, Common rooftop garden

Amenities

$$
\begin{aligned}
& \text { Garden } \quad \checkmark \text { Variety of Unit Types } \\
& \checkmark \text { Sunlight } \checkmark \text { Visual Aspect } \\
& \checkmark \text { Privacy Iconic Value }
\end{aligned}
$$

Adaptability

Strict structure of tower makes unit plan alterations difficult

Kebbell Classification
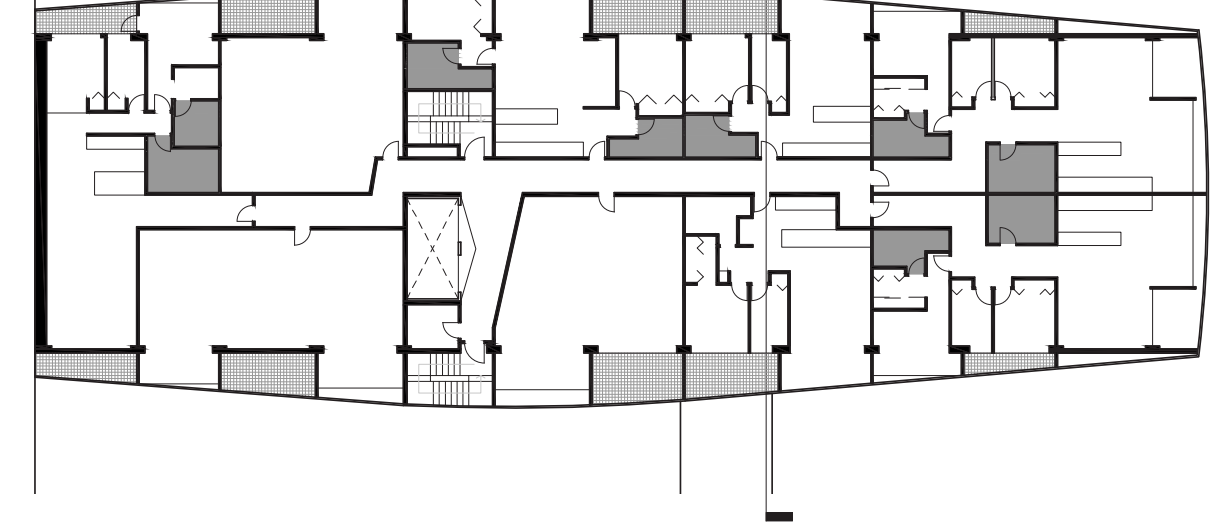

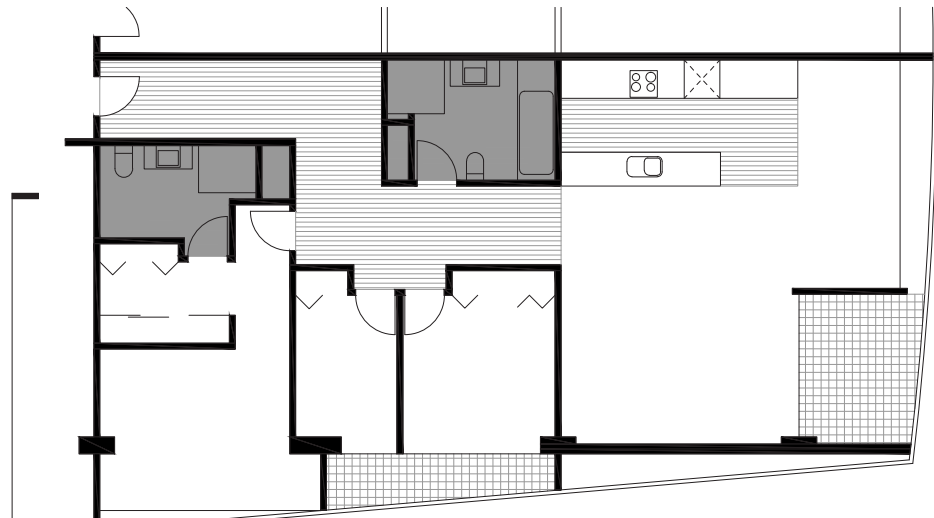

$\bullet \cdot \bullet \cdot \bullet 6$
Figure 0.4.05 Typical Unit Plan $\longrightarrow$

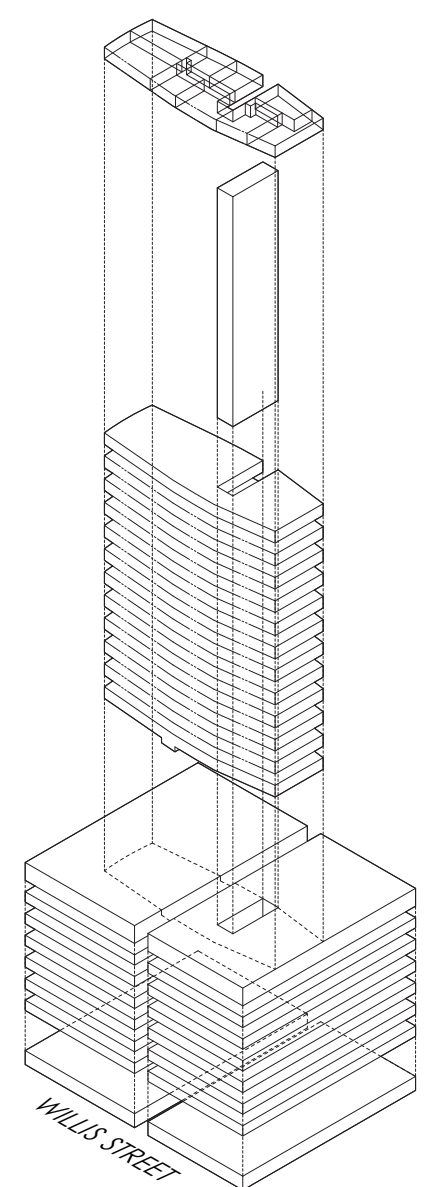

- Inefficient unit plans, often with large amounts of circulation in small units

- Bridged tower form has iconic potential, though is 'badweird' due to 'heavy' proportions and articulation

- Unconventional and difficult connections between

- Garden is difficult to access and thus a token gesture access corridor and living spaces

- Mixed-use development provides greater immediate 

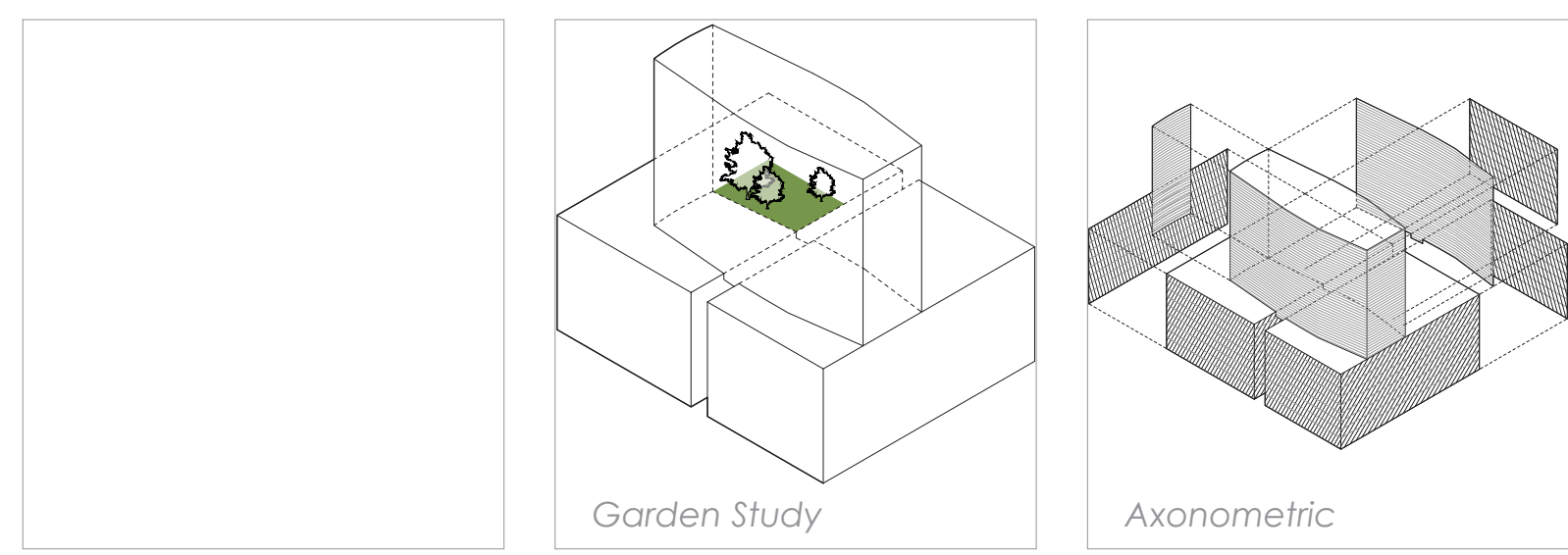

Why this project was selected as a case lessons it exposes

- Example of high density housing in New Zealand

- Suggests required plot size, feeding back into site selection

- Illustrates expected private amenities within units

- Attractive to a few small professional families, although none with children of school age, the kind of families that might otherwise live in suburbia (Dekker, 2012)

- Models how common amenities incorporated within a housing scheme can help offset the perceived amenity loss of the suburbs

- Demonstrates how public amenity access ties directly to the on-going desirability (and ens property value) of a centrally located development.

- Shows the potential for residential developments to enhance the city; in this case by developing existing ane and activation of street edges
Figure $0.4 .08 \mathrm{Ke}$
section through

lane 1.500

P

Figure 0.4.09 Public Private Common study Figure 0.4.10 Circulation Study Figure 0.4.11 Demographics Study

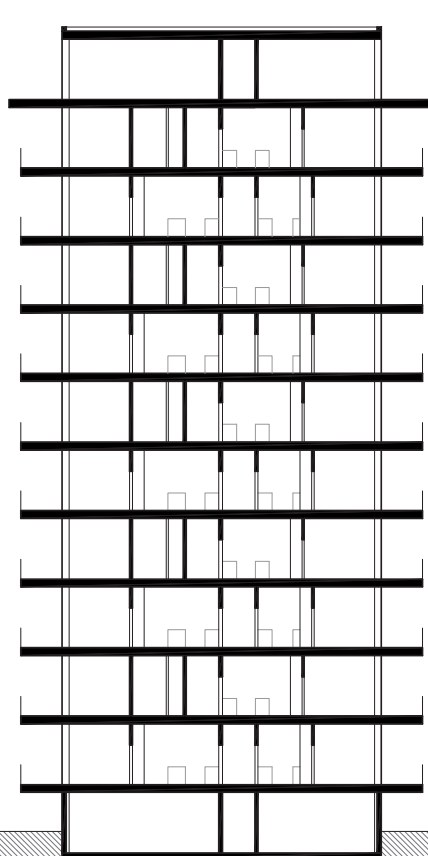

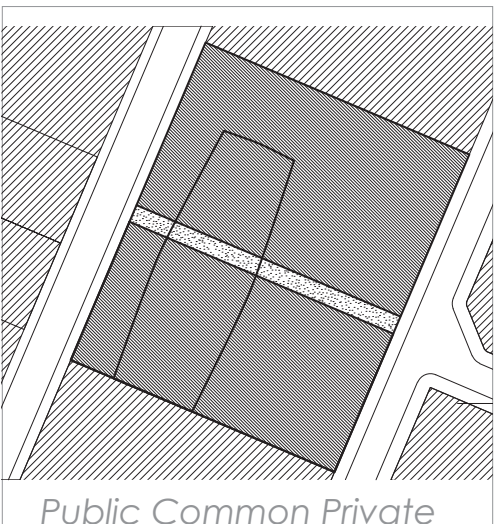

Public Common Private

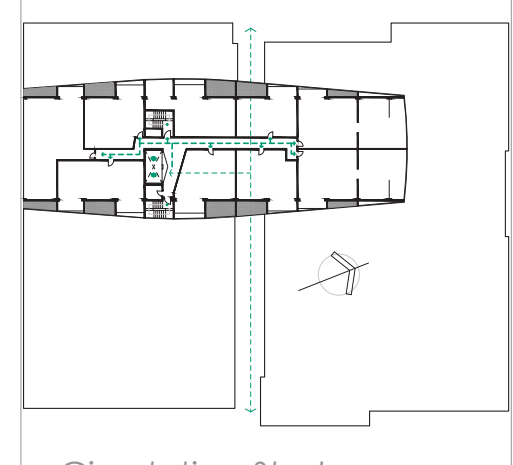

Circulation Study

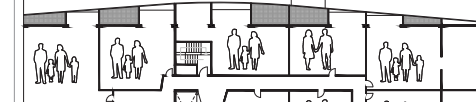
- $=1$ 
candur

01 
Architect

Date

Date
SHOP Architects

New York

2003

Residential, Commercial

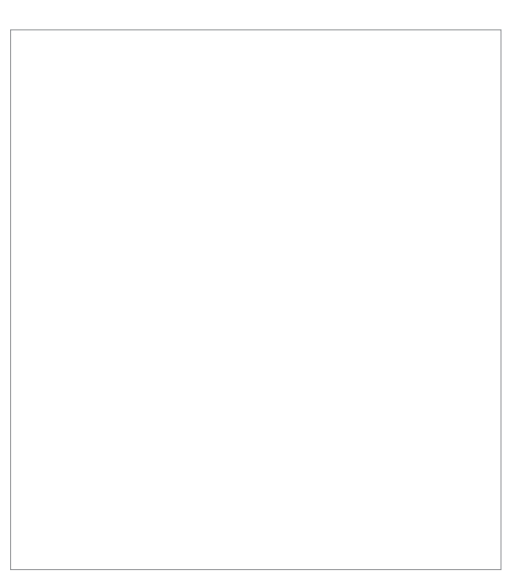

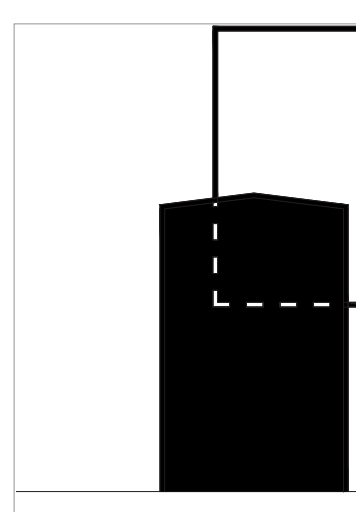

Parti Diagram
450

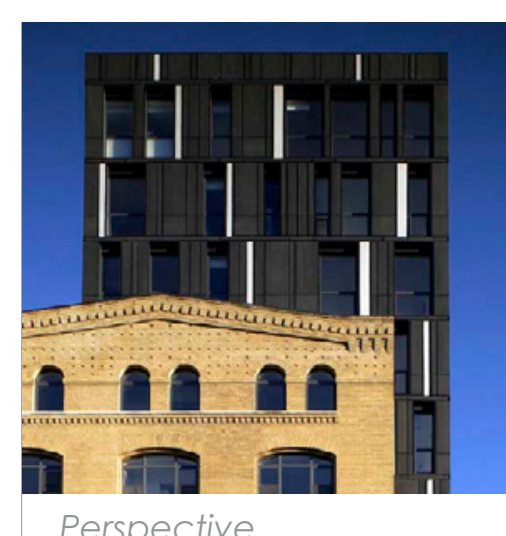

Porter House is an iconic work of

apartment architecture, 'desired for its beautiful design, confident identity, and the reflection these have on unit owners (Malnar \& Vodvarka, p. 179).

It is interesting to note that the penthouse apartments are not on the top storey, but are instead defined by their garden access and situated midway up the building (Figure 1.0.10)

These gardens do not feed directly into the building's iconic value though would be significant in affecting desirability in New Zealand, aiding adoption of the apartment type . 
Scheme Typology

Circulation Type

Adaptive reuse and extension of historic warehouse Internal

Dwelling Typologies

Apartments - triple aspect; Studio apartments - single aspect $\begin{array}{ll}\text { Garden Typologies } & \begin{array}{l}\text { Two luxury units at junction between historic and new have } \\ \text { private rooftop gardens, A third of units feature a recessed }\end{array}\end{array}$ balcony

Amenities

$$
\text { Garden }
$$

$\checkmark$ Variety of Unit Types

$\checkmark$ sunlight

Visual Aspect

$\checkmark$ Privacy

$\checkmark$ Iconic Value

Adaptability

Floor plans include built in fumi

to adapt for alternative uses
Kebbell Classification

Good-weird

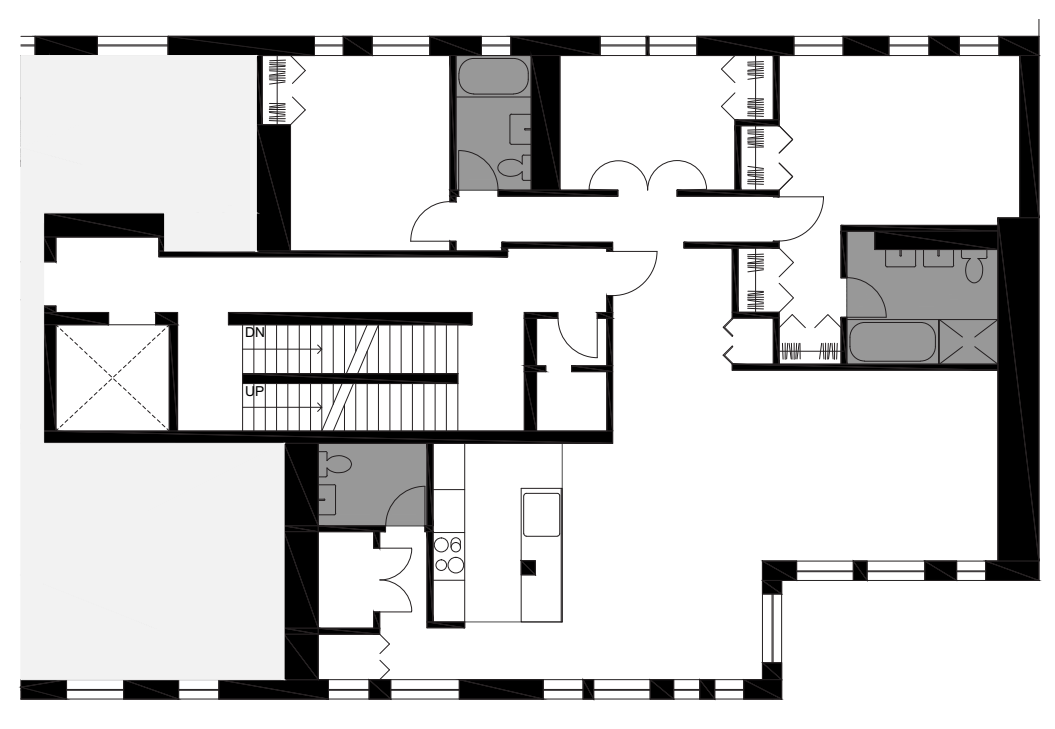

- Iconic architecture created through an unusual yet striking overall form

- Iconic architecture enhanced through unusual articulation of static and dynamic form

- Iconic architecture enriched through contrasting materials

- Cantilevered and lowered new extension optimises available space for residential units

- Contextual relationships drawn between building and New York's traditions of sky scrapers and historic retrofits (Figure 1.0.09)

Points of Limitation

- Adaptive re-use developments are often difficult to make financially viable in New Zealand as they typically involve expensive restructuring and retrofitting in locations not as valuable as Manhattan Island

- Exclusive private garden access for only two unit owners. It is likely that the remaining units will not appeal to suburban New Zealand buyers

Figure 1.0.03

1:200

- Desirable parking spaces not included thus not suitable to New Zealanders

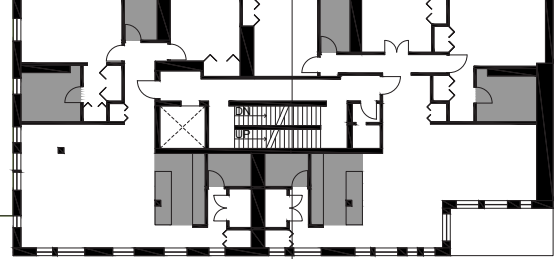



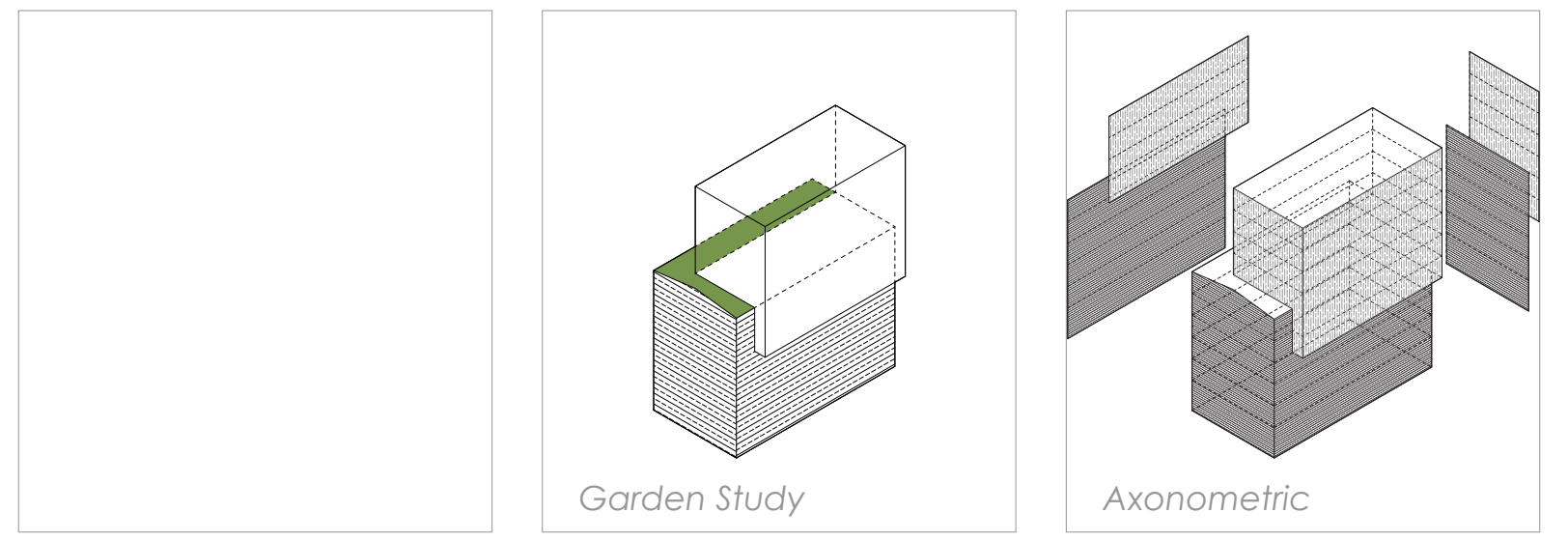

Figure 1.0.08 Ker

Section 1:500

Figure 1.0.09 scraperselsky $\rightarrow$

- Typifies how the 'architect as developer' role prevents the sacrifice of design quality and icon value

Why this project was selected as a case learnt

Illustrates the influence of iconic architecture on the desirability of the development

- Demonstrates the value added through an icon design proven when units sold for three times more than

Figure 1.0.06

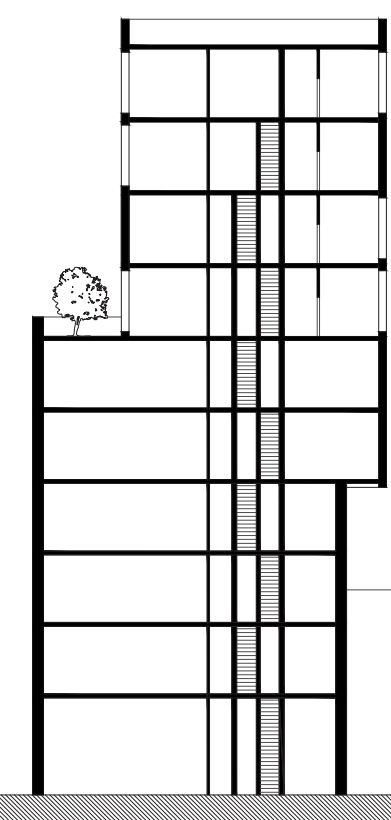
Garden Study Figure 1.0.07
Axonometric
Figure 1.0.10 Public Common Pivate study Figure 1.0.11 Circulation Study Figure 1.0.12 Demographics Study
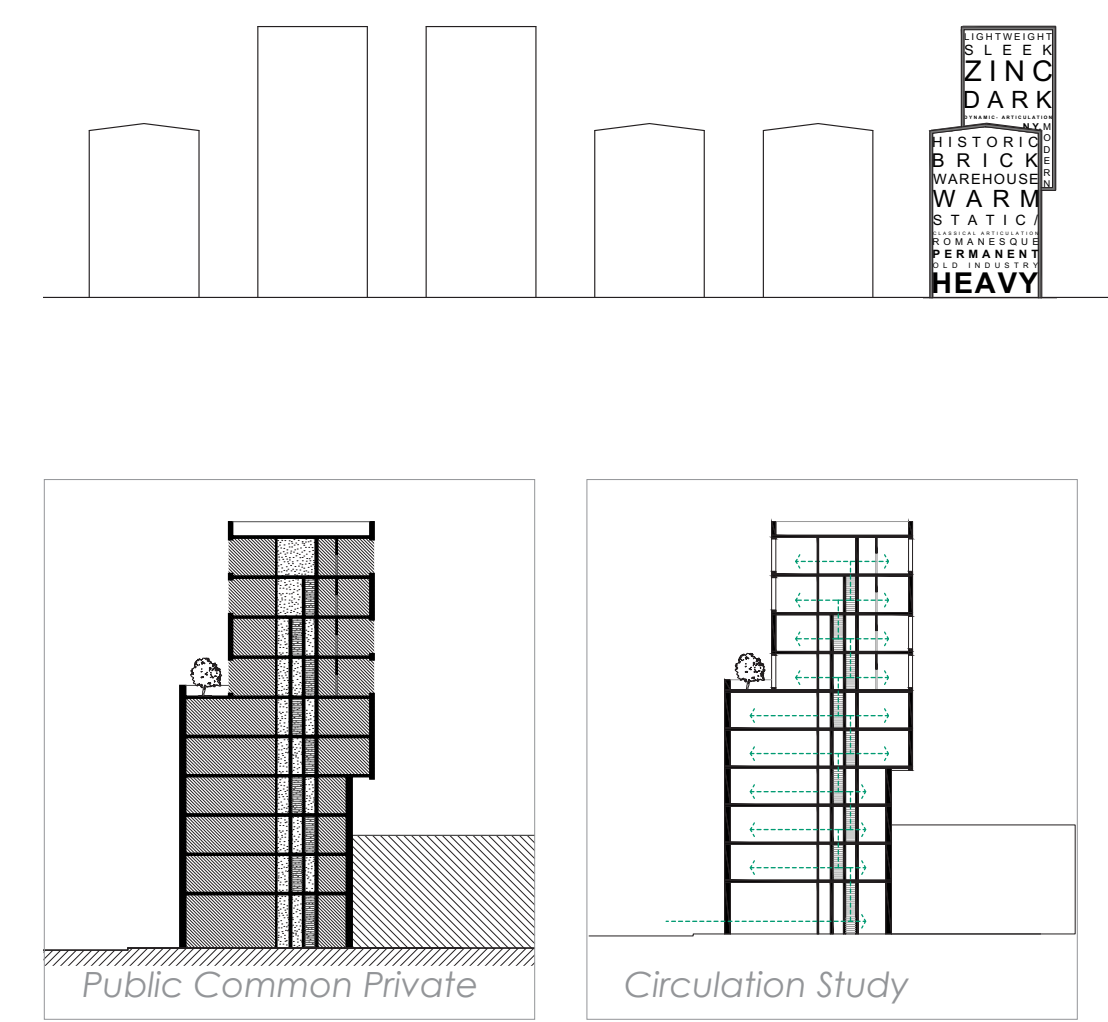

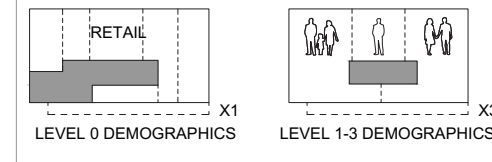

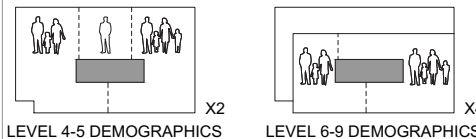

Demographics Study 
Design Development

Mediums

Project Date

Key Drivers
Gold foam models, Hand drawin Digital modelling

Month 3 (May)

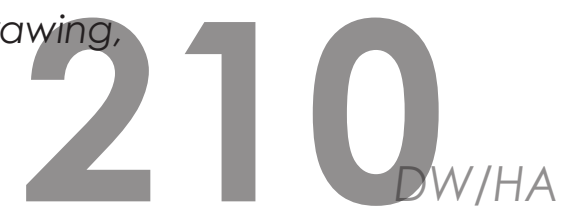

Achieving solar access into the central courtyard and all apartments year-round

Understanding volume and scale required to produce targeted 250 DW/HA yield

- Familiarisation of site and site conditions

Developing a design methodology
Designing with reference to the "Kebbell classification Residential, Ground floor retail
Design testone uses case study reflections

and intuition to respond to the initial brief: addressing all 29 CHRANZ attributes and achieving the 250 DW/HA density target on site. Although not all goals are met. a benchmark is established for further iterations to improve upon.

Initially this design is model driven, in the physical realm then later refined digitally, to quickly experiment with design strategies.

Twelve initial physical (goldfoam) models are documented and weighed to give an indication of their expected volume. This ensures models are within the correct massing range for the target density and appropriate for digital development (Figure 1.1.03 - Figure 1.1.15). 


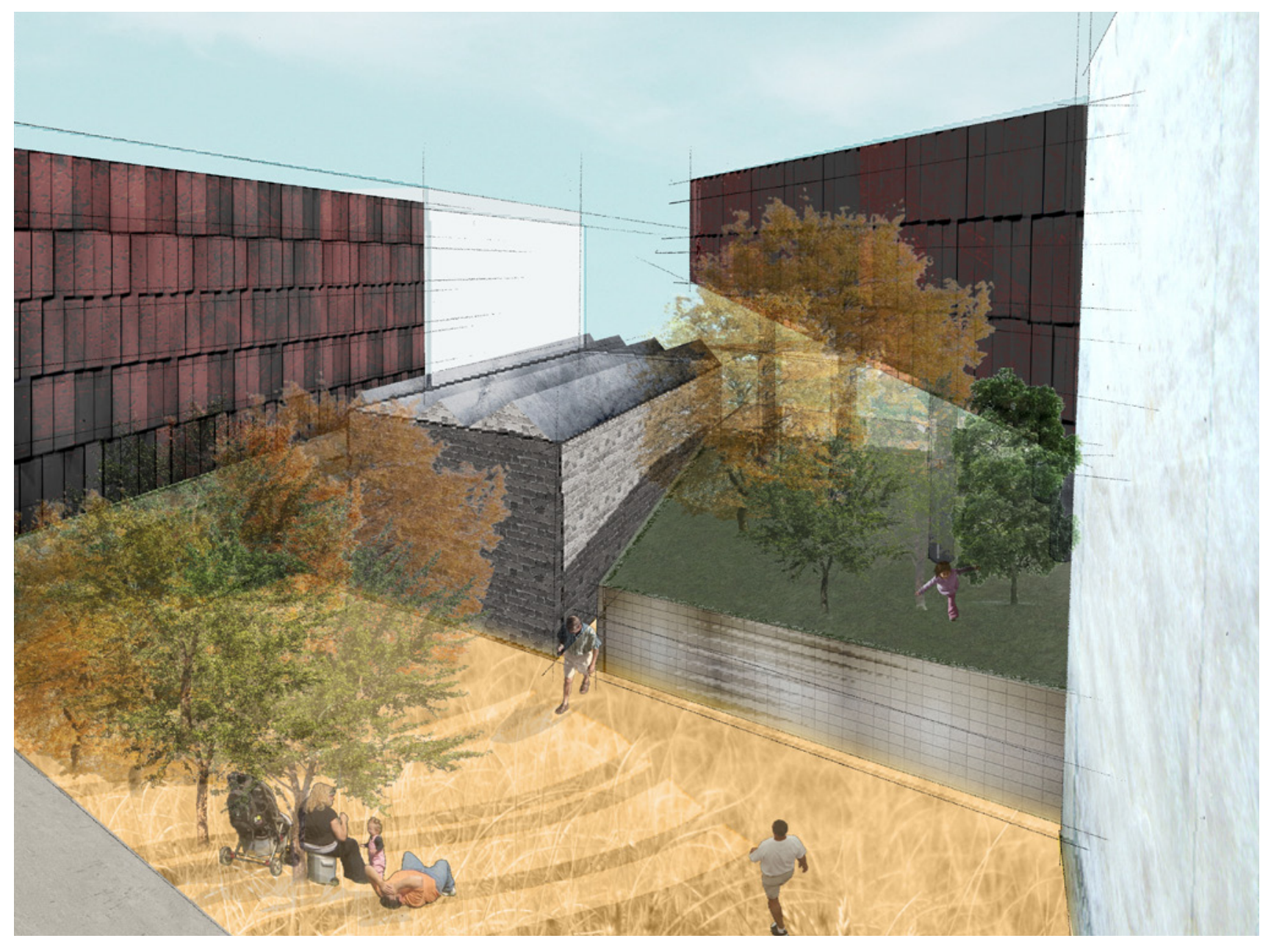

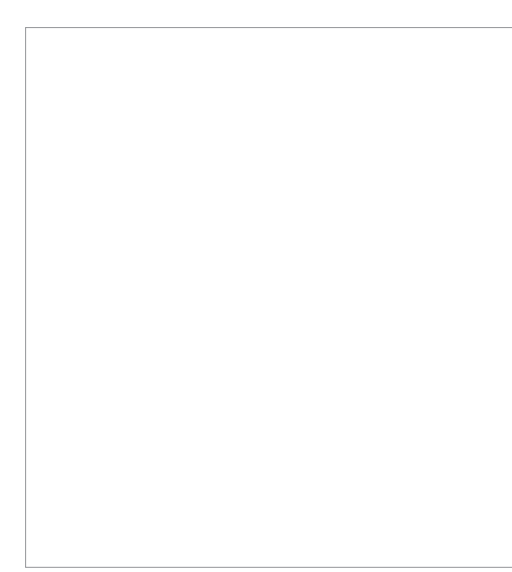
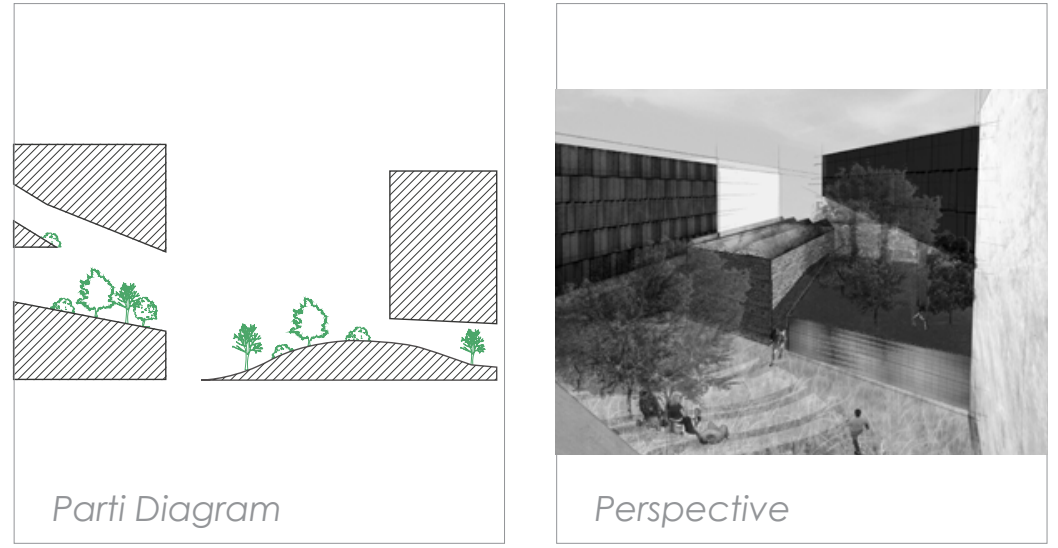

Scheme Typology

Infill perimeter block

Circulation Type

Dwelling Typologies

Garden Typologies

Apartments, Maisonettes

Common courtyard, Void garden

Amenities

$\checkmark$ Garden

$\checkmark$ Sunlight

$\checkmark$ Privacy

Figure 1.1.01 Parti diagram

Figure 1.1.02

Perspective from

a unit overlooking

area

Adaptability

Kebbell Classification
NA

Good-weird 


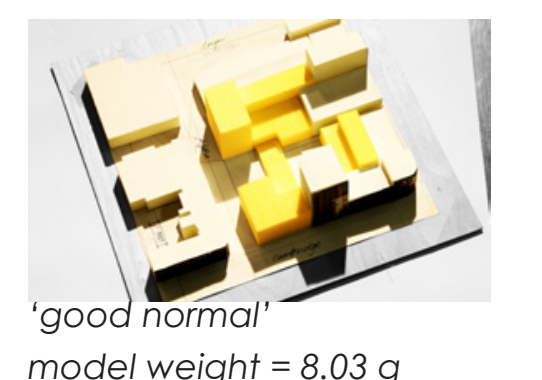

model weight $=8.03 \mathrm{~g}$

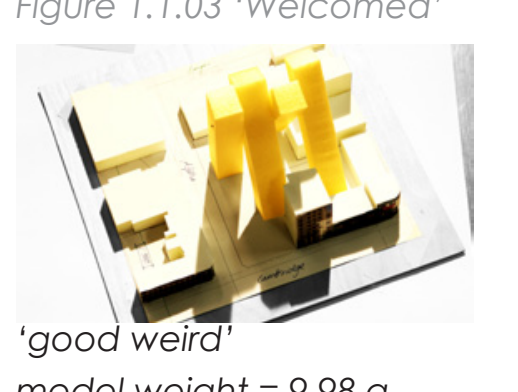

model weight $=9.98 \mathrm{~g}$

therefore 12,300 m2@1:1

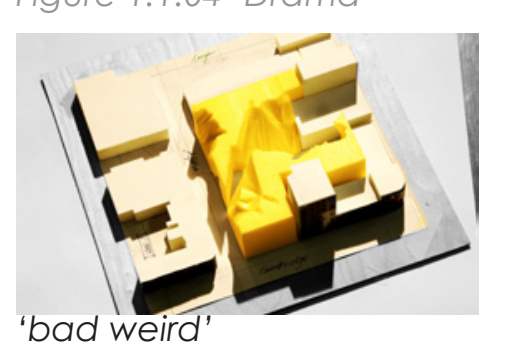

model weight $=13.04 \mathrm{~g}$

therefore 16,100 m2@1:

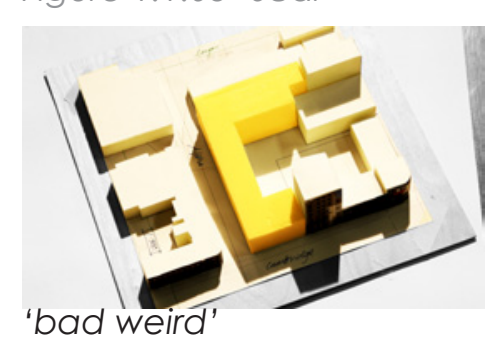

model weight $=7.99 \mathrm{~g}$

therefore 9,870 m2 @ 1:

Figure 1.1.06 'Perimeter Context'

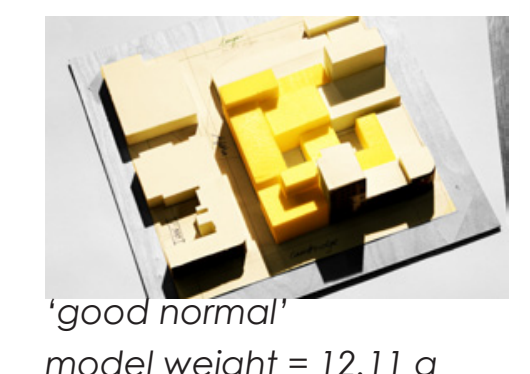

model weight $=12.11 \mathrm{~g}$

therefore 15,000 m2 @ 1:1

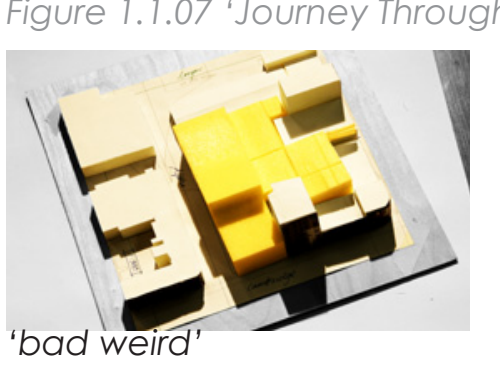

model weight $=11.44 \mathrm{~g}$

therefore 14,100 m2@ 1:

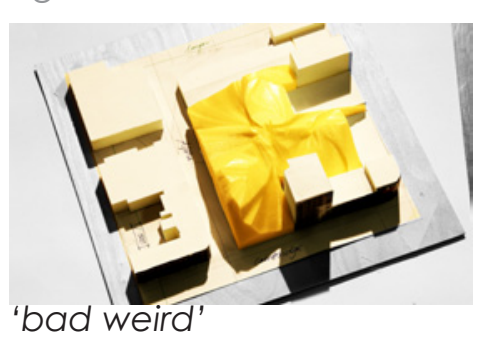

model weight $=13.22 \mathrm{~g}$

therefore 16,300 m2@1:

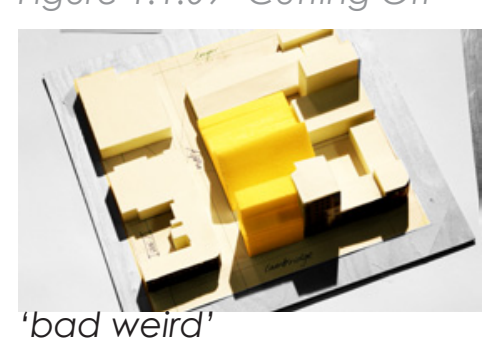

model weight $=8.46 \mathrm{~g}$

therefore 10,500 m2@ 1:

igure 1.1.10 'Reflective State'

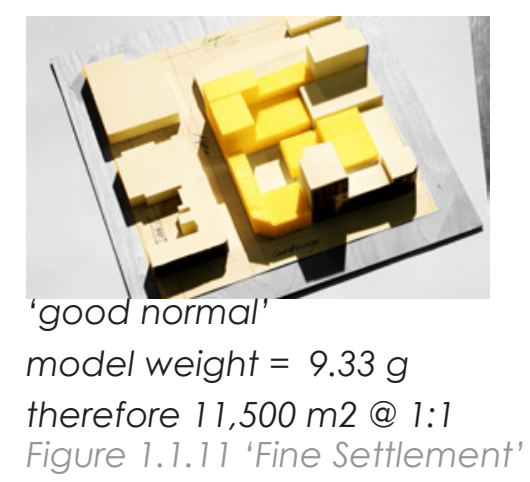

Target Density

250 DW/HA

site area $=3230 \mathrm{~m}^{2}$

minimum area required
for $250 \mathrm{DW} / \mathrm{HA:} 12,000 \mathrm{~m}^{2}$

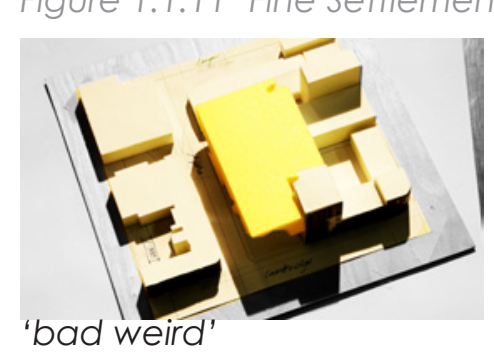

model weight $=10.67 \mathrm{~g}$
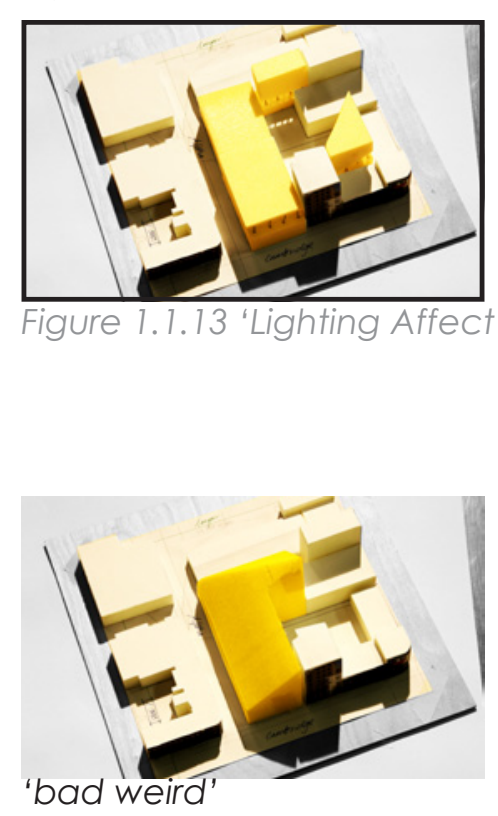

model weight $=12.46 \mathrm{~g}$

therefore 15,400 m2@1:1

Figure 1.1.14 "Intuition onto Context"

Finances

Playfulness

Context

Behaviour

- Time

- Memory

Metaphor

Light and
Shadow

built

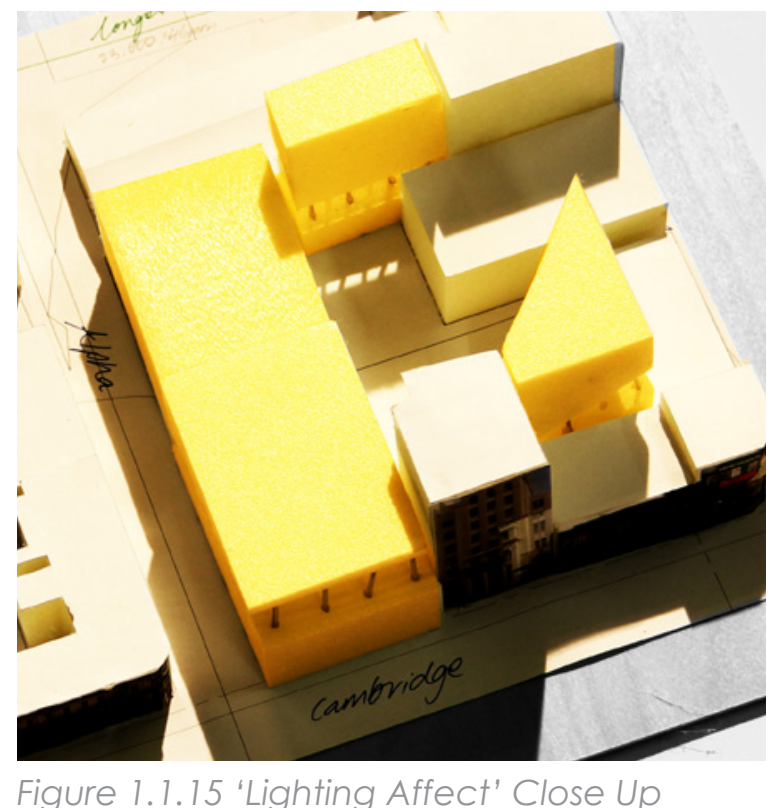

Summary:

Light is brought into the courtyard all year

round
Structural development will alter shadow

patterns and wina breakdown

respectful way to existing context

- Enhanced views

- Dwelling possible
Iconic building

The Gap/not

'Lighting

model weight $=$

therefore $13,200 \mathrm{~m} 2$

Floor area

requirements

met

Council

height limit

restrictions

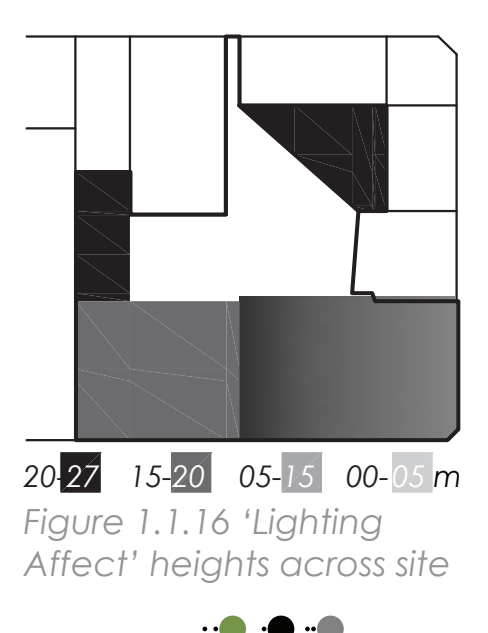

$\bullet \bullet \bullet \bullet \bullet-62$ 


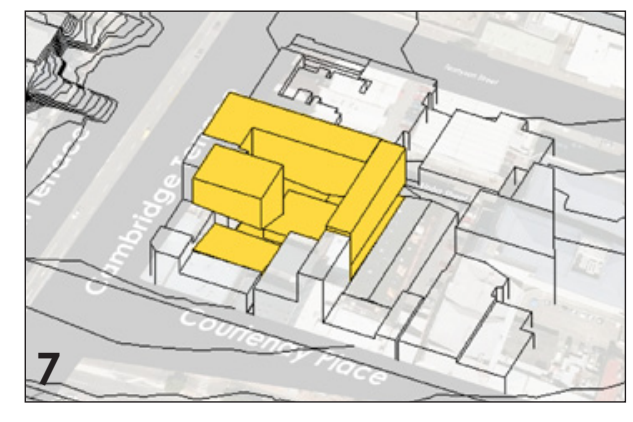

Figure 1.1.17 Raised internal platform in wunlight access to the central common area.

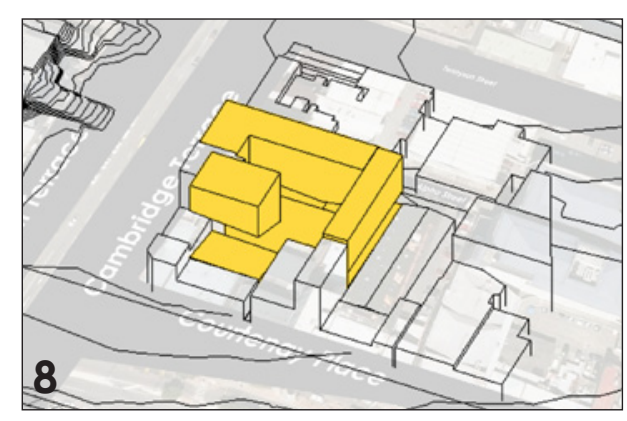

Figure 1.1.18 Raised internal platform ove

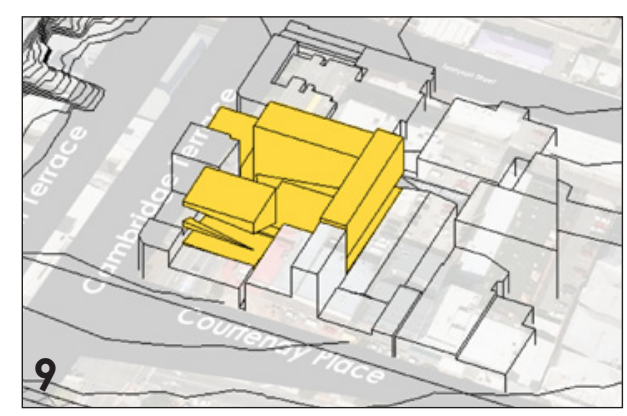

Figure 1.1.19 Lowering of perimeter buildings he existing fabric.
Of the goldfoam models the preferred design, 'lighting affect', is selected for further digital development. Chosen as a 'good-weird' propositional icon it also acknowledges the symbolic role of garden in New Zealand housing. This goldfoam study creates opportunities for a range of striking naturally lit moments formed by cutting voids through the building envelope to create evocative and memorable human scale spaces filled with garden.

High quality light is not often associated with high density housing, yet this design achieves it year round. In the digital realm the concept is explored with accurate solar studies to realise its feasibility (Figure 1.1.17 - Figure 1.1.20, Appendix page 239). The optimised massing is then retrofitted to suit the 29 CHRANZ criteria.

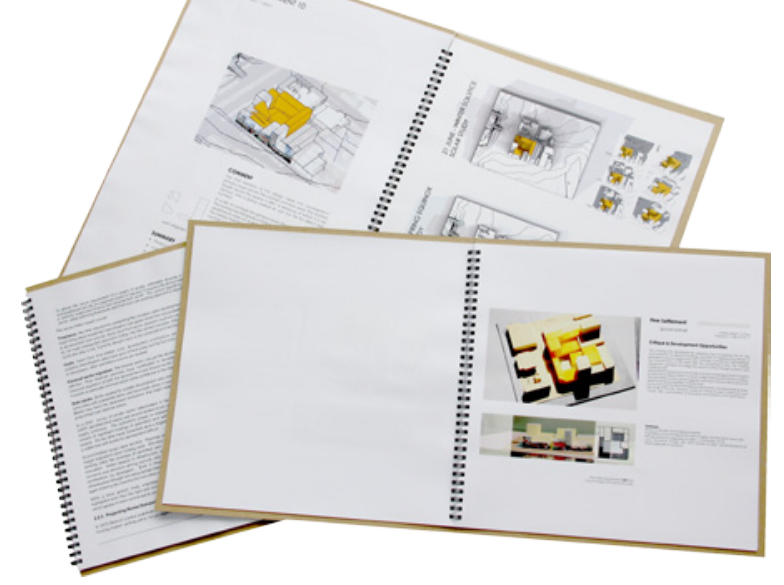
Figure 1.1.20 Image of workbooks feature

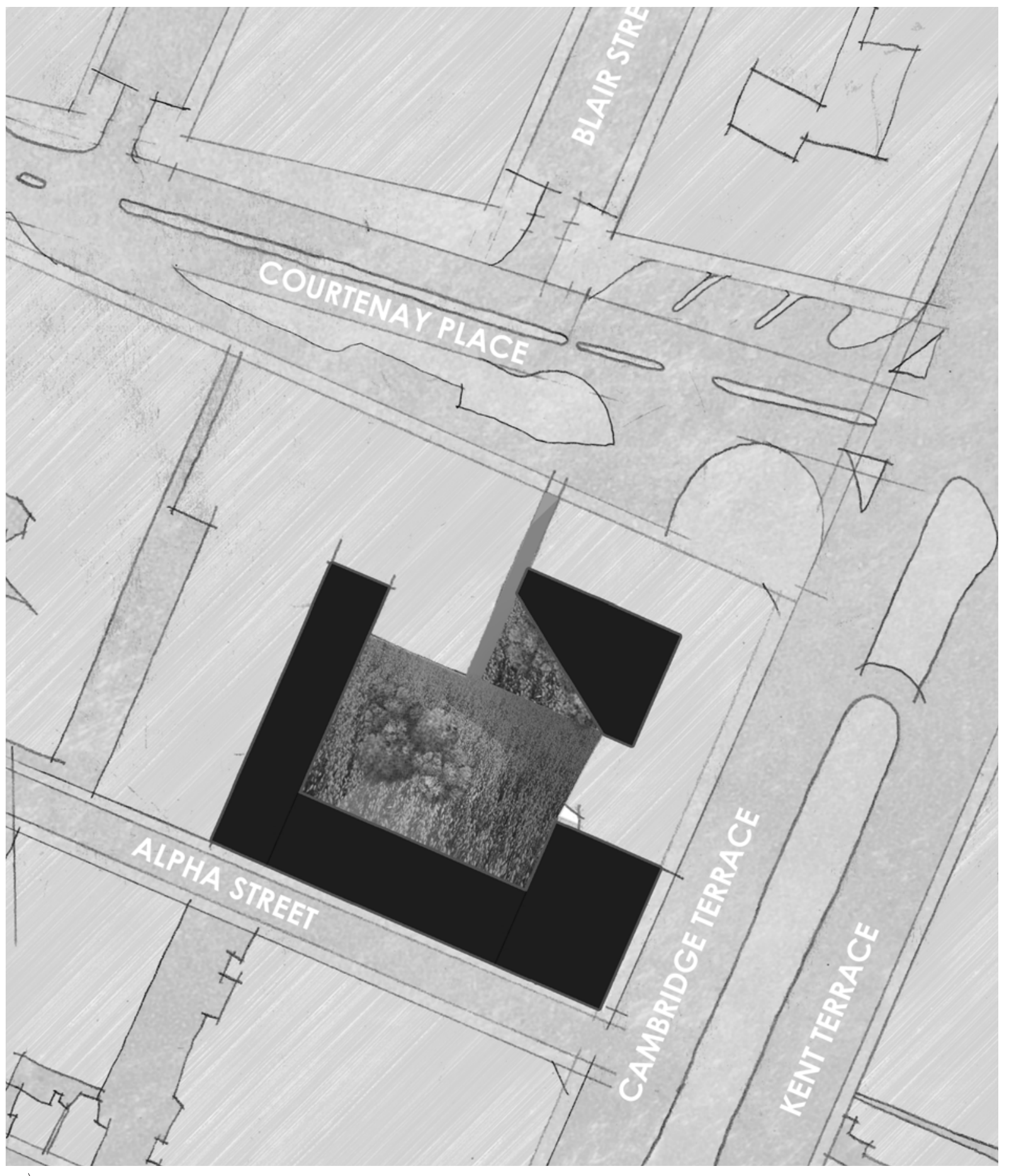

D $1: 500$ 

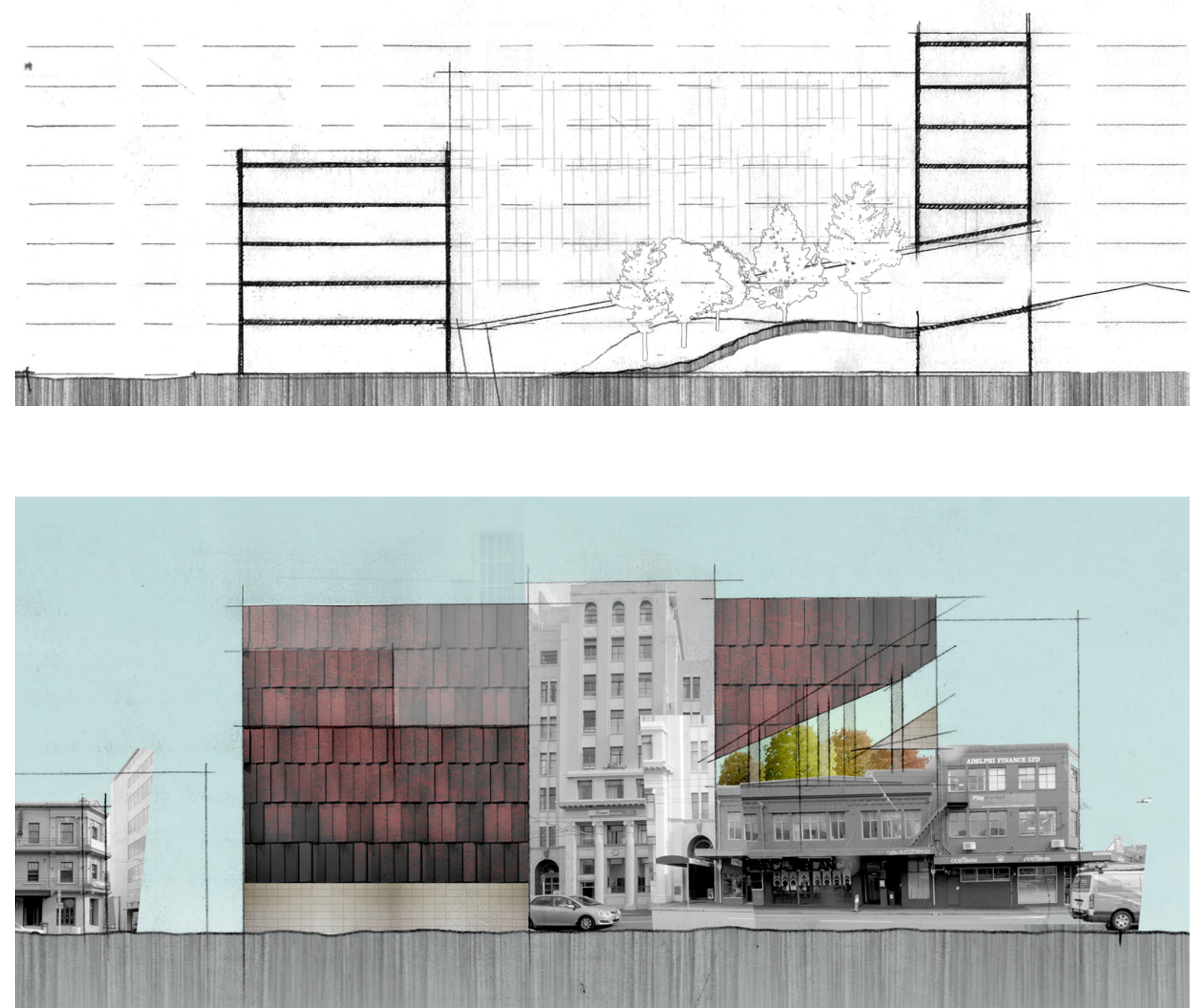

Figure 1.1.22

East-West section

showing raised

courtyard

$\longleftarrow$

Figure 1.1.23
Render from Blair Street illustrating Iconic potential

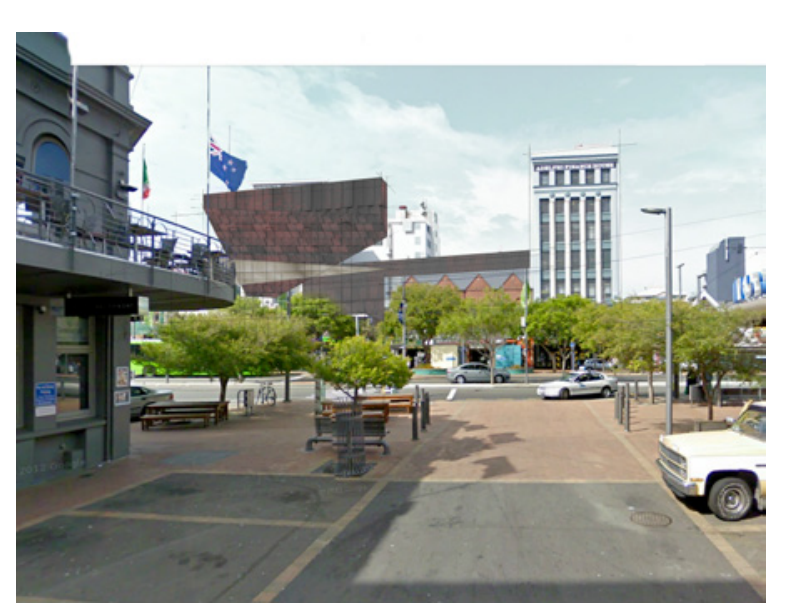

This design test is the first with garden space, an element that runs through each consecutive design as an intuitive and later formalised response to what would make this desirable to New Zealanders, and forms part of a 'goodweird' design solution.
Figure 1.1.24

cambridge

Terrace

$\longleftarrow$

Figure 1.1.25

Street elevation Courtenay Place

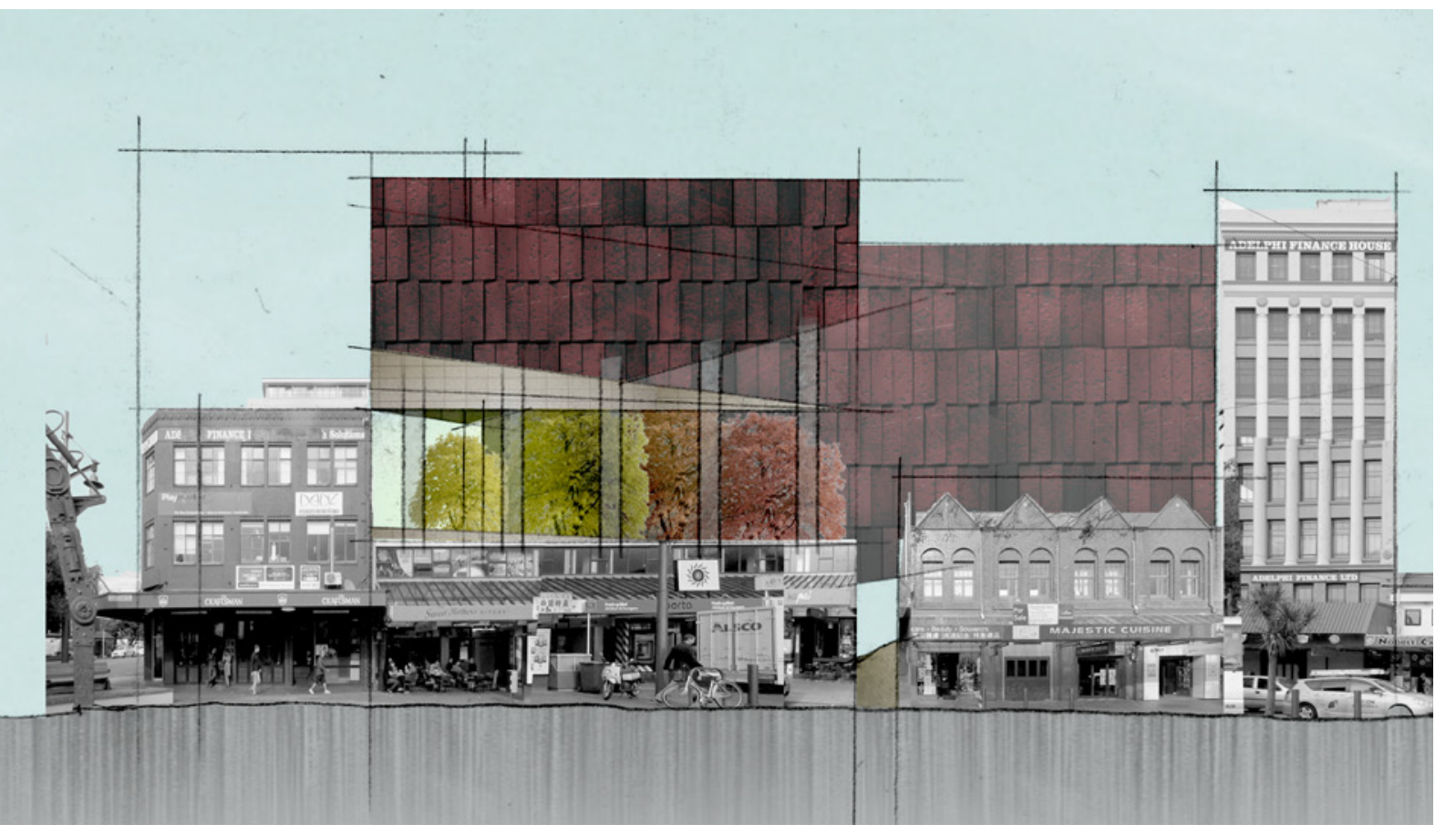


Points of Innovation

- Planning optimises solar access into central courtyard and units

- Lifting ground plane to face the sun improves courtyard solar access

Creating voids in the building envelope introduces an opportunity for garden within these

- Garden void architectural language offers potential for iconic architecture

- Internalising views to large common garden reinforces symbolic role that connection to nature plays in defining house and home

- Alpha Street activation through master planning public thoroughfare of site

- Year round sunlight to courtyard space and all units

Limitations to Address in - Garden and void types have potential for vertical integration

- Circulation yet to be considered in this initial design tes

- Unit layouts require rule formalisation to help solve for key attributes
Figure 1.1.26 North-South section showing cuts

and garden

interventions within $\longrightarrow$

Figure 1.1.27

Figure 1.1.28

Garden Study

Figure 1.1.29

Figure 1.130 Public

Common Private
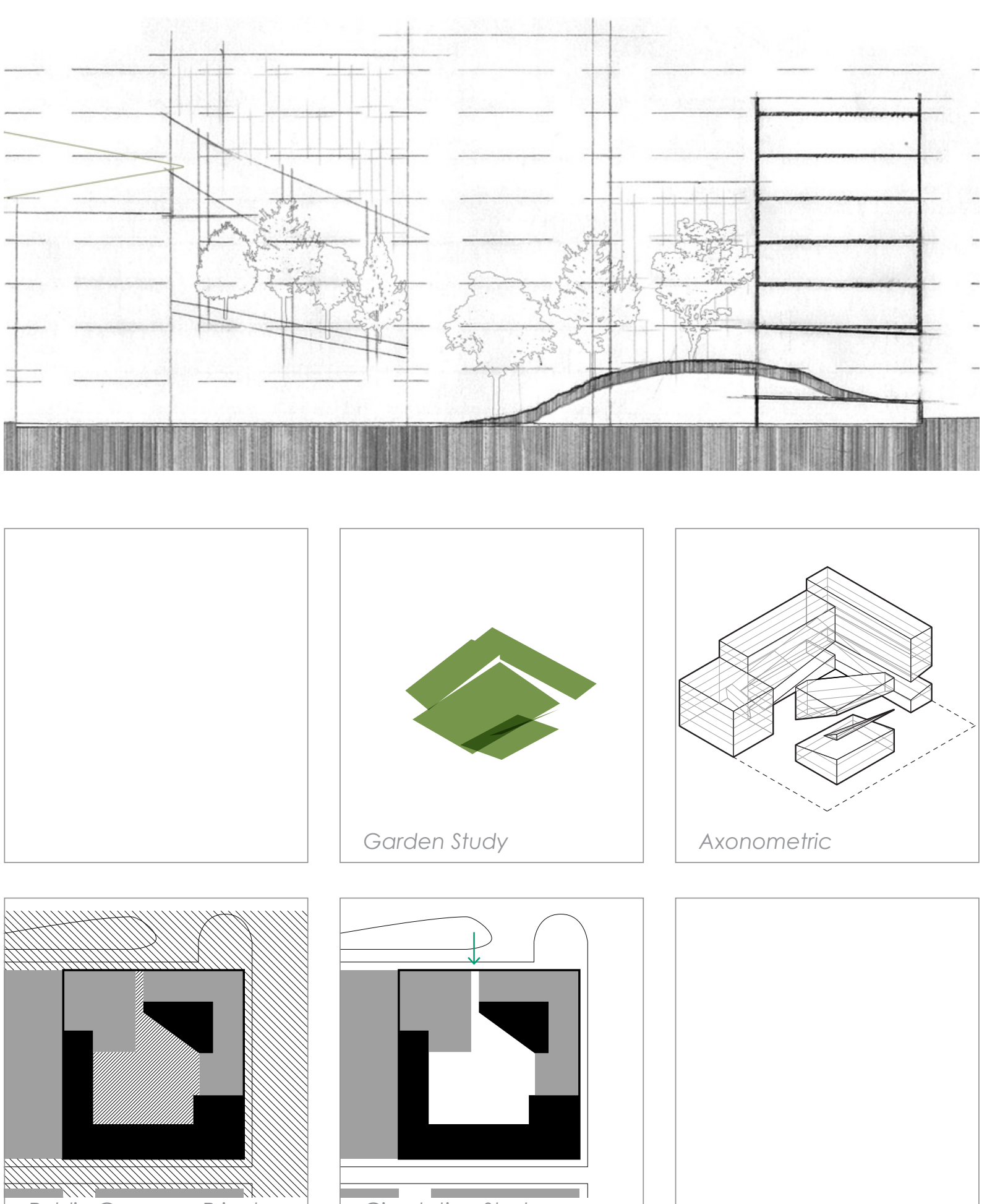

Circulation study

Public Common Private

Circulation Study

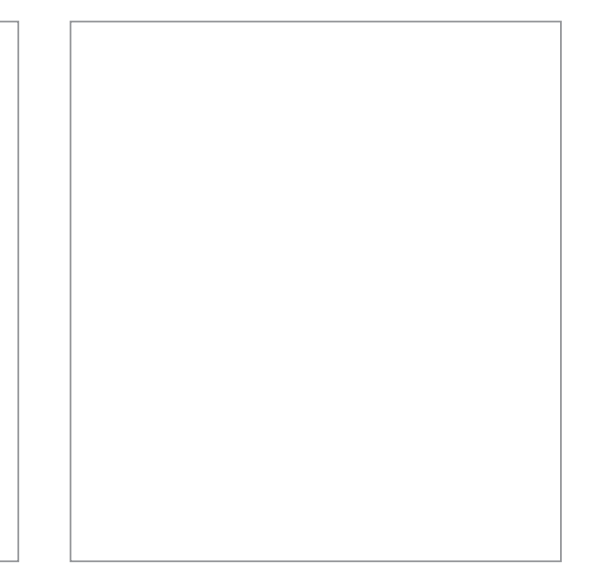

$\bullet \cdot \bullet \cdot 68$ 
CHAPTER 2
Design Test

Two

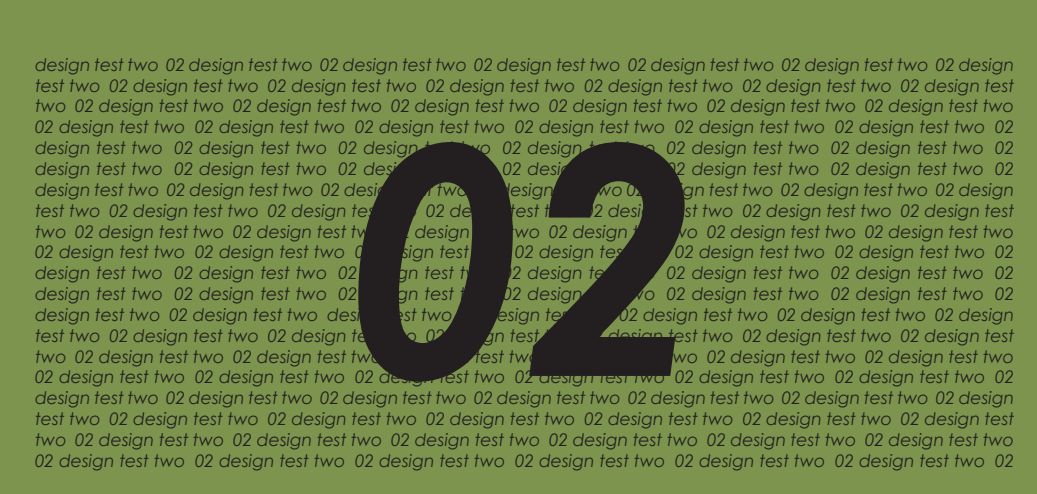


Architect

Location

Date

Programmes
Warren and Mahoney Architects Wellington

2000

Residential, Parking

sts

10
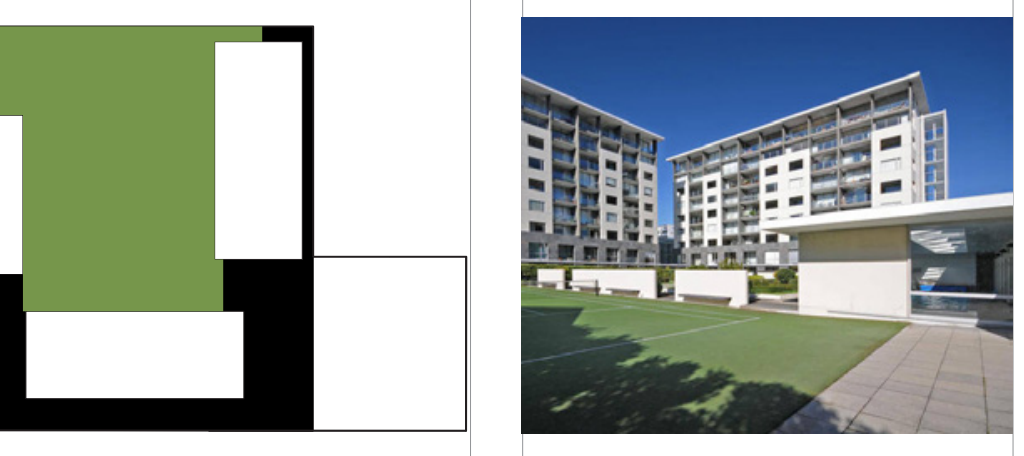

Perspective

Wellington's Sanctum Apartments is selected as a case study to help establish what contributes to enduring apartment desirability (as indicated by its consistently high unit prices).

Double storey apartments (maisonettes) feature in two thirds of unit cases,

a characteristic more commonly associated with detached housing (Leupen, et al., p. 142). Each unit enjoys a recessed balcony offering private outdoor space which helps to increase its desirability to New Zealanders.

Including a large common garden space, secure solar access and privacy, all positive CHRANZ attributes, sanctum prioritises similar amenities to later design tests.

This project helps gain an understanding of local desirable architecture and presents an uncommonly efficient circulation system which is applied during design test two. 
Dwelling Typologies

Maisonette - double aspects, Studio apartments - single aspect

Garden Typologies Courtyard, Ground floor units
$\checkmark$ Garden
Variety of Unit Types
$\checkmark$ sunlight
Visual Aspect
$\checkmark$ Privacy
Iconic Value

Adaptability

Flexibility in the double bay structural system allows potentia variety in unit compositions

Kebbell Classification
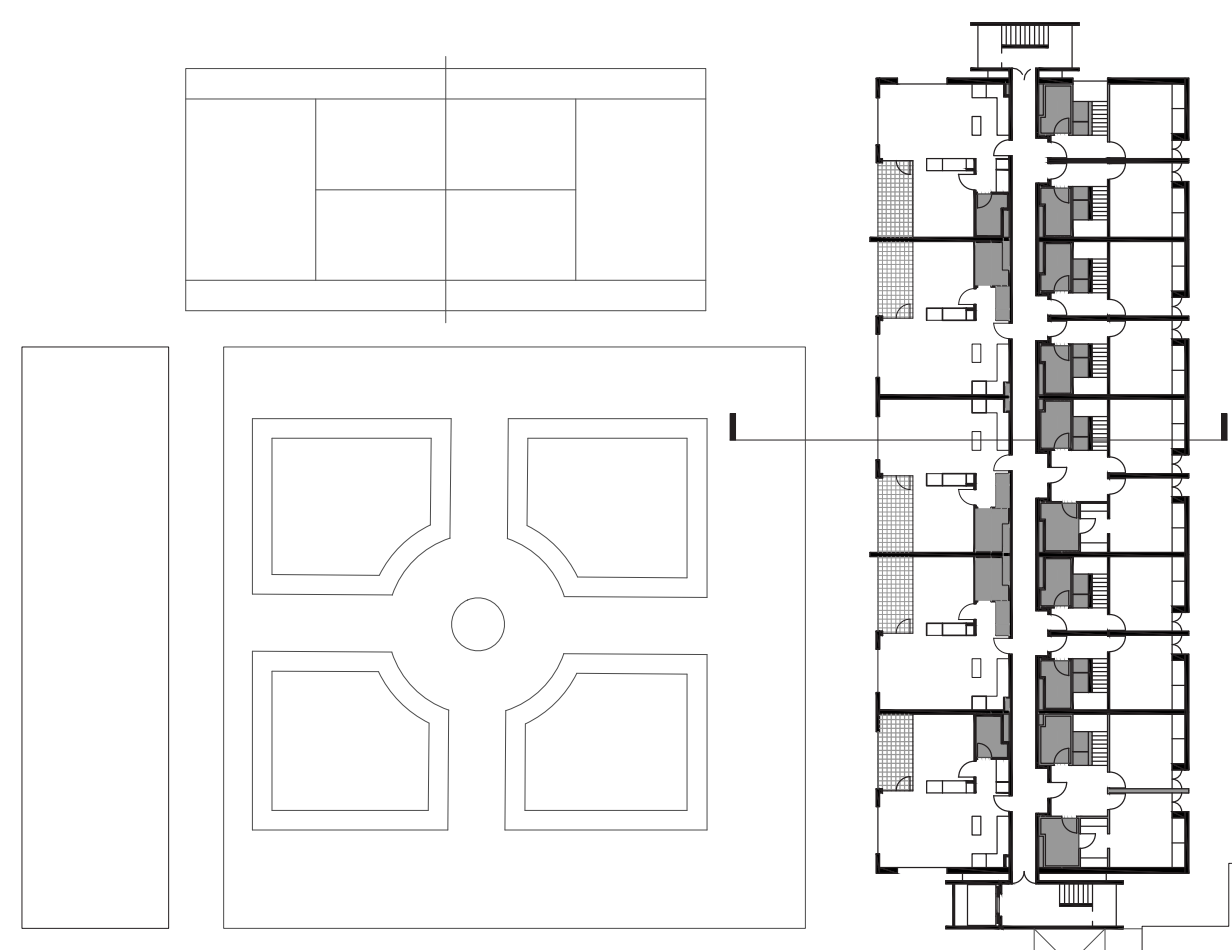

Figure 2.0.03
Typical Floor Pla

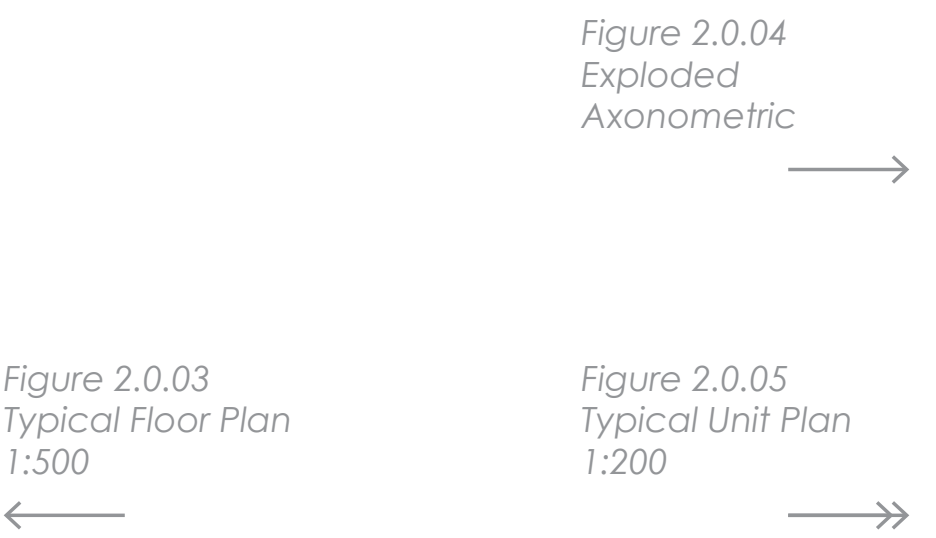

- Proven high resale values

- Designed for the New Zealand market; prioritising sunlight and privacy to individual units

- Double bay structural system allows for flexibility of unit arrangements in the appropriate ownership situations

Points of Limitation

- Set apart from its surroundings, with only a parking building along the street edge, the scheme does not

- Floor plans include inbuilt furniture rendering the rooms difficult to adapt for alternative uses

- Garden courtyard is infrequently used due to its visual exposure to the complex, rather it serves purely as a visual aspect and orientation device

- Units with balconies are sometimes home to families, although none with children between three and nine

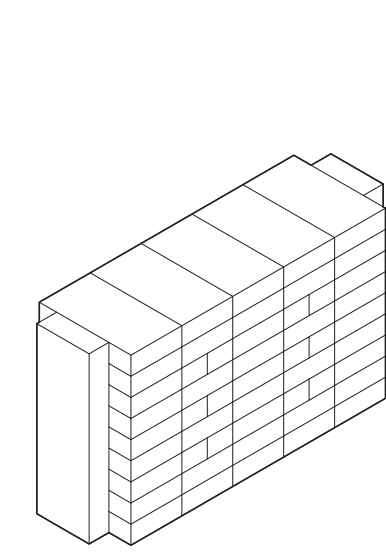

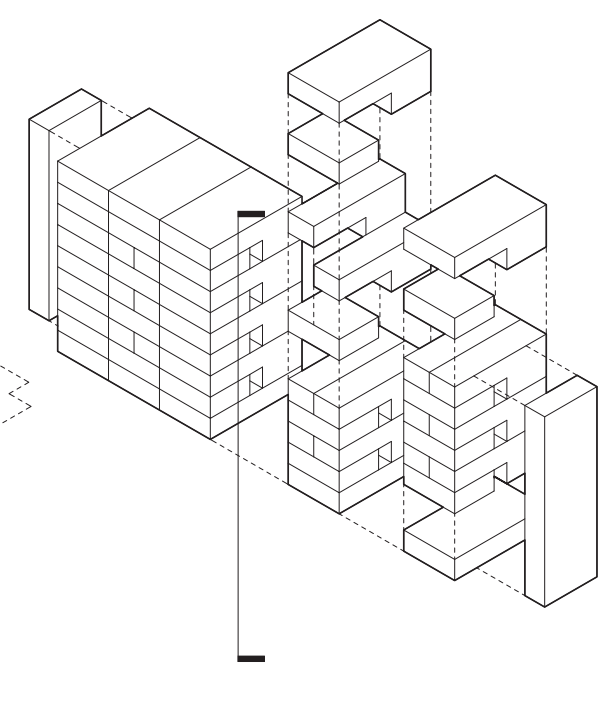
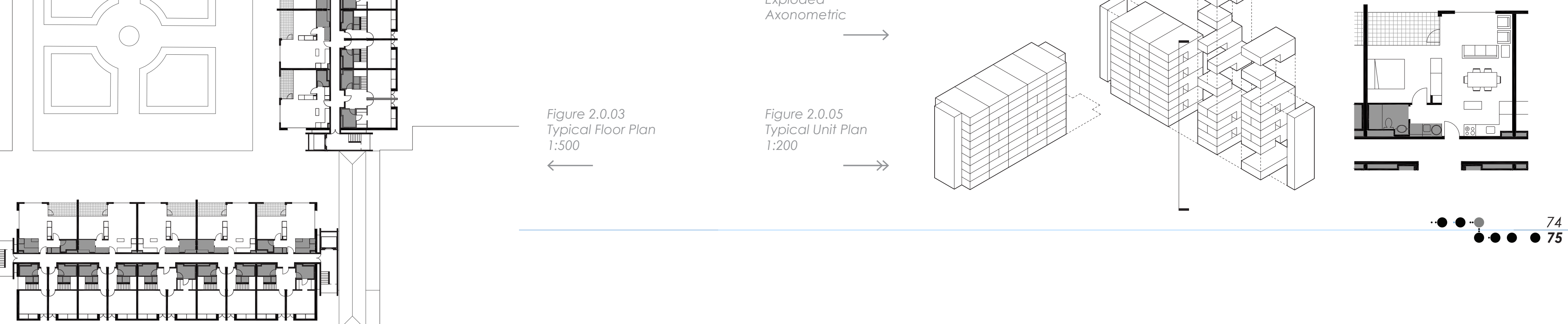

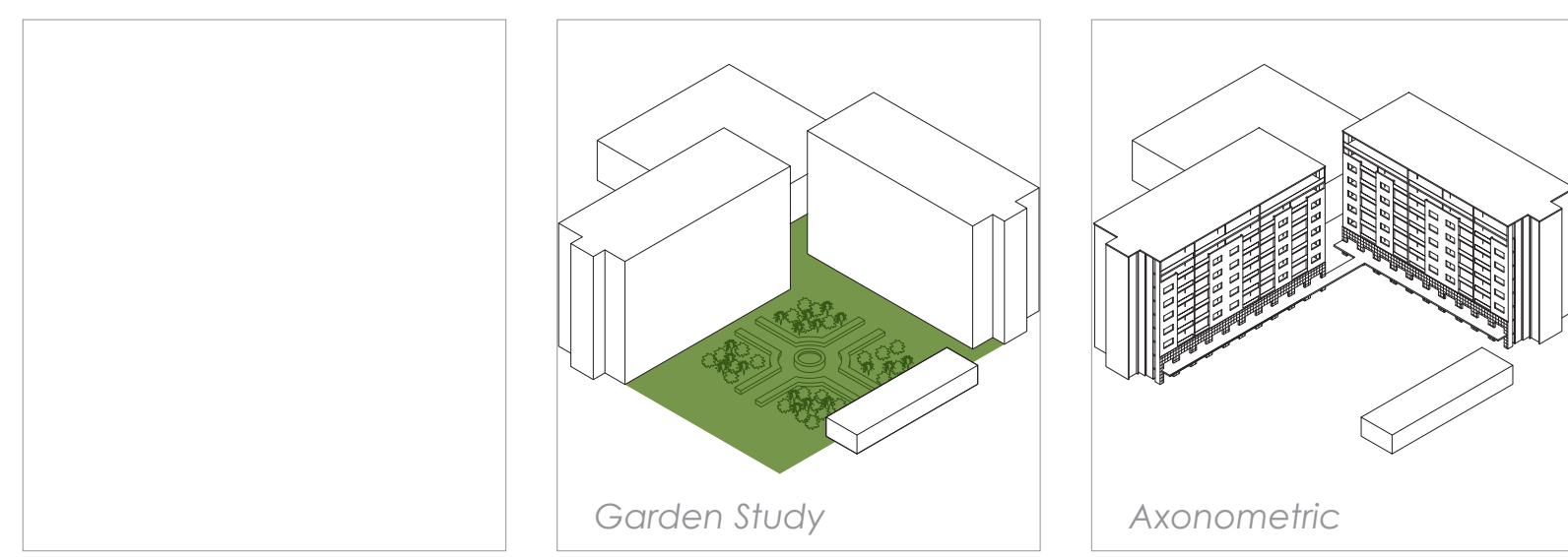

Figure 2.0.08 Ker

Section 1:500

Why this project was selected as a case

study and what was

learnt

- Introduces a circulation strategy with reduced corridor area, and associated unit layout oplions, allowing larger units or a reduced volume for the same sellable area

- Responds directly to sunlight and privacy concerns two design drivers prioritised following design test two Criver is also addressed although not integrated

- Confirms on-going desirability in relationship between prioritised design drivers and high resale value

- Implies arelationship between 'occupiablegarden' and the absent 'family with young children' demographic

Figure 2.0.09

Public Private

Common Study

Figure 2.0.10
Circulation Study
Figure 2.0.06

Garden Study

Figure 2.0.07
Axonometric

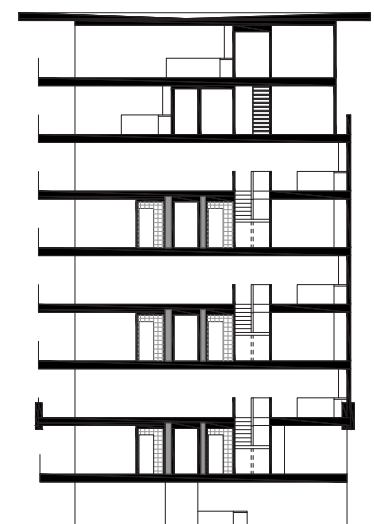

Figure 2.0.11

Demographics

Study

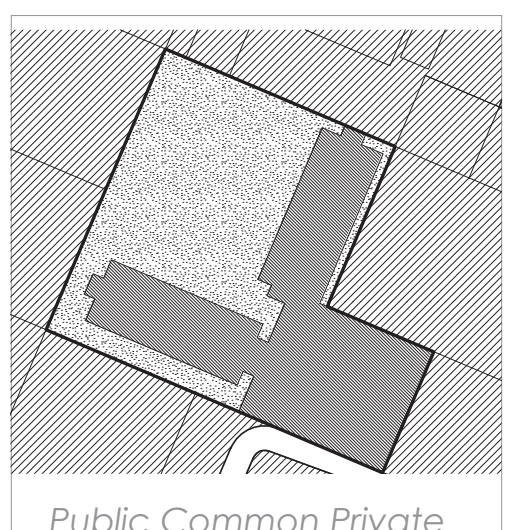

Public Common Private

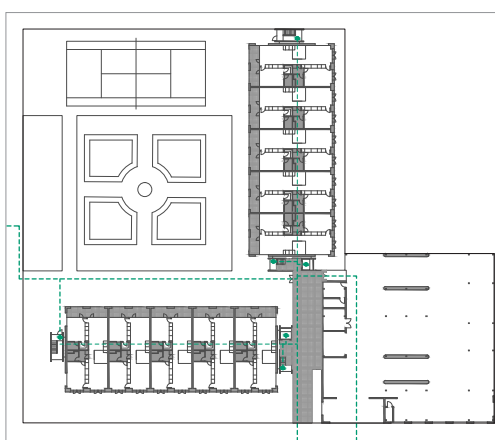

Circulation study

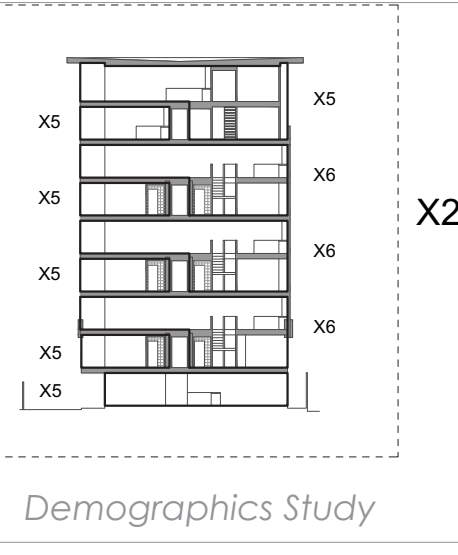


Design Development Mediums

Project Date

Key Drivers

Programmes
Hand drawing, Digital modelling Month 4 (June)

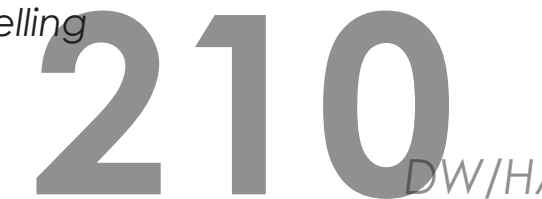

Testing different circulation and unit arrangements

Developing design rules to achieve high levels of natura light amenity to all units: 'double aspect' or 'shallow north facing to a requirements

- Introducing garden aspects to all dwellings

Residential, Ground floor retail
Design test two integrates iconic vertical garden stratifications to balance the hardness of high density housing with the softness of garden spaces and establishes how massing can be informed by garden.
Garden is used as the primary organisational device to optimise unit space and circulation layout. These three elements were kept separate but intersected to provide sequentia relationships to each (Figure 2.1.03, adapted Sanctum (Chapter 2.0)! 

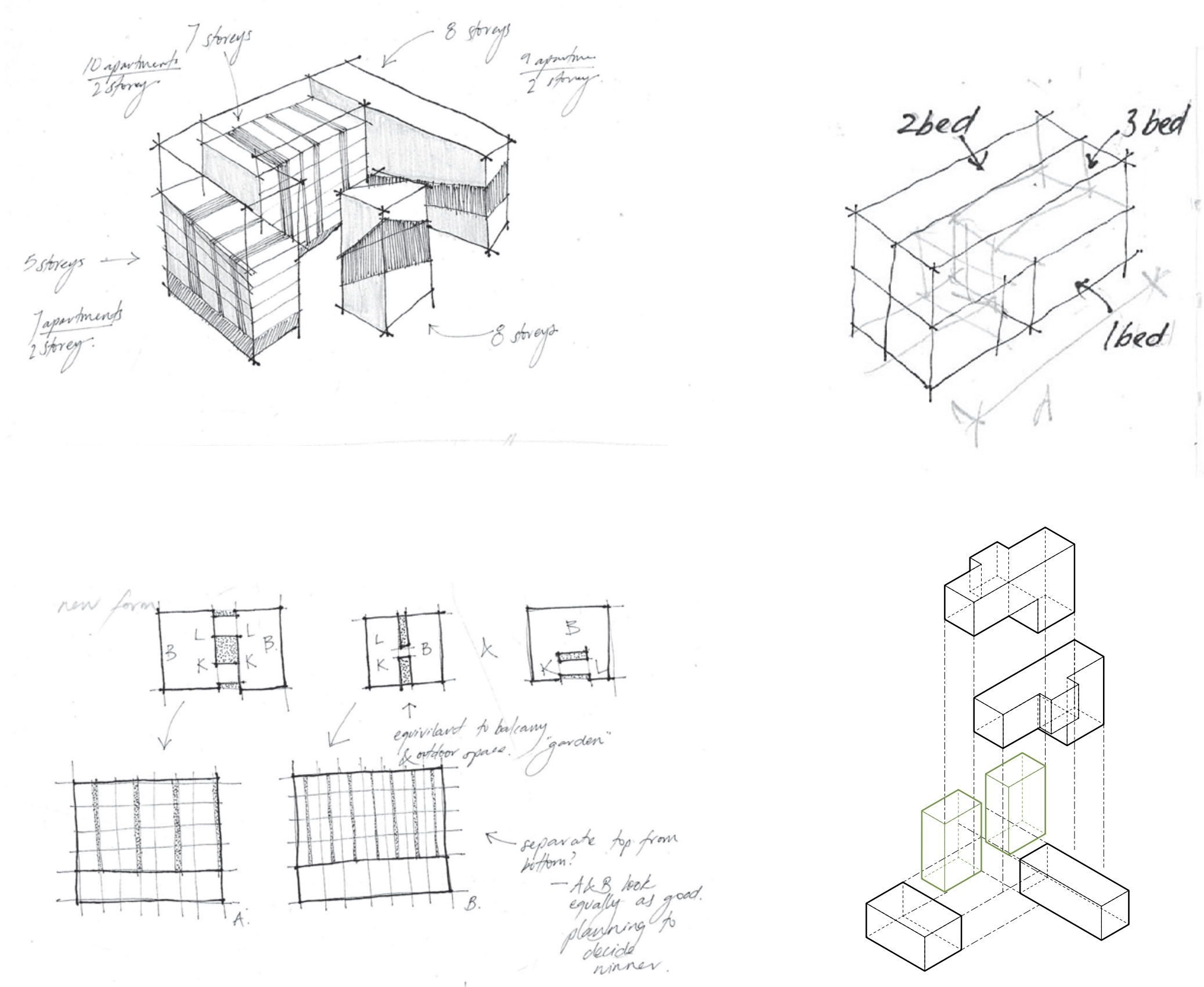

Studying how narrow a garden can be before it becomes uninhabitable, and

before it cannot be used as a screening

device, establishes this design test's 2-4m

vertical garden strata borders (narrowe end of screening). These borders provide light and privacy between the units within the $13 \mathrm{~m}$ deep floor plate.
Figure 2.1.01 Initial studies integrating garden with direct access from units

$\longleftarrow$

Figure 2.1.02 ion to unit study

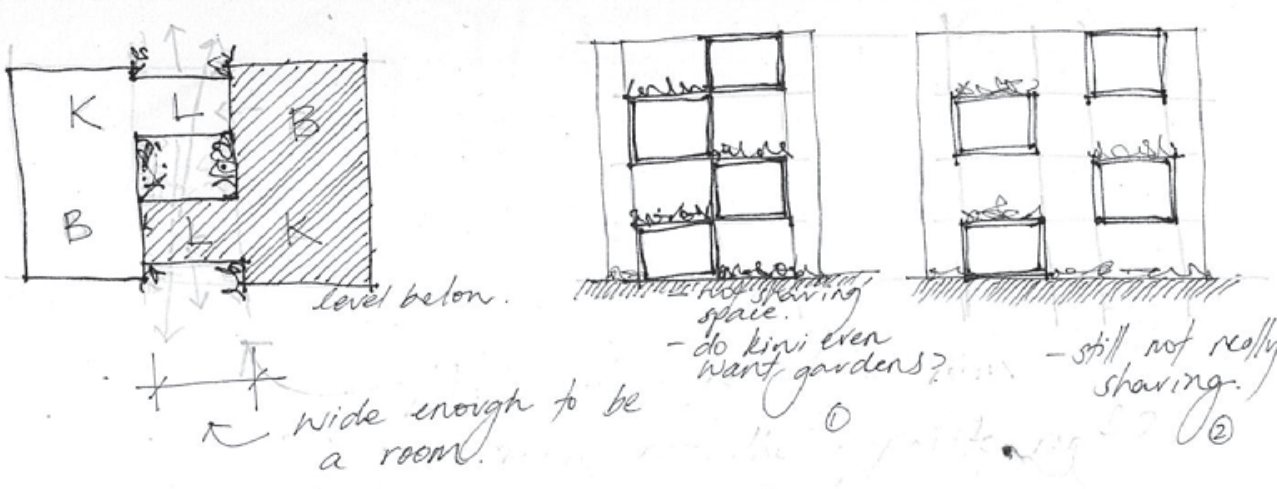

Figure 2.1.03 Diagram of
circulation, garden and unit relationship $\longleftarrow$
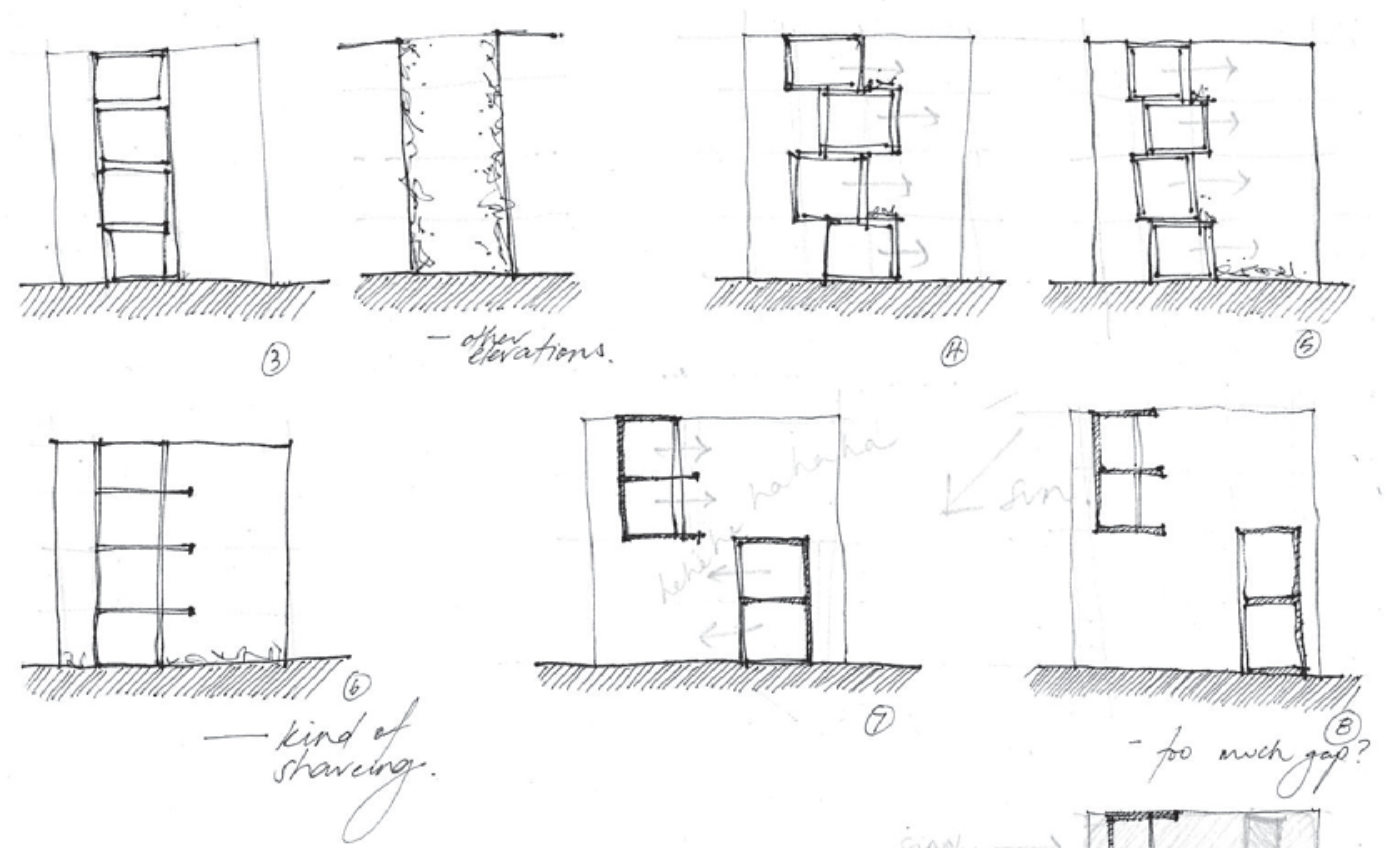

Figure 2.1.04 Vertical garden inserting between each unit stack

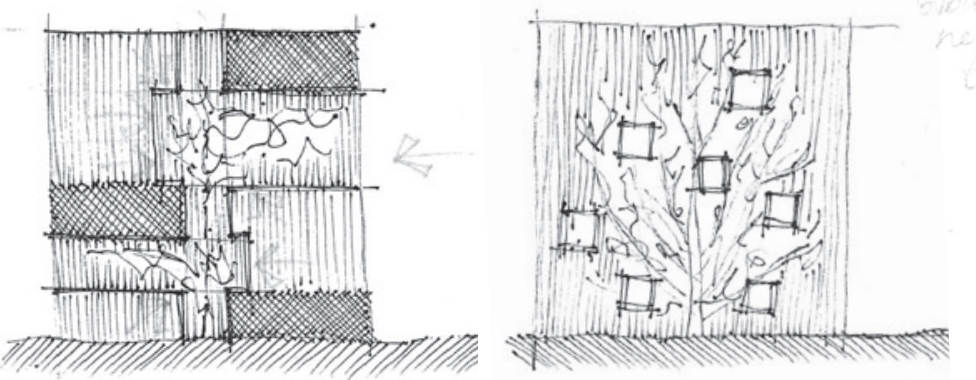




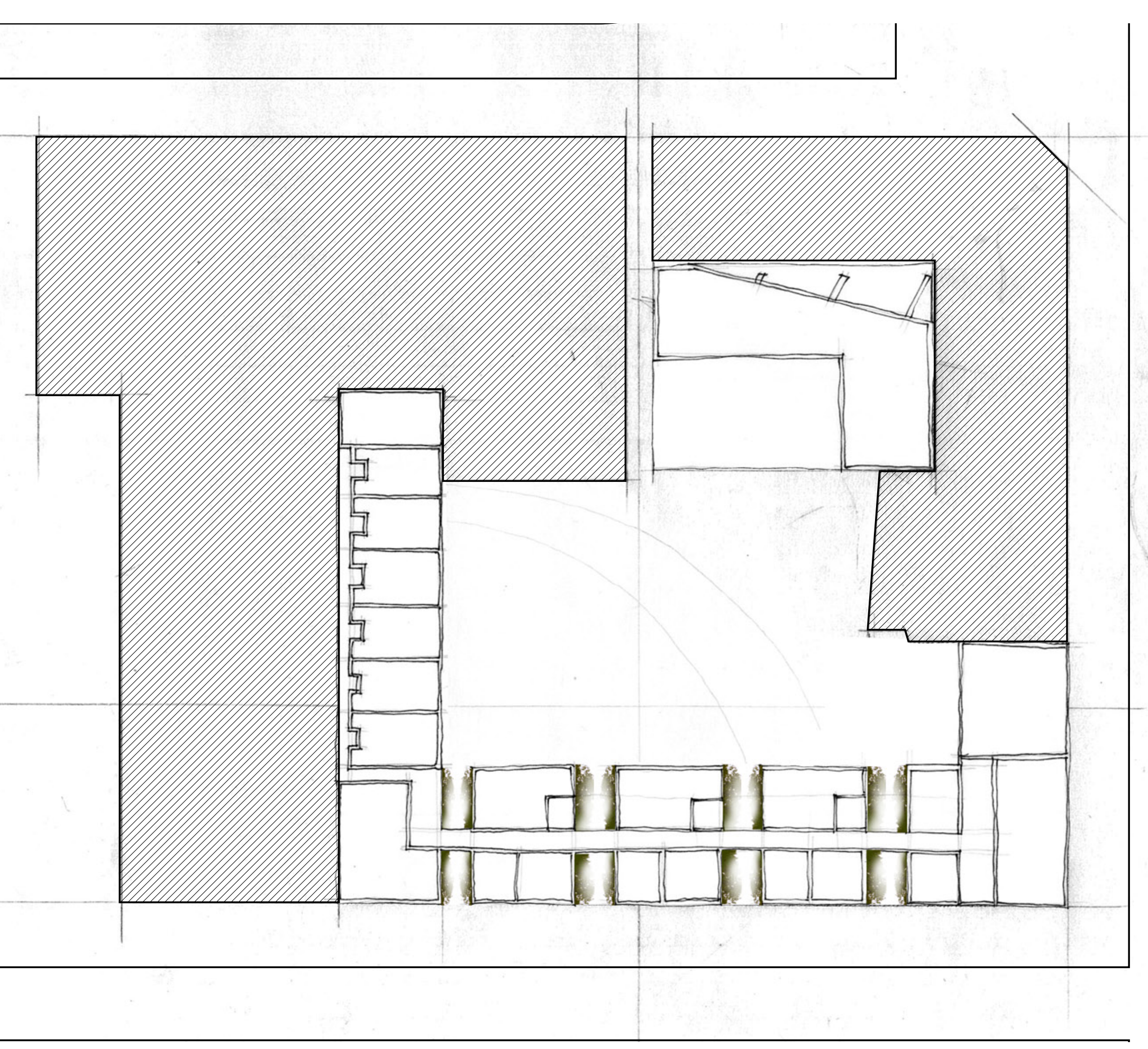

Figure 2.1.05

Typical floor plan

as presented in

June

Figure 2.1.06

East-West section/

elevation showing

interventions

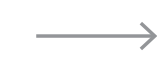

"Must have parameters people look for in their sanctuary are much the same in medium density as in conventiona and secure

environment

privacy; space,

light, and warmth:

and flexibility in

how it may be

(CHRANZ p. i)

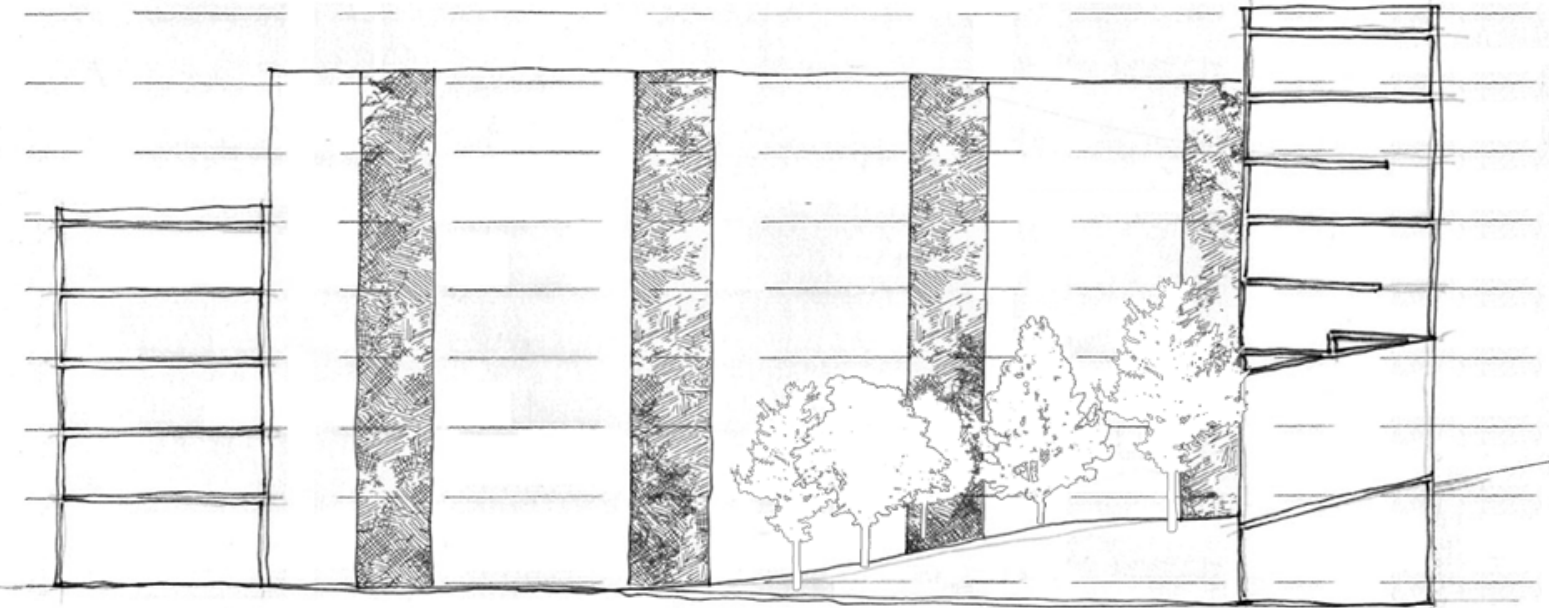

Indoor-outdoo

living is also

important, both

space it offers and

to meet a desire

for good light an

one hand and

access to the

outdoors on the

other.

(CHRANZ P. 57)
'Gardens remain a significant priority This may be to do with a sense of self-sufficiency, the satisfaction and tending a garden brings. or aesthetics and the ability to create something

(CHRANZ p. 57)
Balancing 29 CHRANZ aspects, six additional incentives, site constraints and a 250 DW/HA density criteria simultaneously proves to be challenging. Thus a prioritisation of design constraints is introduced following this design test. Returning to the primary text, three design criteria are brought forward above the others to be used to design all further iterations: the desire for garden space, sunlight and privacy. 

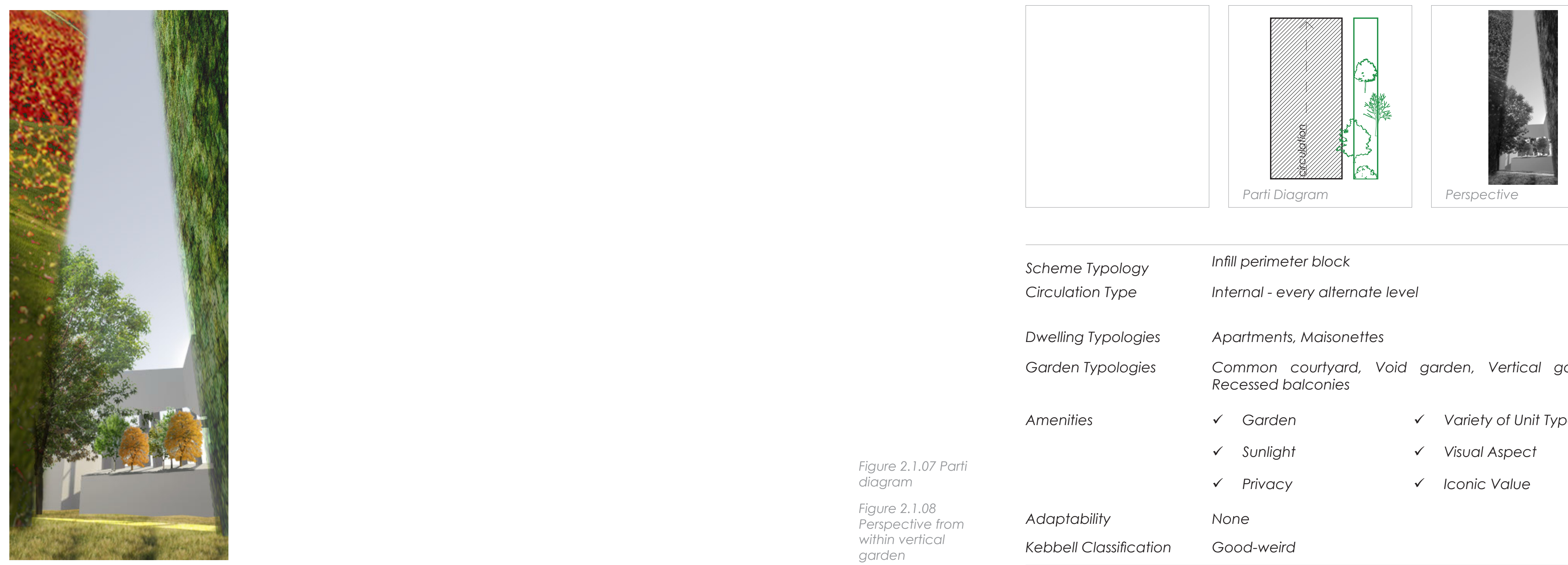

Scheme Typology

Infill perimeter block

Circulation Type

Internal - every alternate level

Dwelling Typologies

Garden Typologies

Apartments, Maisonettes

Common courtyard, Void garden, Vertical gardens,

Amenities

$\checkmark$ Garden

Variety of Unit Types

Figure 2.1.07 Part

Figure 2.1.08

within vertical

Adaptability

Kebbell Classification

$\checkmark$ sunlight

$\checkmark$ Visual Aspect

$\checkmark$ Privacy

$\checkmark$ Iconic Value

None

Good-weird 
Points of Innovation

- Iconic potential in vertical gardens

- Horizontal circulation spaces have multiple relationships with vertical gardens

Units with openings into vertical gardens provide individual verdant connections for all

- Efficient circulation network operates on every alternate storey

- Accurate understanding of project's yield/volume relationship

Scheme has lost public permeability reducing its capacity to activate Alpha street and give back to its surroundings

- Potential for future development on adjacent western site not addressed. If this site is built out to the council's compromised and the western block's solar access defined form becomes redundan

- Relationships of units and circulation spaces to garden is limited to aspect only with no potential for individual engagement
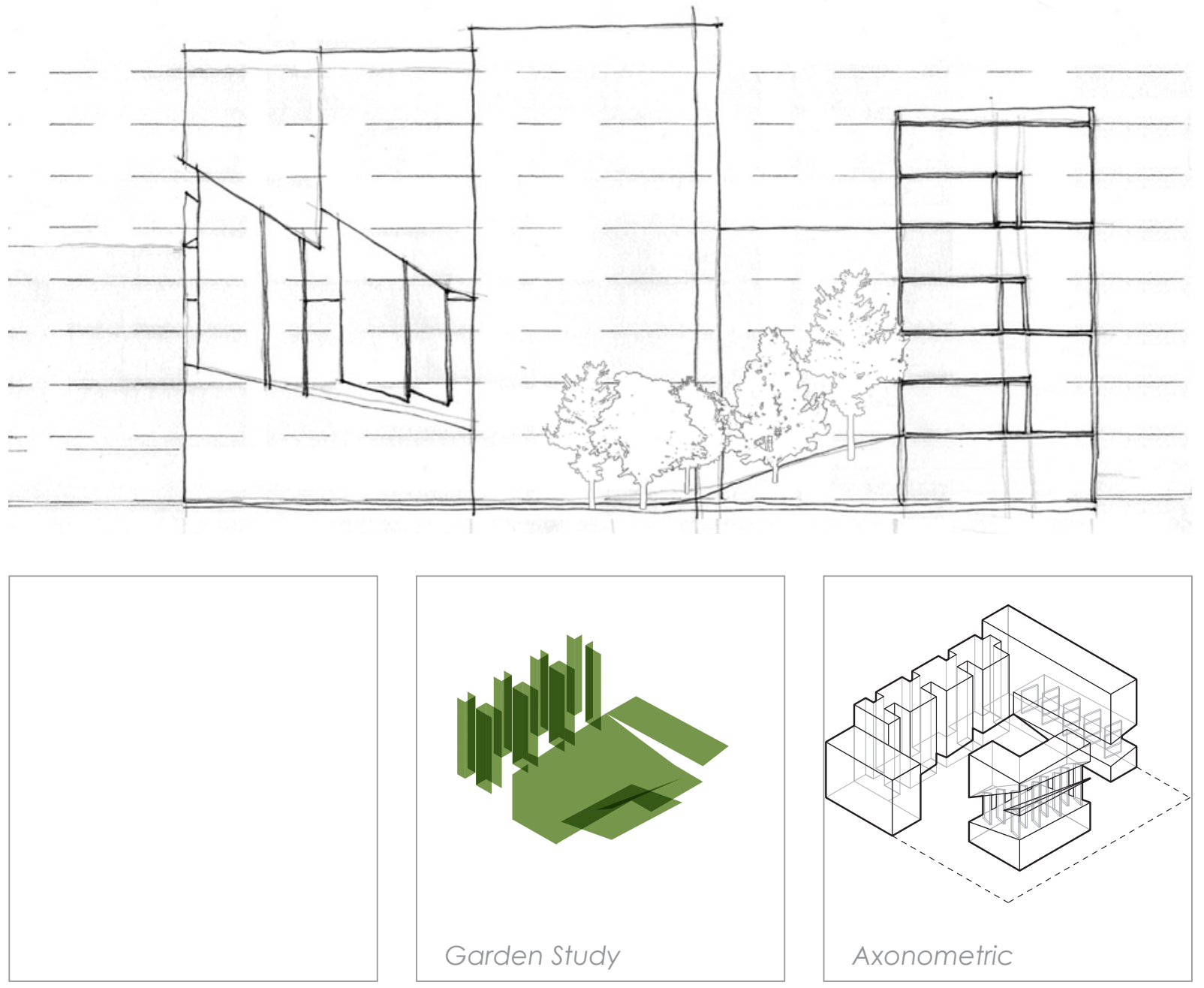

Figure 2.1.10
Axonometric

Figure 2.1.11

Garden Study

Figure 2.1.12
Circulation Study

Circulation study

Figure 2.1.13 Public

Figure 2.1.14

Perspective from

northern garden

void
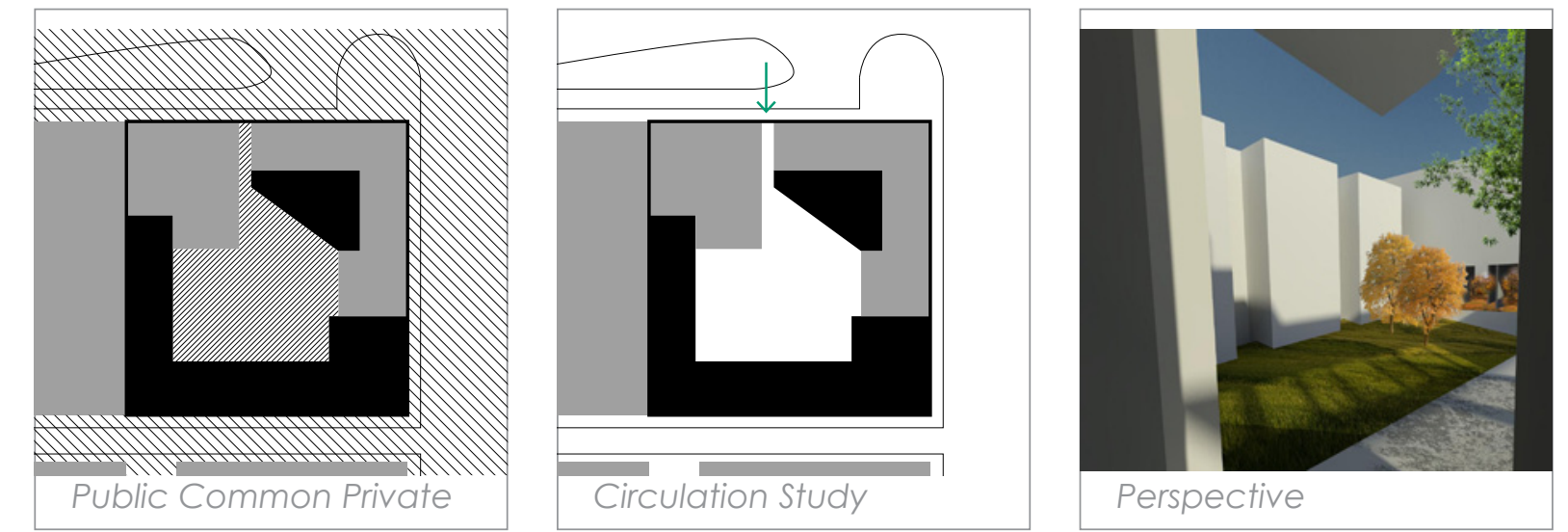

$\bullet \cdot \bullet \cdot \bullet \bullet \quad 86$ 
2.2 Question Identified

Garden, sunlight and privacy are established as the primary desirable amenities of any New Zealand dwelling. In an effort to attract suburbanites away from single detached homes these amenities may be reconfigured at urban densities to make this type of living more desirable.

The question posed for this research is as follows:

"How can a high density housing scheme

that responds with prioritised garden. sunlight and privacy amenity be used to develop a desirable inner city housing model? 


\section{Pant 2}

RESEARCHING AN ANSWER Solving using architecture 
CHAPTER 3
Design Test

Three

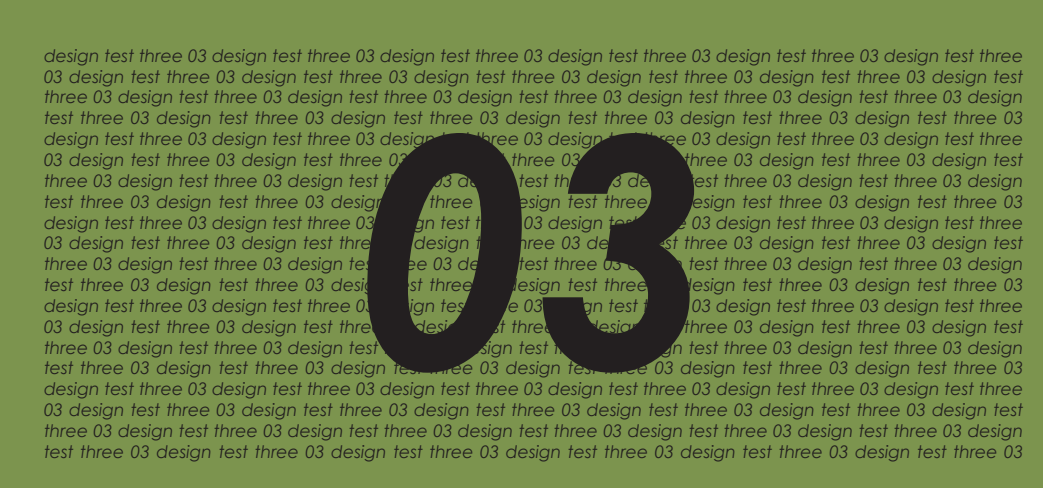




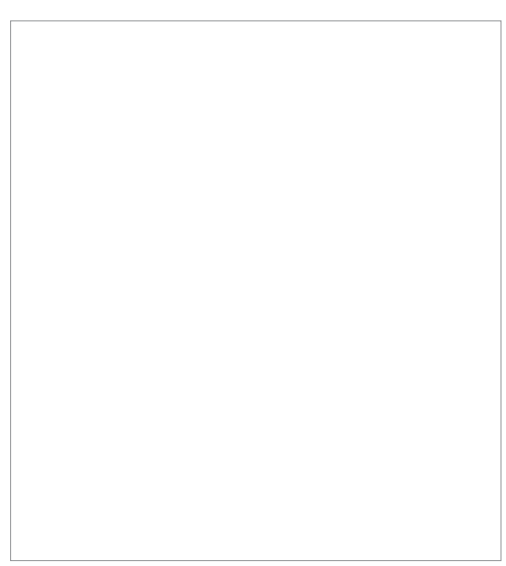
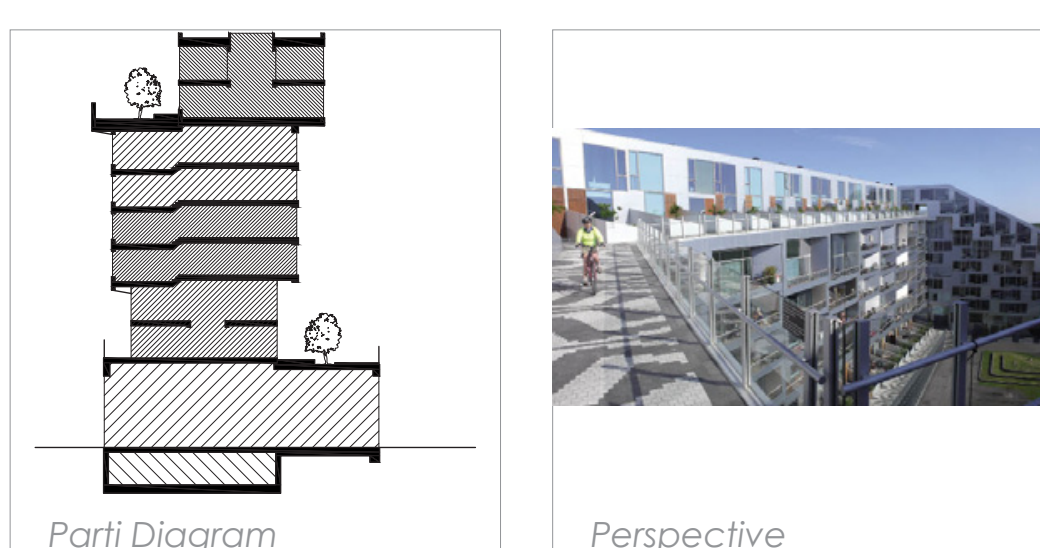

The 8 House is a highly significant buil work that includes many innovative and contemporary responses to modern and traditional issues from built form through to lifestyle.

The block's morphology reinvents the perimeter block to achieve higher density and a more interesting architectural form in this mixed use development.

by inviting a broad footpath ('Street in the Sky') to meander through the development catalysing community interaction. Additionally this footpath provides external access to apartments, a garden walk and vistas to the country beyond the latter two 'borrowed landscapes' (Chapter 7 page 205).

Lifestyle is considered in the notion of

Desirability is further enhanced through Bjarke Ingels' name, a famous Danish 'Neighbourhood Street', facilitated

architect, attracting a demographic of design conscious residents. 
Scheme Typology

\section{Perimeter Block}

Circulation Type

Dwelling Typologies

External 'Street in the Sky', Internal stairs and lifts

Garden Typologies

Terrace house, Apartmen

Terraces, Courtyards

$\checkmark$ Garden

sunlight

$\checkmark$ Variety of Unit Types

Privacy

Visual Aspect

$\checkmark$ Iconic Value

None

Adaptability
Kebbell Classification

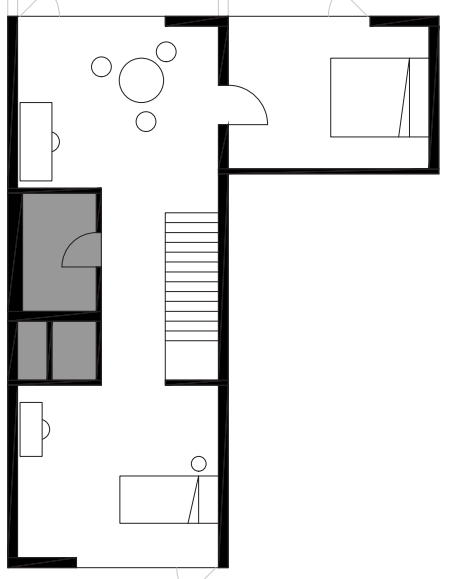

Figure 3.0.04 Unit Upper Level Plan

igure 3.0.05 Un pwer Level Pla

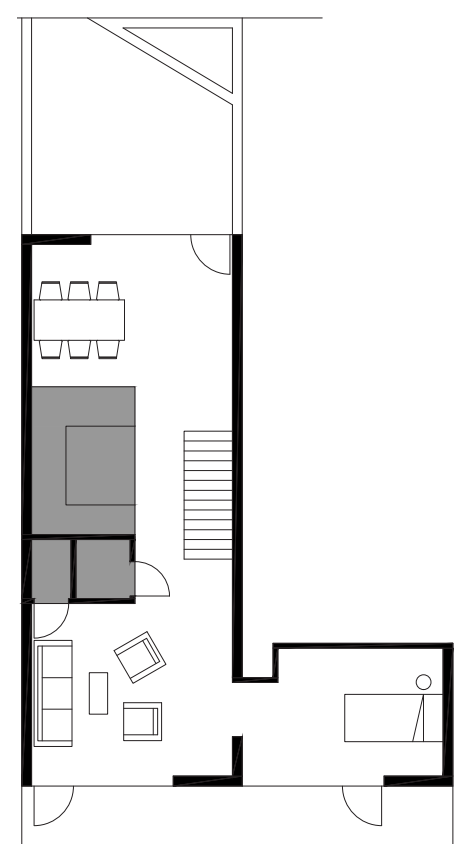

Figure 3.0.03 Typical Row Hous Level Floor Plan 1:500

Figure 3.0.07 Assembled

Figure 3.0.06 Axonometric

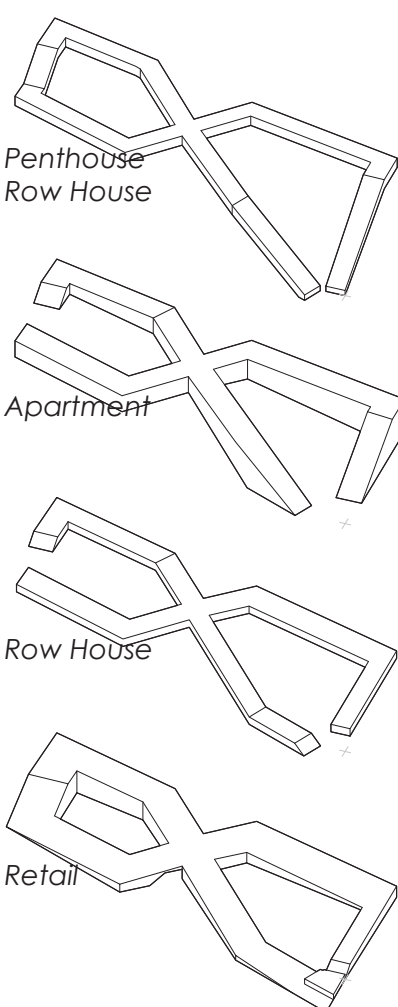

Points of Limitation
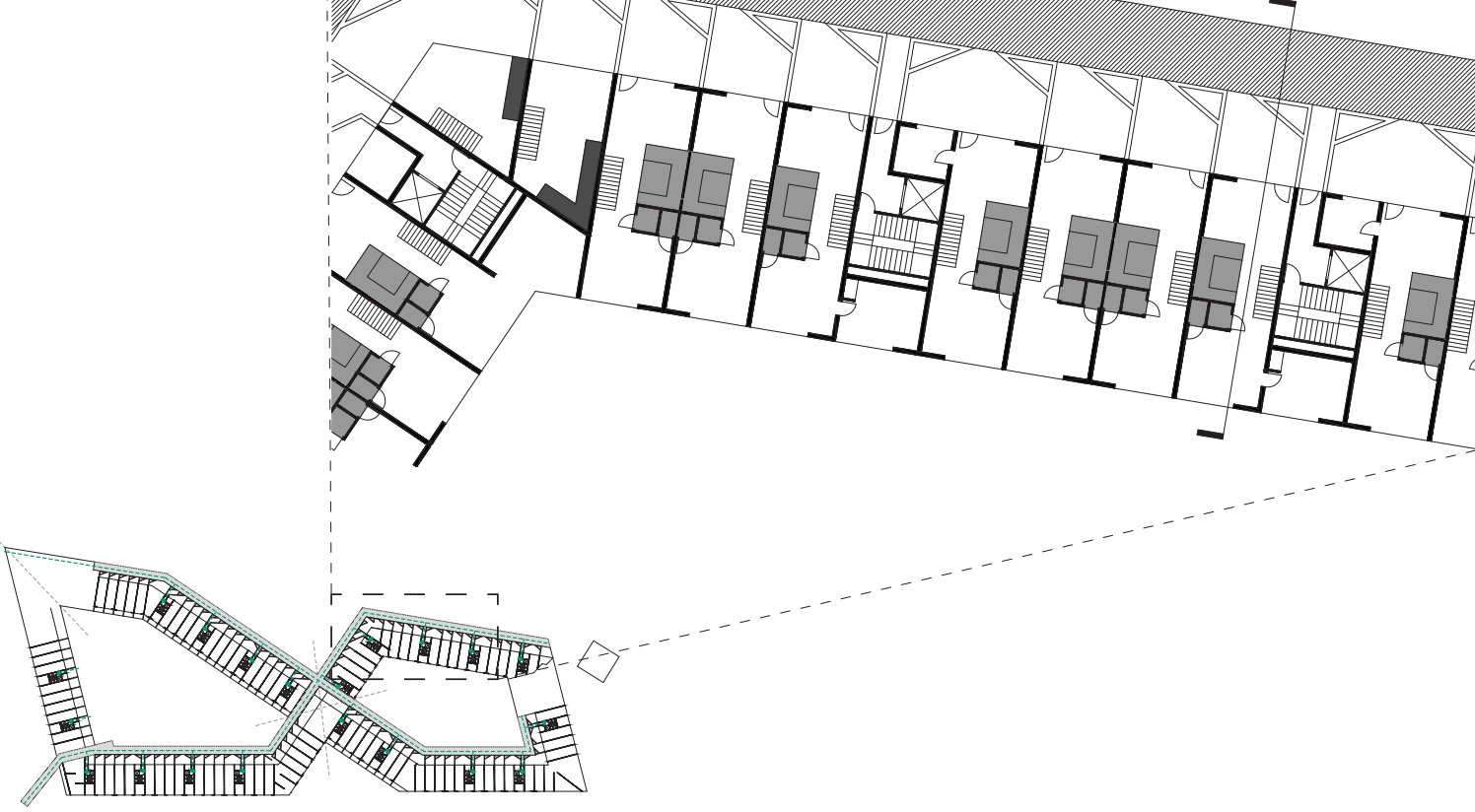

- External garden based circulation ('Street in the Sky') creates a pleasant pedestrian, cycle friendly and occupiable circulation area that uses planting as a

- Garden used as screening to provide privacy between common circulation and private garden areas and

- Mixed-use development provides greater immediate amenity access

- Common amenities including a cinema, cafe and courtyards, add value to the neighbourhood

- Variety of unit types ranging from 2 to 6 bedrooms over three different typologies (terrace, apartment and penthouse). Units vary between $58 \mathrm{~m}^{2}$ and $181 \mathrm{~m}^{2}$ with gardens of up to over $30 \mathrm{~m}^{2}$ each. This housing variety the family cycle. the family cycle.

- Iconic, simple and innovative design preposition based on twisting a perimeter block. This block typology is consistent with its Copenhagen context

- Plans are forced into an unusual overriding form causing inefficient use of internal space. These are causing ine ficient use of internal space. These are units, by space restrictions

- This development is in a newly released section of infrastructure so cannot draw upon local amenities 


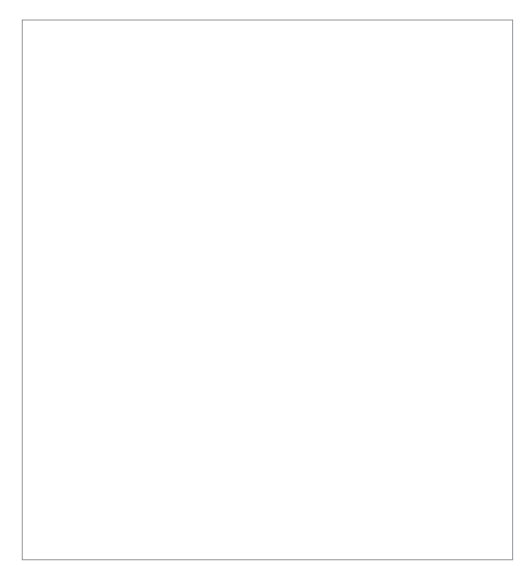

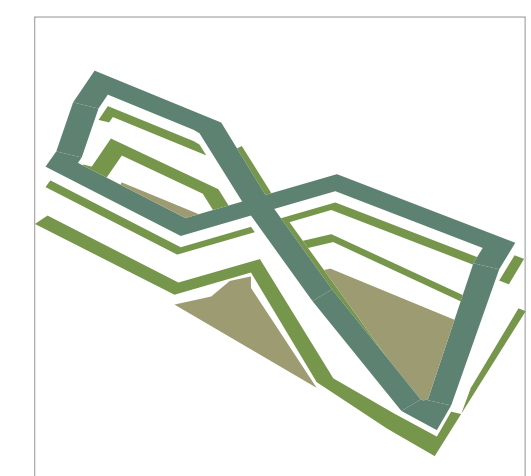

Garden Study

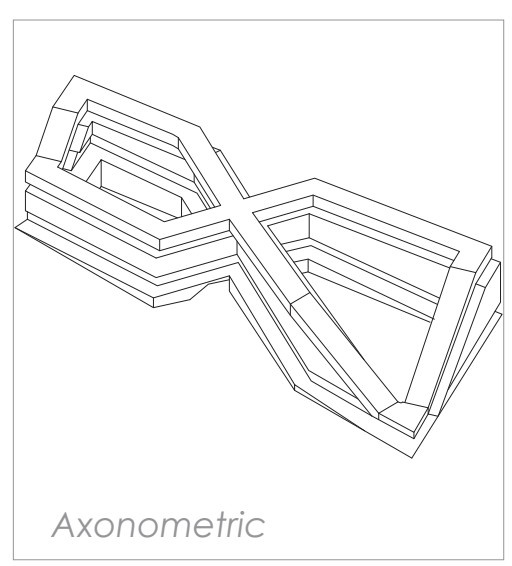

Axonometric
Why this project was selected as a case

- With public access provided through the site, and a boundaries can be applied in future design tests

- External circulation network shows how much space is required to produce an effective, and social, common space

- Complex unit stacking options demonstrating possibility for diverse floor plan options study and what was similar target density, the public, common, private
Figure 3.0.10 Key

$\square$

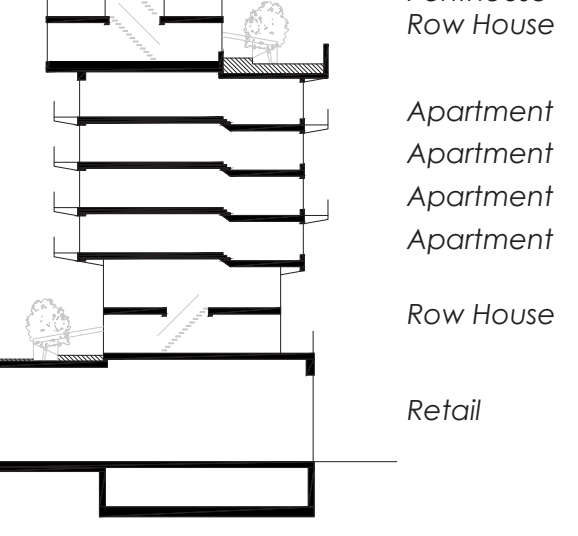

$\square$
Figure 3.0.08 Garden Study Figure 3.0.09
Axonometric
Figure 3.0.11 Public Private Common study Figure 3.0.12
Circulation Stu Figure 3.0.13 Demographics Study
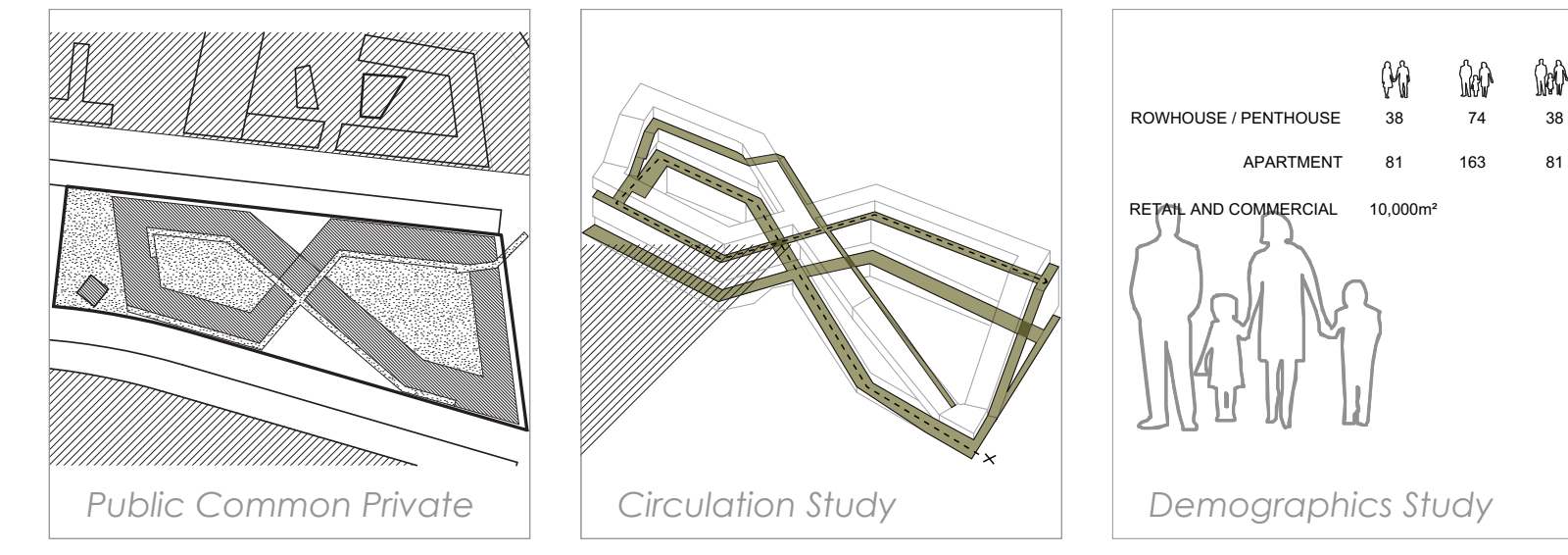
3.1 Common Green Network

To structure and combine the priority amenities a 'common green network' driver was introduced. Conceptually, external landscapes are integrated as the primary circulation and privacy screening device to provide garden sunlight and privacy for all dwellings.

The concept's initial application in design test three (A) provided public garden courtyard and play-area platforms, overlaid and offset, circulating up a central area to rooftop level. However, the platforms required numerous stairs and bridges to connect units which compounded a solar access issue, did not address all amenities and looked awkward (bad-weird). 

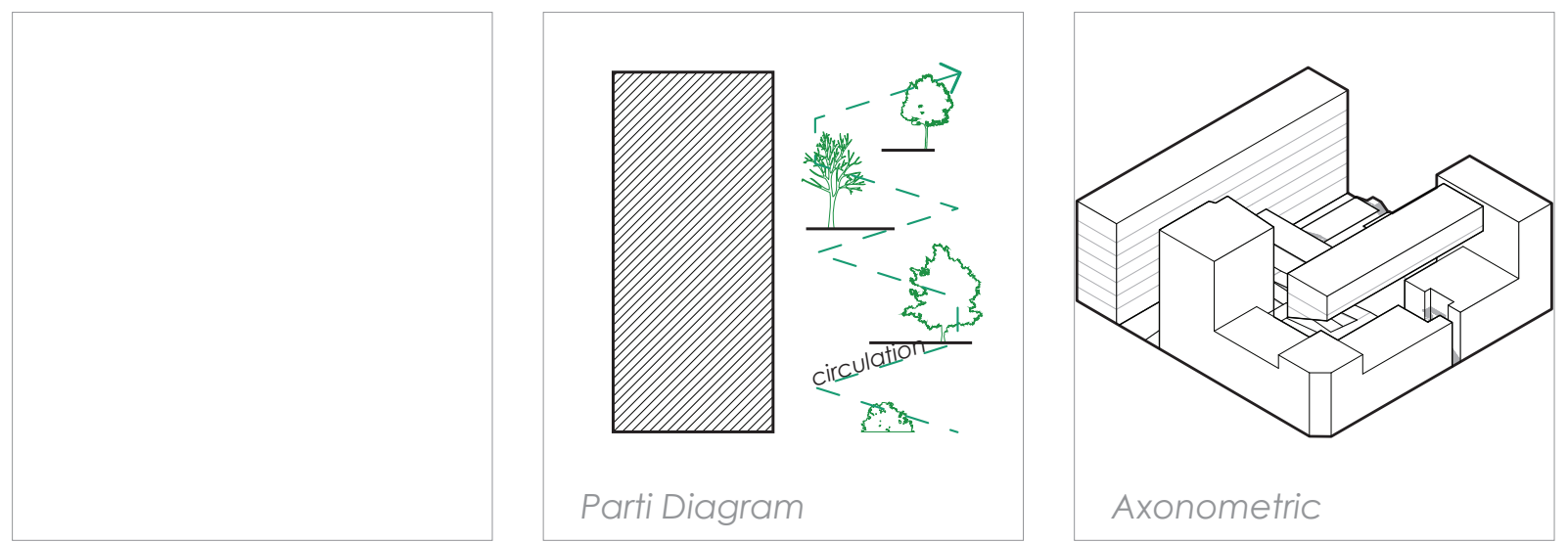

\section{Design Developmen}

Mediums

Project Date

Key Drivers

Physical modelling, Digital
modelling Digital collage

modelling, Digital collage

Month 5 (July)

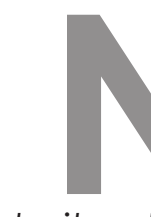

- Providing acr

- Giving public access to rooftop gardens upon existing

buildings along Courtenay Place

- Retaining secured solar access to all units 

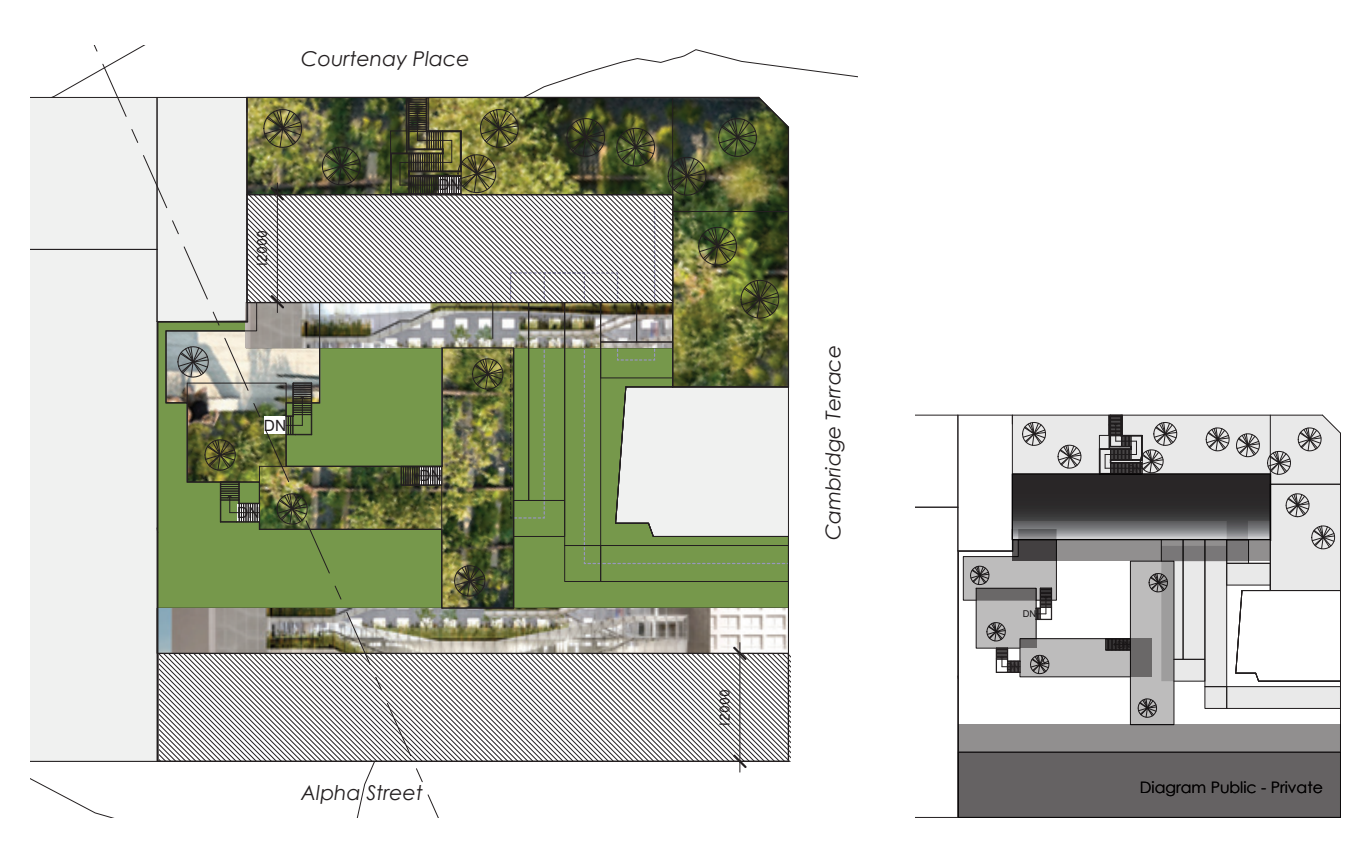

Figure 3.1.03 Site

Plan rendered to

show overlaying

platorions in the

Common Gree

Figure 3.1.04

Public, Common,

Light grey = public

through to dark
grey = private

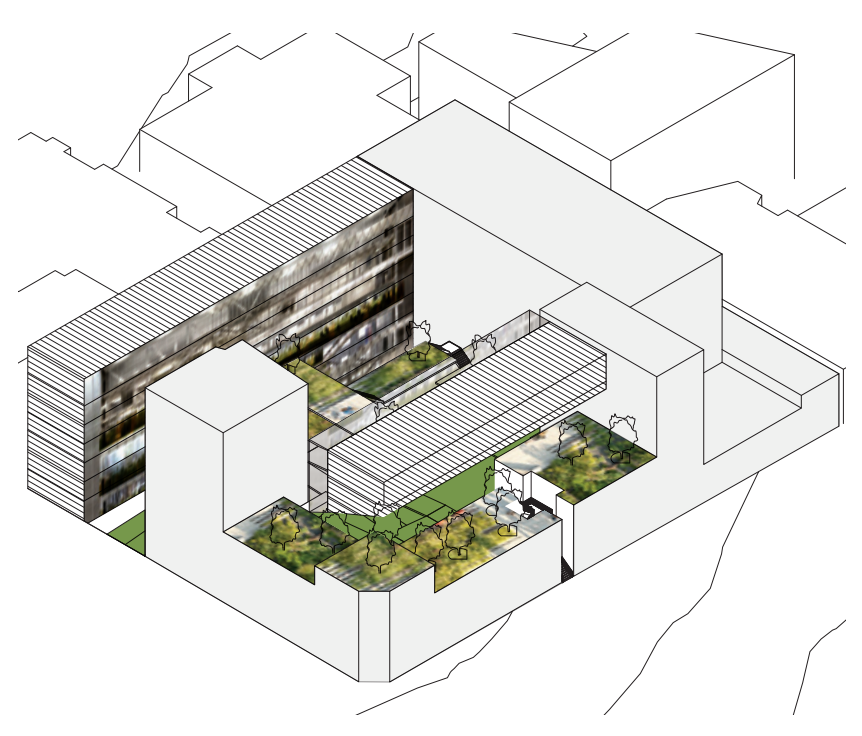

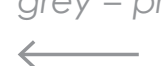

Figure 3.1.06

政

rendered showing

to public roof

gardens on the

$\longrightarrow$

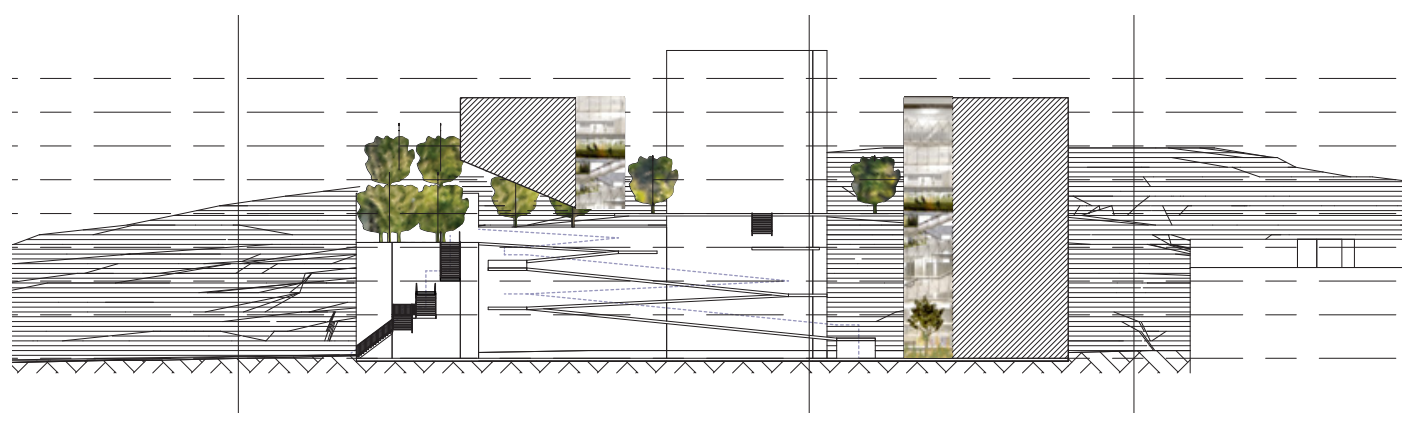

Figure 3.1.07 East-

west section

vertical platform

produced large

Figure 3.1.05

Rendered isometric

Common Green

Network in contex

shows negative

affecting the

lower apartments

and streetleve

$\longrightarrow$

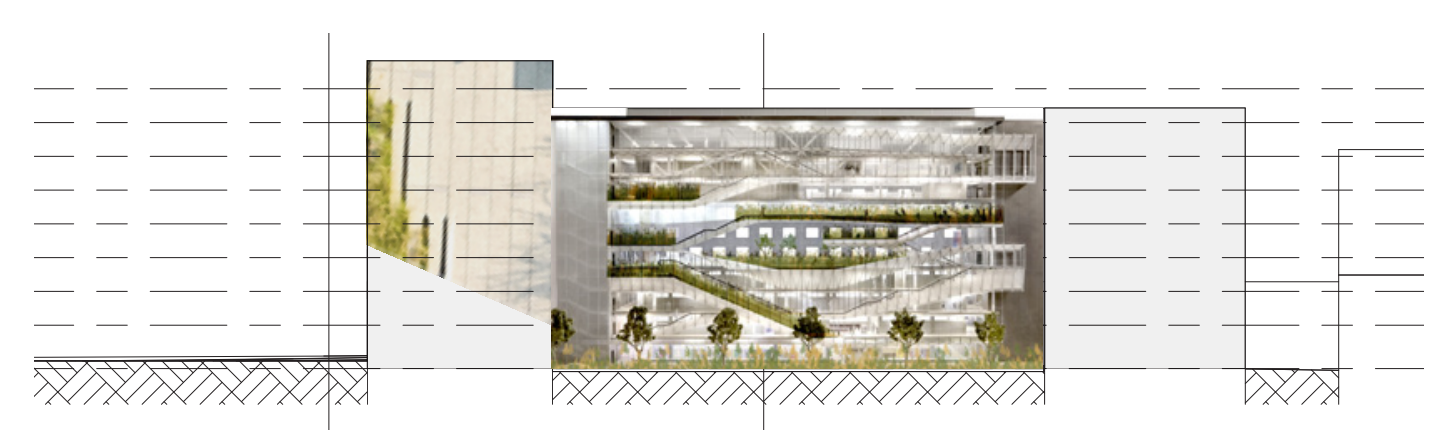


Figure 3.1.08

Building to green
space relationship

tests

$\longleftarrow$

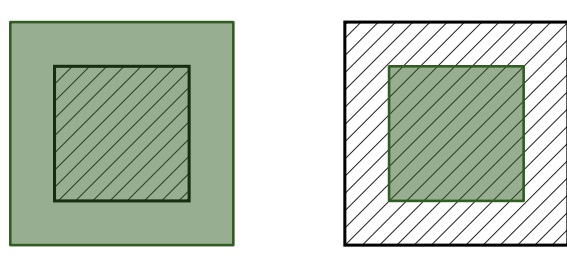

IIIII IIII

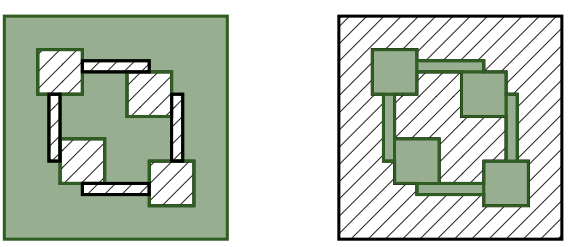

\section{$\square$}

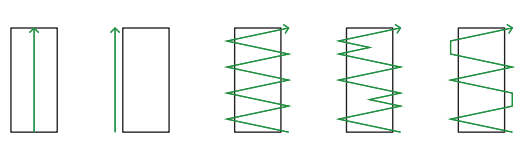

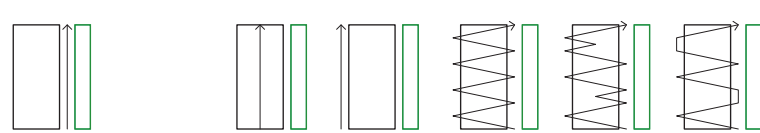

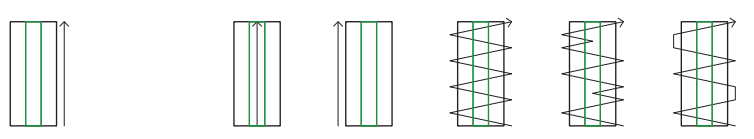

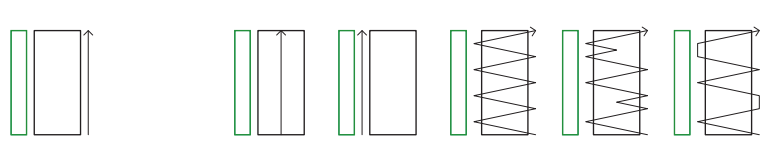

$\square \quad \square \square \square \square$

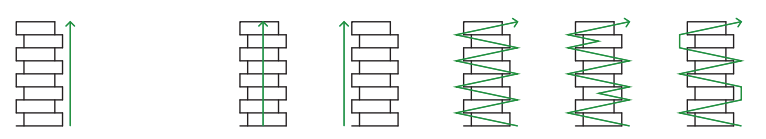

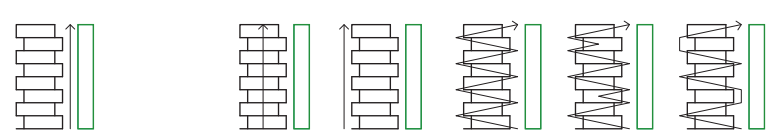

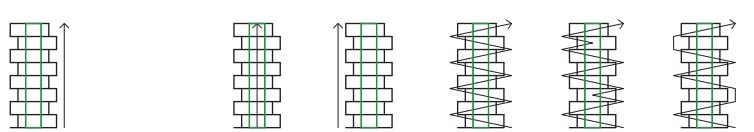

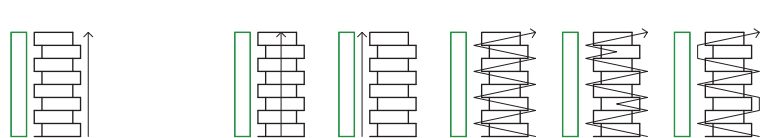

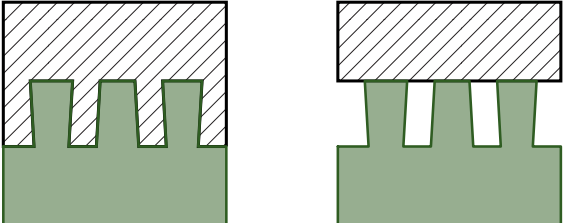

Figure 3.1.09 Initial study of circulatio in relation to green space where

green represents landscape, and an
arrow represents circulation locatio $\longleftarrow$

Figure 3.1.10 Urban Vision for Living. Developed as a mechanism landscape and circulation into the same organising feature
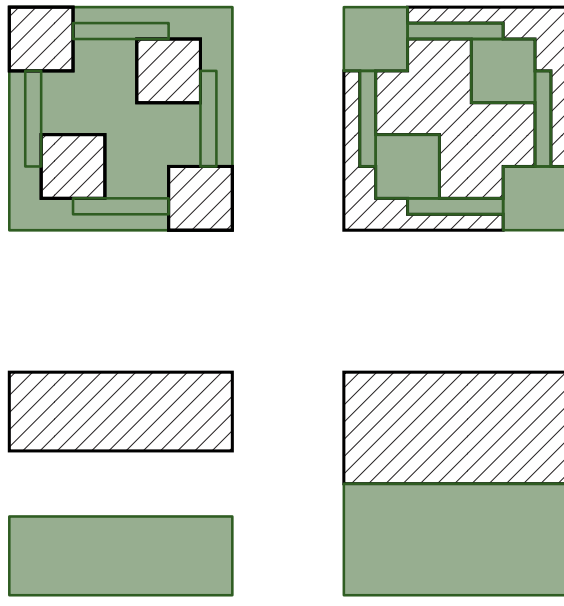

Chapter 3

Figure 3.1.11 Green Vision for
Living. Developed to indicate the desired affect the garden spaces would have on the

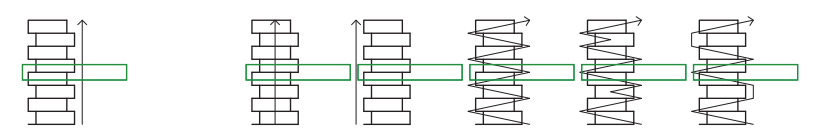

To address the solar and articulation problems of the commongreennetwork's first iteration, two seductive collages of urban and suburban environments are produced (Figure 3.1.10 - Figure 3.1.11). These suggest a means of façade integration and an attractive vision for tying the prioritised amenities together. In combination with scale studies of garden/built form relationships and case studies these tests lead the concept to the articulation of design test three (B) (Chapter 3.4 page 121).
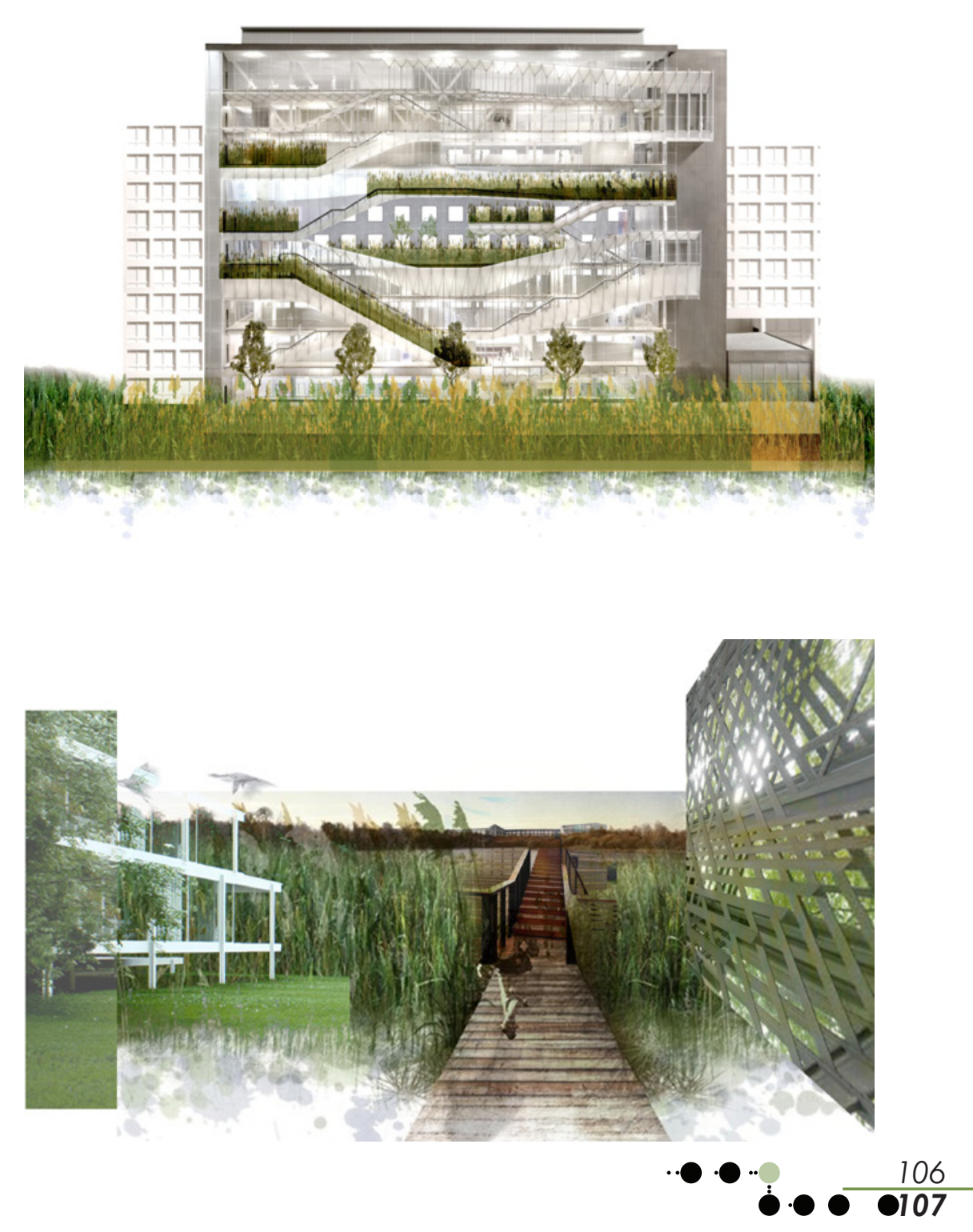


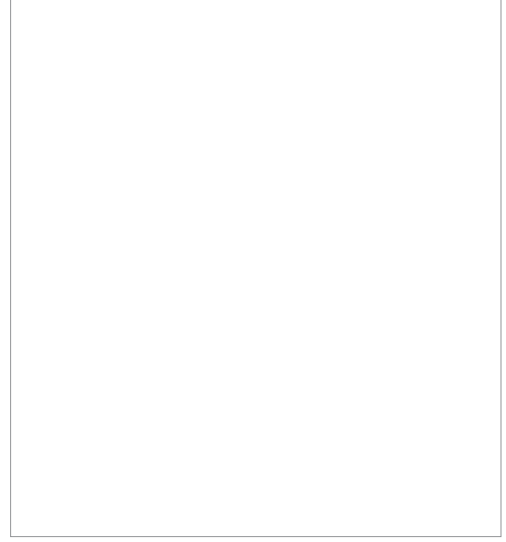
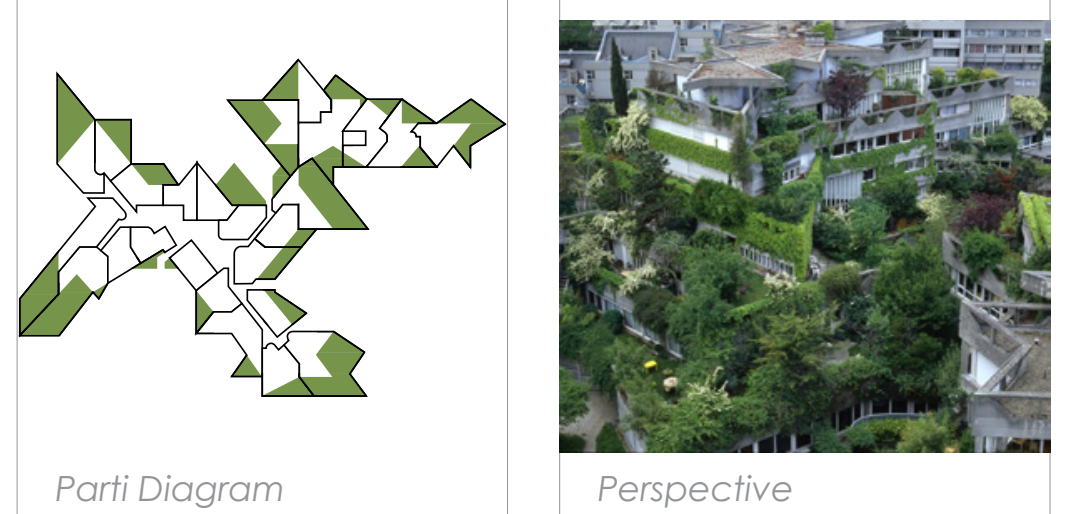

Named after the heroic Burgundian battle-woman of 1456, Jeanne Hachette defies 1969-1975 French housing standards to provide individual gardens and units for 39/40 households.

use development brings an intensity of people and amenities to the area.

Gardens and individuality, Renaudie demonstrates and argues, are a social and human right issue, offering freedom

Over the entire development footprint these dwellings reach a density of 61 DW/HA. However, with a $6481 \mathrm{~m}^{2}$ 


\section{Circulation Type}

Dwelling Typologies

Garden Typologies

Amenities

Adaptability

Kebbell Classification

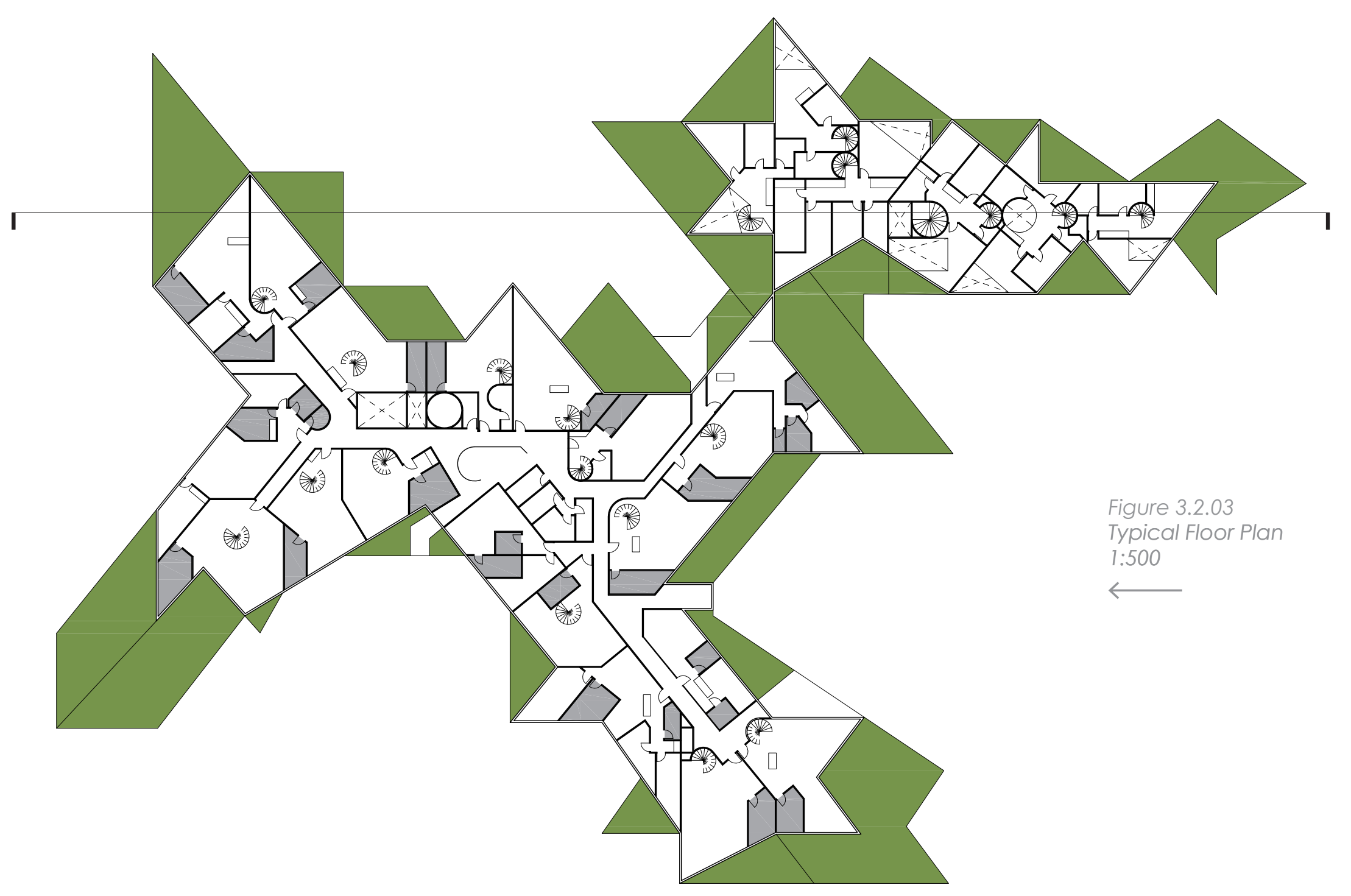

- Key to this design is the provision of a substantial garden

- The presence of garden is felt in each unit, integrated into daily lives

- Designed for individual identity, with no unit the same and each garden customised by its residents

- Mixed-use development provides greater immediate amenity access$$
\checkmark \text { p }
$$
Visual Aspect
$\checkmark$ Iconic Value
Garden
Variety of Unit Types
Privacy

Figure 3.2.04 Exploded

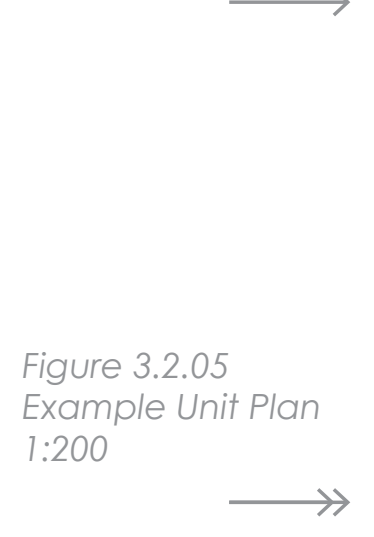

- The cost premium of building an irregular social housing design created tense political issues during construction (scalbert, p. 47)

- Irregular plans are sometimes difficult to furnish with much wasted space in triangulated areas

- Internal circulation, predominantly artificially lit, is not particularly welcoming
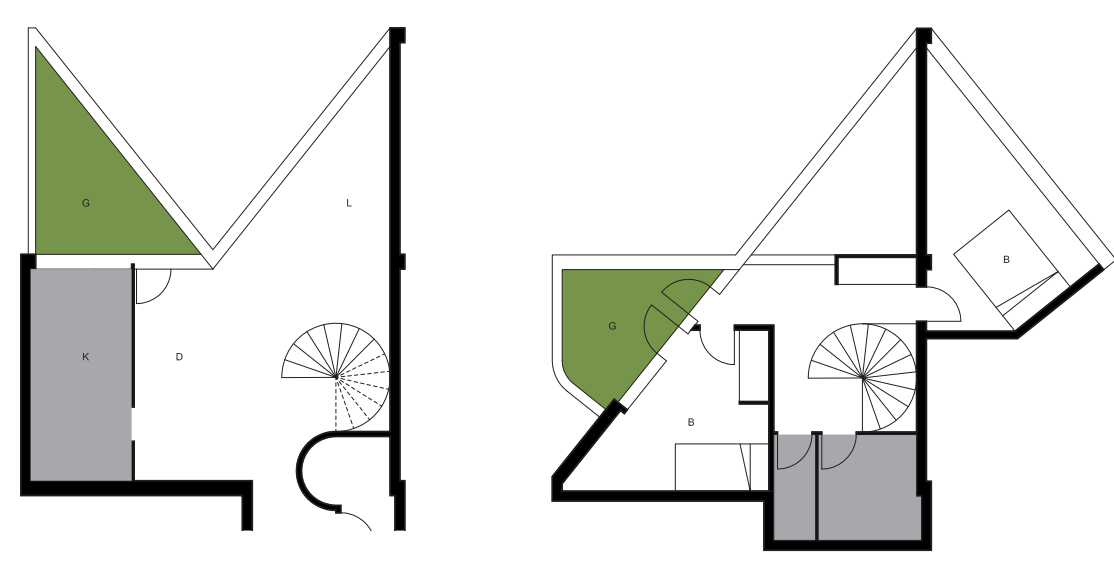

$\bullet \bullet \bullet \bullet \bullet \bullet-110$ 

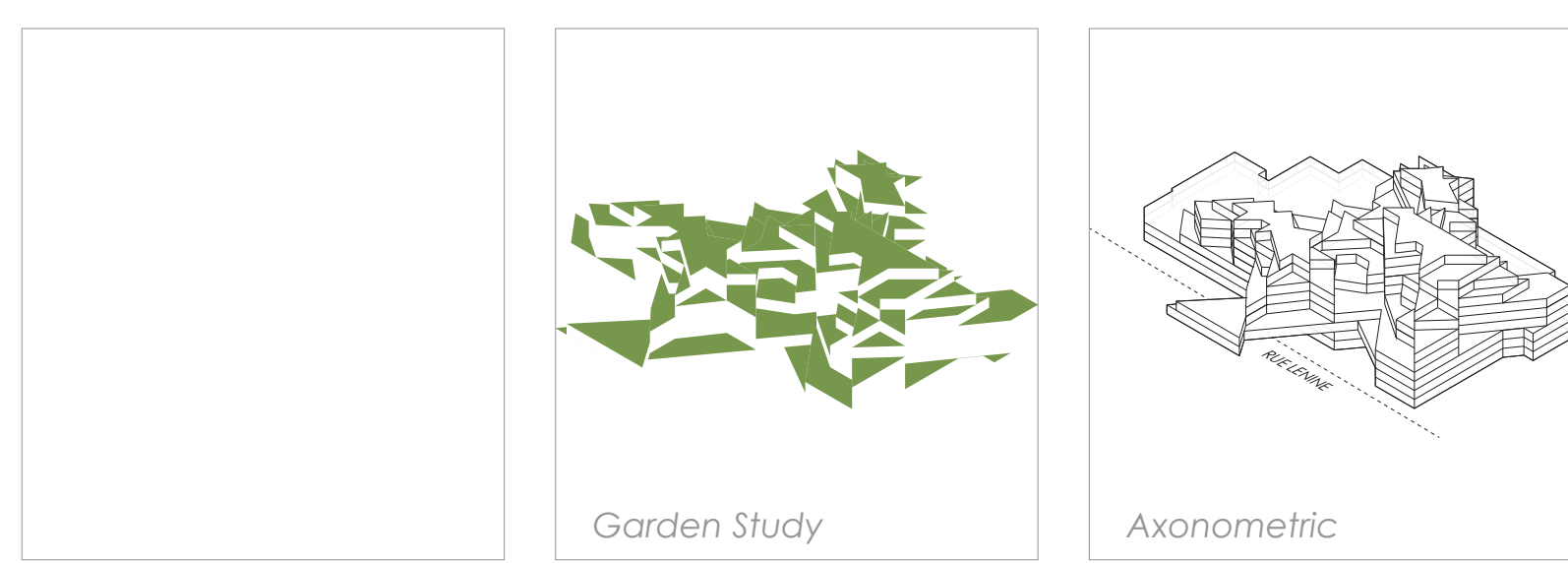

Why this project was selected as a case study and what was$$
\text { Garden Stud }
$$

Axonometic

Demonstrates it is possible to achieve quality garden at high densities

- Foregrounds garden and geometry resulting in the creation of an iconic building

- Illustrates highly complex tessellation of units to produce individuality in each apartment while also allowing garden spaces to stack

- Renaudie's design technique of overlaying papers to quickly design offers a method for design test development

- Political slight aside, the existence of this building proves feasibility of gardens at high density

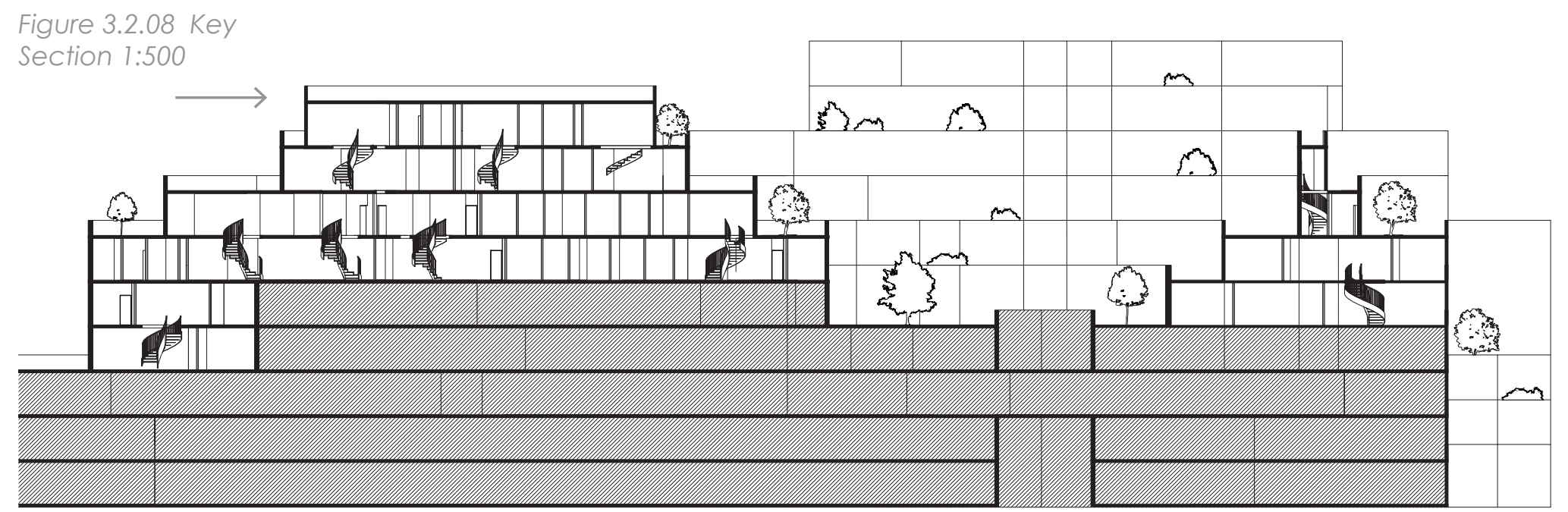

$\begin{array}{ll} & \text { Figure 3.2.09 } \\ & \text { Public Private } \\ & \text { Common Study } \\ & \text { Figure 3.2.10 } \\ \text { Figure 3.2.06 } & \text { Circulation Study } \\ \text { Garden Study } & \text { Figure 3.2.11 } \\ \text { Figure 3.2.07 } & \text { Demographics } \\ \text { Axonometric } & \text { Study }\end{array}$
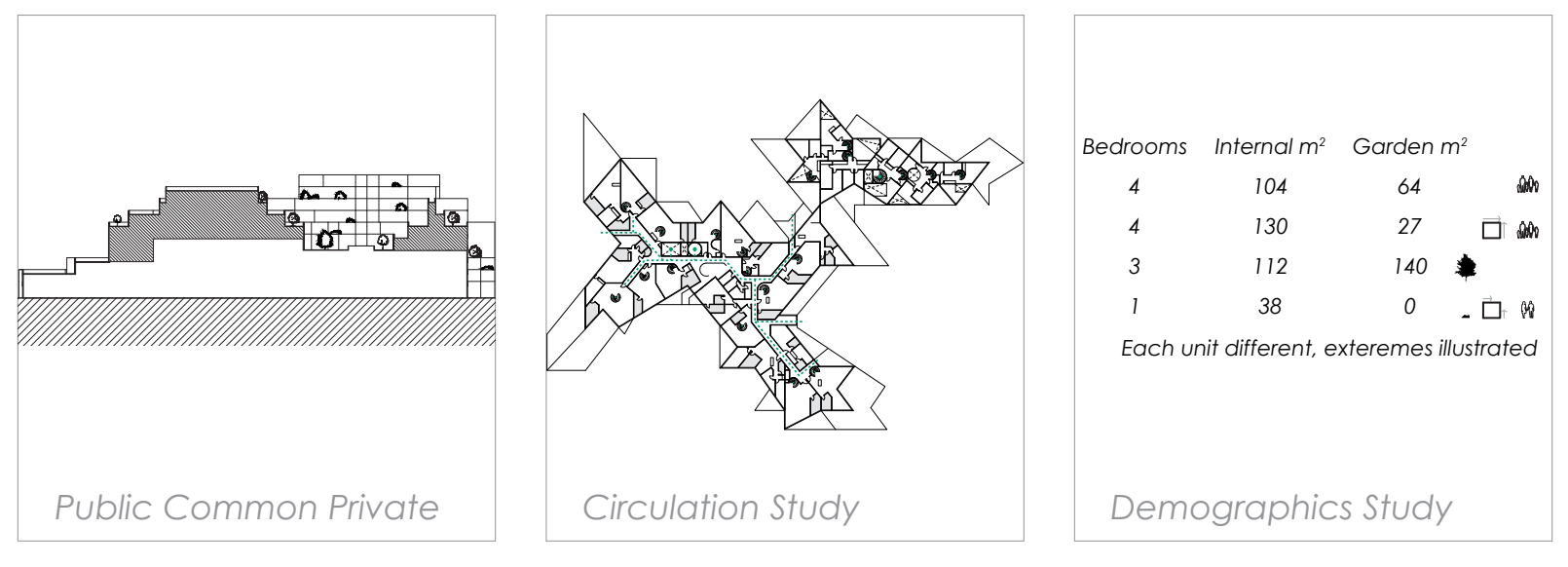


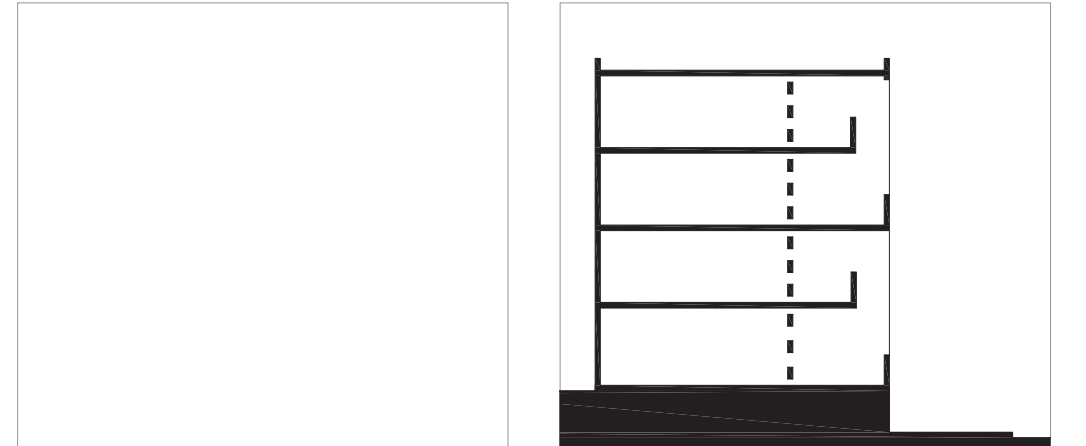

Parti Diagram

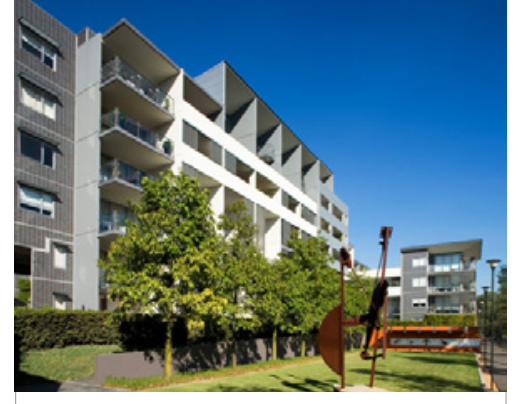

Mondrian Apartments demonstrate liveable apartment lifestyle facilitated by

plants of tropical trees furthering privacy multiple double storey, double aspect. amenity rich apartment designs with large private external double and single height outdoor spaces.

The scheme is also generous to its context, giving over a public planted park to the scheme's north which, as with the common planted areas, provide garden

These external spaces can be controlled by closing large louvres to provide solar or wind protection. Often these spaces interaction for all residents as they access their units.

are further customised to feature pot 

areas (Figure 3.3.10)

Circulation Type

\section{Interna}

\section{Dwelling Typologies}

Apartments, Maisonettes

Garden Typologies

Amenities

Adaptability

Kebbell Classification
$\checkmark$ Garden
$\checkmark$ Variety of Unit Types
$\checkmark$ sunlight
$\checkmark$ Visual Aspect
$\checkmark$ Privacy Iconic Value

Apartments awarded sustainability prizes for operable elements that use passive cooling and watering techniques

Good-normal
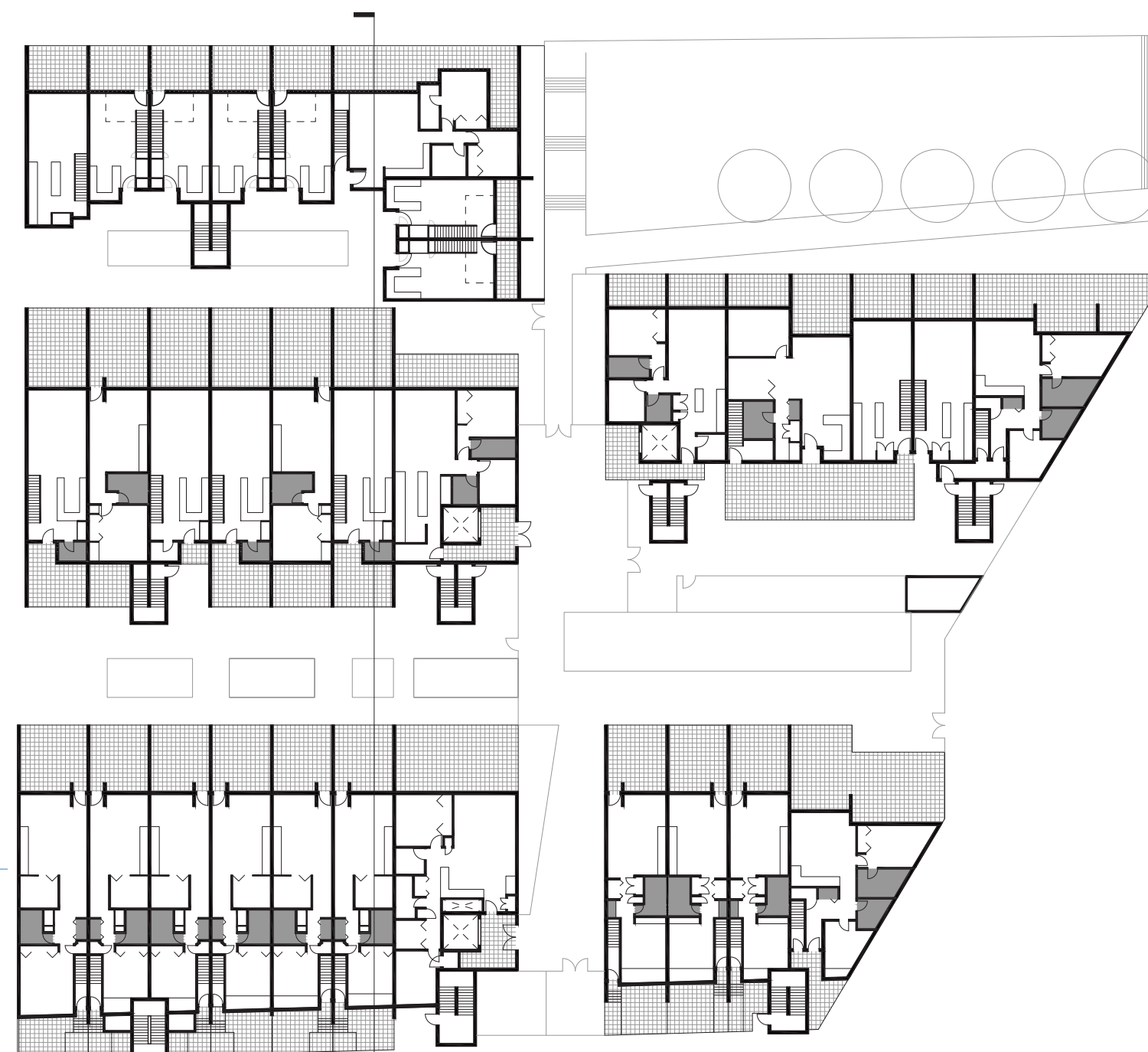

- Generous double height private outdoor spaces

- Large external louvres operable allowing control over balcony spaces

- Semi-common planted courtyards between each slab block contribute to smaller sub-neighbourhood atmospheres

- Contextual; sets a new environmental and aesthetic standard for apartment developments in Sydney (de vulder, s; et al.)

- Well-proportioned façade, achieved through double height apartments, defined by louvred balconies, that effectively reduce the apparent building scale

Points of Limitation

- Due to differences in Sydney's and Wellington's climate, not all innovations can be directly applied to the New Zealand context

- Dark central areas of units due to deep and narrow floor plans

- Although efficiently planned using open planed (up to $0 \%$ or the total area in some with internal stairs

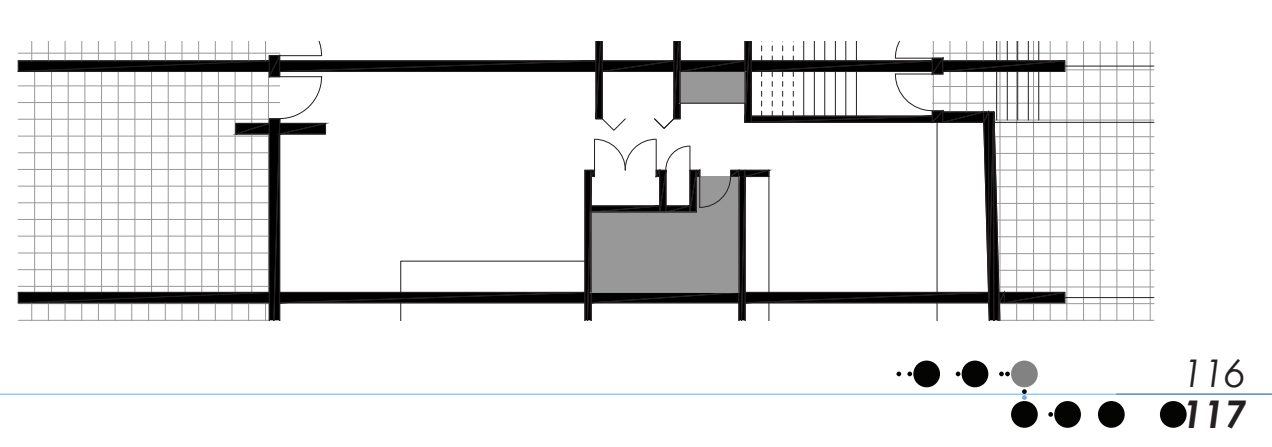



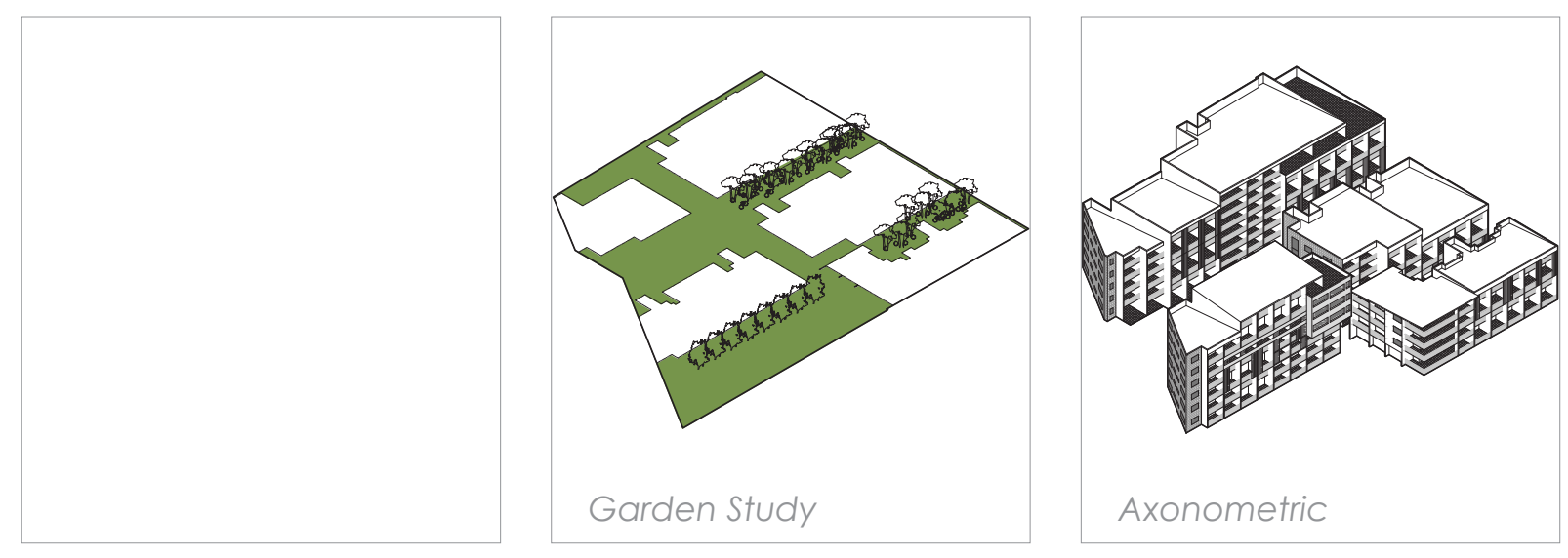

Axonometric

Why this project was selected as a case tearnt

- Facilitates outdoor living at high densities through double height balconies and units

Encourages sub-neighbourhoods through semi common gardens

Suggests an alternative to the perimeter arrangement that achieves high density and high amenity

- Makes apartments attractive and liveable in a country with similar lifestyle values as New Zealand
Figure 3.3.07 Key
Section 1:500

$\longrightarrow$

\section{.}

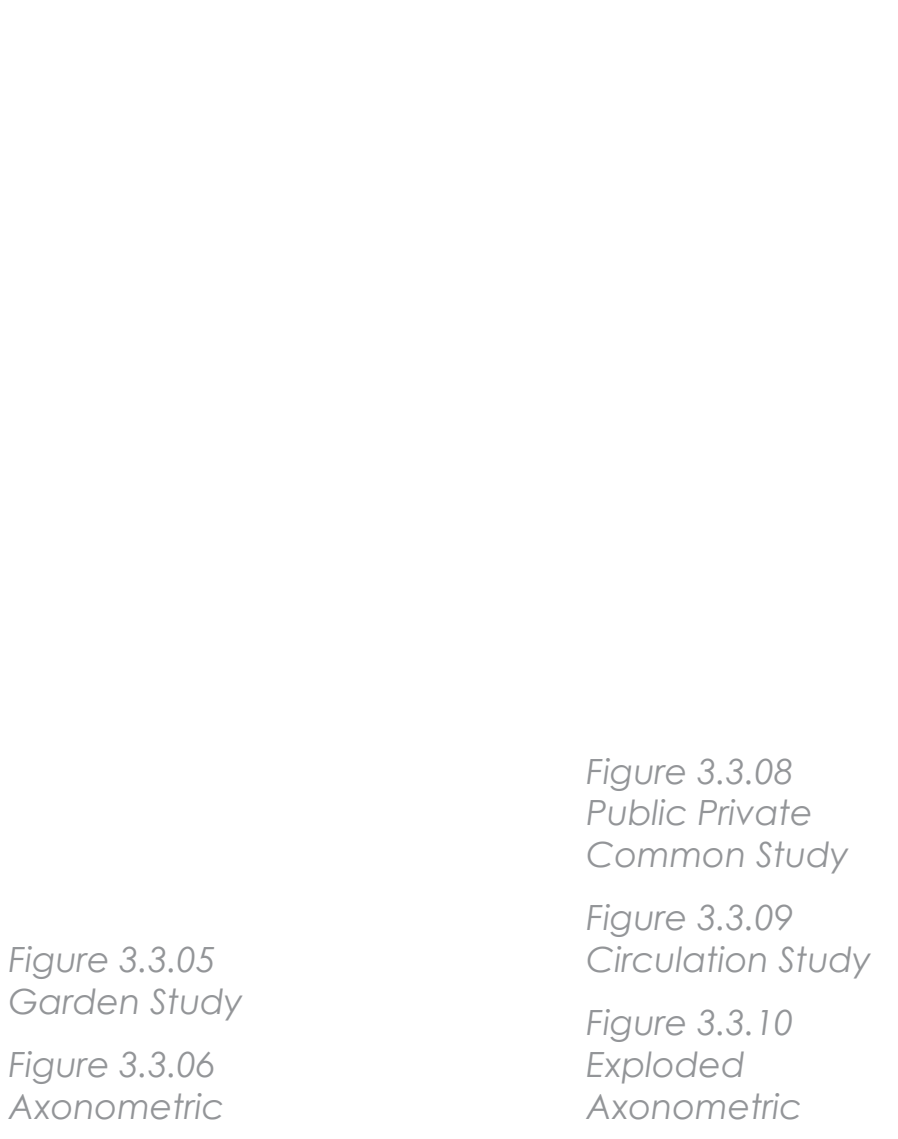

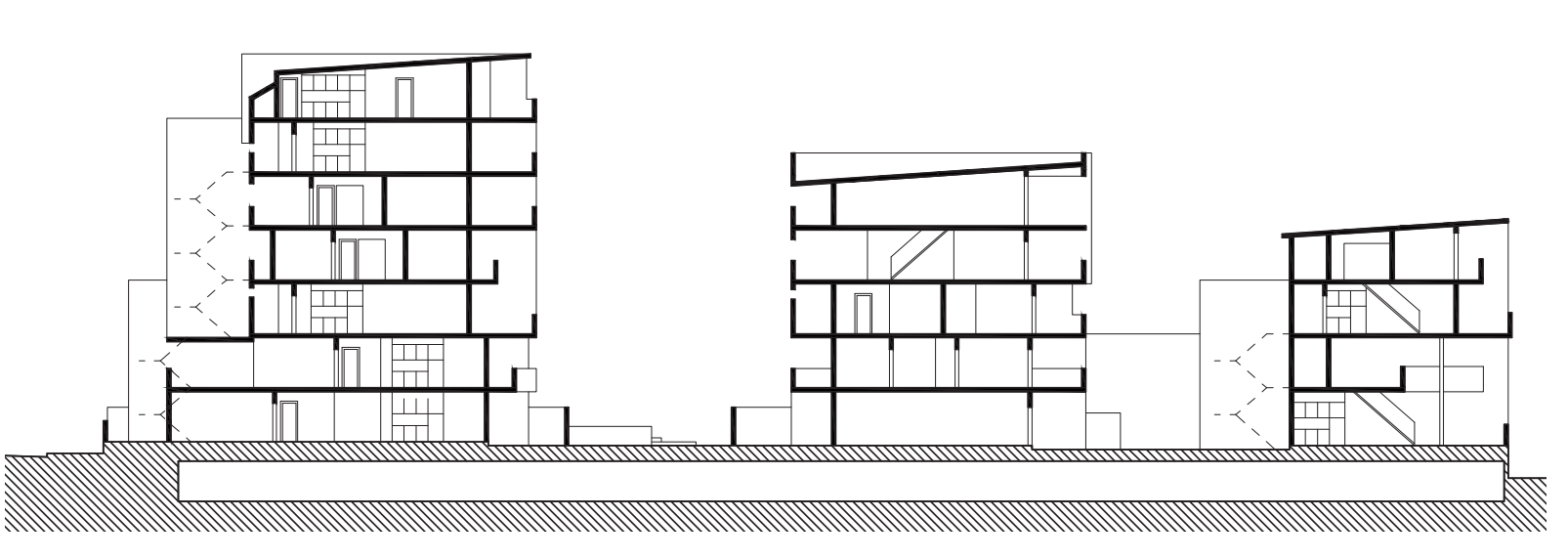

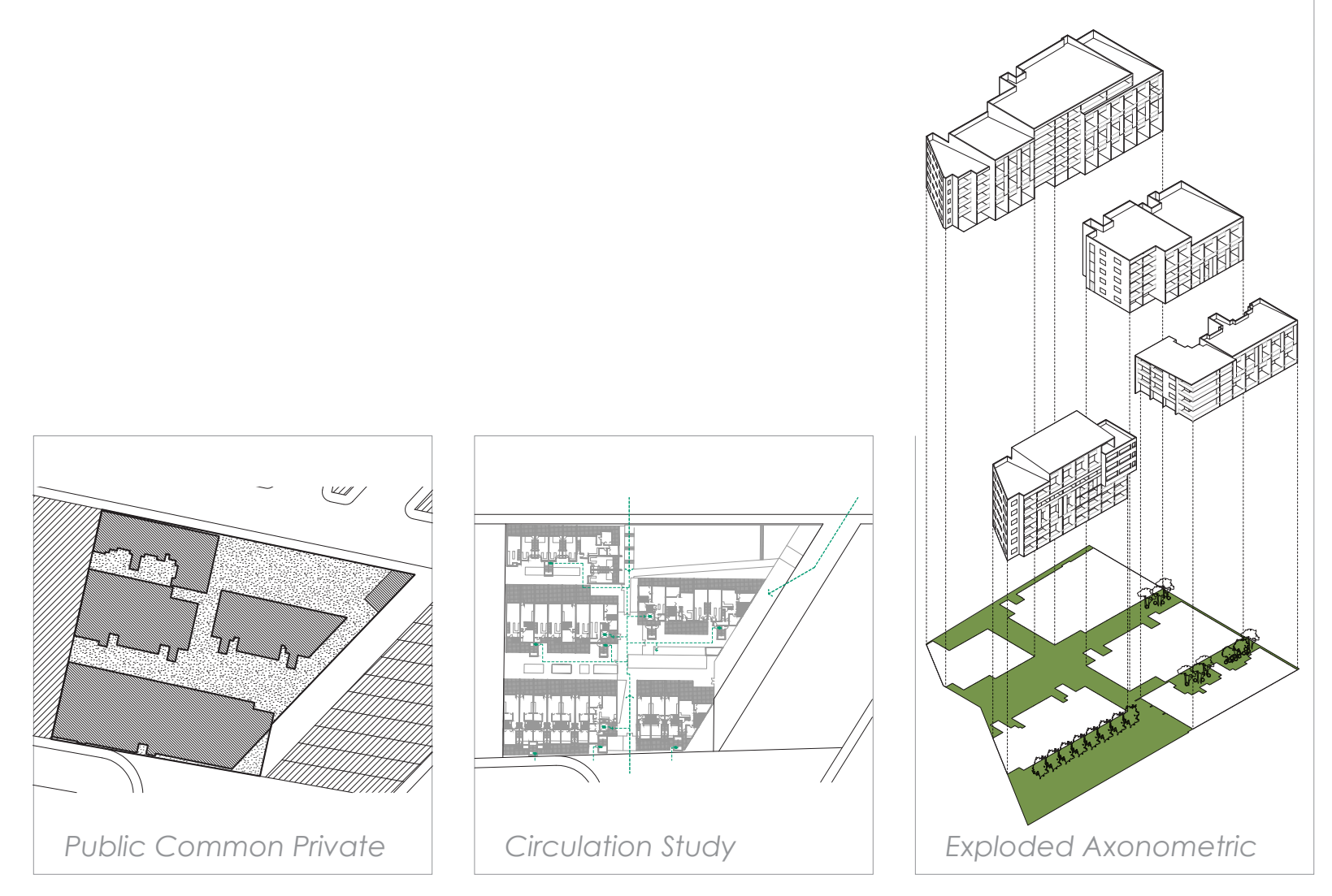

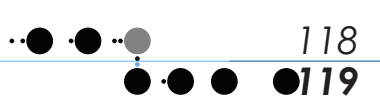


Design Development

Mediums

Project Date

Key Drivers

Programmes
Physical modelling, Digital modelling Digital collage

Month 5 (July)

- Providing access through site at an elevated level

Giving public access to rooftop gardens upon existing buildings along Courtenay Place

- Retaining secured solar access to all units

Residential, Ground floor retail, Public greens
Design test three (B) uses the common green network urban collage as inspiration to combine circulation and garden in a feasible way. With a layering technique, developed in built models and diagrammatic studies, it delivers unit access and private gardens.

However, to achieve the collage's effect a deep building envelope is required to allow the space under the network's circulation to be of a useful size for utilisation. Yet with a deepening floor plate a reduction in unit sunlight (priority amenity) occurs.

This façade network is used in combination with a 'high line' intervention to connect to Courtenay Place. Existing buildings are retrofitted with rooftop gardens to become part of the network, connecting the development in a cohesive way. 


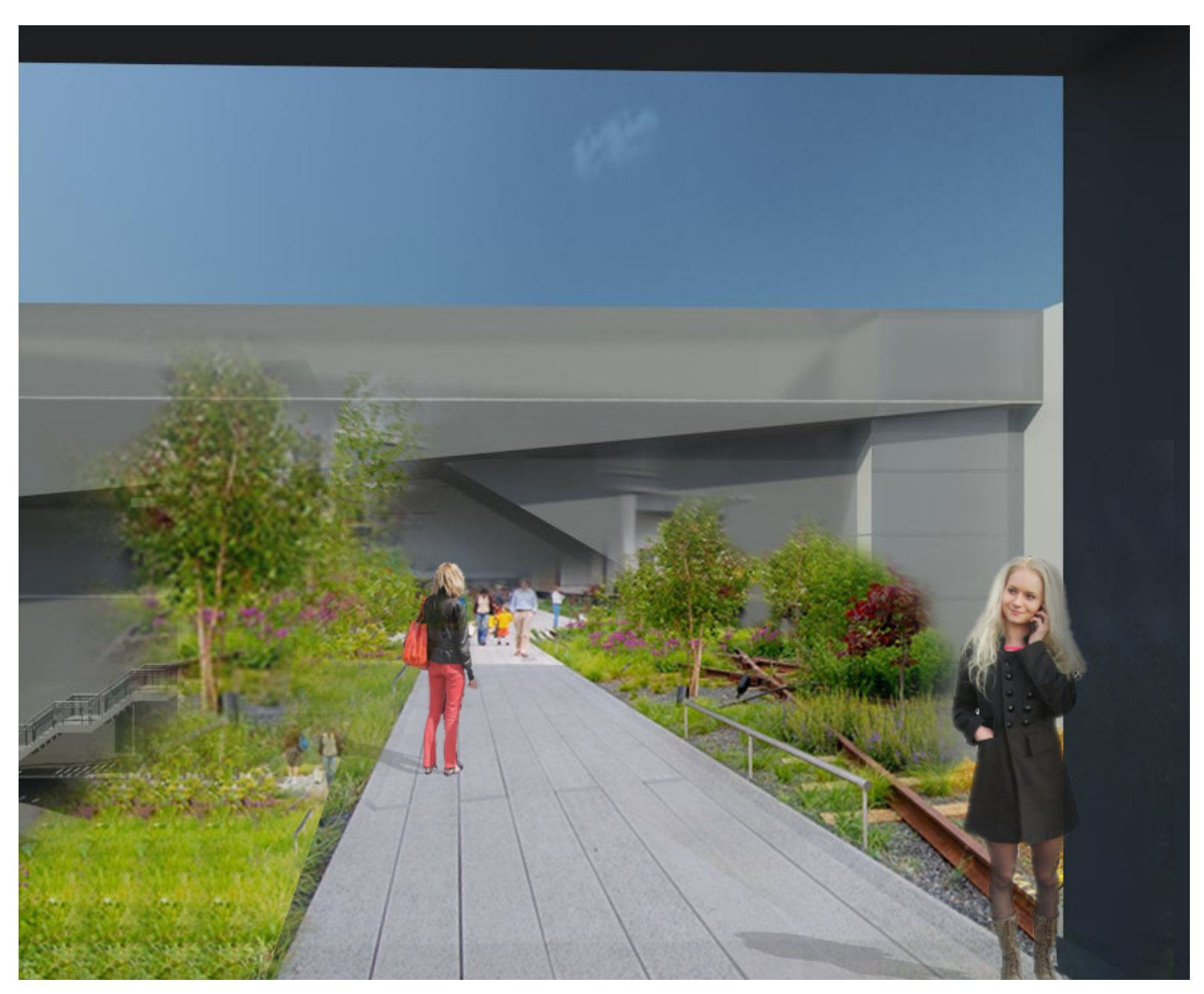

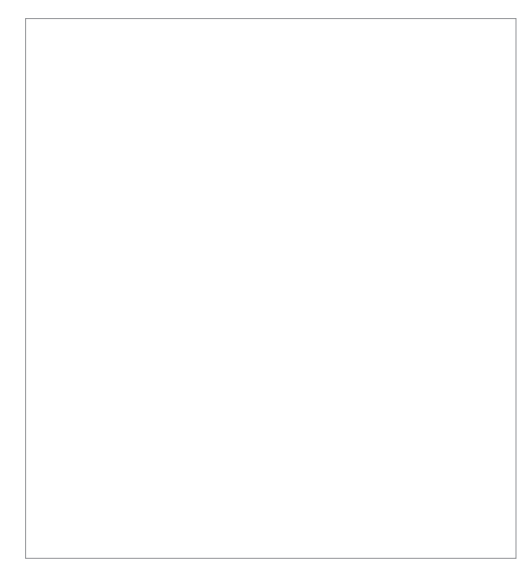

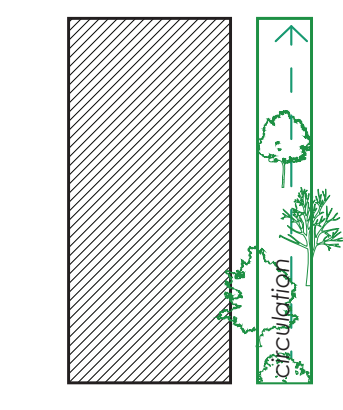

Parti Diagram

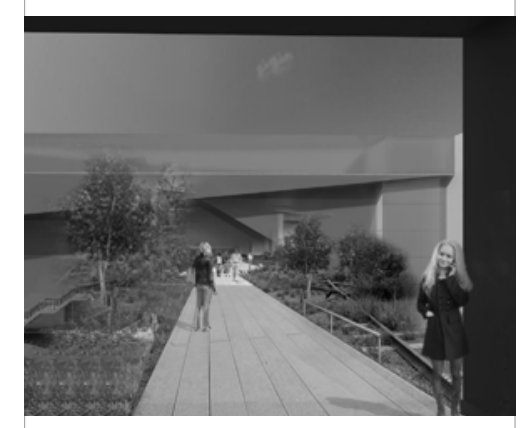

Perspective

Scheme Typology Circulation Type

Dwelling Typologies

Garden Typologies

Amenities

Adaptability

Kebbell Classification
Infill perimeter block

External - with vertical circulation paths along the building face planted, and a 'high line' through the complex

Apartments, Maisonettes

Common Courtyard, Vertical Circulation Gardens, Private attached Gardens, Rooftop Gardens

sunlight

Privacy

$\checkmark \quad$ Variety of Unit Types

$\checkmark$ Visual Aspect

NA

Good-weird 


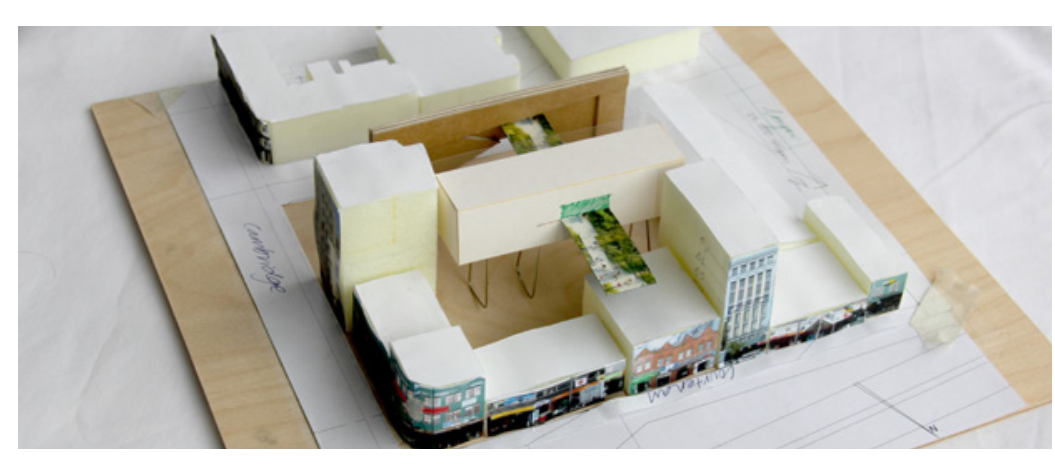

Points of Innovation

- 'Common green network' concept proved feasible way to integrate the primary garden sunlight and privacy amenities

- External circulation provides direct engagement with garden for all residents

- Removing western building volume and designing as if the adjacent plot is built out secures sunlight

- Private gardens integrated into the units adjacent to the common circulation areas further enhances garden

- Privacy is compromised in this design test to achieve the common green network, a more verdant screening option could help solve this problem

- Although solar access is secured by the building volume. the 'high line' and circulation overhangs reduce sunlight to some units

- Circulation is not designed through the entire scheme thus many potentially difficult areas, such as the block's corners, remain unresolved
Figure 3.4.04 North-soulh section showing large high ine through irom retrofitted on existing buildings to
new apartments Design test physica model study

Figure 3.4.05 Eastwest section

carved out mass

of the Alpha Street building $\longrightarrow$
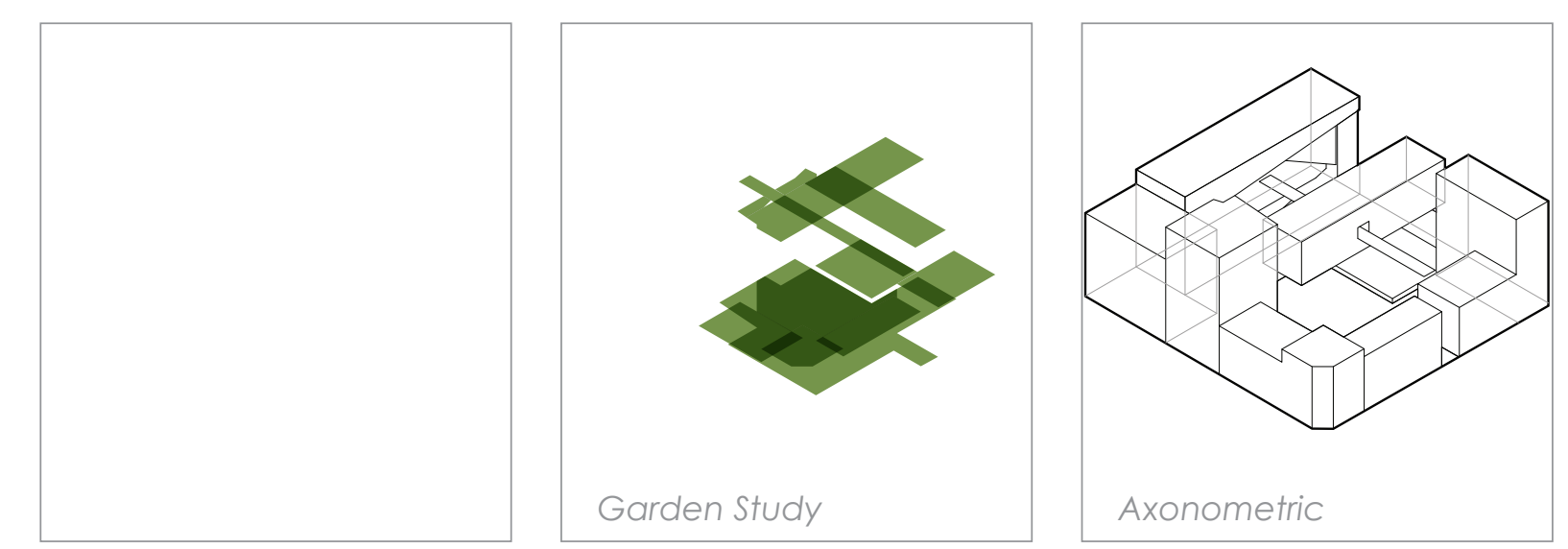

Figure 3.4.06 Axonometric Figure 3.4.07 Figure 3.408 Figure 3.4.08 Figure 3.4.09 Public Common Private Figure 3.4 .10
Perspective
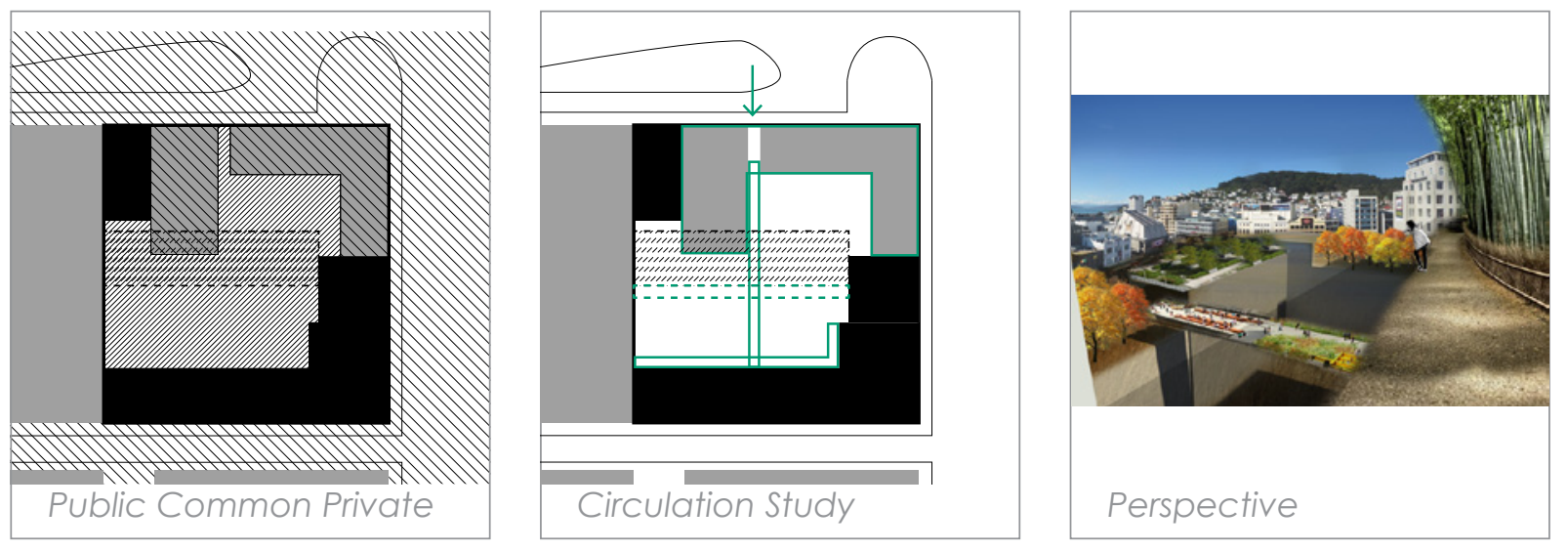

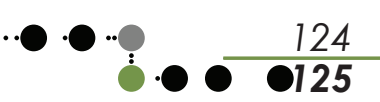


camme

04 
Reviewing landscapes through the lens of taxonomy aids understanding and inspires hybrid landscape solutions. Over the course of the thesis landscape images were collected, which are now ordered and categorised in relation to shared characteristics. Presented on the following pages, in order of size, are exemplary images of each landscape typology (Figure 4.0.01 - Figure 4.0.10).

As with unit typologies, where differen types suit different situations, landscape

types also create and suit different situations (Figure 4.0.11).

Maisonette and apartment situations suit internalised gardens such as balconies or conservatories. A terrace house suits an intermediate scale of garden which backs onto the dwelling, such as a conservatory or terrace.

A terrace has two definitions in landscape architecture:

A level paved area or platform next to a building.

2. Stepped flat areas made on a slope used for cultivation.

A terrace (garden) in this thesis fits into the crossover area in these definitions, a raised paved or cultivated area next to a (terrace house) unit. 
External (open sides)
$\begin{aligned} & \text { Typically private } \\ & \text { Attached to dwelling } \\ & \text { Borrowed landscapes, }\end{aligned}$

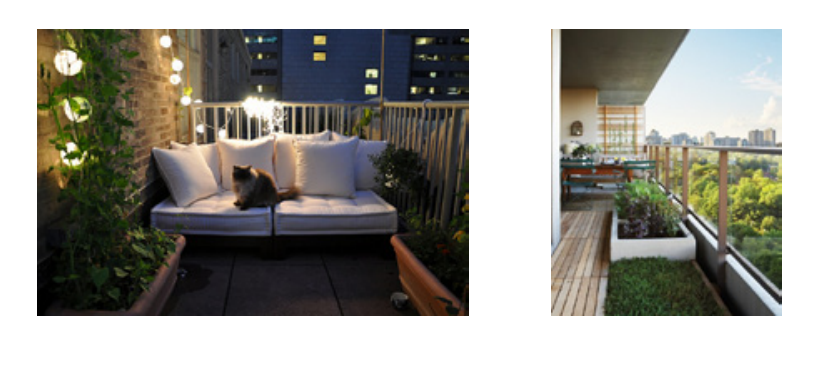

Figure 4.0.01
Balcony examples

$\longleftarrow$ Balcony exar

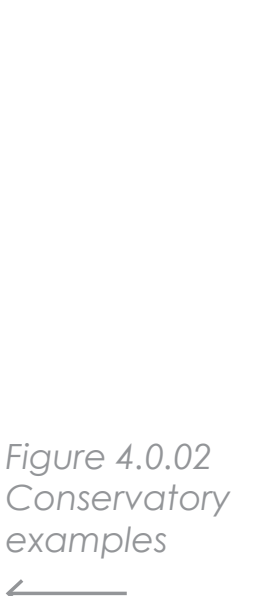

examples

Typically private

$\infty$

Conservatory

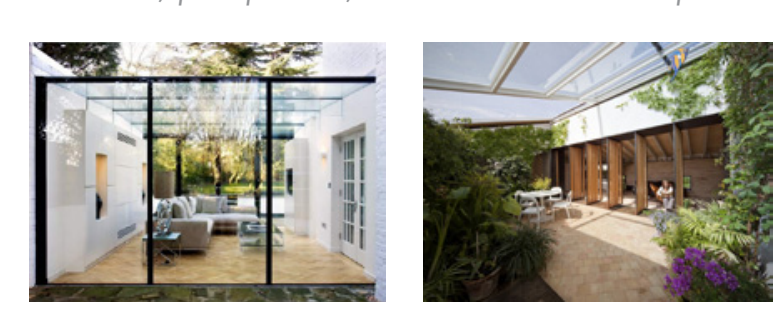

courtyard

External (open roof)

Typically private/common

Within dwelling

in

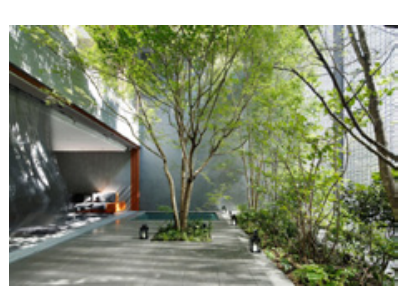

Figure 4.0.03
Courtyard

Courtyard
examples
Figure 4.0.04

Terrace garde

examples $\longrightarrow$

都合

Terrace Garden

Attached to dwellin

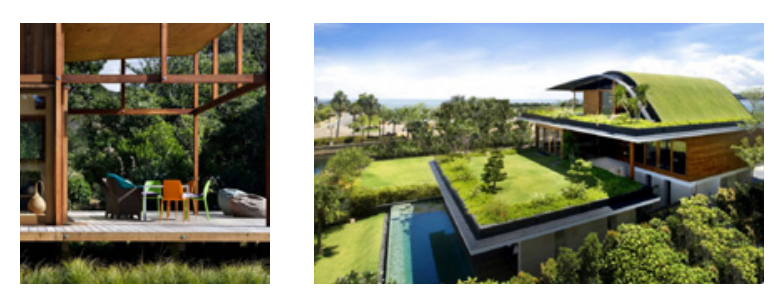

Garden Void

ypically common/public

Not related to individual dwelling

Planted, borrowed landscape

Figure 4.0.05

Garden void
examples
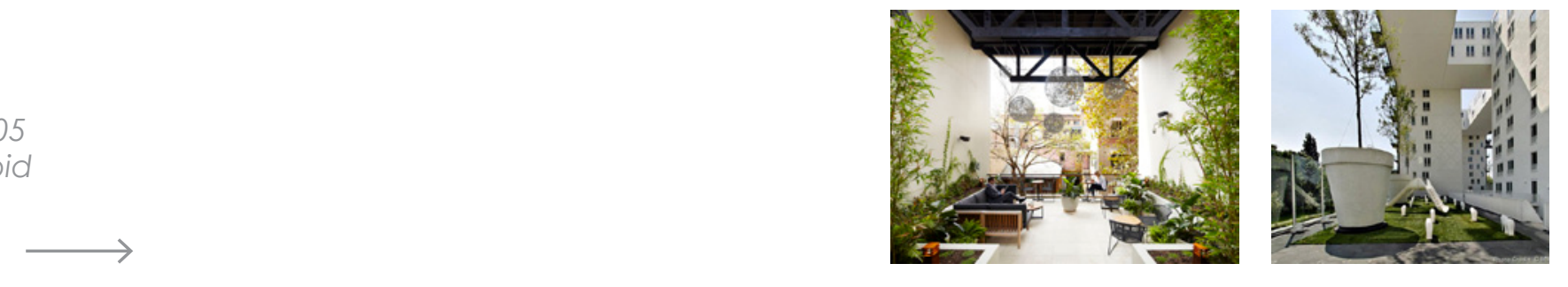

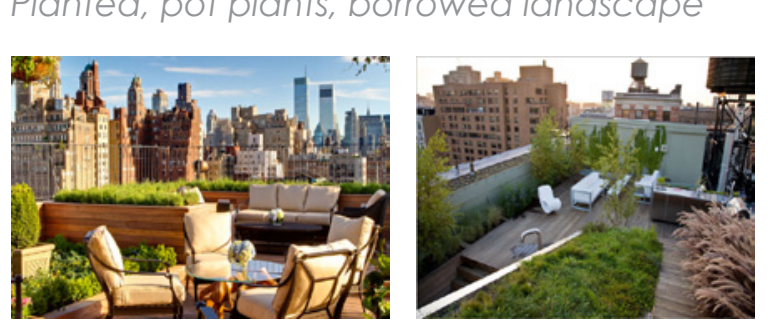

Figure 4.0.06 examples
Rooftop Garden External (atop mass)

Not related to individual dwelling

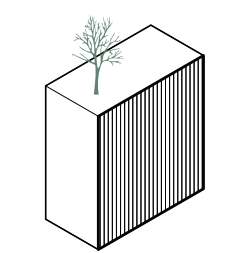

$\bullet \bullet$ 


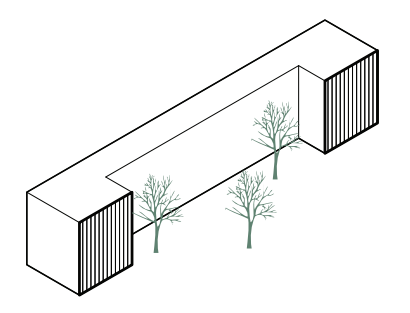

Green

Not related to individual dwelling
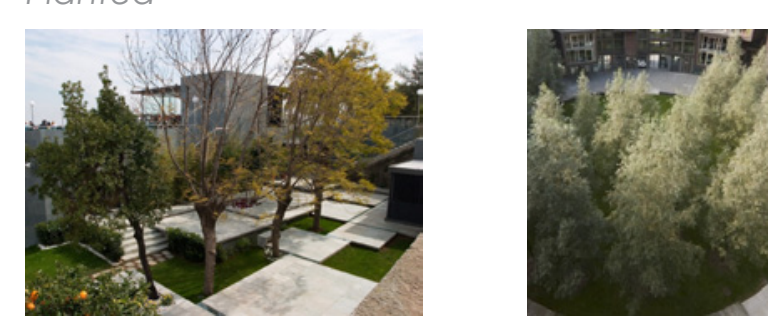

Figure 4.0.07
Green examples

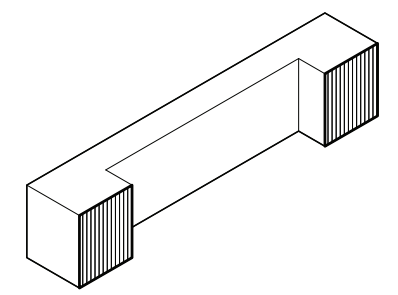

Plaza

ernal (open on all sides)

Not related to individual dwelling

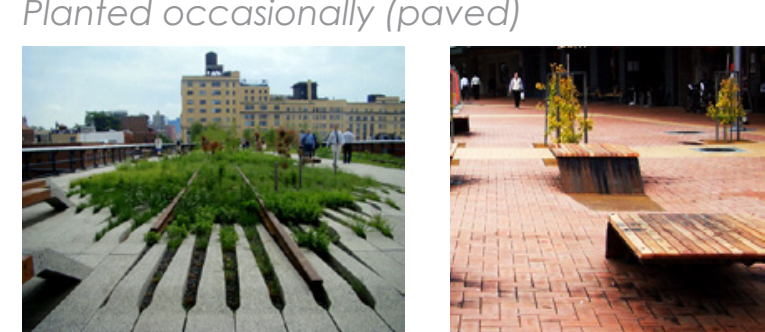

Figure 4.0.08 Plaza

examples

External/internal (portable)

Private

Not occupiable

Planted

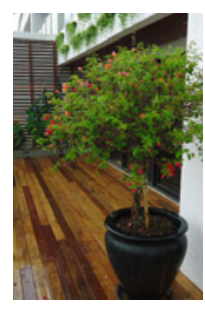

Figure 4.0.09 Po plant example

Figure 4.0.10 Path

Figure 4.0 .10
example

$\longleftarrow$

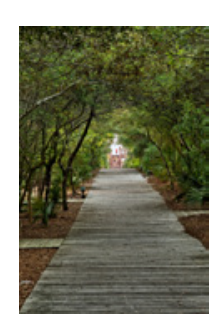

Figure 4.0.1

Typological

relationship

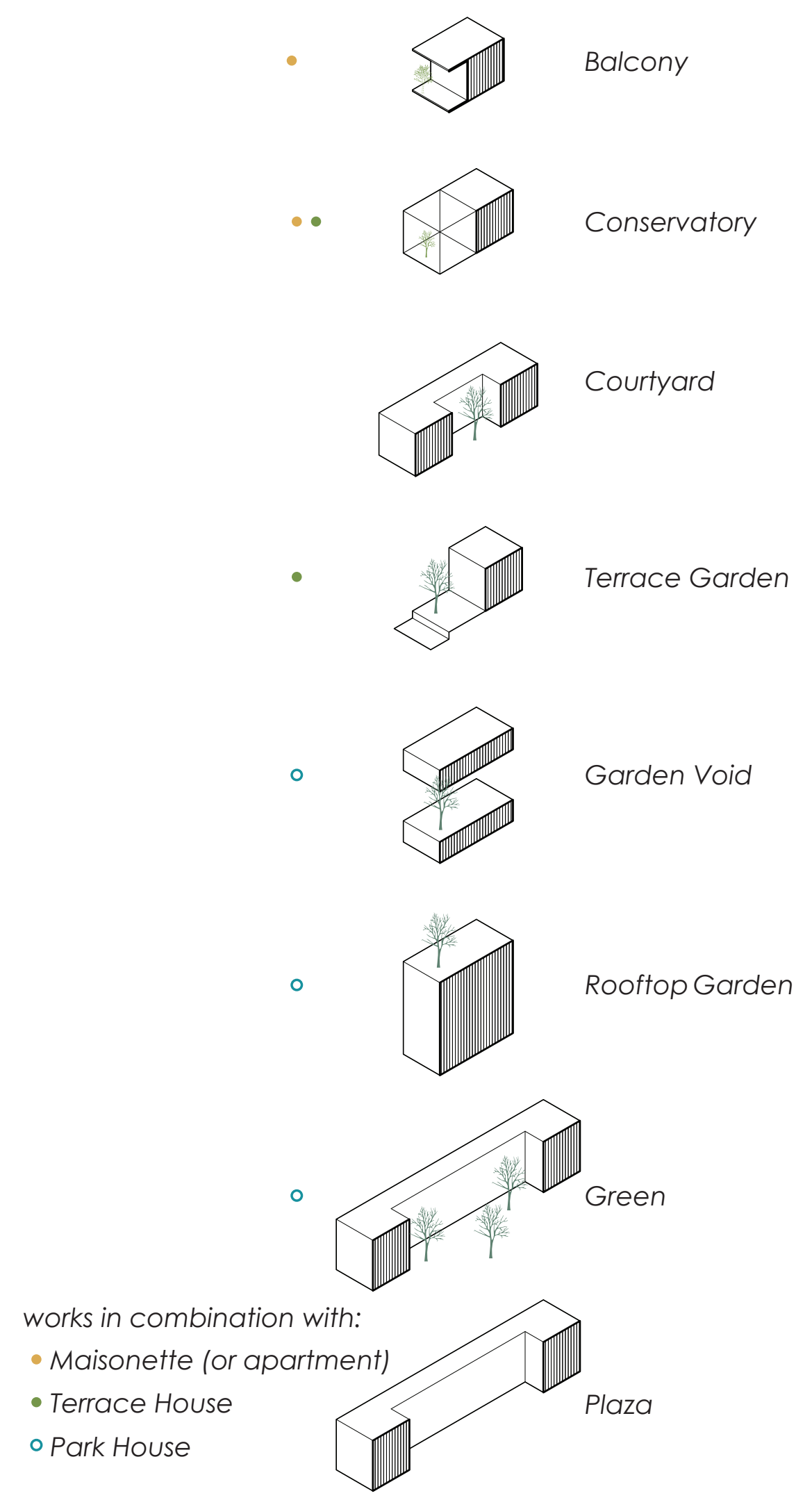

Later, as every unit in the development is planned (Chapter 5), a 'park house' typology emerges which is defined as a dwelling typology with a direct relationship onto larger common and public spaces.

Landscape in all situations is what comes to define the topology of units.

A further observation is made from these landscape typology studies; the circulation method of landscapes, paths, has the potential to be applied to architecture. This would work especially well in conjunction with the terrace house typology, where a raised terrace garden could secure (the primary amenity of) privacy above a common path.

The final garden type referenced is the pot plant and planter type. Suitable for use in conjunction with any garden type as soil is provided above floor level, this typology has the potential to be used extensively in all areas of the development. 
Design Development Mediums

Project Date

Key Drivers

Figure 4.1.01 Unit
to circulation to circulation section

Programmes
Diagrammatic studies Hand

drawing, Digital modelling

- Offering a variety of unit types linked through a 'common green network'

- Integrating circulation
organisational device

- Delivering privacy, sunlight and other amenities for all

Providin

public access and amenity in the form of rooftop gardens and block permeability

Residential, Ground floor retail, Hospitality in retrofitted historic buildings, Public plaza

Design test four aims to provide circulation via a series of external landscapes that weave through the building and then knit themselves back to the ground and into the city.

A new approach is developed, where circulation, garden and unit type are studied in unison (Figure 4.1.01). To begin some parameters are set which are 


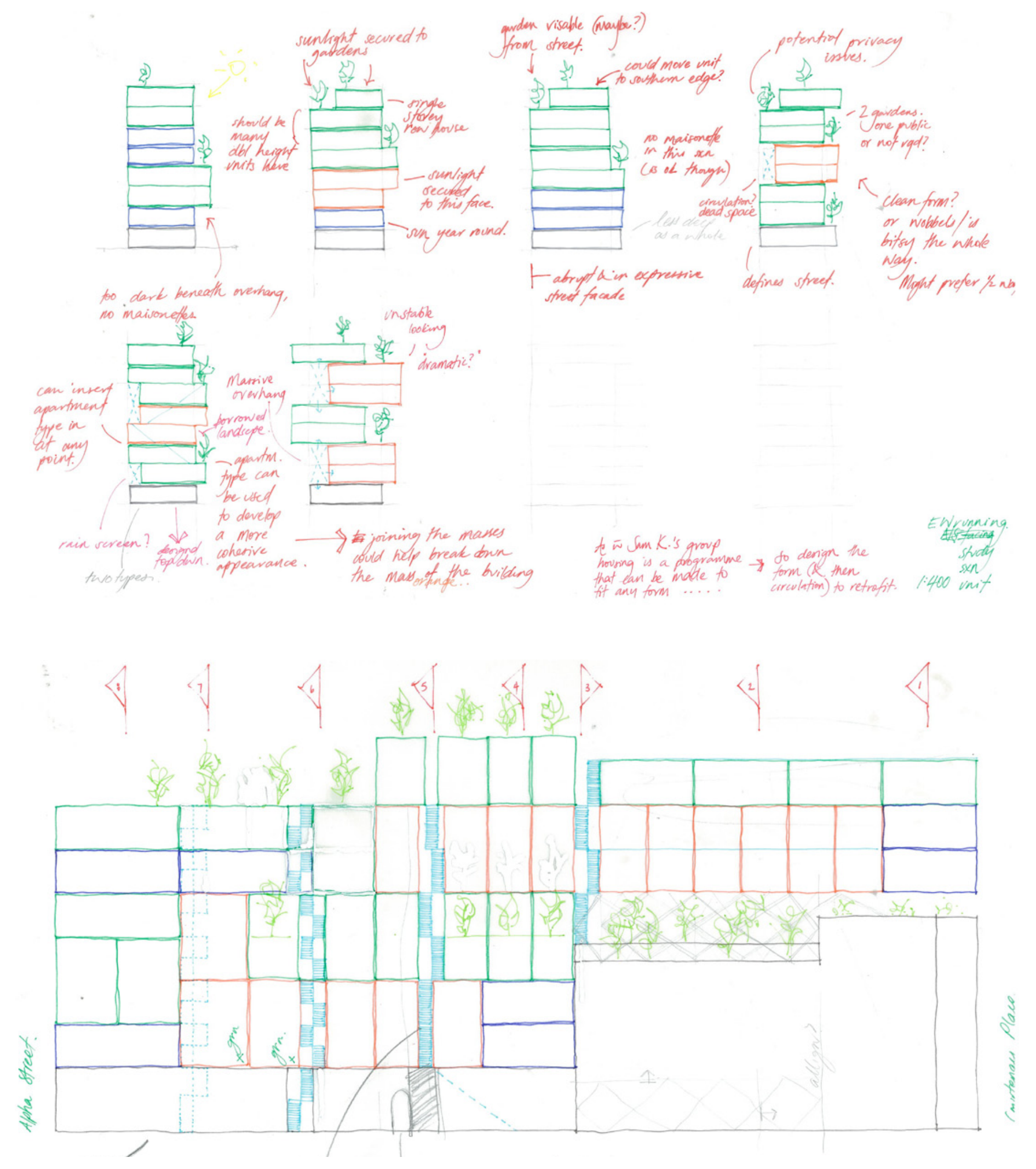

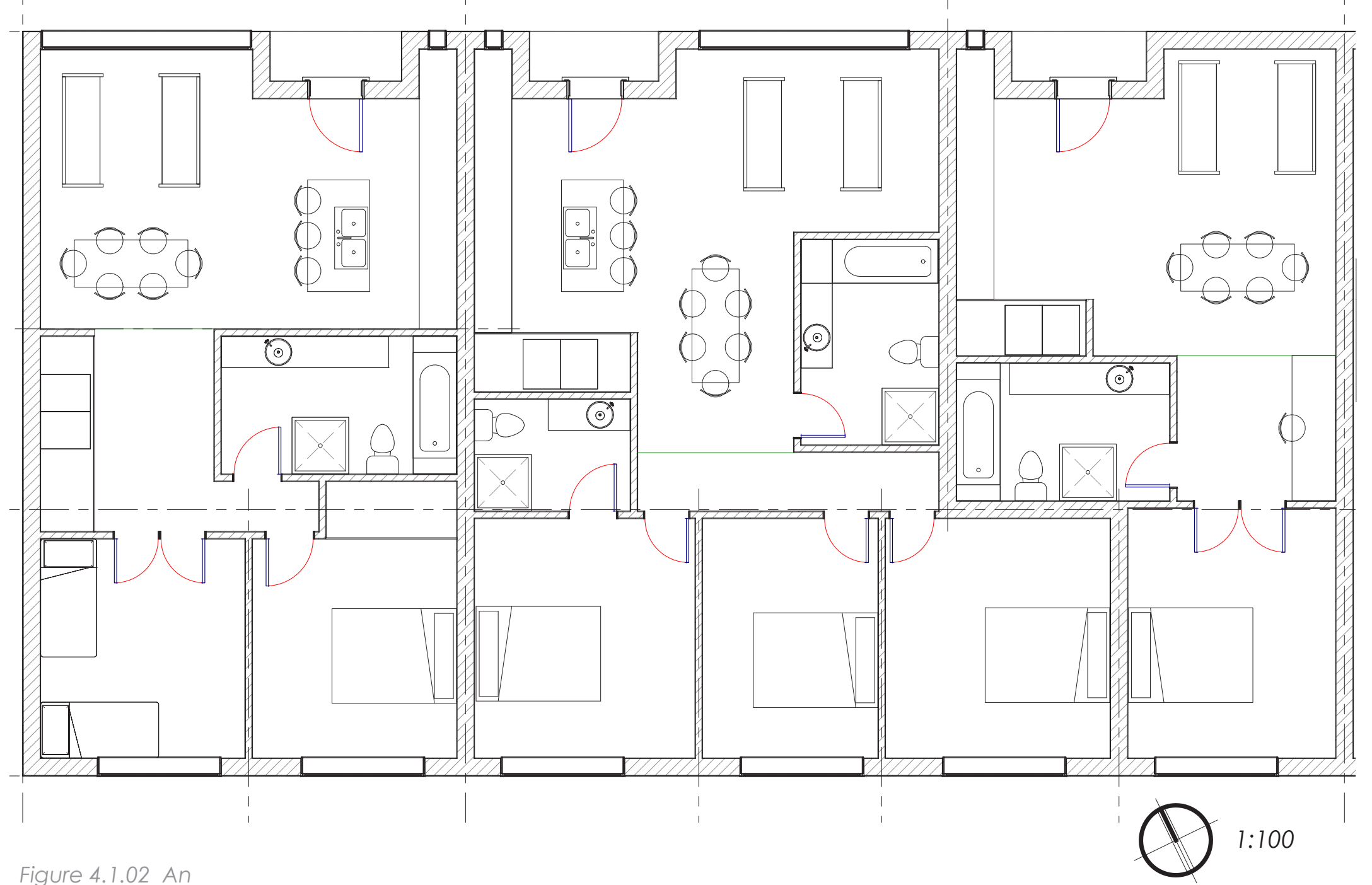

Figure 4.1.02 An example of the

types of sectional,

plan and $3 \mathrm{D}$ 1:500
diagrammatic

reviewed regularly to assess their on going relevance. Initially $50 \%$ of the units are set as terrace houses (single or double storey units with a private garden linked to the common green network [green]), $25 \%$ of the units are set as apartments (single storey garden-less units [blue]) and $25 \%$ are set as maisonettes (double height garden-less units [orange]].

studied in plan, section and elevation to develop a 'salt and peppered' model, where units are grouped by type and dispersed throughout the volume. These studies (Appendix 4.1) quickly clarify intuitive design decisions about building footprint location. These studies also introduce asymmetric voids through the volume for vertical movement to work in combination with the horizontal Each unit type is assigned a colour and 'boardwalk' paths. 

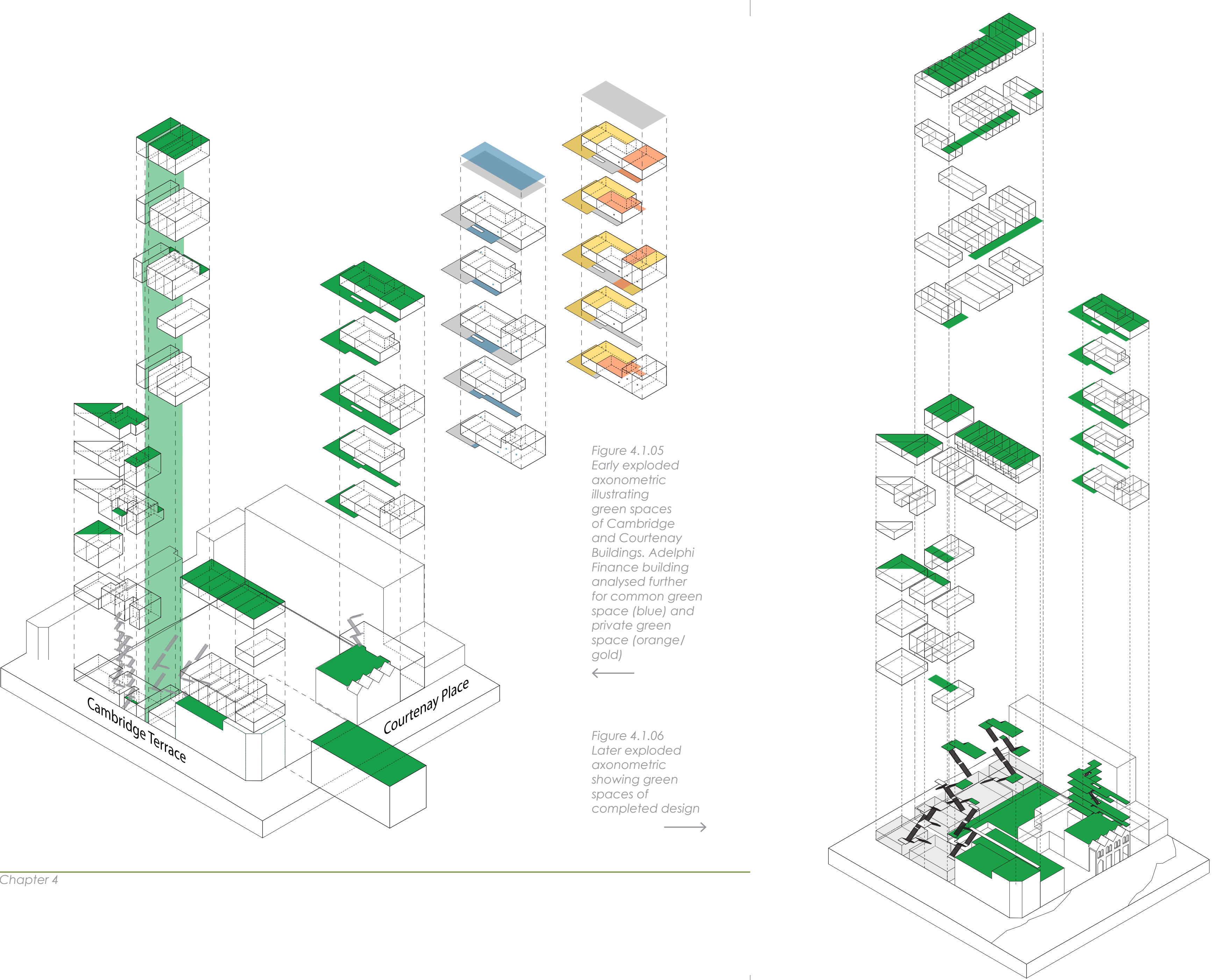

A further move to demolish existing buildings that do not have heritage value on the Wellington City Council register is taken. Design testing around these buildings sacrifices solar access and density. Additionally it makes the design less propositional and applicable to other locations due to its site specificity.

In this scheme the presentation and communication methods begin to develop. Renders and exploded isometrics showing garden spaces successfully communicate the complex nature of the common green network.

Despite being formed from ilagrammatic studies this design test is in fact more nuanced, even in renders where unit definitions are visible. This is partly due to the sophisticated and extensive diagramming process, and partly due to its response to site conditions, especially the continued presence of selected existing buildings, creating a good-weird relationship between the two. 

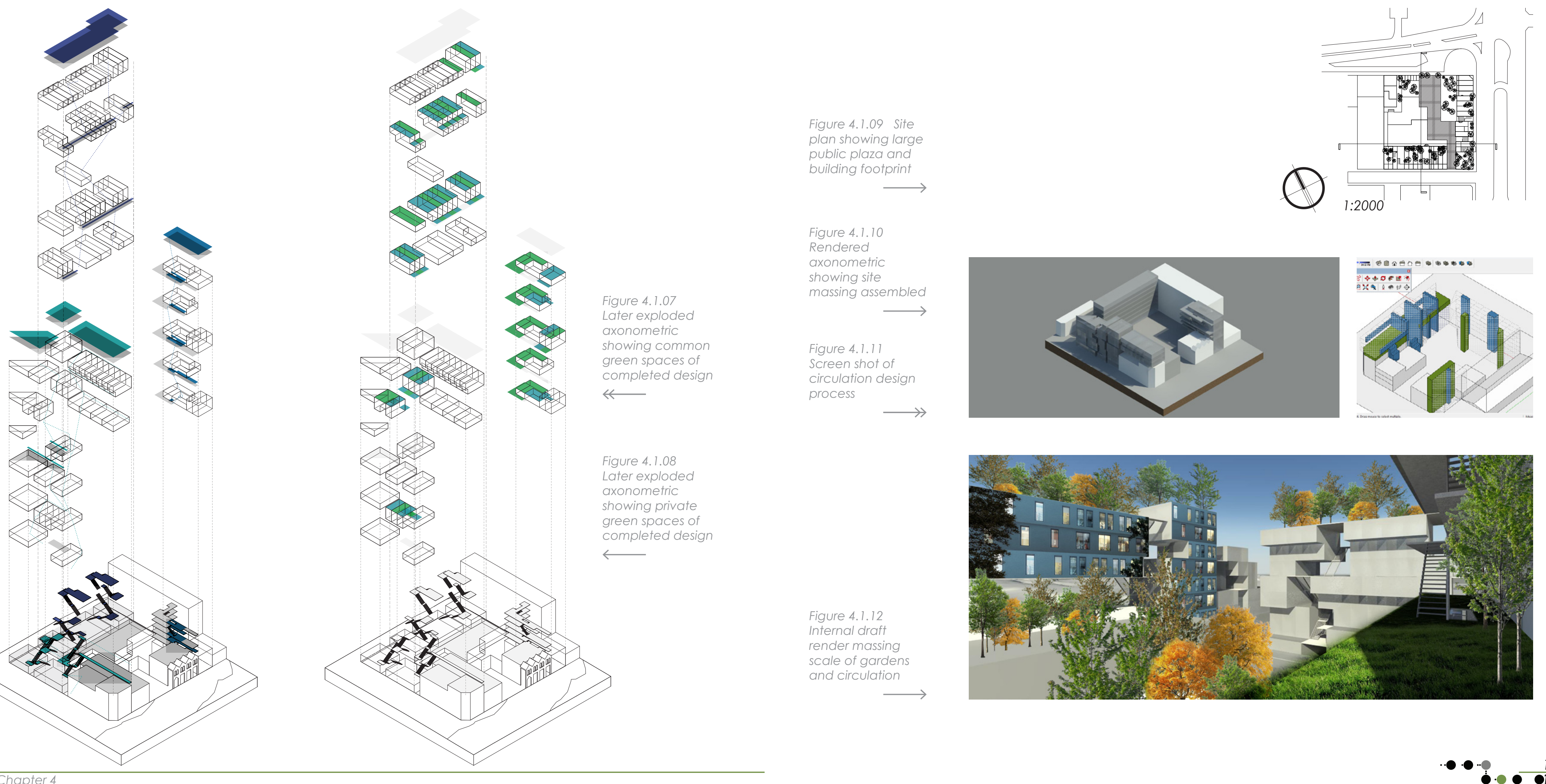

$\bullet \bullet \bullet \bullet-\frac{140}{\bullet 141}$ 

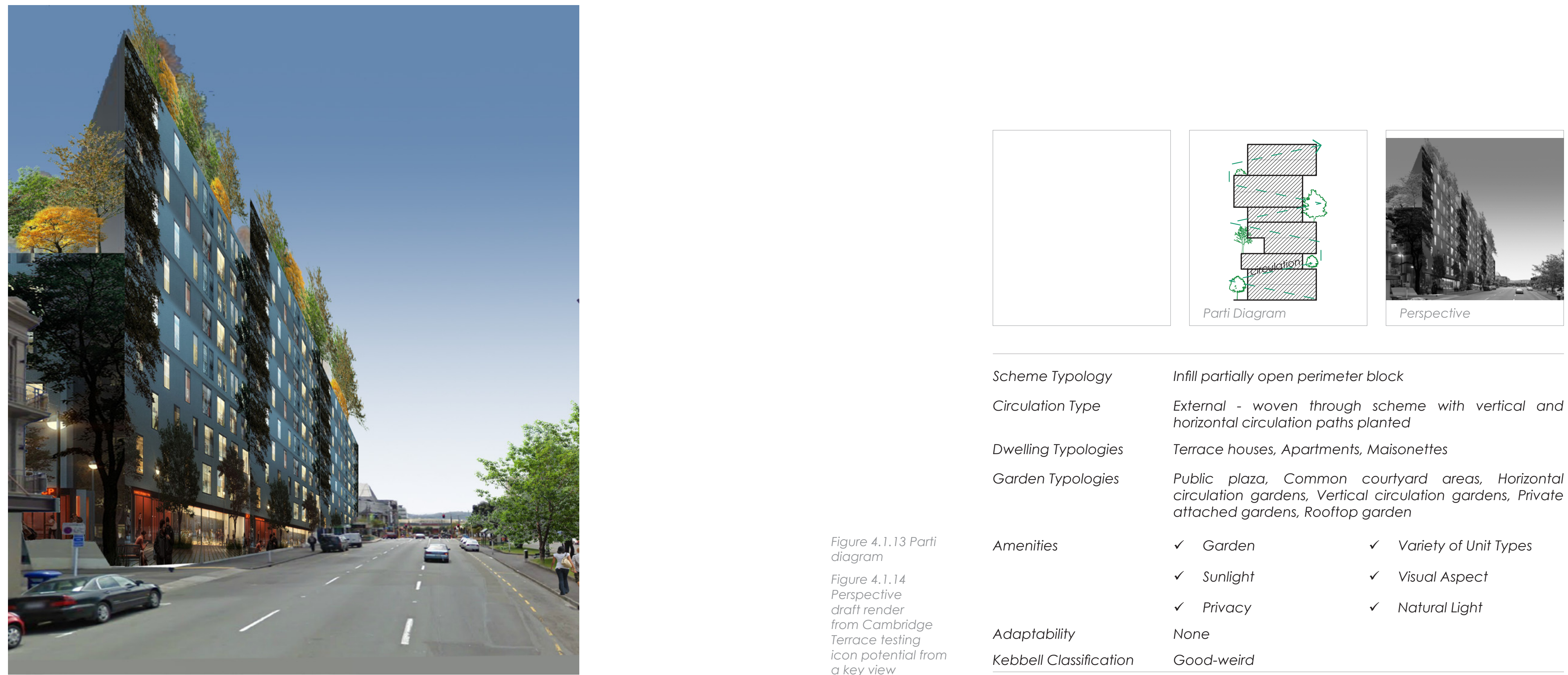

Scheme Typology

Circulation Type

Dwelling Typologies Garden Typologies

Figure 4.1.13 Parti

Figure 4.1.14
Perspective

from Cambridge

Terrace testing

icon potential from a key view

Amenities

Adaptability
Infill partially open perimeter block

External - woven through scheme with vertical and horizontal circulation paths planted

Terrace houses, Apartments, Maisonettes

Public plaza, Common courtyard areas, Horizontal circulation gardens, Vertical circulation gardens, Private attached gardens, Rooftop garden

$\checkmark$ Garden

$\checkmark \quad$ Variety of Unit Types

$\checkmark$ sunlight

$\checkmark$ Visual Aspect

$\checkmark$ Privacy

$\checkmark \quad$ Natural Light

None

Kebbell Classification

Good-weird 
- Design process is well documented providing a clear record of design decisions

- Design test responds directly to, and offers a solution or, all three prioritised aspects, amongst other a

- Entire external circulation network is planted and andscaped in various ways to create different relationships and spaces for differing uses

- Morphology for circulation paths is developed. Carved and woven voids, that are light and planted, provide vertical and horizontal circulation

- Vertical garden voids are visible from inside and outside the development. These create a strong, distinctive

- 'Salt and peppering' of different unit types throughout the developmenthelps create diversity in the community as well as the built form

- The design research process is comprehensive, using iterations of hand drawn explorations in plan, section and axonometric to develop a sophisticated approach to a common garden network

- Design test begins to take on preferred proportions and

Points of Limitation

- Solution does not respond to all 29 previously identified design criteria from CHRANZ, nor the six additiona parameters, in particular those solved at a unit pla evel

- Designis too site specific because it is builtaround existing buildings limiting the model's possible applications to

- Fenestrations and other elements required for dwelling, that have a dramatic effect on a building's appearance, are not studied

- Ground floor requires development so as not to detract from the ideas of this housing study.
Figure 4.1.15 through plaza illustrating selected stacking technique

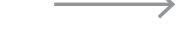

Figure 4.1.16 Rendered
axonometric

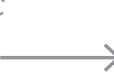

Figure 4.1.17 Axonometric Figure 4.1.18
Garden Study Figure 41.19 Figure 4.1.19
Circulation Study Figure 4.1.20 Public Common Private Figure 4.1.21
Perspective
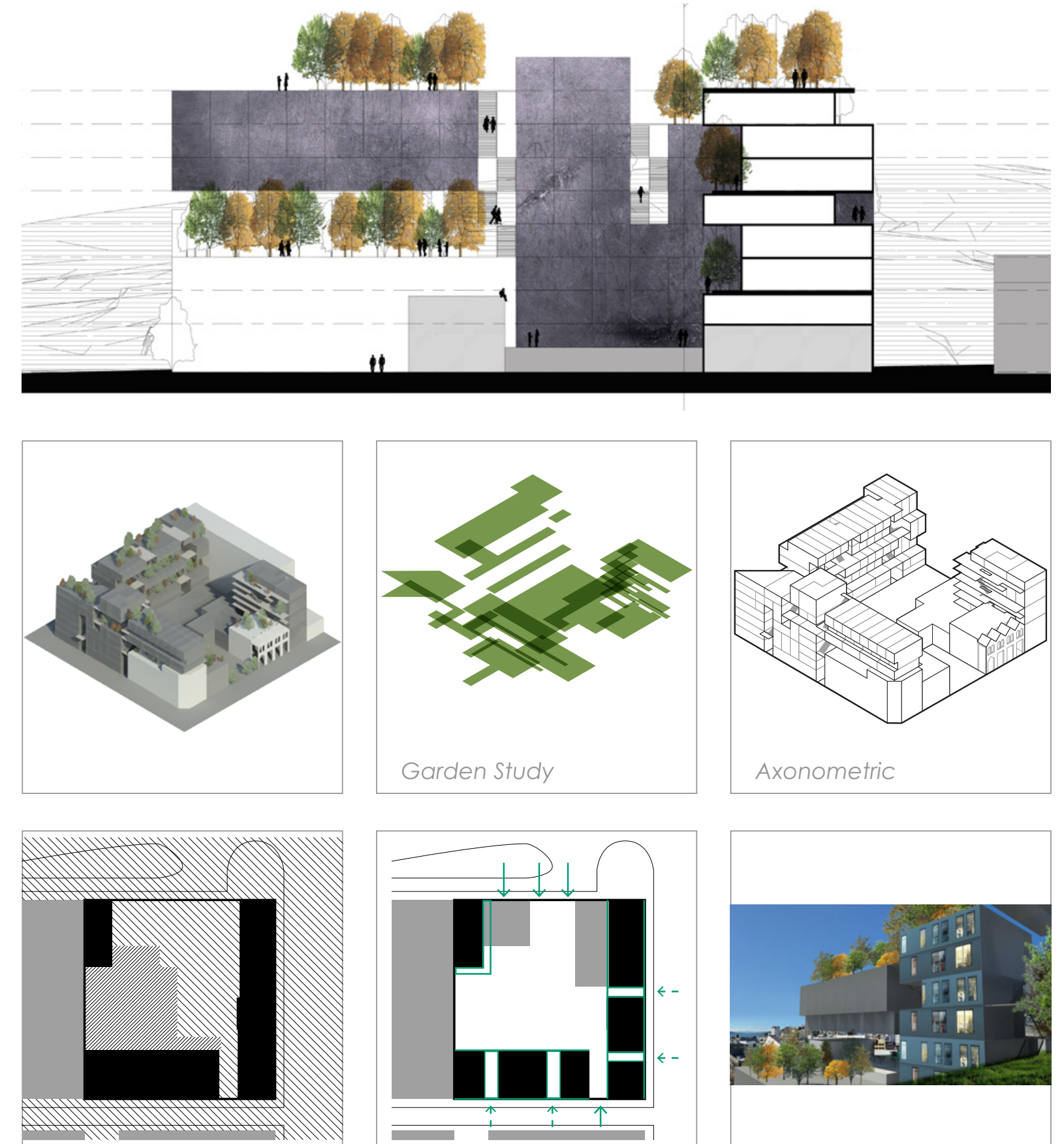

Public Common Private Circulation Study

Perspective

$\bullet \bullet \bullet \bullet \bullet-\frac{144}{\bullet} \cdot \bullet 45$

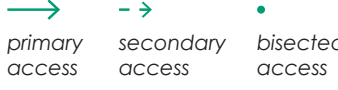




\section{Parts}

FINAL DESIGN TEST PRESENTATION 
CHAPTER 5
Design Test

Five

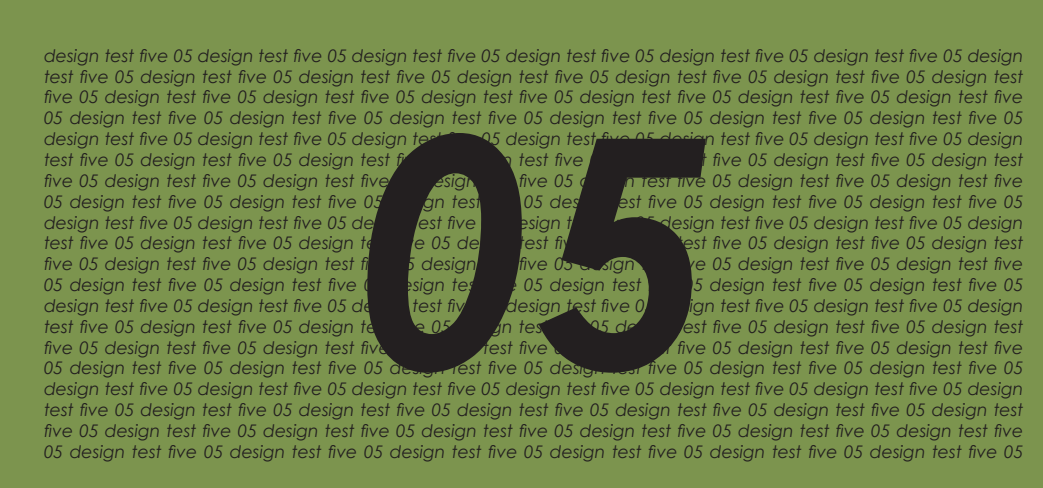



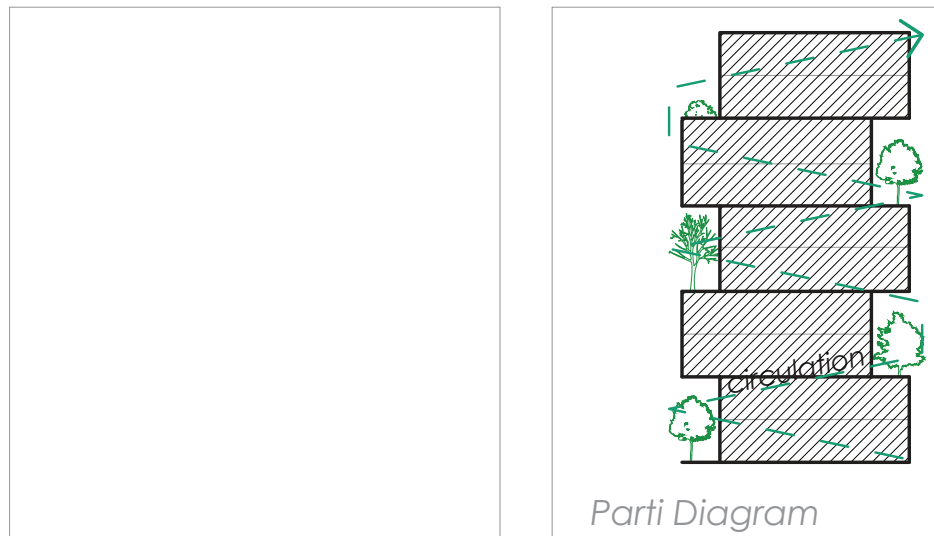

Parti Diagram
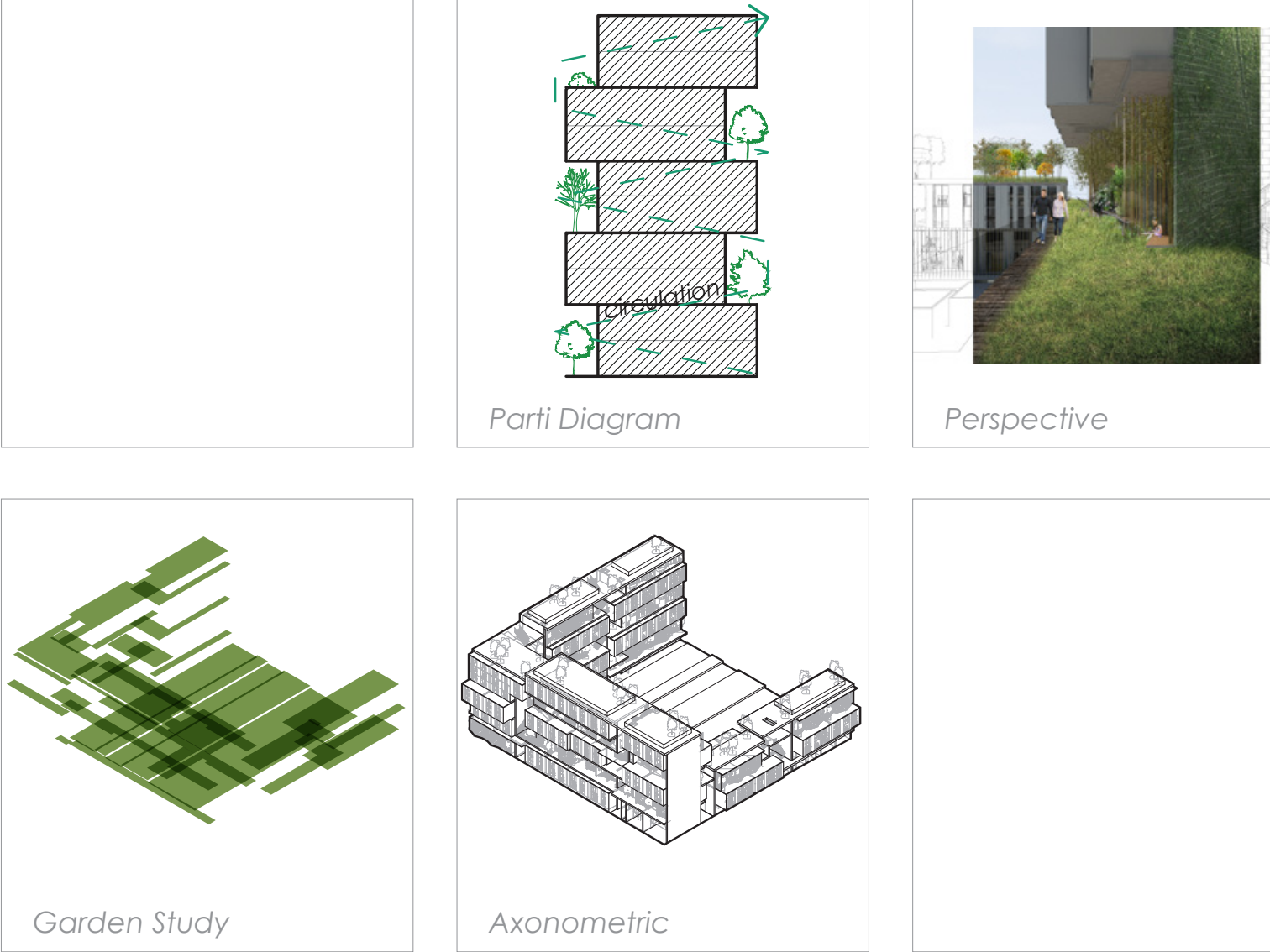

Perspective

Design Development Mediums

Project Date

Key Drivers

Programmes
1:500 and 1:200 studies, Hand

Month 8-9 (September-October)

- Flexibility for evolving family situations and household makeups

- Creating a plausible scheme that responds to all design criteria including CHRANZ amenities, six additional amenities, site requirements and density

Grictic garden, Ground floor crèche 
- Solves for the six additional design parameters, the targeted 250DW/HA density and site requirements such as height restrictions

- scheme also provides missing public and common amenities identified during site selection (crèche and public green - Chapter 0.3, Figure 5.4.05)

- Flexible structure developed using a mega-structure that allows two to three apartments to be arranged within a larger frame

- 'Sliding' architectonic developed to refine the appearance of the design

- 'Park house' typology discovered - defined by direct access onto larger common areas such as those beside

- High percentage of terrace houses totalling 77/134 (57\% - highest of all design tests)

- Propositional design created by removing all existing buildings, thus site specificity does not complicate lessons so they can easily be transferred as a model to different sites and conditions
Scheme Typology

Circulation Type

Dwelling Typologies

Garden Typologies

Amenities

Adaptability

Kebbell Classification

Figure 5.0.03 Garden Stud Figure 5.0.04
Axonometric

Figure 5.0.05 Public Private Common Figure 5.0.06 Public Circulation Stu Figure 5.0.07
Perspective
Perimeter block

External - woven through scheme with vertical and horizontal circulation paths planted

Terrace houses, Verte maisonettes, Park houses

Public courtyard, Horizontal circulation gardens, Vertical circulation crevasse gardens, Private attached terrace gardens, Rooftop gardens, Herbaceous screens, Loggias, Balconies

$\checkmark$ Garden

$\checkmark$ Variety of Unit Types

$\checkmark$ sunlight

$\checkmark$ Visual Aspect

$\checkmark$ Privacy

$\checkmark$ Icon value

Double bay and double height structural system allows for a variety of internal unit arrangements that can be retrofitted as family situations change

Good-weird
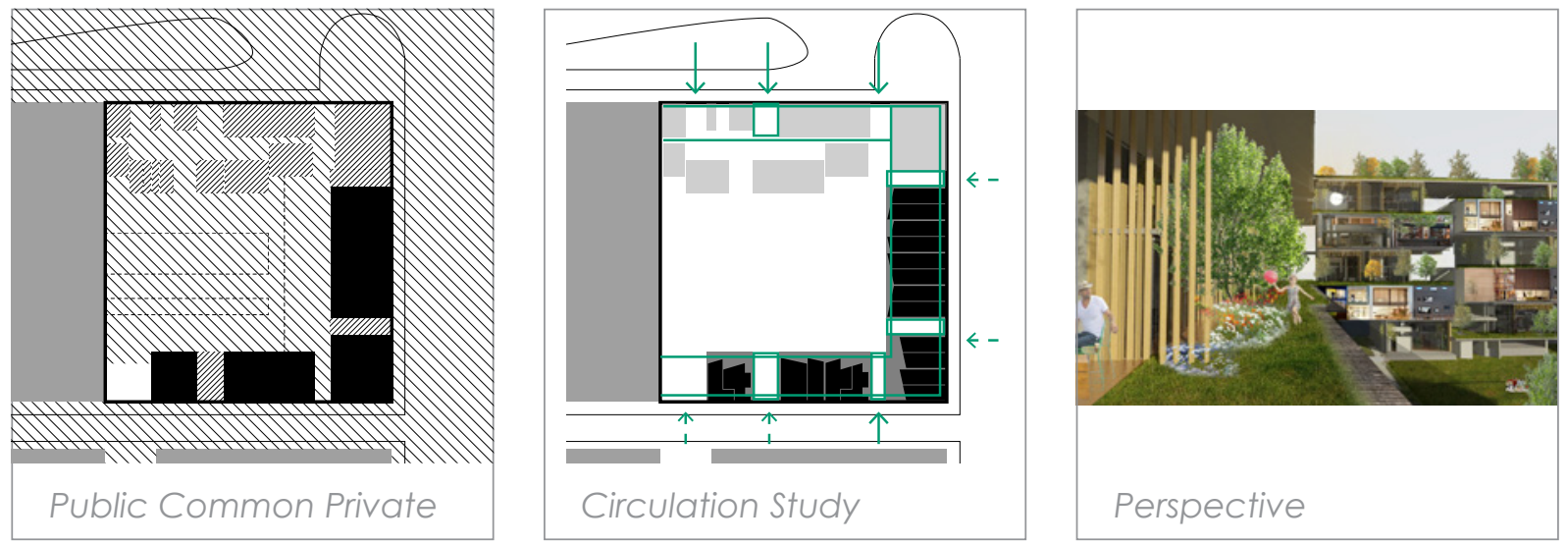

Circulation study

$\bullet \cdot \bullet \cdot \bullet \frac{152}{\bullet \bullet} \cdot 0153$ 
Design test five is the conclusion of a design-led research process that combines knowledge gained in early experiments into a cohesive scheme. This scheme contributes to the architecture profession new and propositional thoughts on housing. With the combination of many design drivers a new typology of higher density housing is created, in which vertical and other garden types combine, bringing

\section{$259^{\mathrm{mom}}$ 259

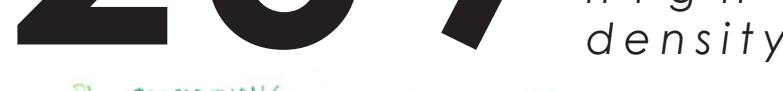

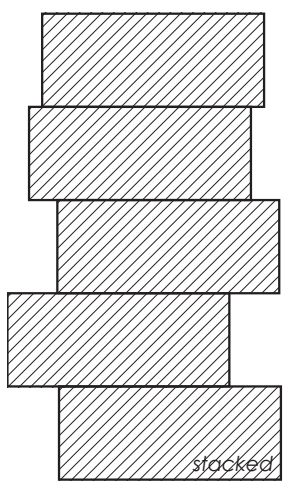

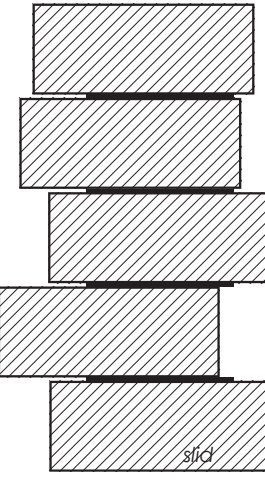

verdant living option to inner city Wellington.

This scheme had an earlier iteration with similar ideas, massing and structure designed with a 'stacking' architectonic. However this 'stacked' design had a visual heaviness to it which led to the development of a preferred 'slid' architectural language (Figure 5.1.01).

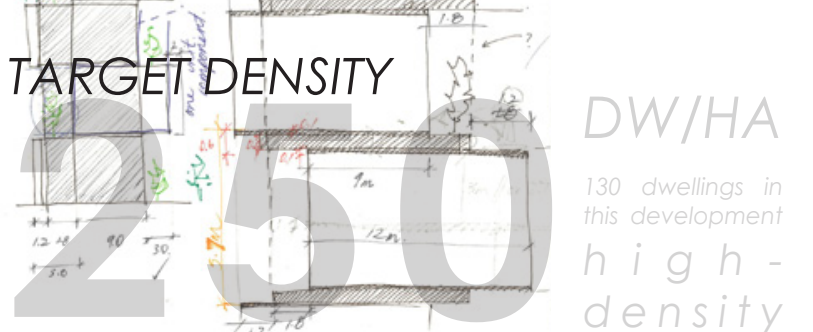




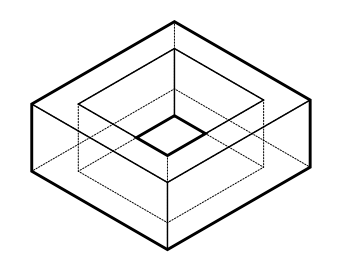

Perimeter Block Typology Built to Maximum Height

- double aspect rule established for sunligh

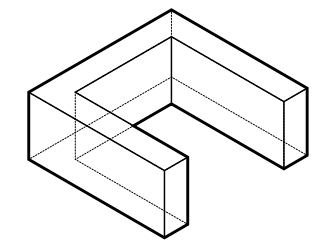

Privacy Addressed in Reaction

to Future Developments

- future proofs double aspect rule
- reaction to external condition

$\rightarrow$

Northern Edge Lowered

- ensures sunlight to central common area

- ensures sunlight to all apartments for at least

allows views out of the development to the

Access and Block Permeability

H or Vertical Circulation

access from the street at crucial points to
break mass into identifiable sub blocks

进

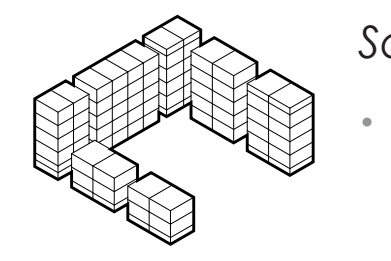

alt and Peppering of Unit Types offers a diversity of housing types from
terrace houses with attached private gardens, to maisonnettes and apartments

develop a fexible double sto

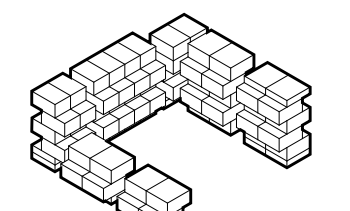

Slide Out Areas for Gardens and Horizontal Circulation

north orientated bocts to race cemponete.

1.1: east/west orientated terrace:maisonete

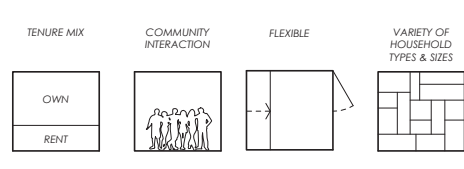

anear smear

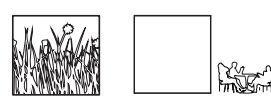

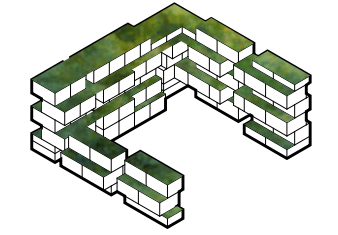

Landscape

shuffe massing and apartment layout within circulation spaces to give the developme

anaox

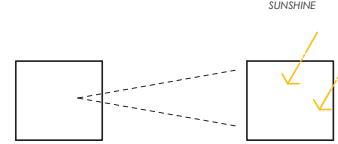

$\square \square_{1}$

moves (not

chronologically

$\longleftarrow$

Figure 5.1.03 Parti diagram (Plan)

Linking landscapes
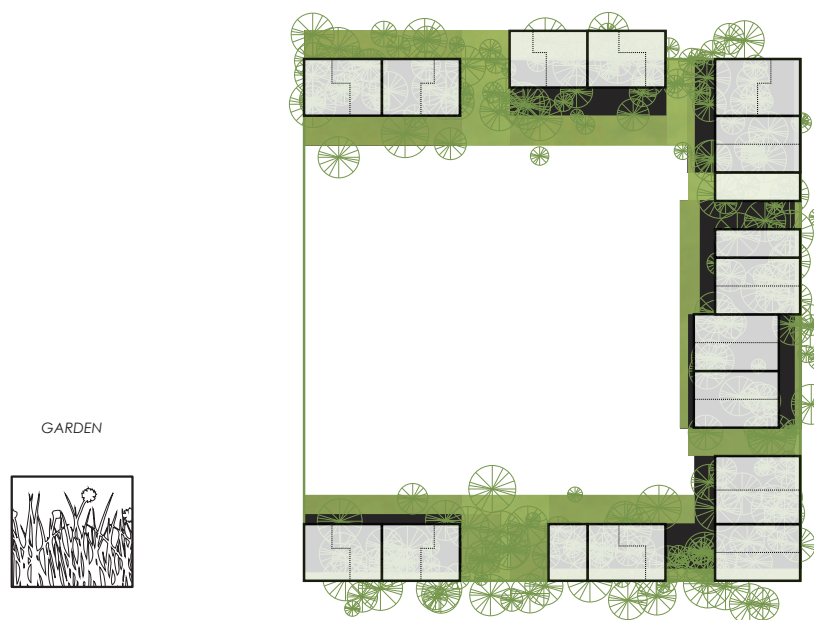

Figure 5.1.04 Parti

diagram (Plan)

orientation and

distance

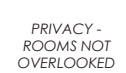

$\square \square \square$

$\square \square \square$

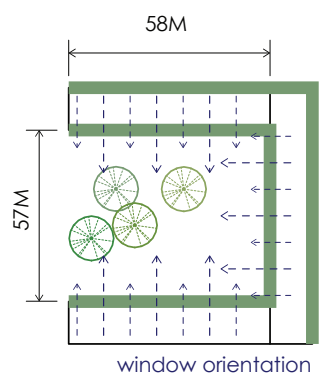

Figure 5.1.05 Panti

diagram (Plan

showing typical

midday shadow

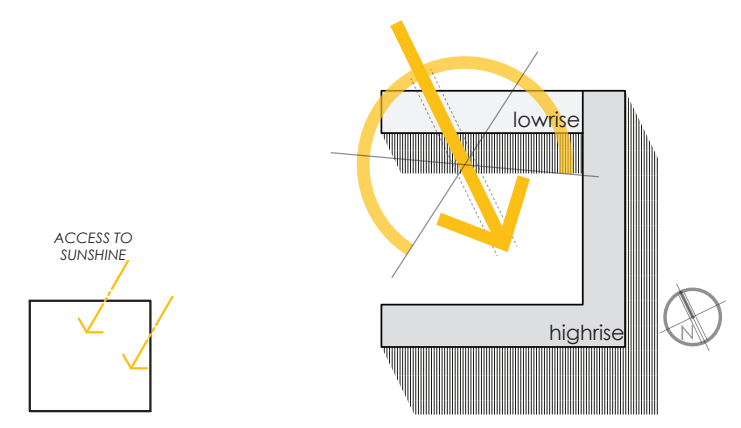




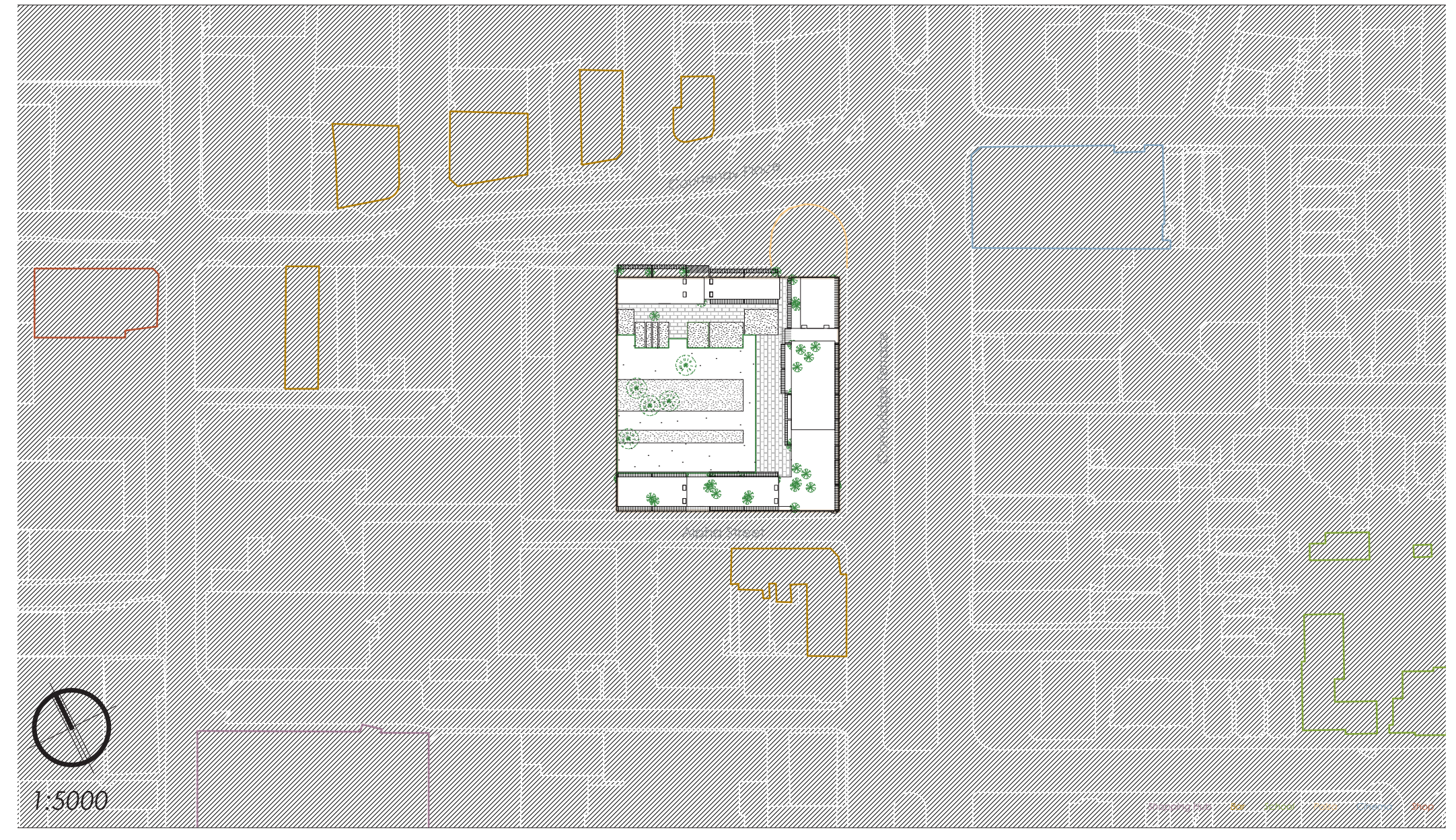

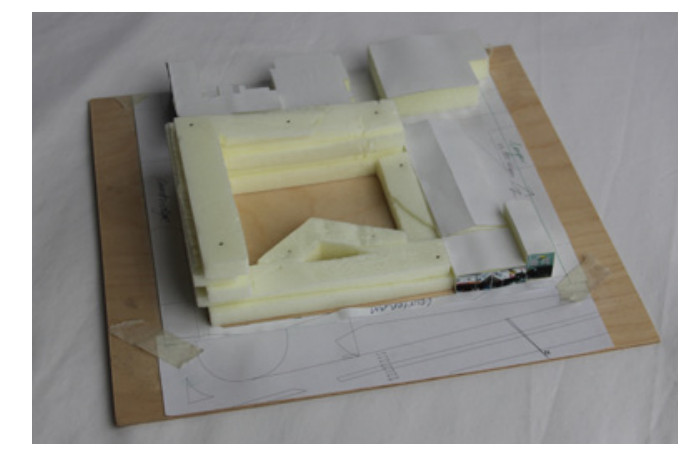
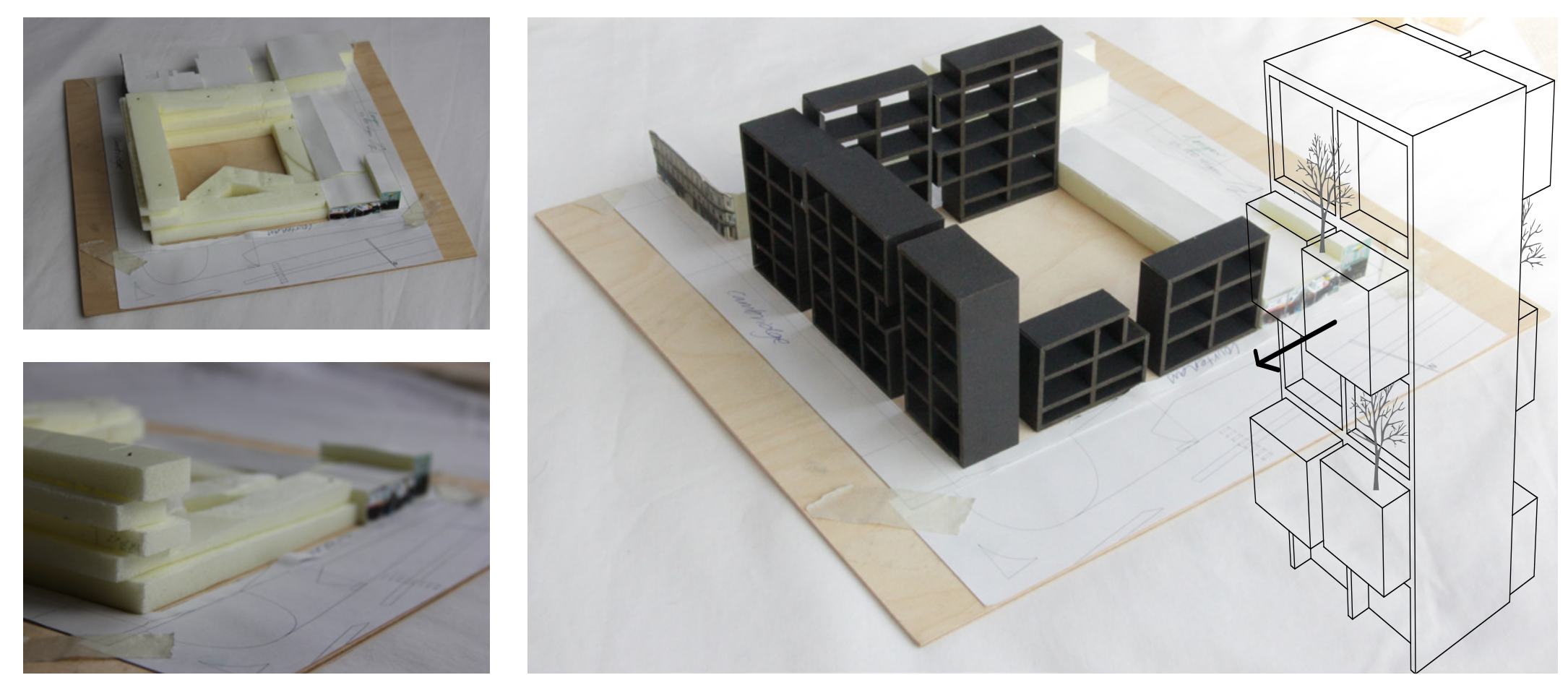

Figure 5.1.06 Site plan with exceptional highlighted

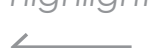

The site is master-planned similarly to previous design iterations, integrating with and activating the public realm in the following ways:

- A public courtyard and plaza is made via the 'sliding out' masses along Courtenay Place (Figure 5. 1.09)

- Level one includes a raised public garden along Courtenay Place, with double storey landscape features (primarily trees) extending from ground level

model with central

$\ll$

Figure 5.1.08

Stacking detail

$\longleftarrow$

Figure 5.1.09

Framework for

sliding model with

$\longleftarrow$
- Retail and office spaces on portions of the ground and first floor further invite the public to the site

- Access to the central public park is designed to be inviting lyet bottlenecks at some entries discourage public thoroughfare through the entire site) 
Figure 5.2.01 Built volume with only highlighted

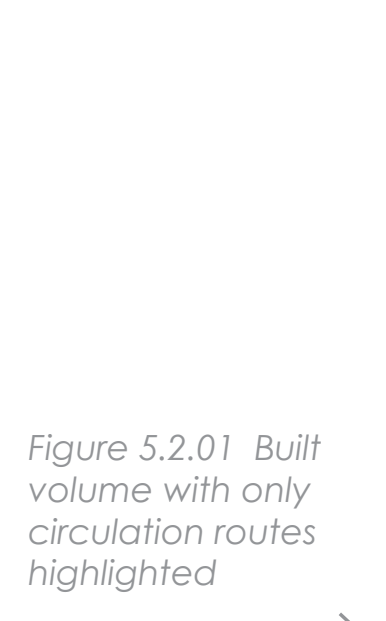

'Linking landscapes' illustrates the common green network concept's articulation demonstrating how landscape infrastructure ties the scheme together physically and conceptually. Within the network various landscape unusually shaped vertical garden voids derived from early forays into salt and peppering unit types, and roof greens which are formalised as part of the circulation routes. These increase the permeability of the network and facilitate access for residents to large common outdoor areas suitable for families to 'break-out' in as well as creating a verdant iconic feature.

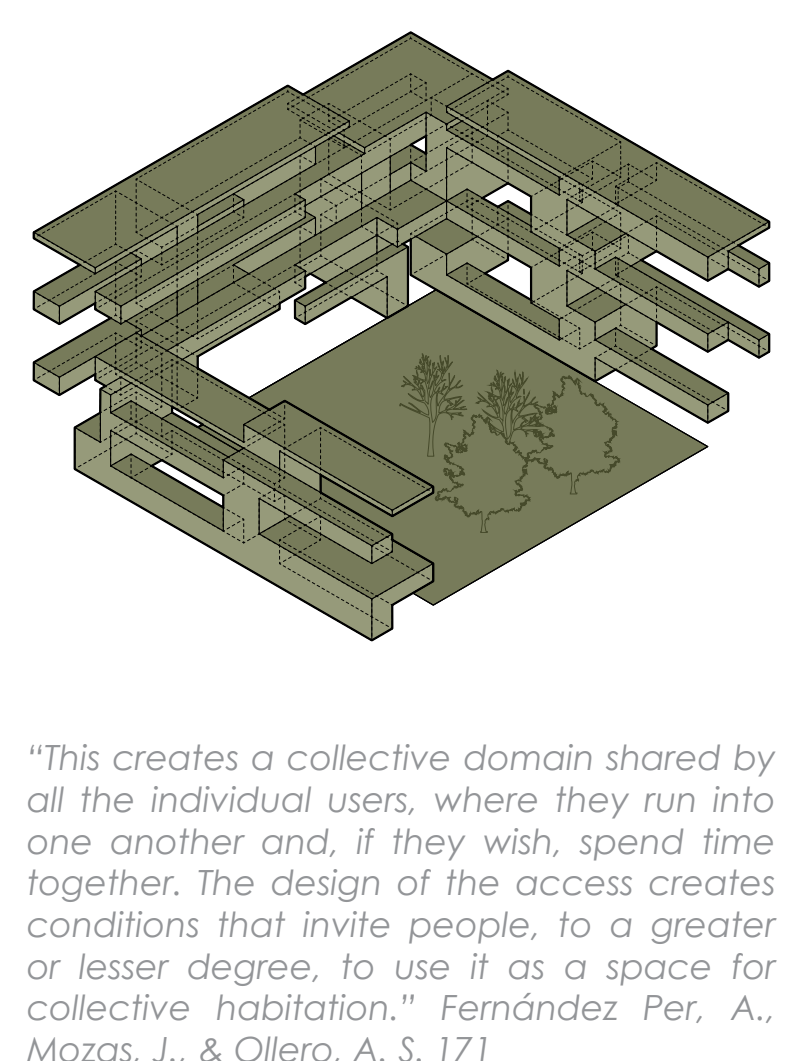

$\bullet \cdot \bullet \cdot \frac{160}{\bullet \cdot \bullet 161}$ 

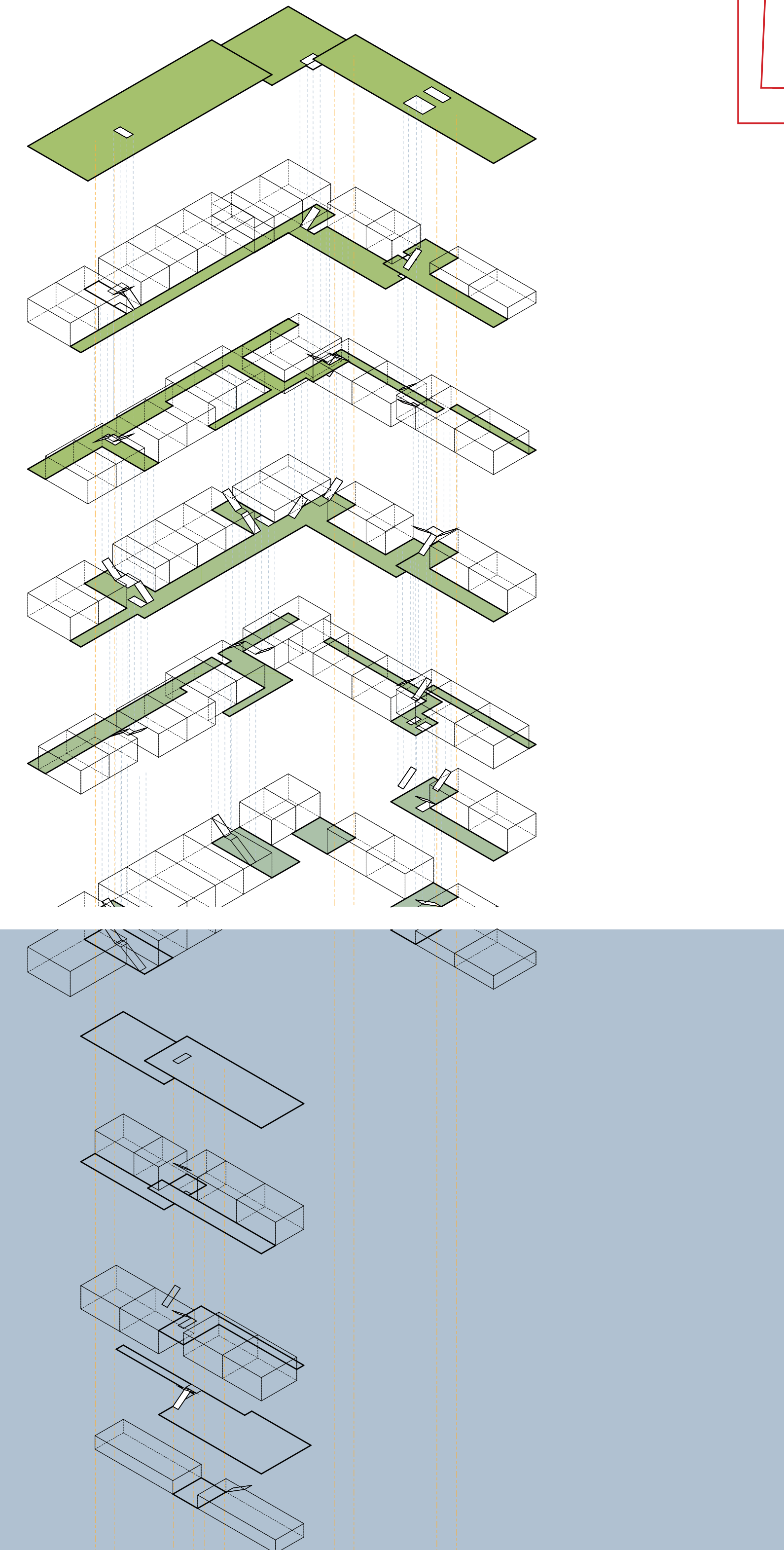

Bh

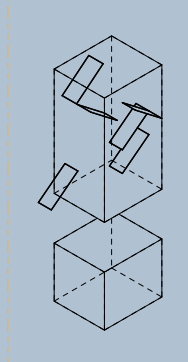

S

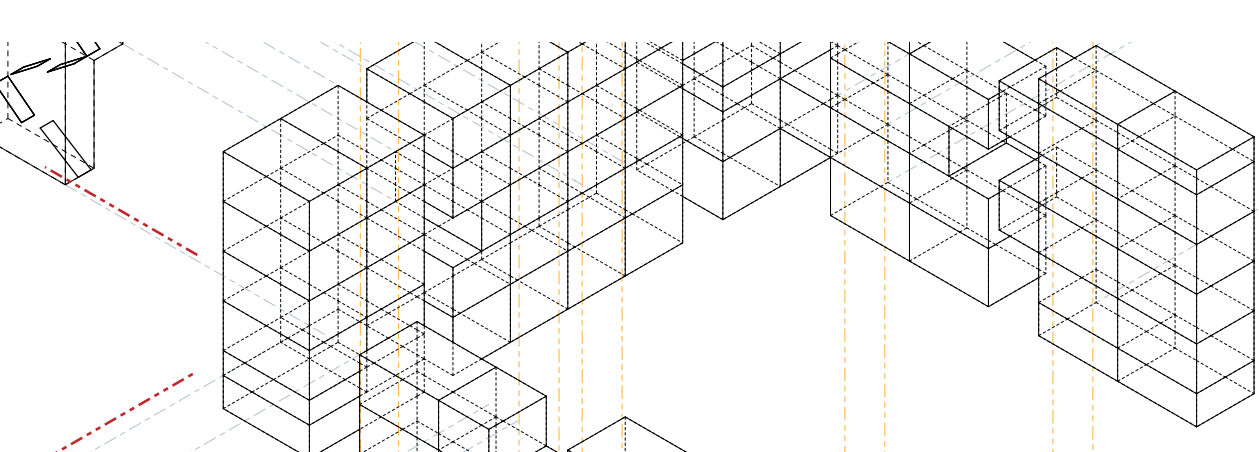

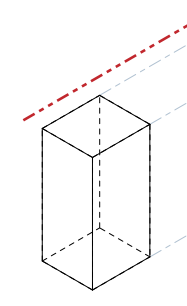

곡

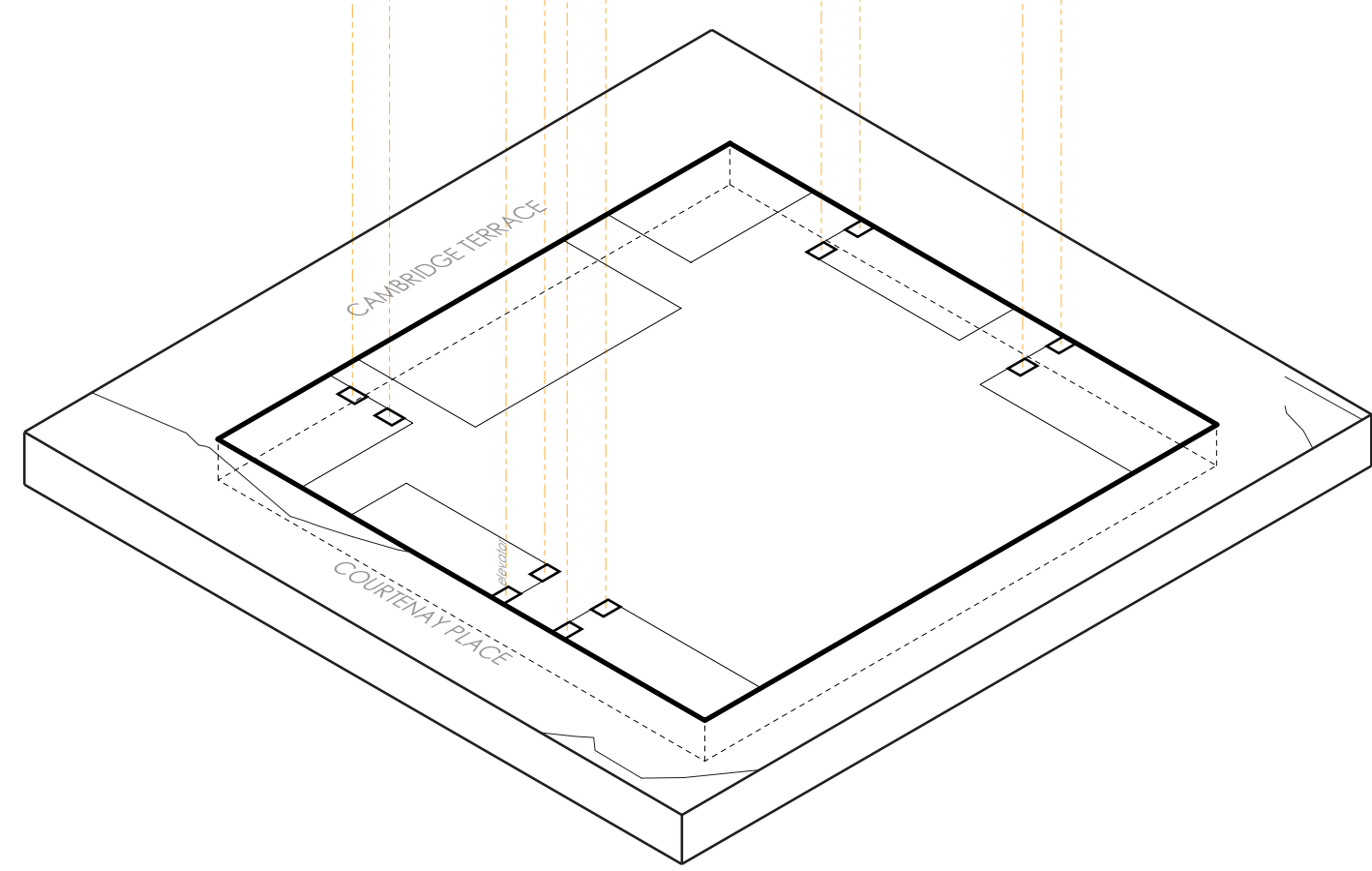

figure 5.2.03 North

Large common

circulation areas
both vertical

and horizontal,
highlighted

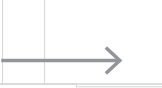

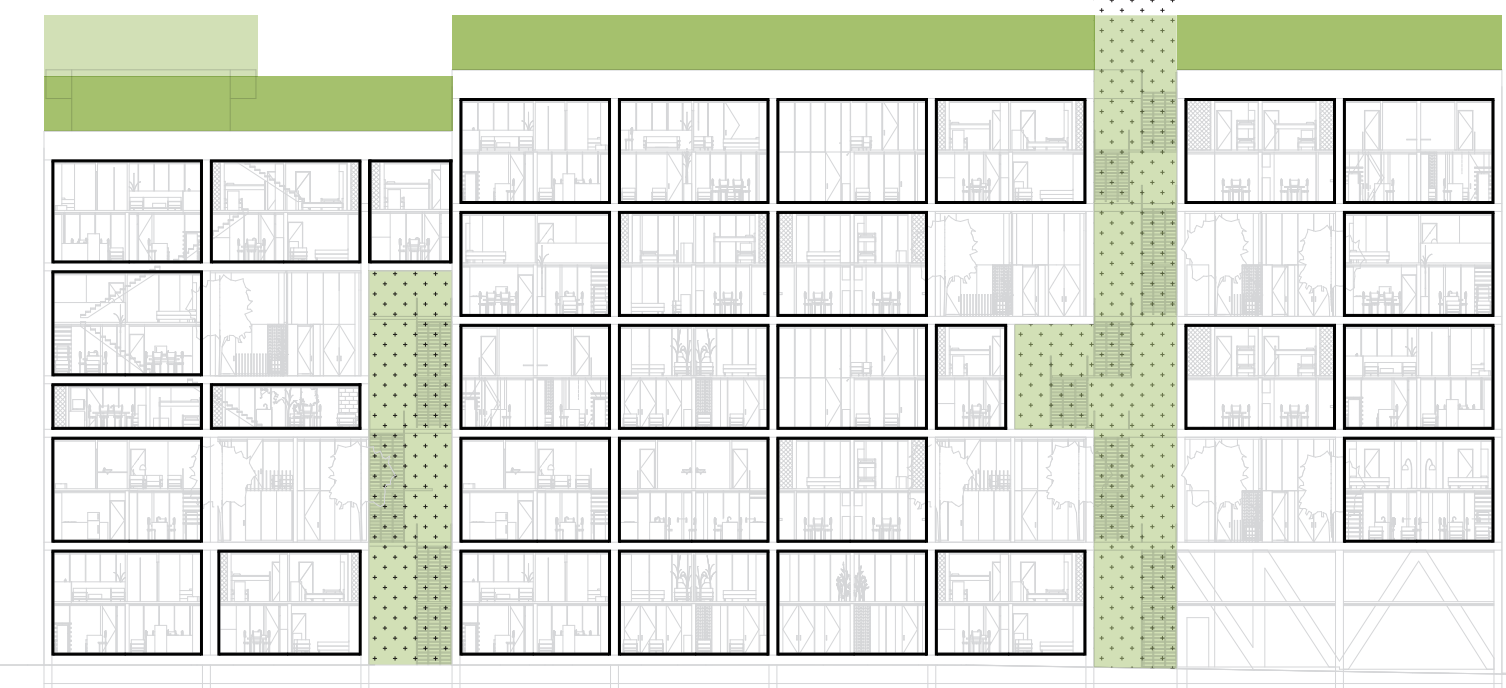

Figure 5.2.04 East West Section 1:500 circulation areas both vertical highlighted

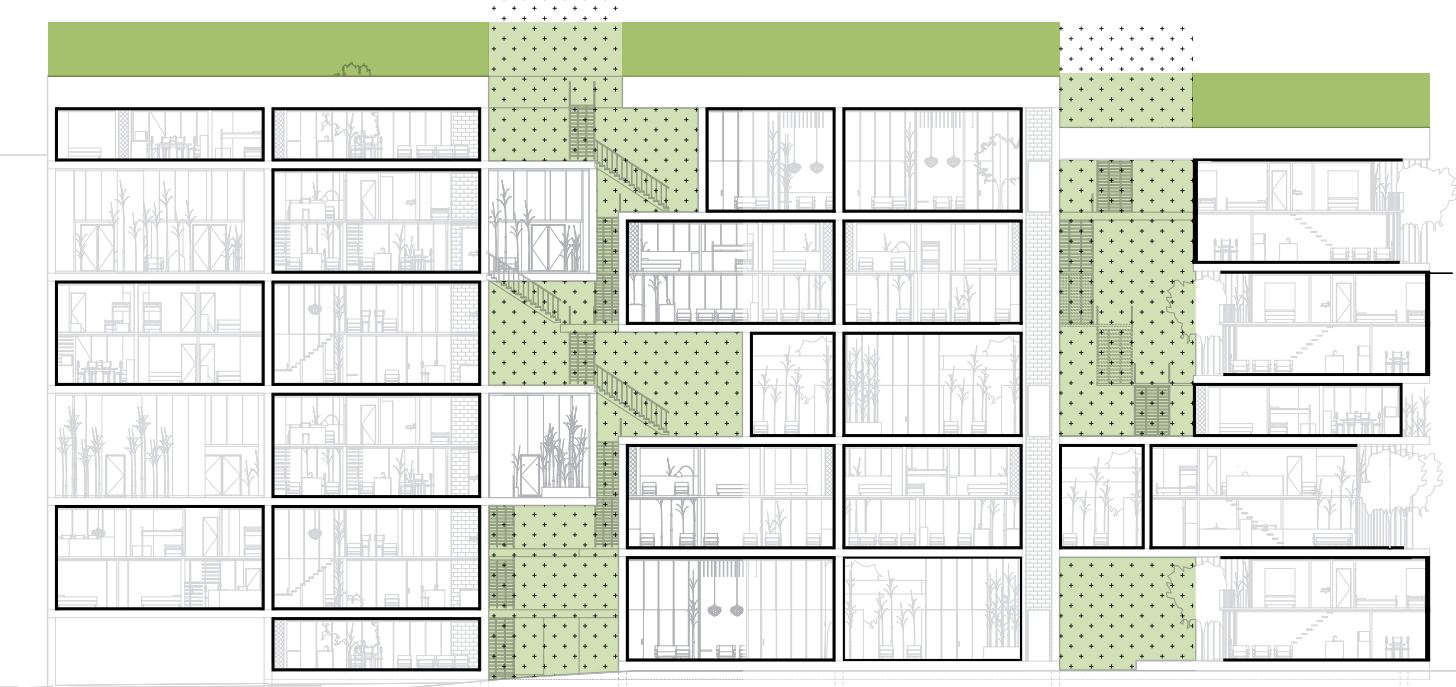

$\bullet \cdot \bullet \cdot \frac{162}{0163}$ 


\subsection{Landscape Typologies}

Knitted through this development are six primary landscape typologies located in relation to different parts of the built form.

\section{Public Green}

Located at street level this green is gifted to the public as a city amenity in a generous response to site selection observations in which a 'green' was identified as absent in this area of Wellington (Chapter 0.3).

Accessed from the public plaza

Courtenay Place and Cambridge Terrace/Alpha Street corner land common vertical circulation gardens, the space is large and landscaped with large trees and level changes. This produces intimate moments that have the potential for temporary division if desired.

Vertical Garden

Vertical gardens are the planted short moments of narrower stair spaces between pocket yards (Figure 5.3.02). With climbing plants forming vertical garden walls these narrow circulation spaces contrast in sequence with the large pocket yards they connect. 


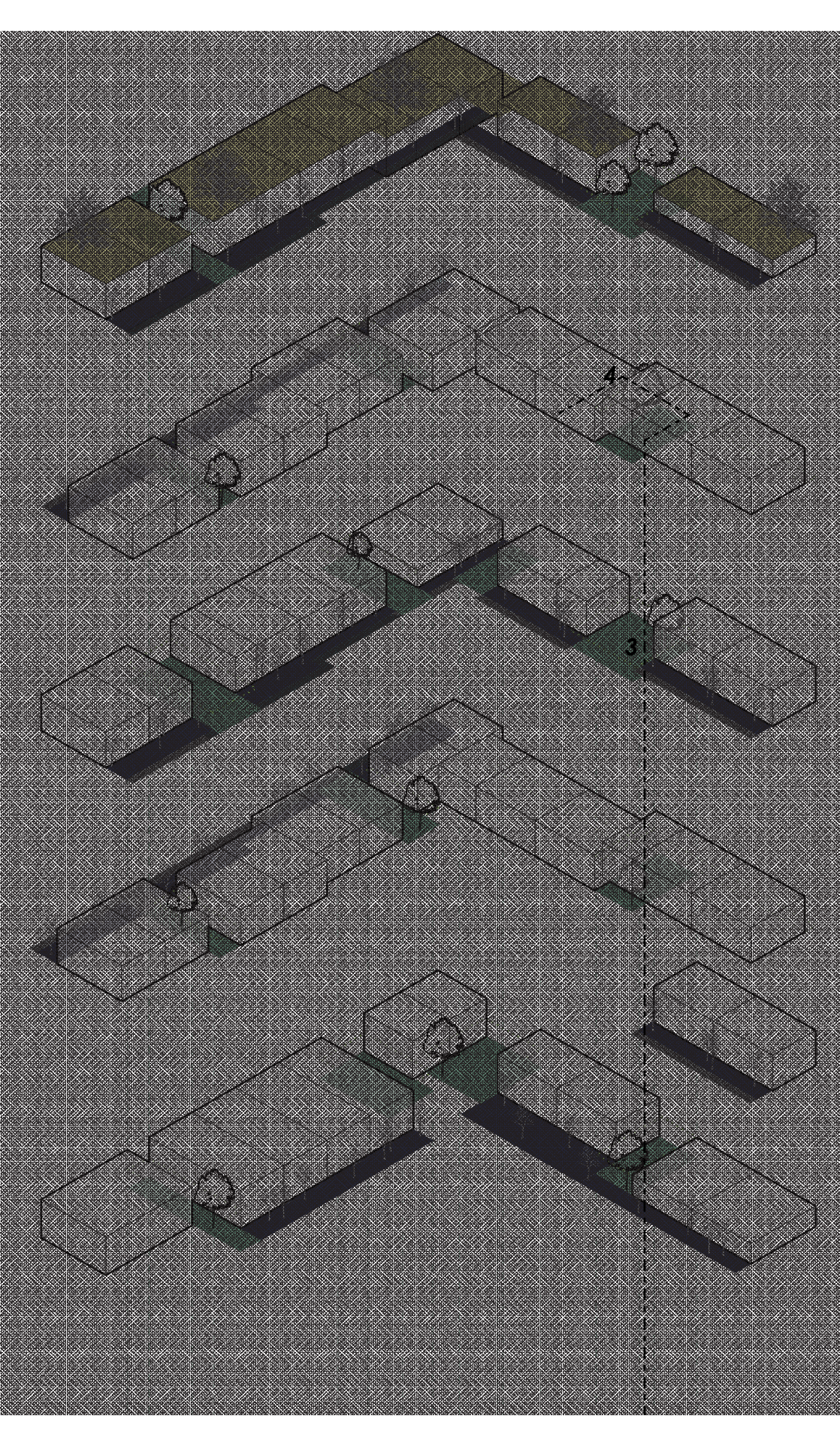

\section{Pocket Yard}

Pocket yards are larger double storey spaces that occur within the vertical circulation voids. Functioning as planted landings these spaces can be used for neighbourhood type activities: trampolines and tree climbing, a place for making daisy chains or hosting a child's birthday party.

\section{Boardwalk}

Double height boardwalks connect between vertical circulation voids to provide access to all units via $1.2 \mathrm{~m}$ wide paths which weave around and through the building mass. The boardwalks use borrowed landscape ideas, where background landscape is incorporated into the composition of a garden. Particularly borrowed landscape references are made to the public green, Mount Victoria or Port Nicholson depending on which side of which block it is positioned. In each scenario the boardwalk also relates to the level it is attached to, sitting $400 \mathrm{~mm}$ below the adjacent private planted terrace gardens (to ensure privacy) and 'borrowing' their landscape also. In the situation where the boardwalk is located on the southern side of the building it is louvred off to protect residents from the prevailing southerly winds but allow ligh in to facilitate the growth of shade-loving plants.

\section{Private Terrace}

Private terraces occur as part of the terrace house typology on the building's northern, eastern and western façades. Here, under the supervision of the family, lawn, shrubs and trees of up to $6.5 \mathrm{~m}$ can grow. This gives the opportunity for kitchen herb gardens, strawberry plants, Monarch butterflies on Swan Plants and deciduous trees giving shelter from the summer sun. A variety of garden subtypologies were developed for use in these areas and are applied in terrace house unit types (Chapter 4.0, 5.4)

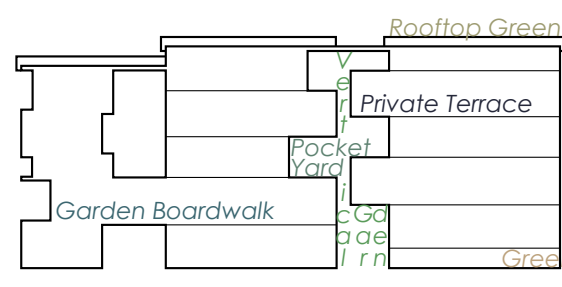

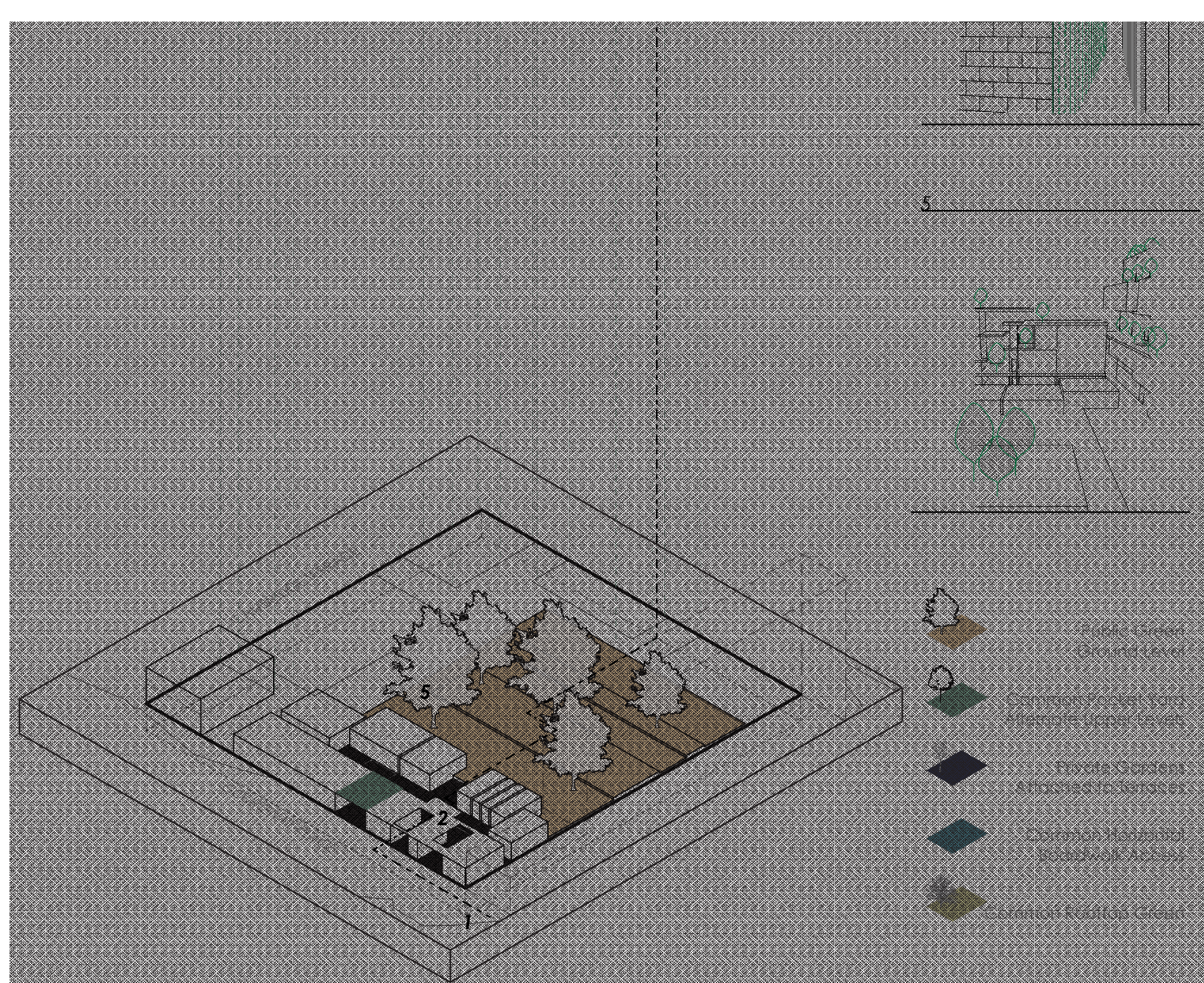




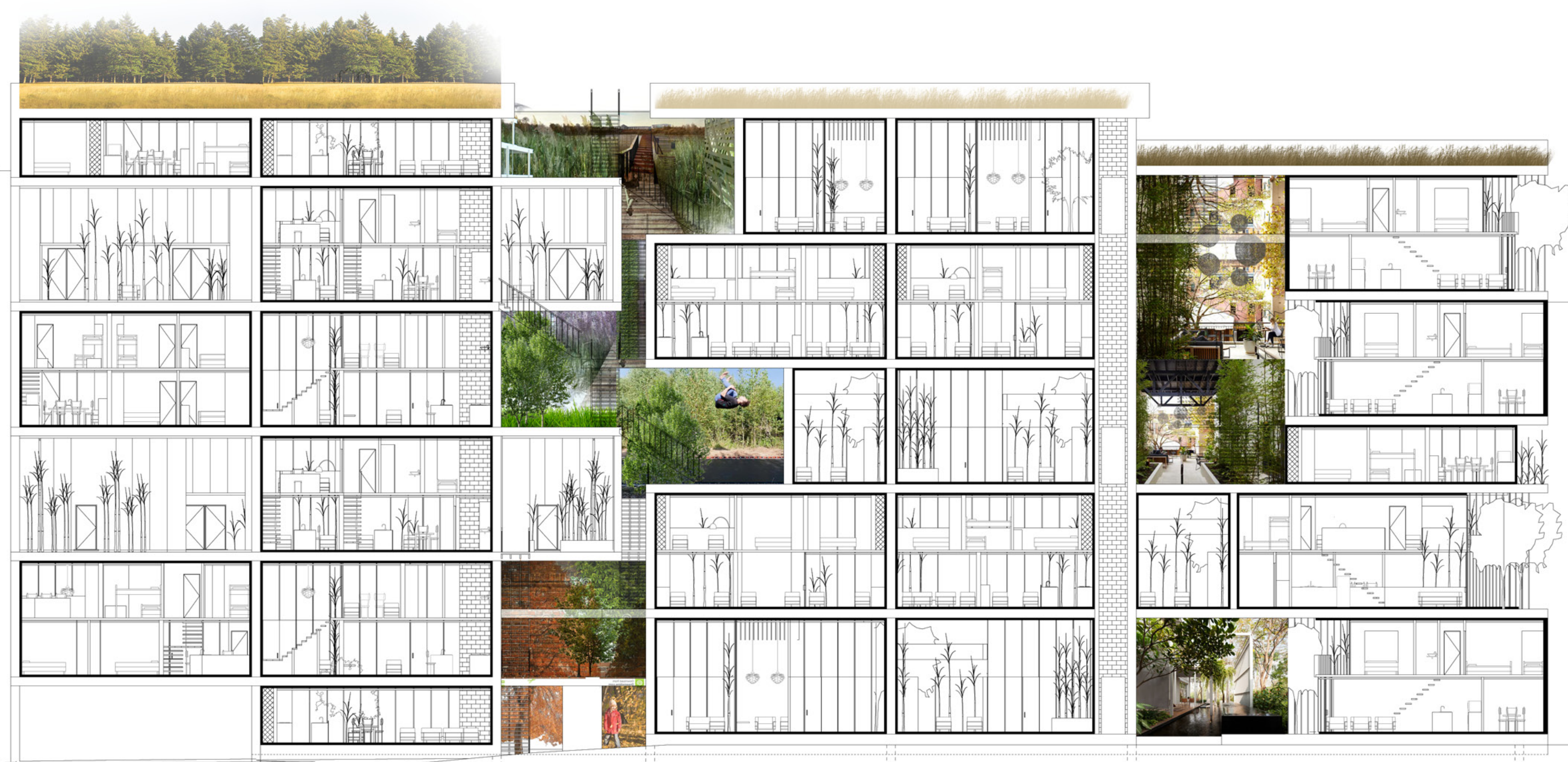

6. Rooftop Green

The common rooftop green brings further permeability to the scheme's circulation network. It offers a large breakout space for children to run around, learn to ride a bike on, or walk the dog in a secure environment. Landscaped to appear 'light' from the street, the bulk of the infrastructure required to grow trees and planting is set back from the edge over different levels. The shifting of massing is used to create sub-spaces, further defined by vegetative screens, to offer exciting and diverse rooftop landscapes. 


\subsection{Unit Typologies}

an effort to emulate suburban housing's desirable trait of adaptability, a framework for flexibility is developed in this design iteration. Using a 'megastructure', where every second storey is structural with up to three units fitting along a bay, the volume is freed up for division in multiple ways. In providing a range of unit types and sizes, a variety of unit prices exist and a diverse community has the opportunity to develop.

A new system of ownership is devised to optimise the flexibility. In this instance it is expected that one party would purchase a whole structural bay that is capable of division into one, two or three units. These units are then designed by project architect to this owner's wishes. This allows the owner to dwell in a primary unit and rent the remaining unit(s). The unit can then be adapted to be dual key as family or living situations change. Also, as the infill is non-structural, the unit can be entirely rebuilt to suit a new situation.

Allowing for a high proportion of owners and long term tenants in a development aids in establishing a core 'community' bringing the network a positive quality of suburban life (CHRANZ, p. 61).

Designing for flexibility requires a return to the initial design assumptions, where terrace houses maisonettes and apartments are used to develop the proposition. The double height structure facilitates the first two typologies easily, yet the apartment type (single storey). is more difficult to design for. While not 


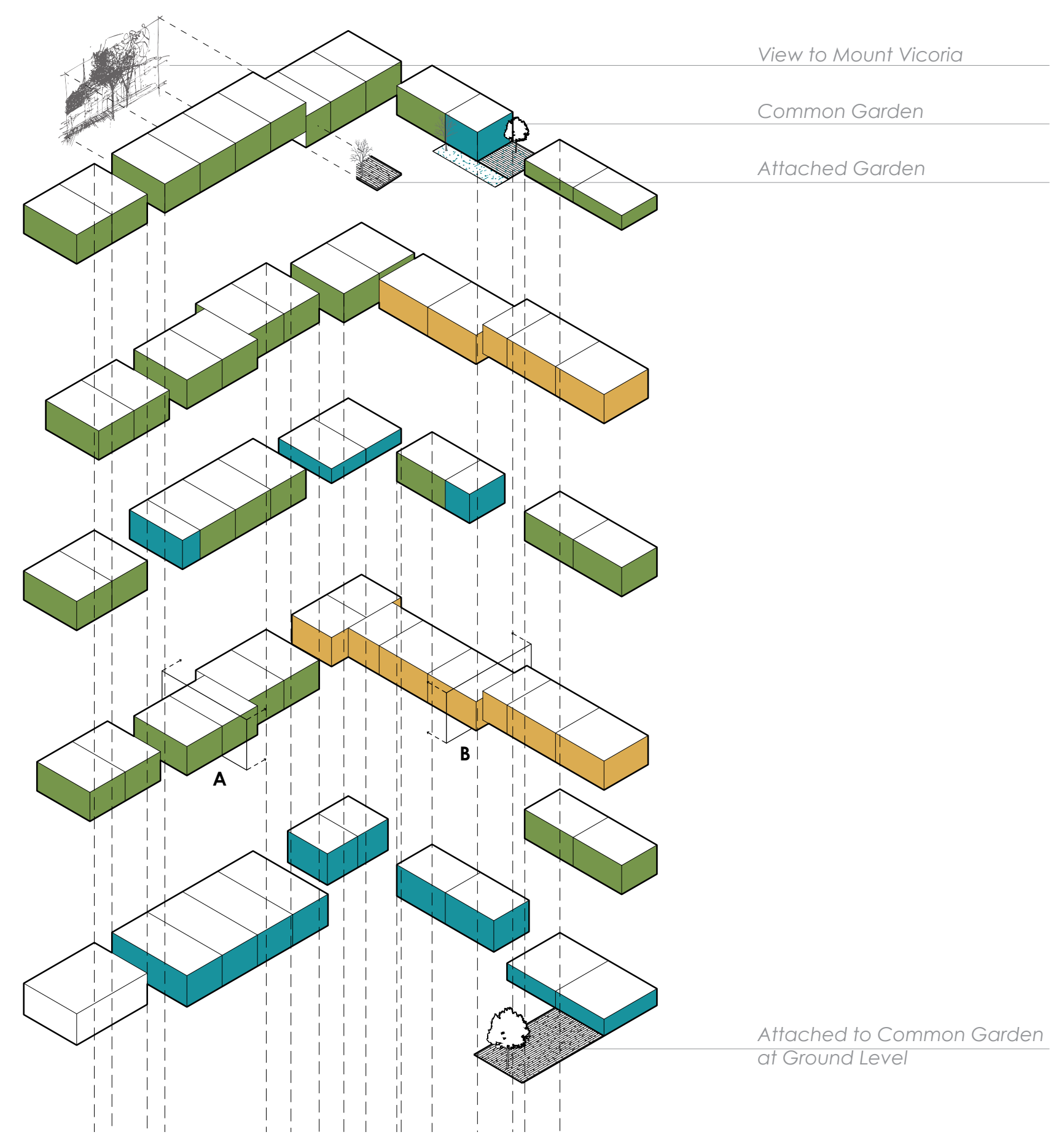

impossible to incorporate, stacked atop each other in a structural bay, apartments are removed as a form driver because they undermine the flexibility of the system and circulation which occurs every second level on alternating sides.

Upon reassessment a third typology becomes apparent: the park house. As with the other typologies, park houses are defined in terms of their relationship to garden and are specifically located adjacent, with direct access onto, the common garden spaces. They appear as the other units do, to be salt and peppered throughout the development offering further diversity (Figure 5.4.01).

Examples are shown on the following pages of each of the unit types, interlocked in different ways to suit a range of family situations.

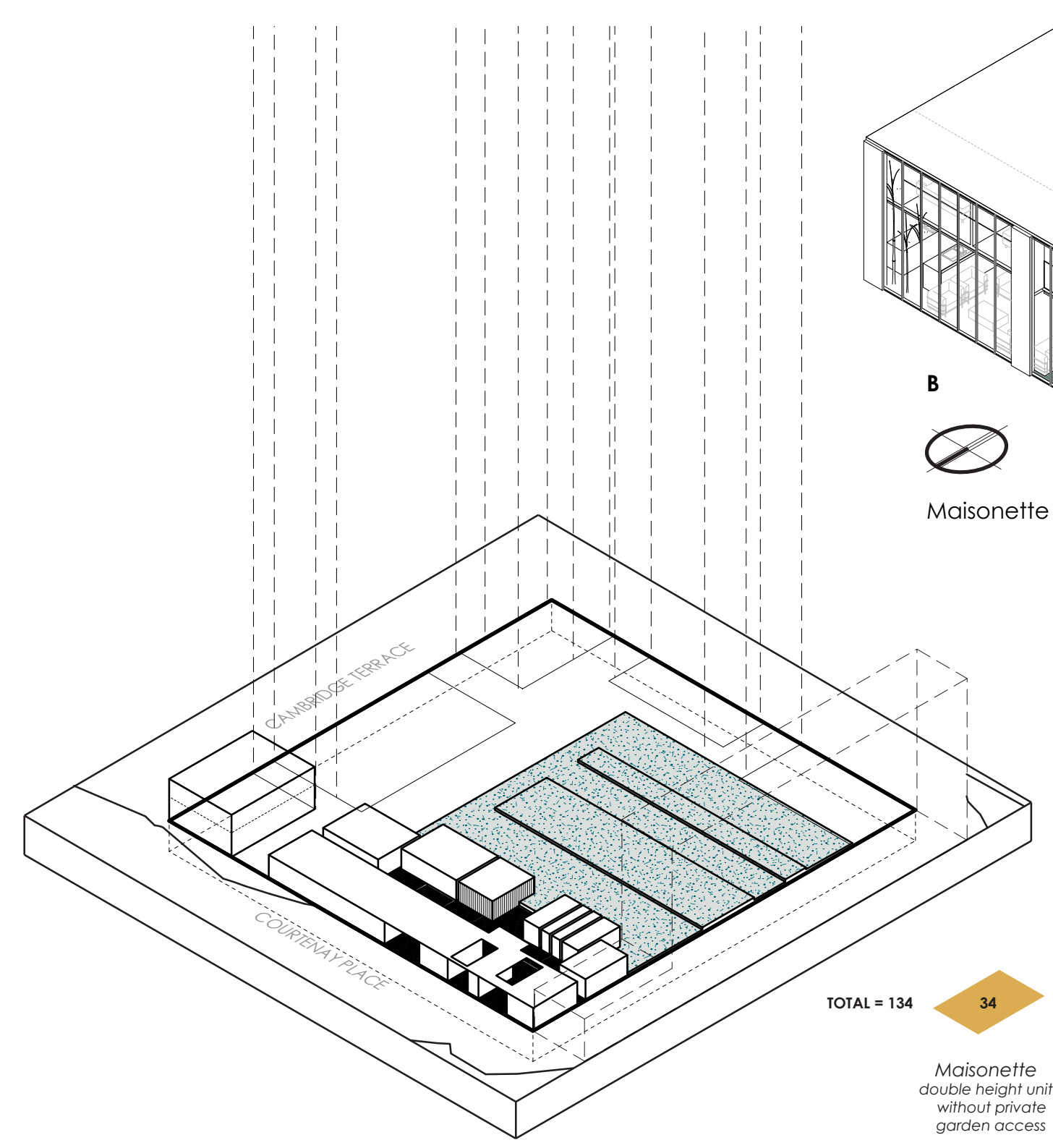

$\bullet \bullet \bullet \bullet \cdot \frac{172}{\bullet 173}$ 


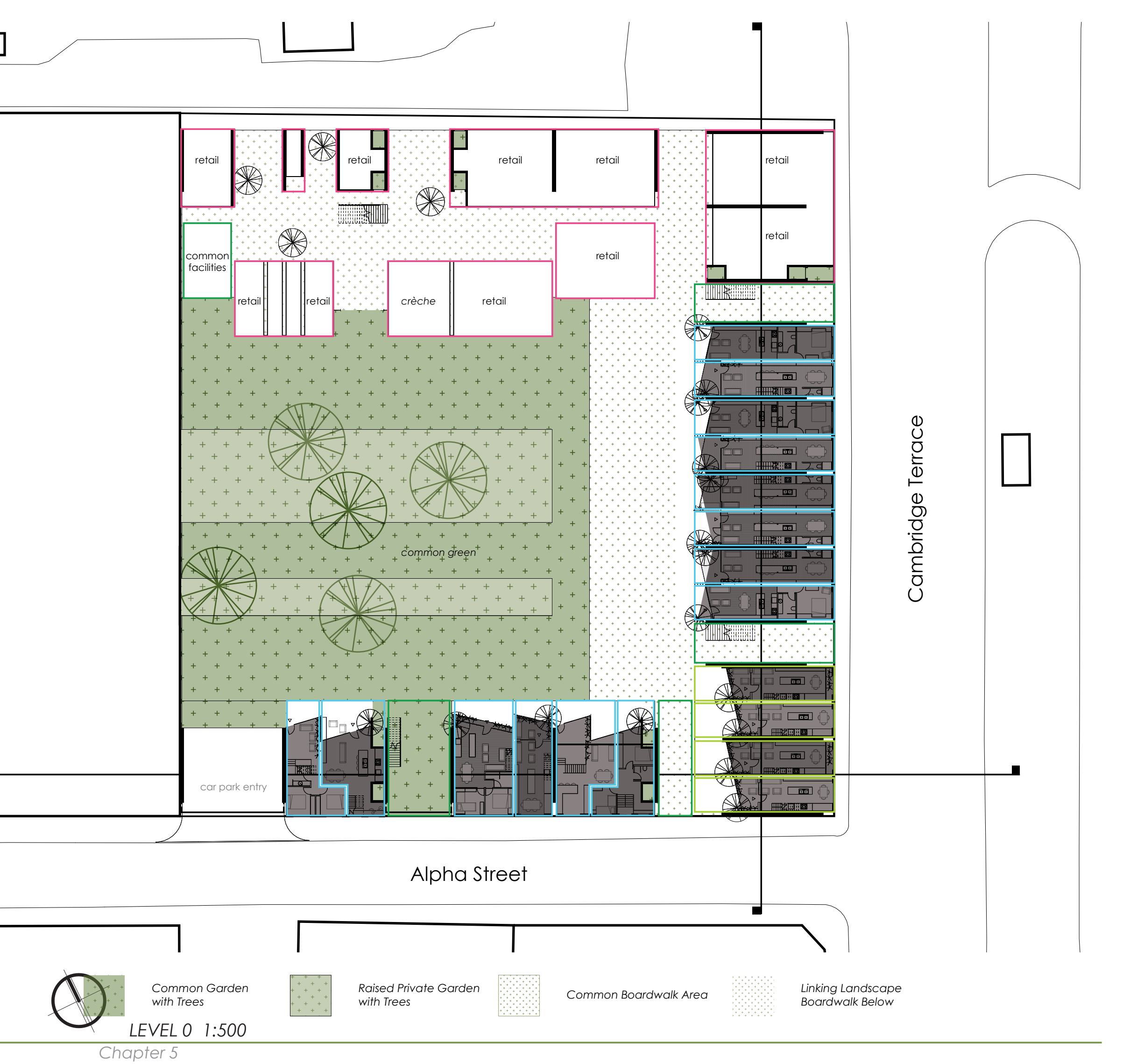

Figure 5.4.04

maisonette detail

Figure 5.4.05 plan illustrating primary public and residential access points as well as locations 1:500

Figure 5.4.06 Typical eastwest and northsouth section denit typology arrangement

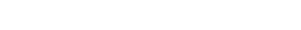

Figure 5.4.07 East-west and through deep soil planters

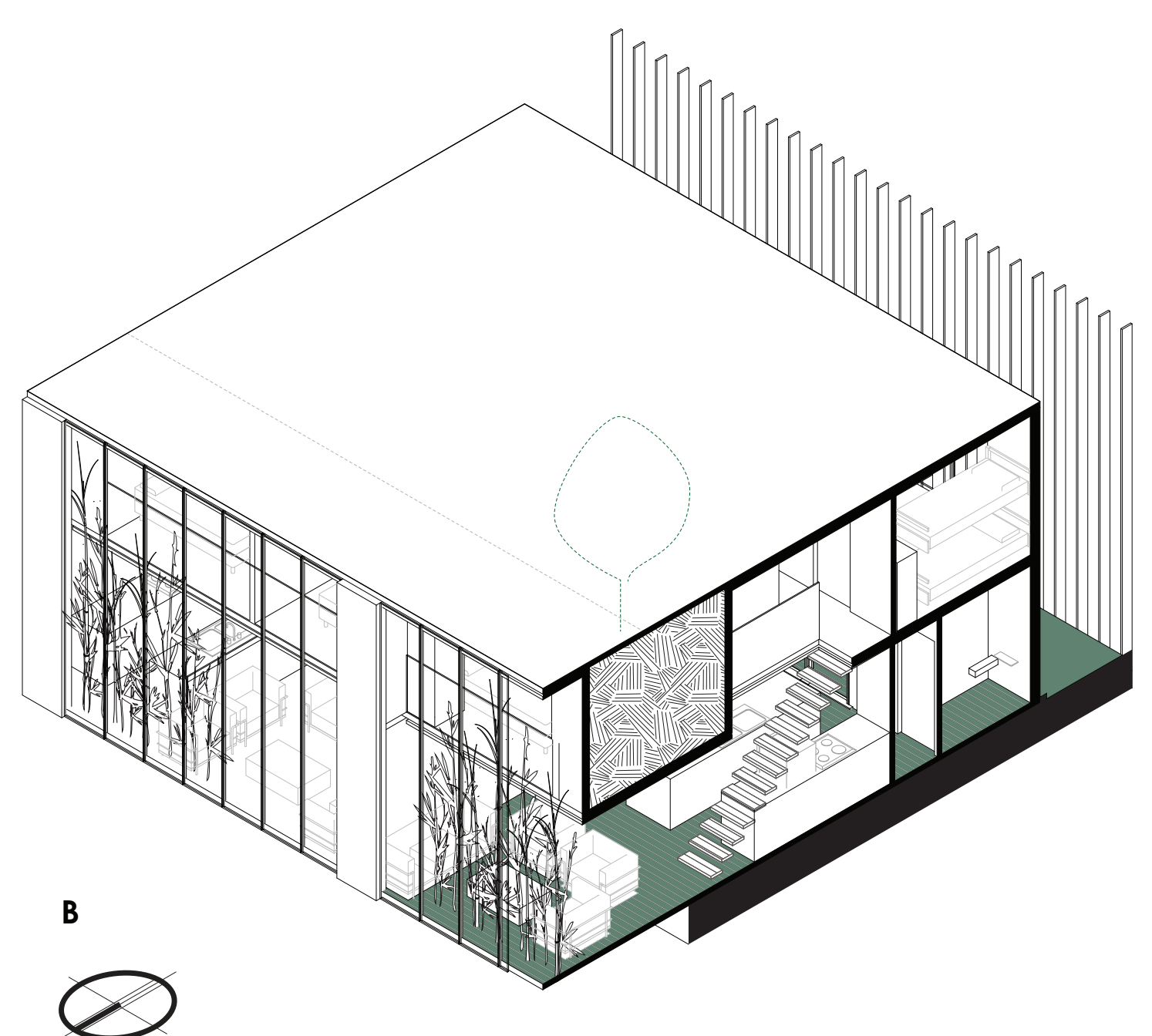

\section{Maisonette Type}

Sectional Axonometric

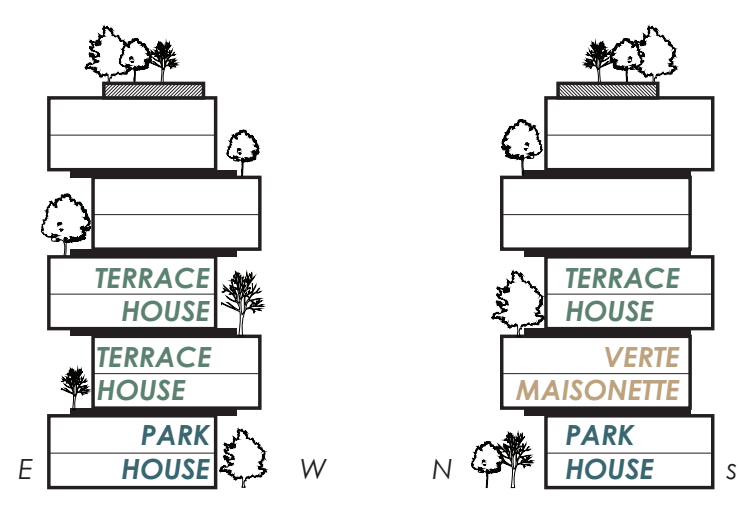

Due to the offset section of the east/ west orientated units, a deep soil planter is imbedded in their upper storey to service as the garden for the unit above. In blocks with north-south orientated units, deep soil planters are only required in the maisonette type apartments offset toward the northern edge to service the alternate level terrace houses (Figure 5.4.07). These planters give the units an unusual void relationship to the landscape.

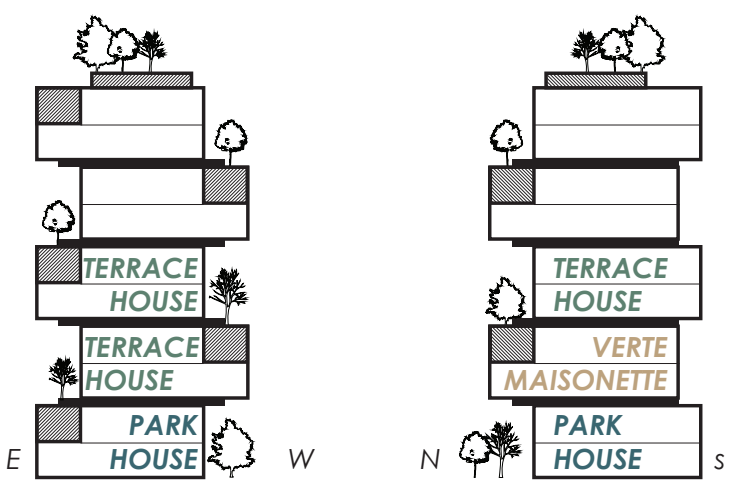



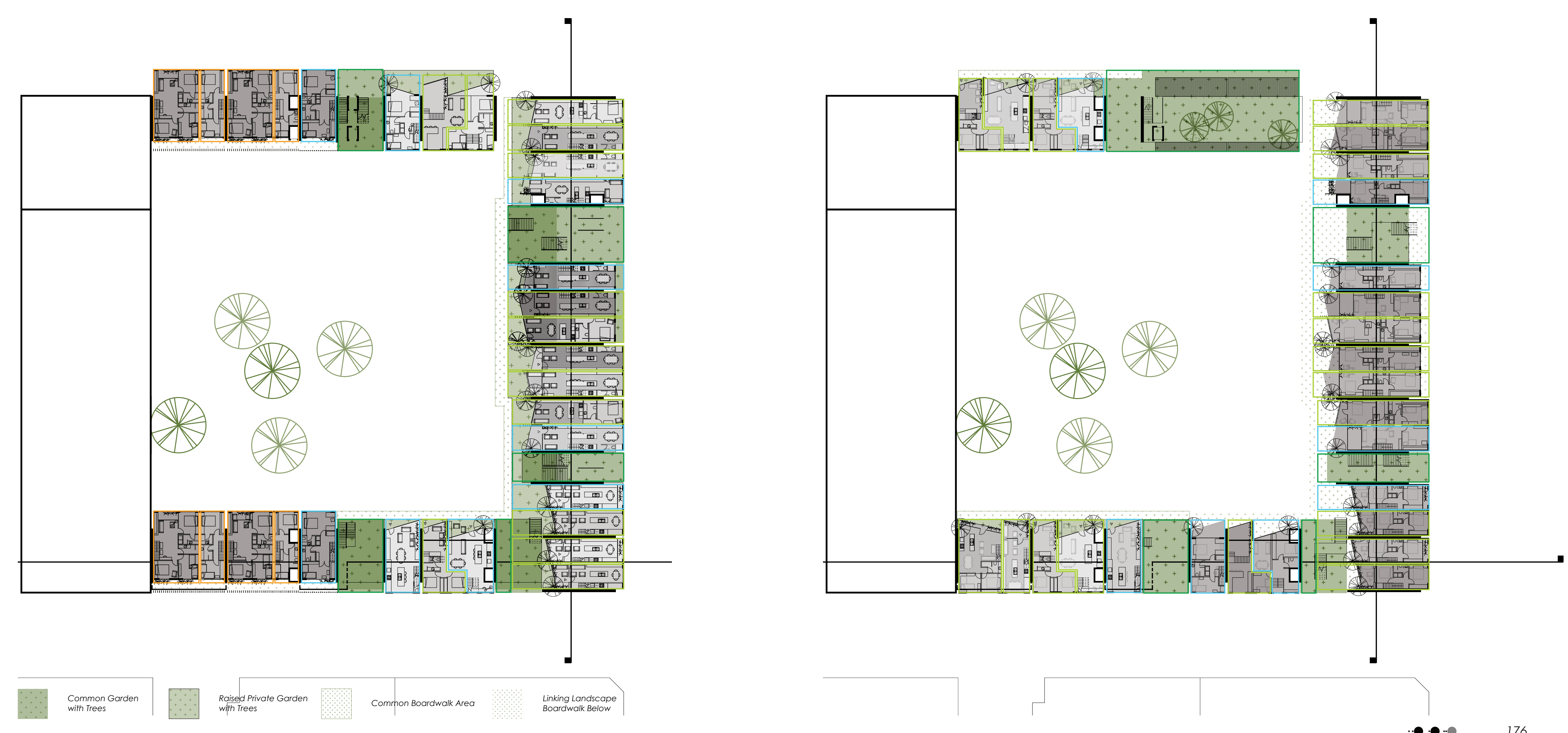
Because each of these bays can be divided into a different number of units the dwellings per hectare of this design is calculated under the assumption that there will be an average of two dwellings per structural bay, giving a total of 259 DW/HA. However, this could easily be

lower or higher, ranging from a minimum of 130 DW/HA to a maximum of 388 DW/

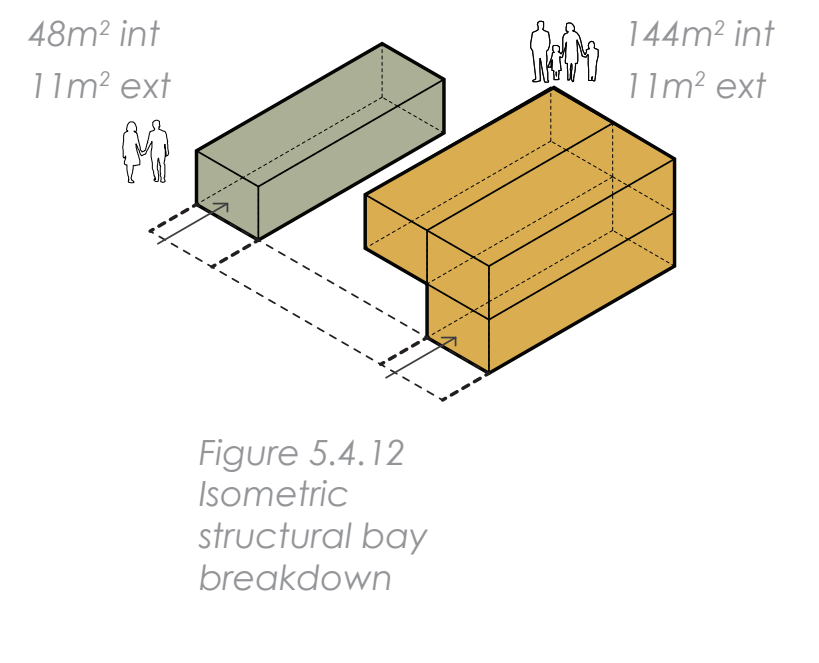

Figure 5.4.10 Level A (

Example of East

West orientated

terrace house.

One unit a studio
for a couple with

a winter garden.

One unit for a

family with a deck

type garden area

and an upper level

with double height

planting between

levels
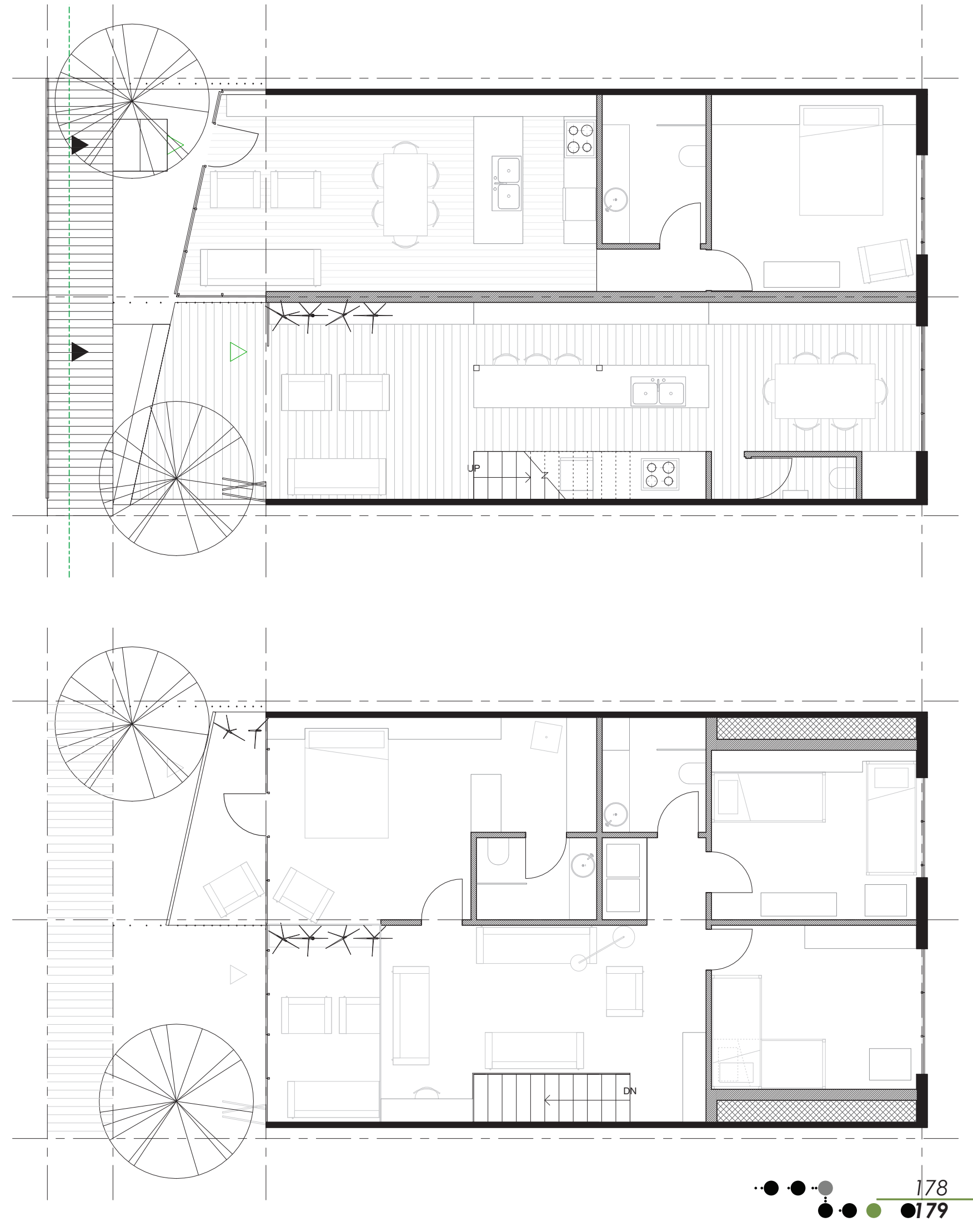

$D^{1: 100}$ 


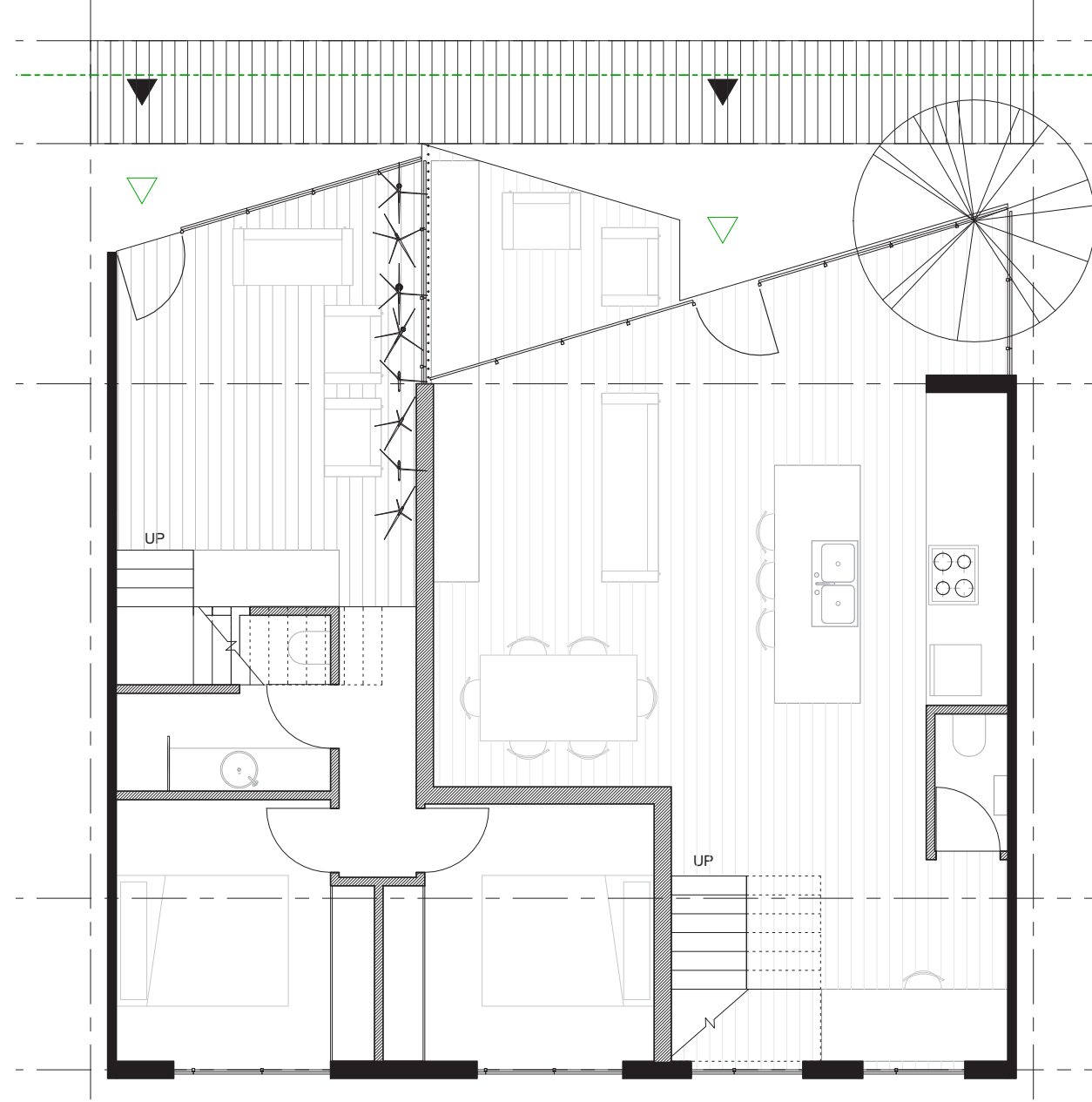

NORTH SOUTH ASPECT ORIENTATION

Terrace House Types

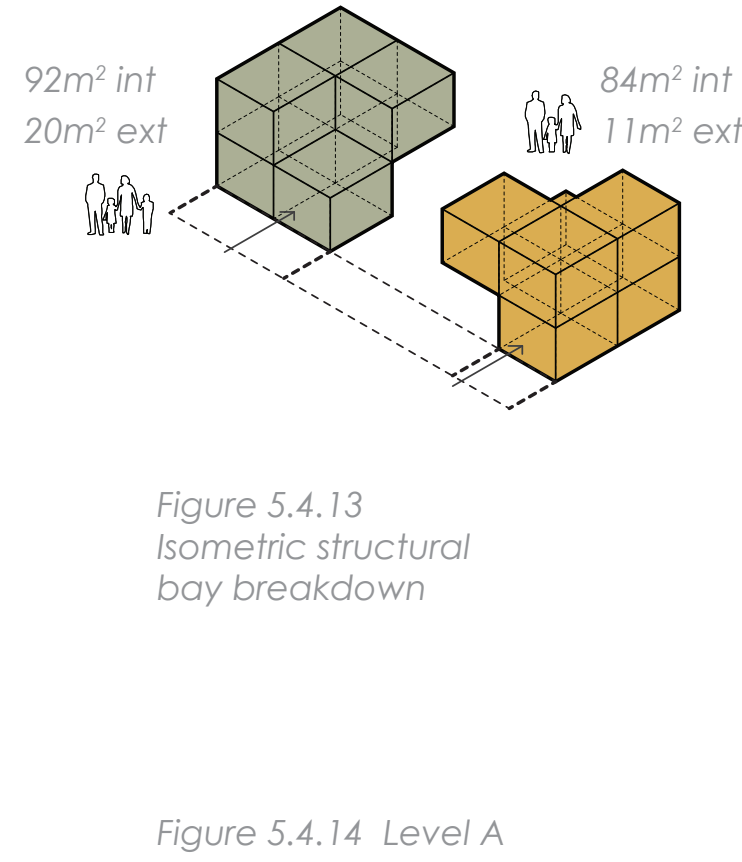

$\longleftarrow$

Example of North

south orientated

One unit suitable

One unit suitable

for a larger family.

Both incorporating

garden within theil

igure 5.4.15 Level B
Figure 5.4.18 Level B

Terrace House Types

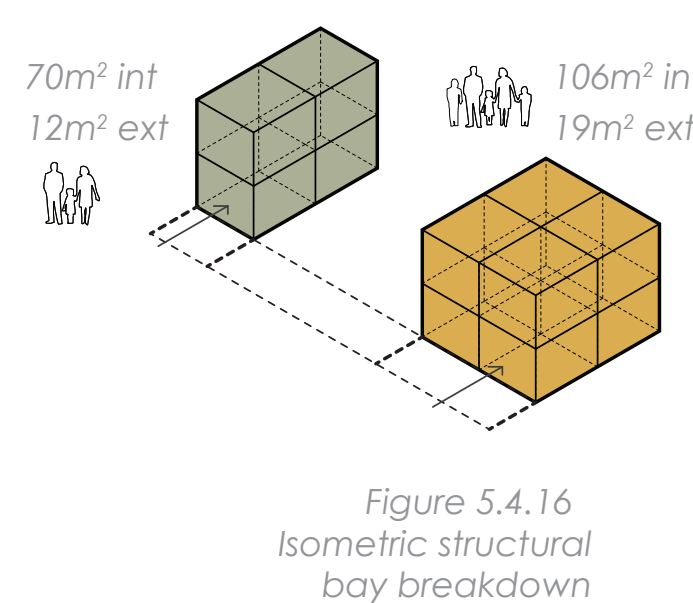

Figure 5.4.17 Level A

Example of North

large and sma

One unit suitable

for a young family.

One unit suitable

generational family

with lower leve

for elderly Both

incorporating

$\longrightarrow$
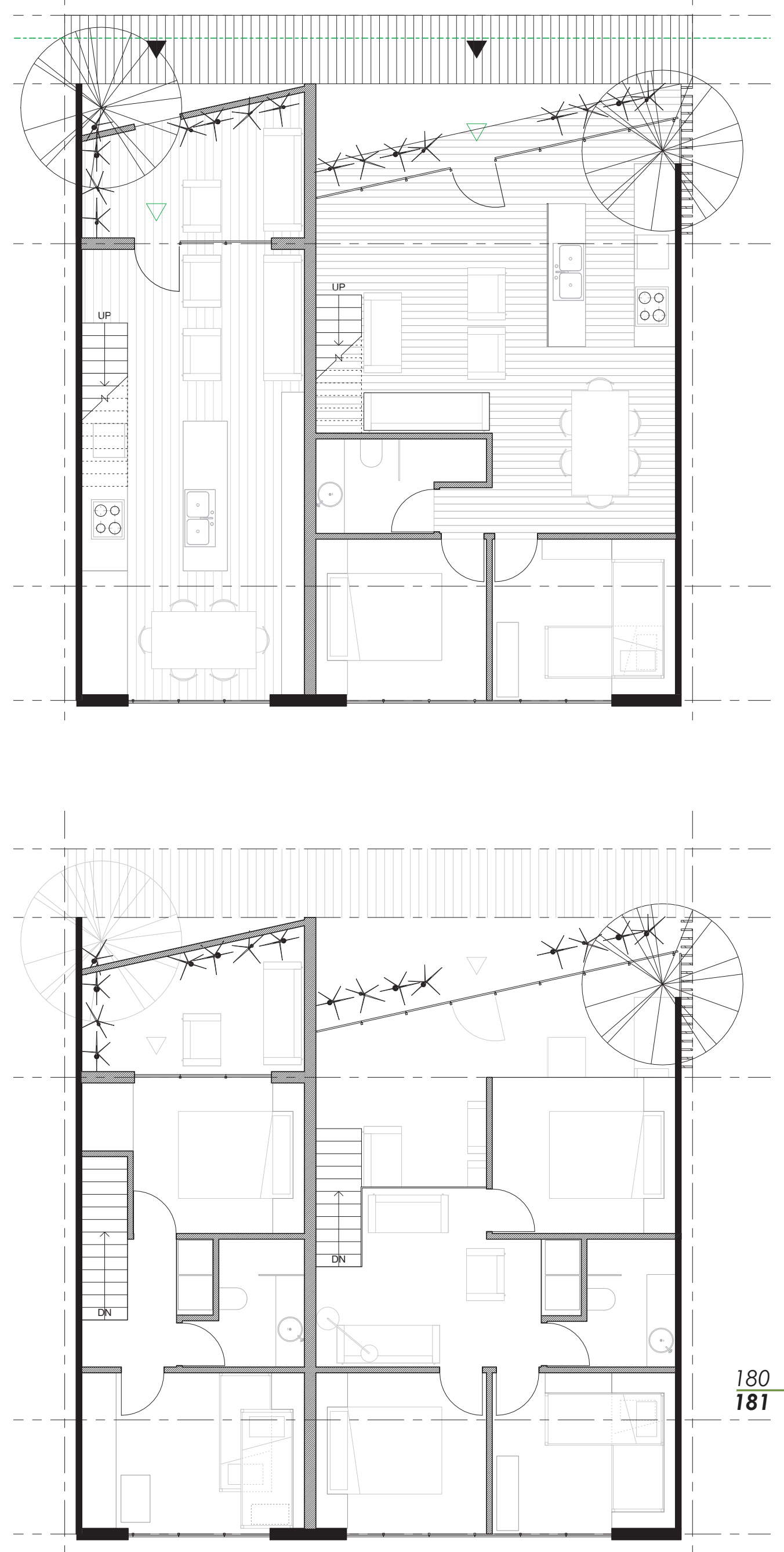


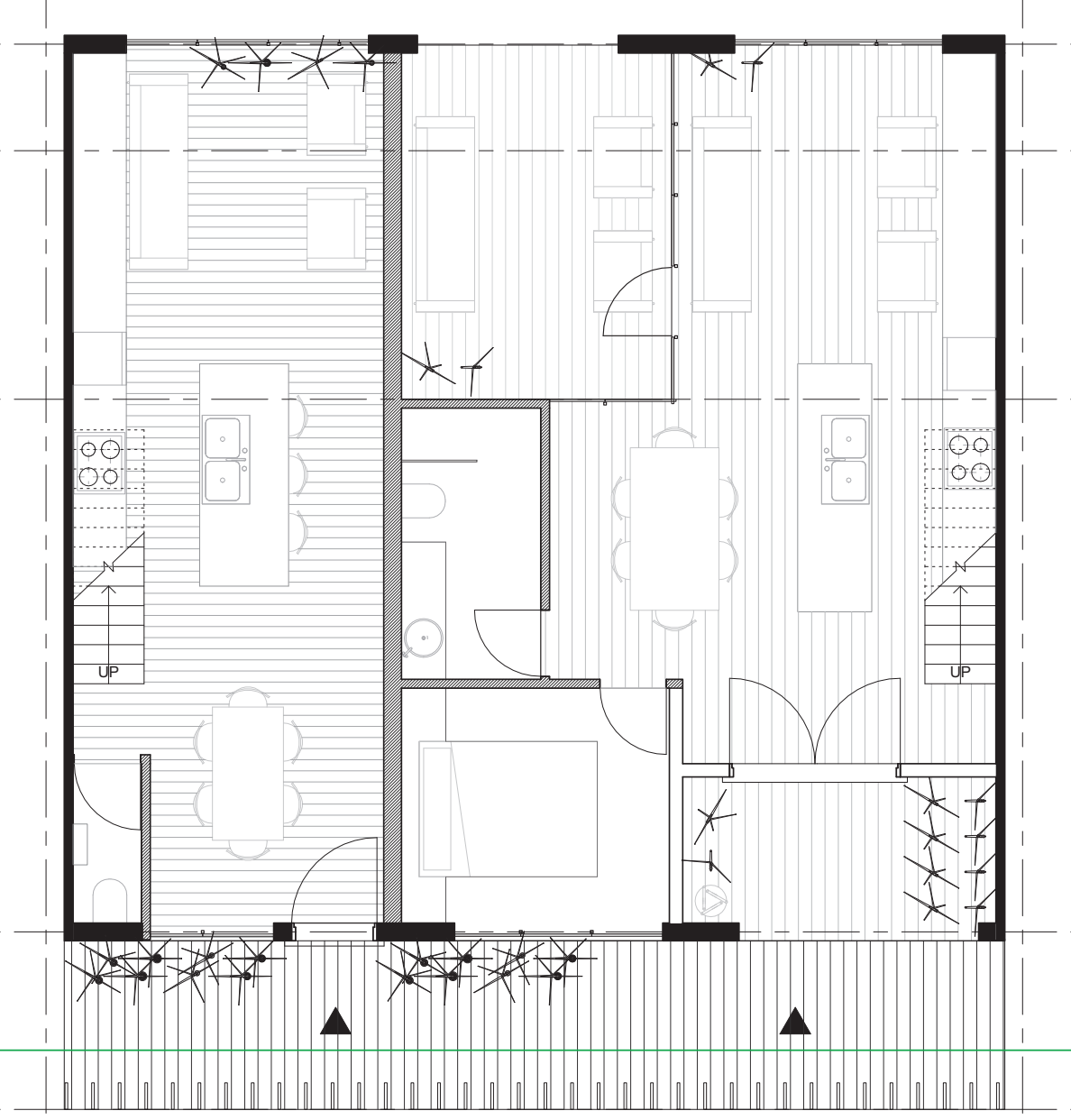

Figure 5.4.20 Level A

Example of North

South orientated

maisonette,

the south with

garden elements

on the north and
south aspects. One

sout suspects. On

a nuclear family.

for a larger multi-

generational family

with lower level

for elderly and 0

northern facade

loggia for outdoor

Figure 5.4.21 Level B

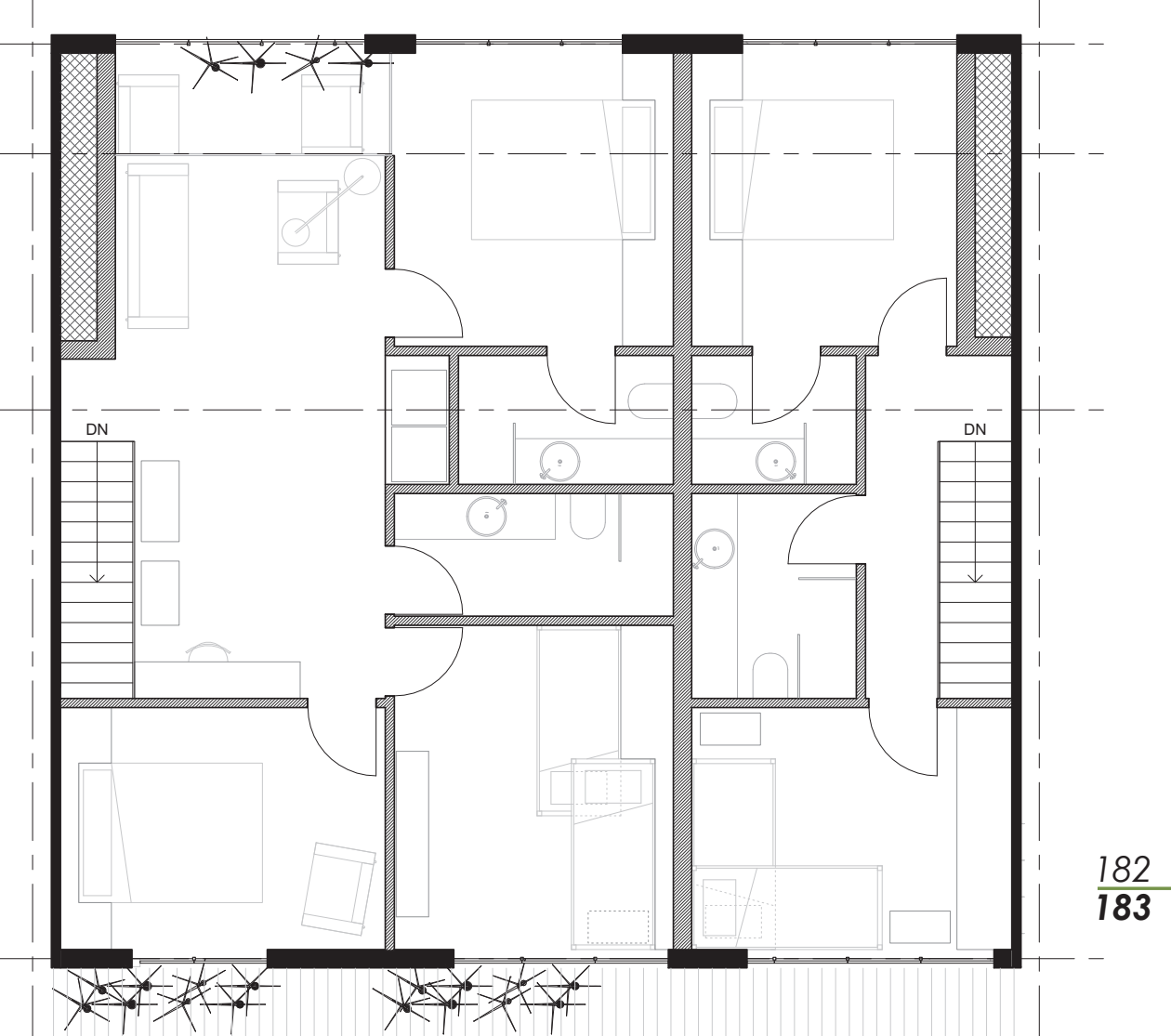

D 1:100

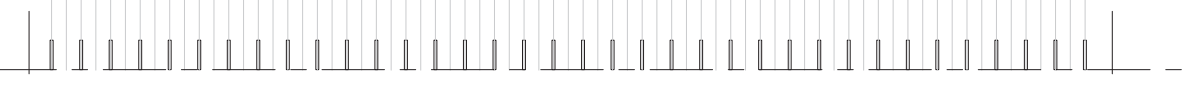




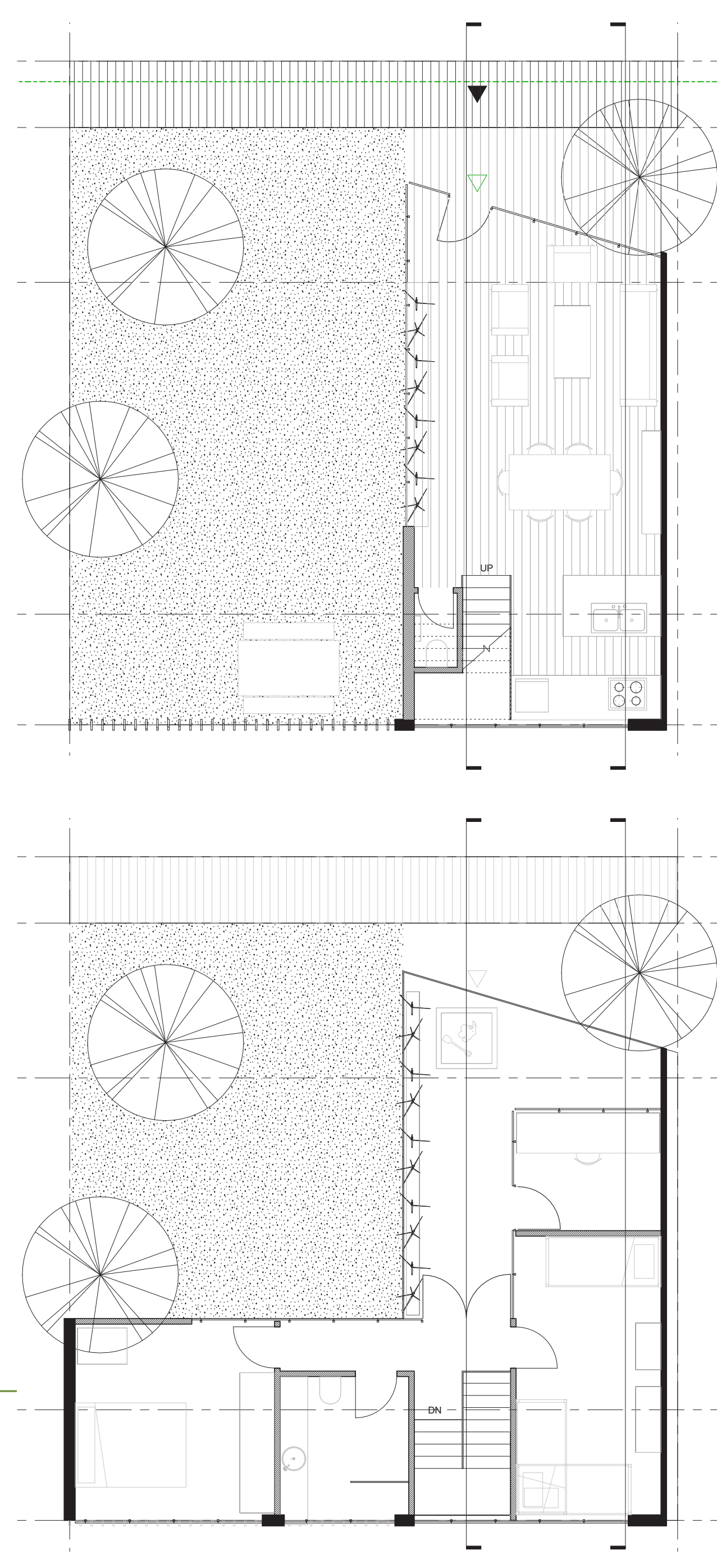

NORTH SOUTH ASPECT ORIENTATION

Park House Type

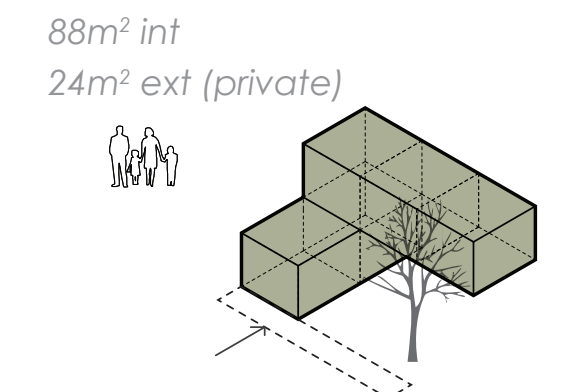

Figure 5.4.22 Isometric structura
bay breakdown

Example of a park house where one unit and one space is provided. space is provided.
This park house provides a pocke yard on level 8 linking in to an adjacent vertical circulation garden provides additiona yard is directly
accessible from the unit's private garden. This particular unit suits

Figure 5.4.23 Level A $\longleftarrow$

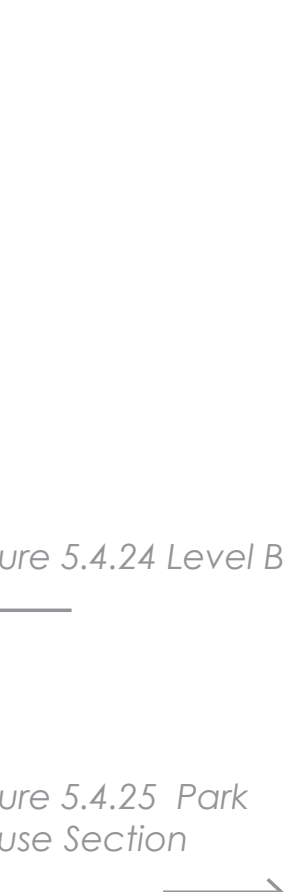

Figure 5.4 .25 Park
House Section $\longrightarrow$

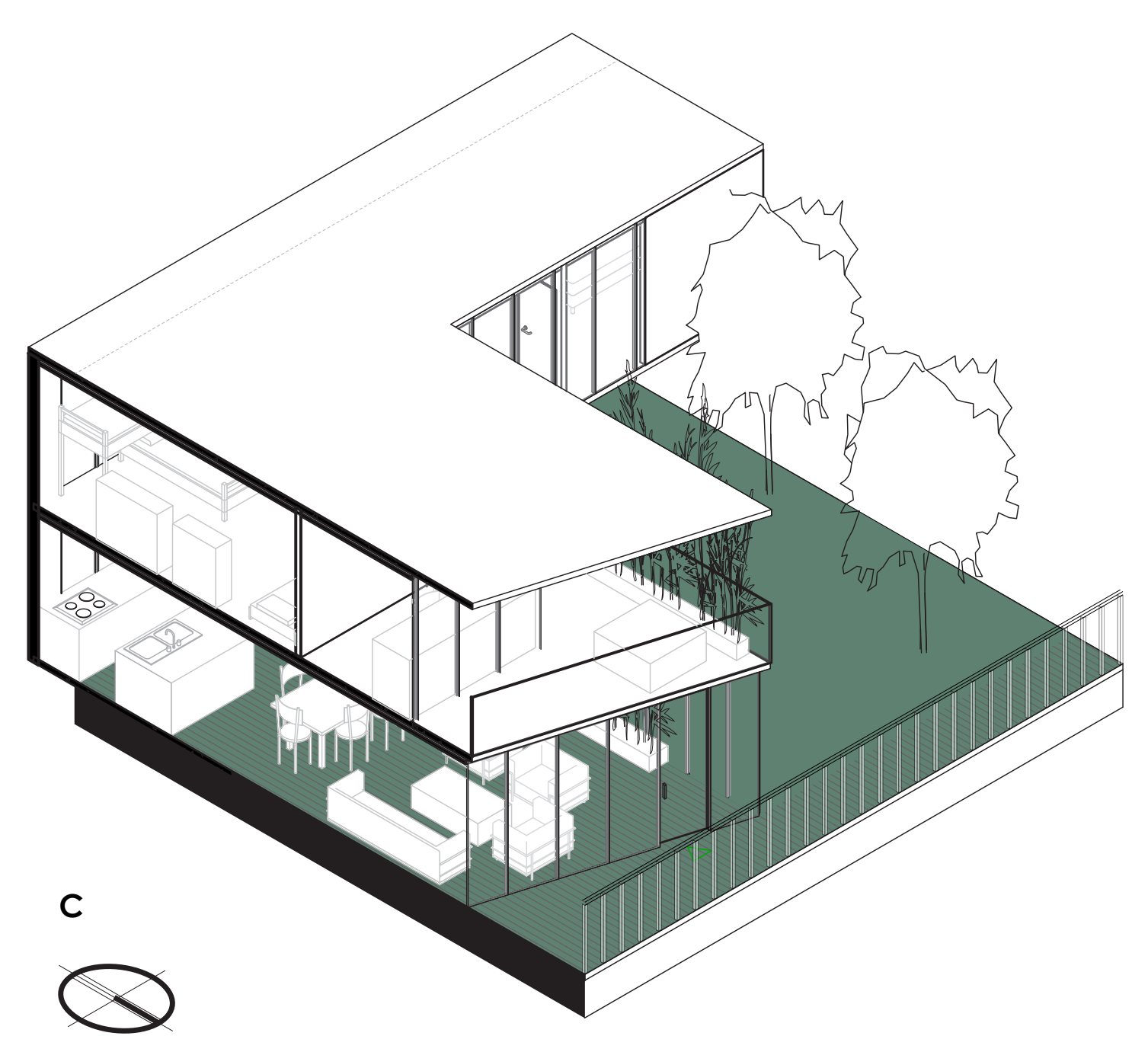

Park House Type

Sectional Axonometric

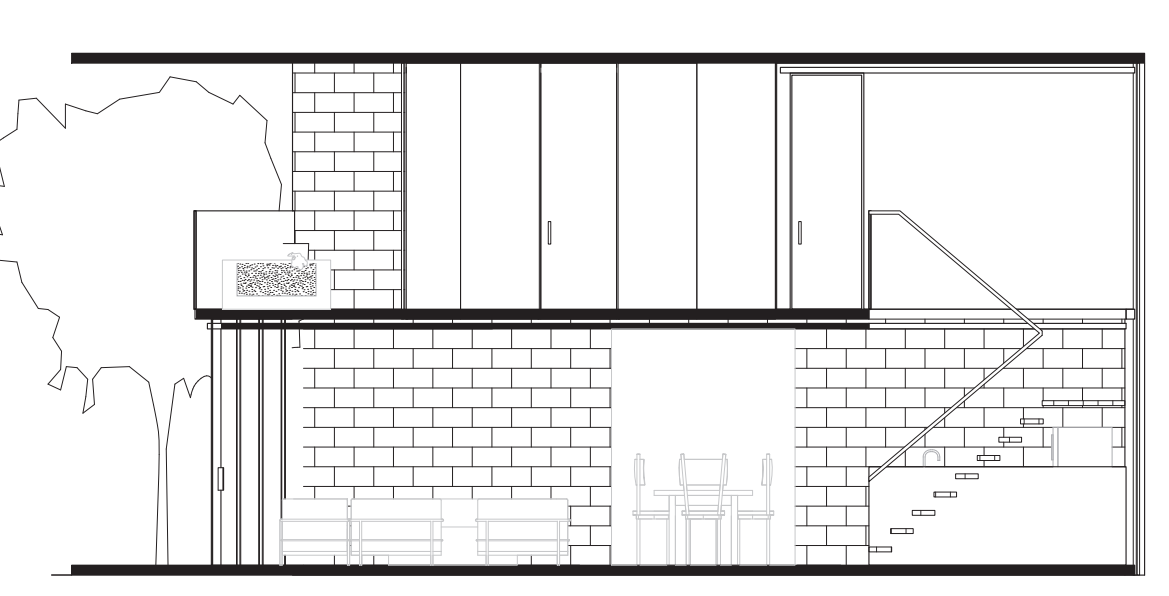

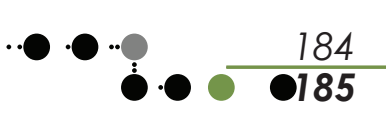


5.5 Vision For Living

Images of landscapes, urban moments, suburban ideals and New Zealand families collected over the thesis period are used to drive the development of design in perspective. The collaging of these images occurs at different scales

conceptually to integrate landscape from the city into individual units; weaving their way between them to bring a cohesive and iconic look to the development

These drawings also explain the livability of the scheme, illustrating the atmosphere and liveliness of the design. The sectional perspective through a sample of the north-south orientated block, featuring a terrace house atop a maisonette, shows a variety of landscape types in their 


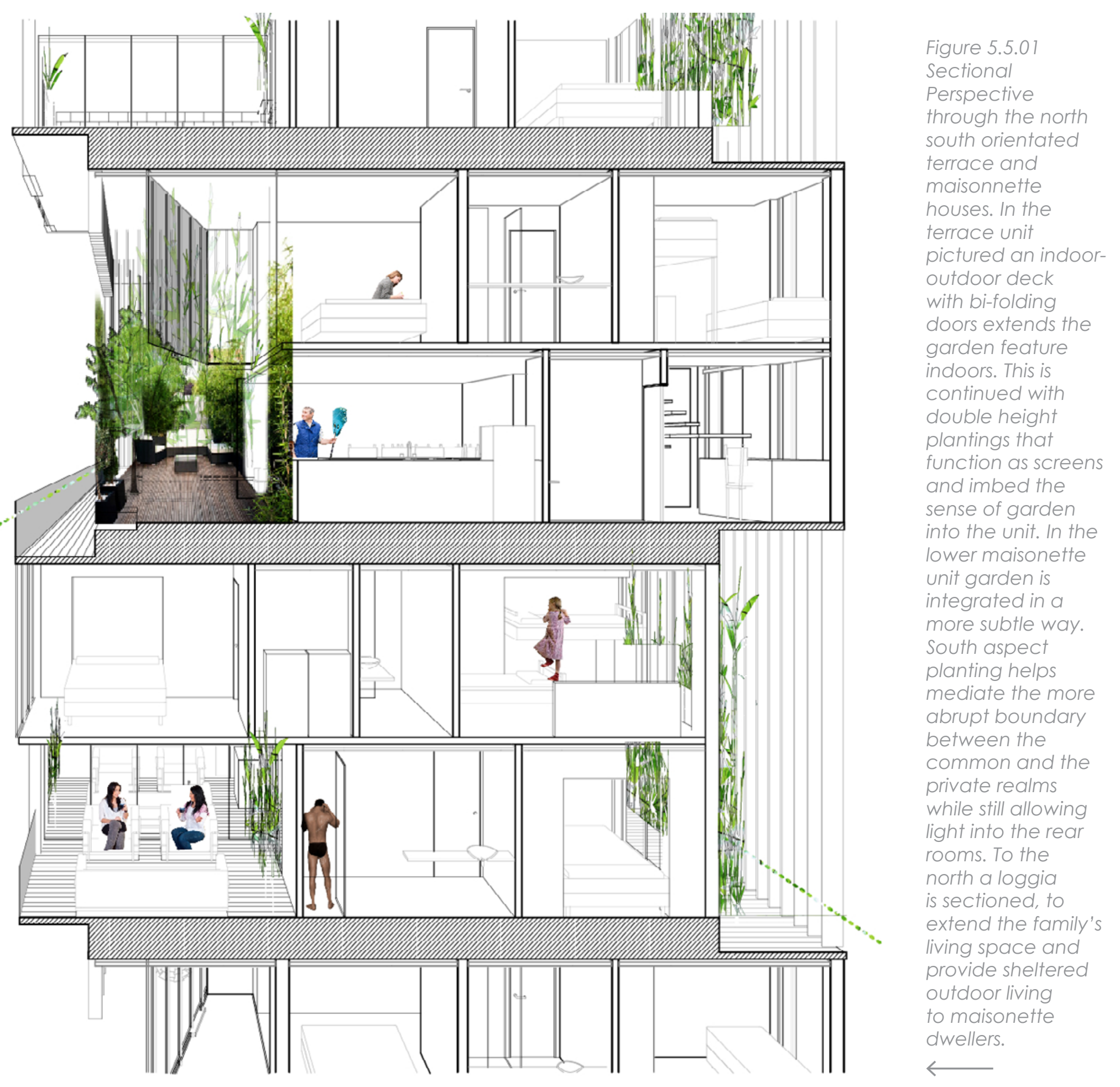

Chapter 5

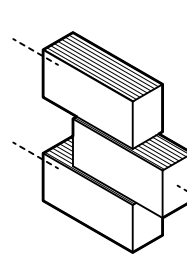

Figure 5.5.02

S

Figure 5.5.03

Constrained

free in the third

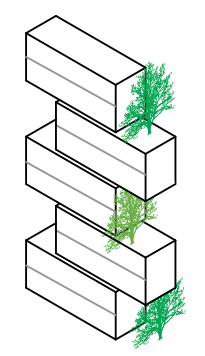

Figure 5.5.04

Double height

units for

and green
interventions reality (Figure 5.5.01). The flow between these landscape typologies bleeds into the unit typologies, with garden features present within all units to varying degrees.

These units are designed to be liveable; an easy and seductive journey for suburbanites from their original 'quarter acre' ideal to the garden units of the city. 


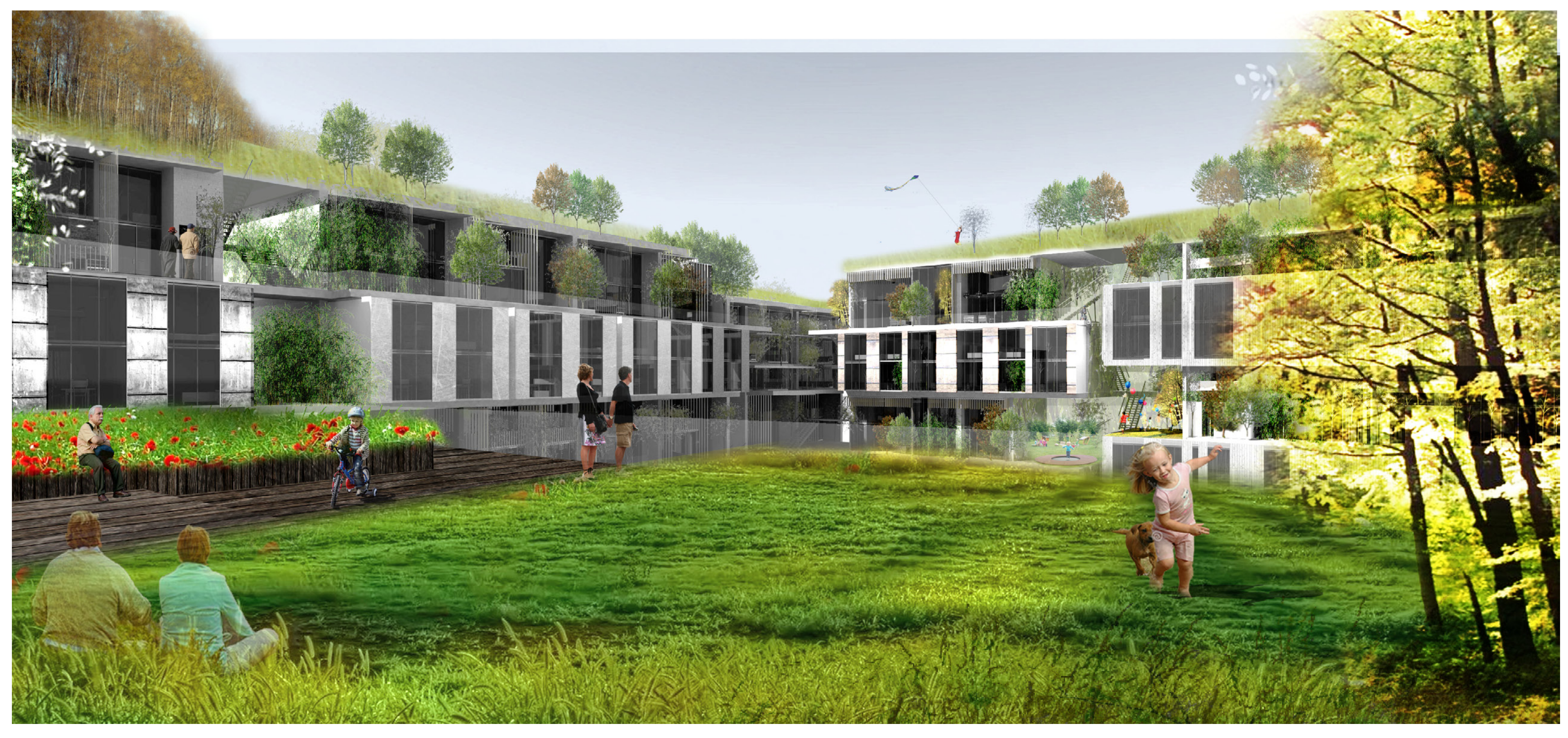



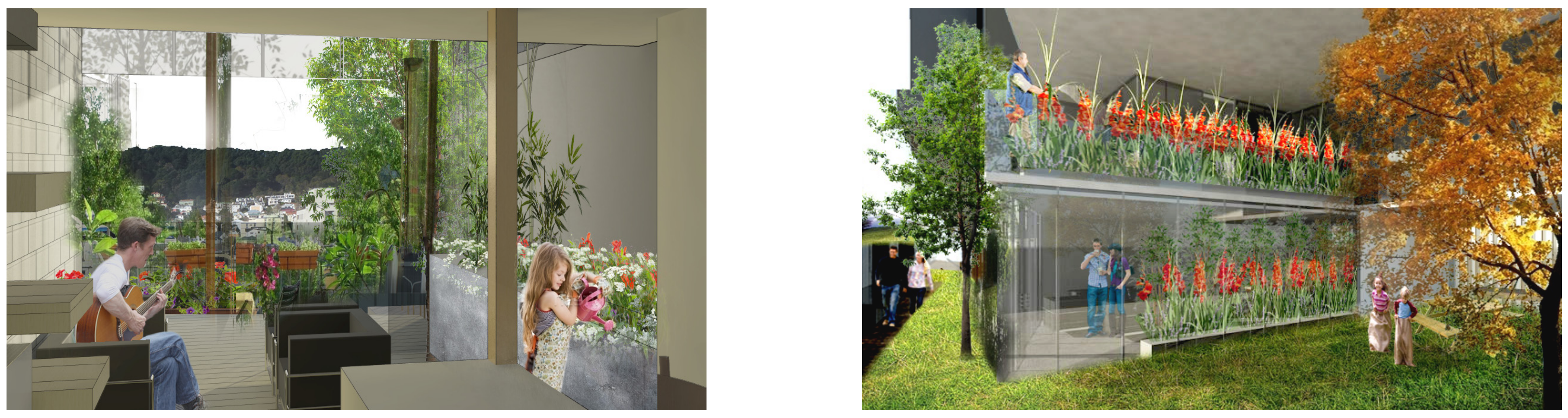


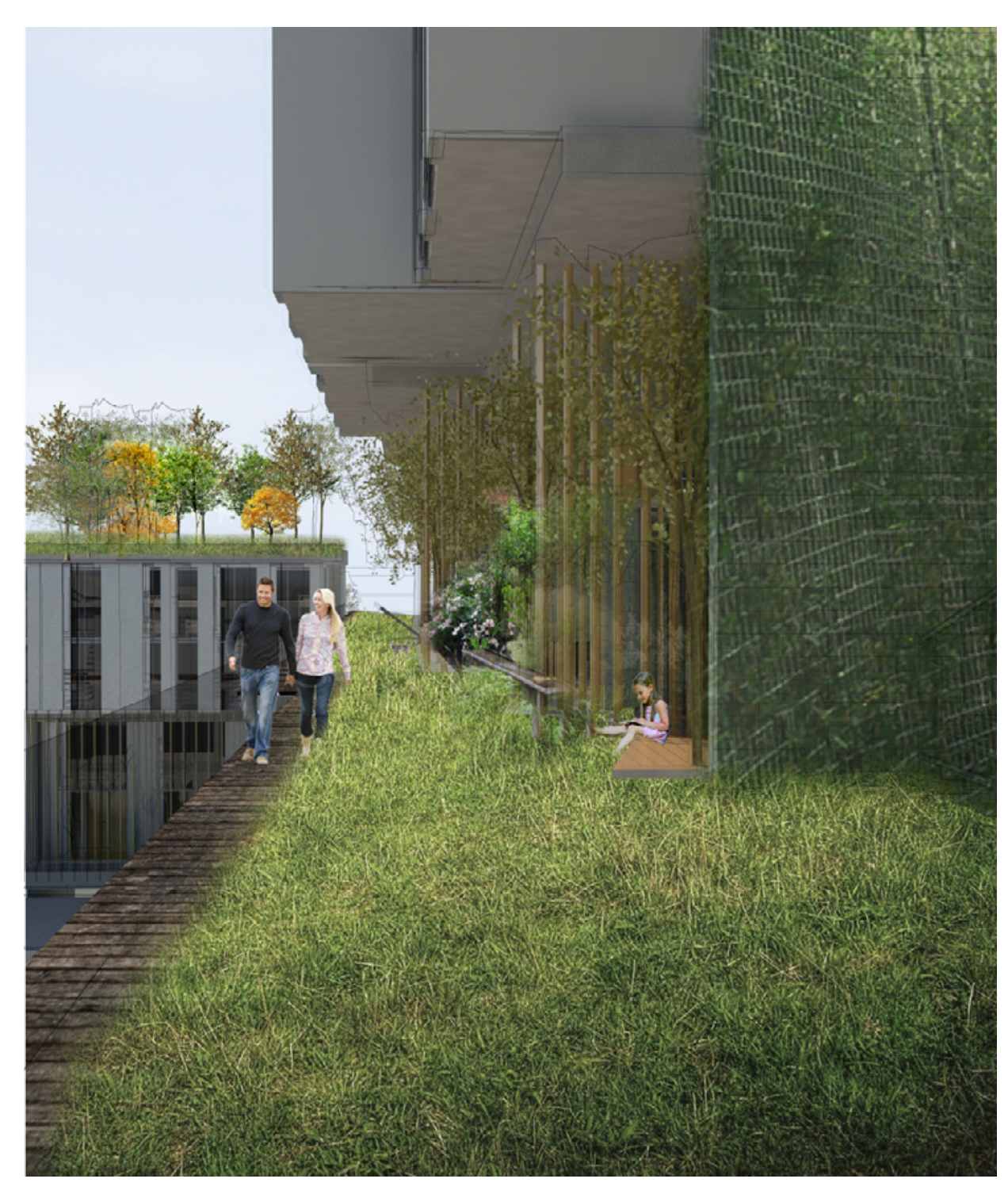

Figure 5.5.08 View From Vertical Circulation Void

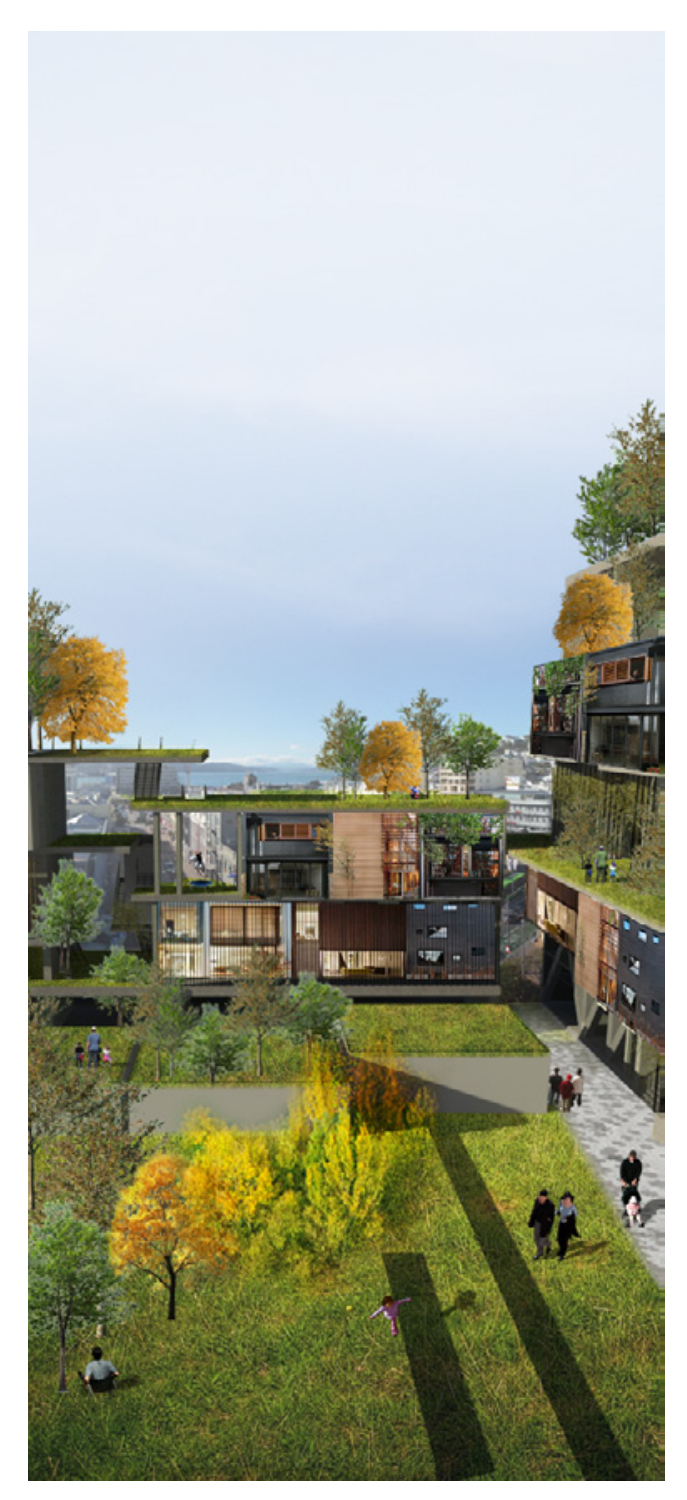

Figure 5.5.09 View From Verte Maisonnette

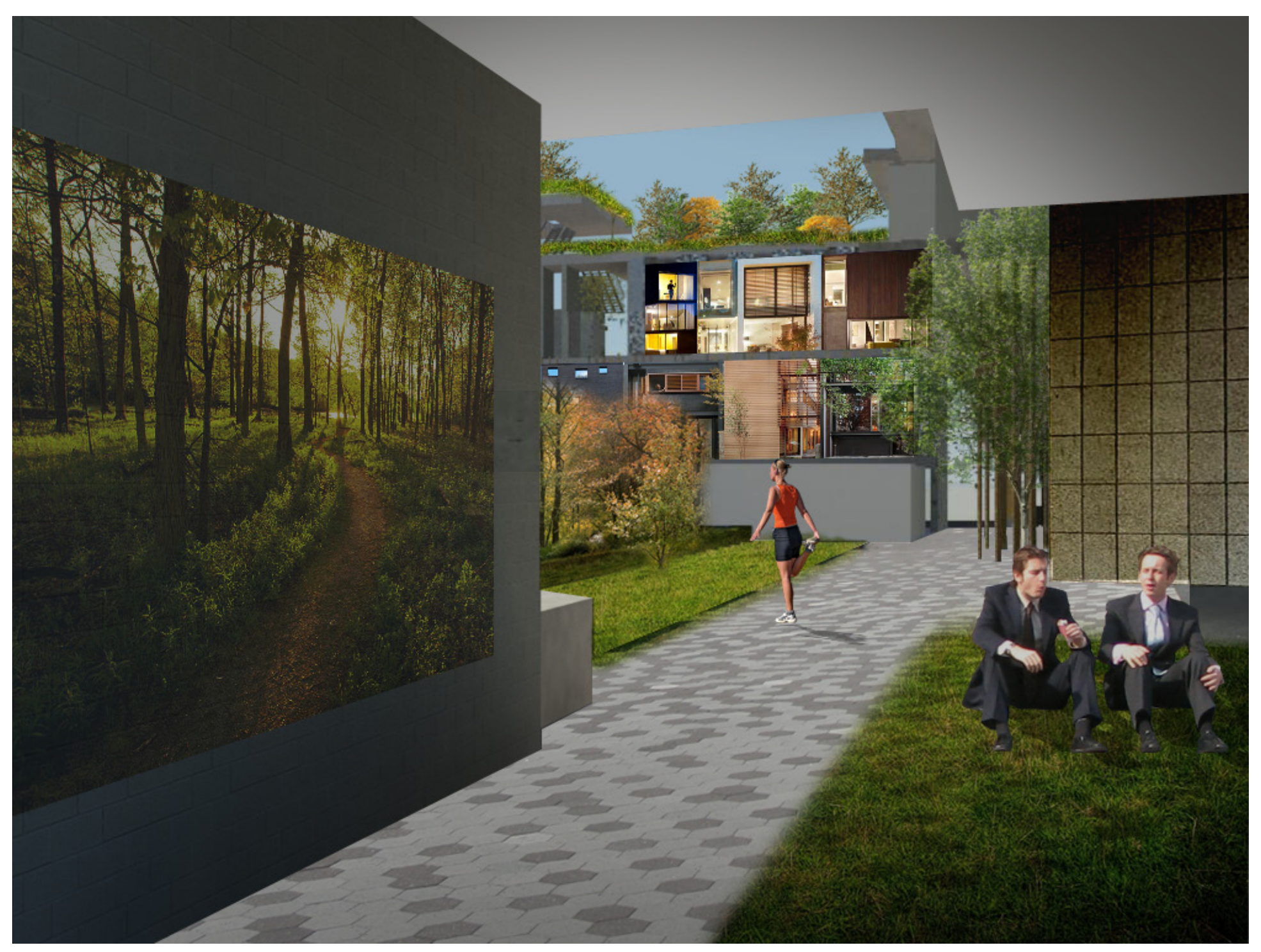

Figure 5.5.10 View of Green from Southern Public Entry 


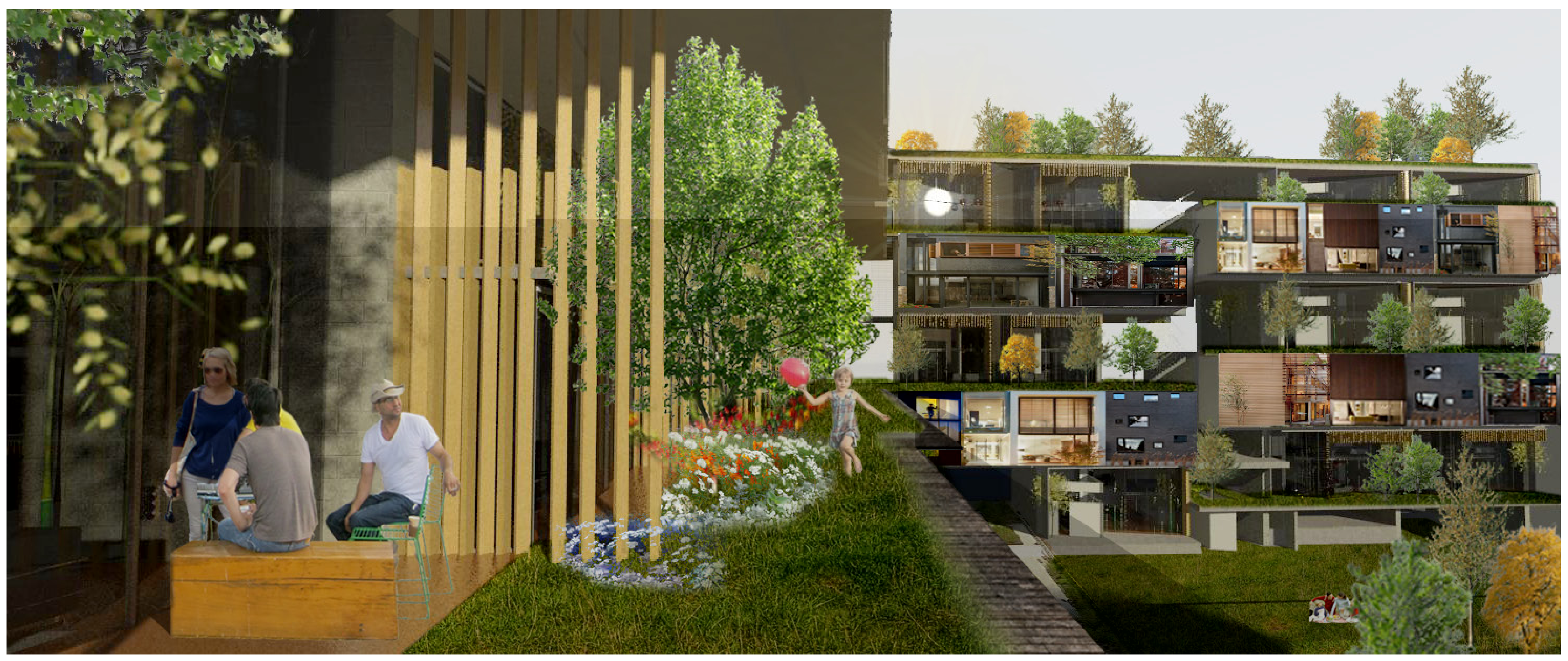




\section{Pard4}

RESEARCH POSITION 
The concept of a common green network is applied to this particular site as a perimeter block type. On other sites other scheme typologies with alternative massing strategies may be more suited. similarly, on alternate sites a lower density might be targeted giving more lexibility in form whilst still maintainin sunlight, privacy and garden amenity as key drivers.

Refocusing to prioritise design around the six additional identified attributes has the potential to increase the uniqueness and 'good-weirdness' of the scheme. Having illustrated it is possible to solve when focussing on the CHRANZ atributes, focusing on the additiona attributes could also further the scheme's generosity. Integrating more facilities such as a tennis court, skate park or BBQ area will likewise increase desirability.

In optimising for the number of terrace houses design test five restricts true diversity. Re-balancing the proportions of each unit typology (particularly park houses) could develop a more varied community. With diversity of dwelling including some smaller and more affordable dwellings, the scheme will move towards greater social diversity.

This design is deliberately propositional with lessons and approaches applicable to multiple sites. Necessarily, the design tests are not overly site specific; however, improved site specificity would increase the concept's appeal. In a further phase this might involve responding to the 

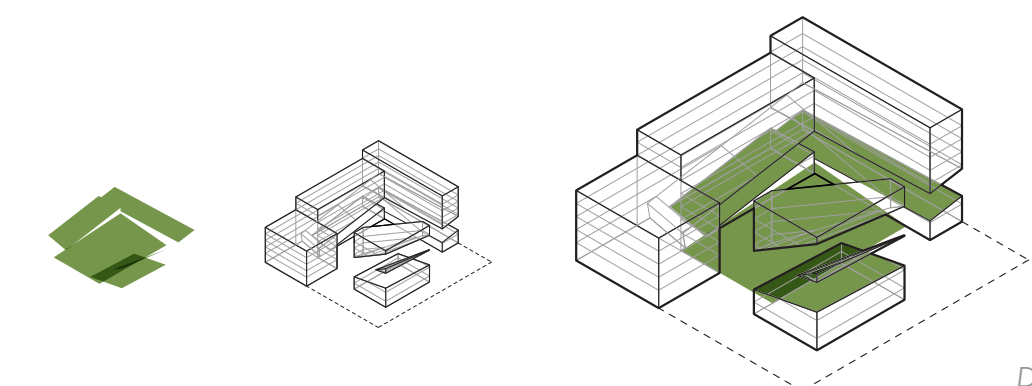

Design Test One
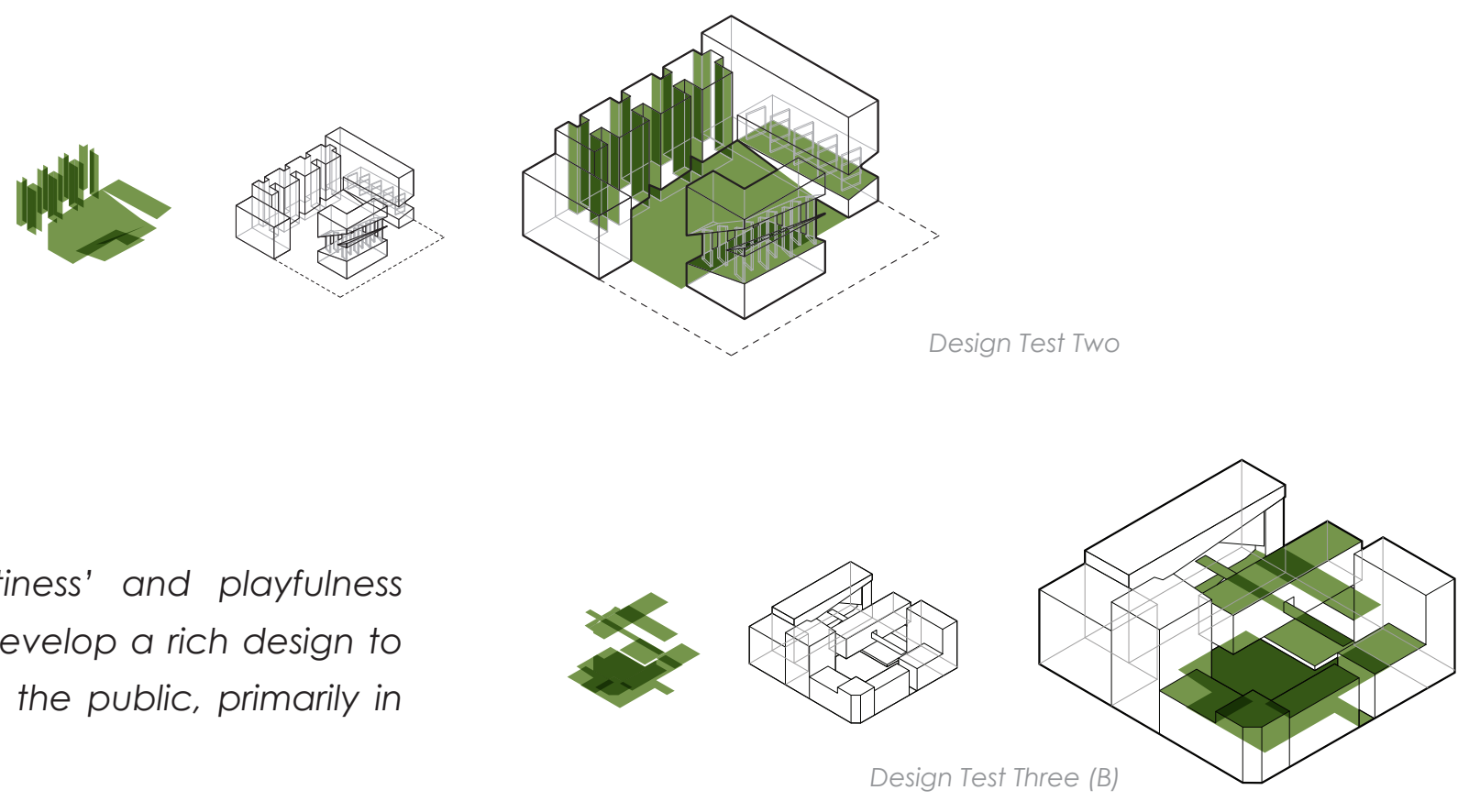

of the area to develop a rich design to

be presented to the public, primarily in perspective.

Further research is required into the cost premium associated with garden integration atan elevated level. Providing structure for such heavy infrastructure is expensive, however, initial research finds that in London having a private roof/attached garden can add 10$15 \%$ to the asking price (Bailey, 2012). Establishing the market's receptiveness to this concept in New Zealand, and the construction cost premium, would aid in assessing the feasibility of this design proposition.

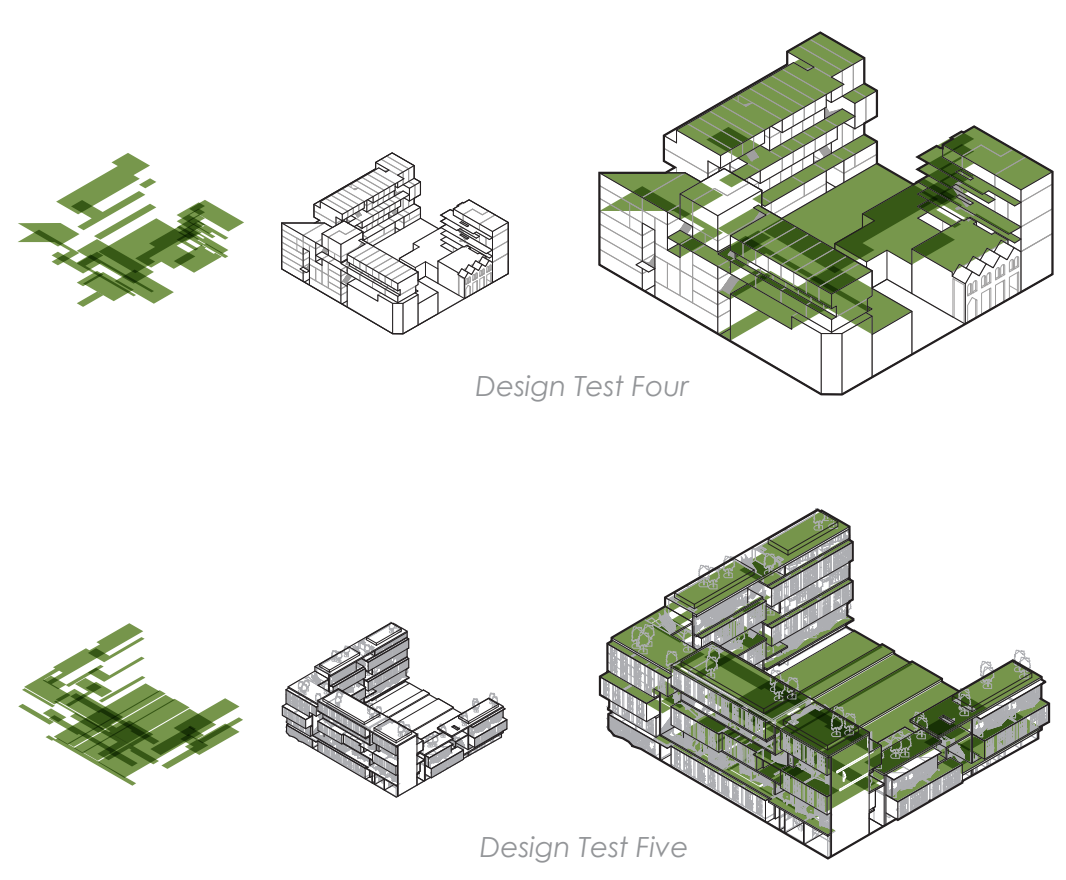

A further expected cost premium lies in the complex servicing of a flexible design. It is not clear how much added value 'flexibility' has. Typically a custom architecturally designed houses have higher property values than others. Thus sing a project architect as required by 'flexibility', as well allowing redesign for evolving family situations (under the innovative ownership model), will increase property values to offset this cost premium.

2013' which aims to enhance housing affordability by facilitating an increase in land and housing supply in places with significant supply or affordability issues. Both new laws endorse and fast-track housing projects increasing the feasibility of such a scheme. However, being so new, their potential impact is as yet unknown.

Using gardens as an integral component of vertical housing has the ability to change what New Zealanders, politicians, and developers consider

inally, recent housing policy reforms in New Zealand also have the potentia to impact on this project. The 'Housing Restructuring and Tenancy Matters Amendment Act 2013' allows any public or private organisation to provide social housing and receive income related ren subsidies, which if applied appropriately could provide an even greater diversity of families. Land subsidies might also be available through the 'Housing Accords and Special Housing Areas Act possible and desirable. This research illustrates the potential architecture has to provide a solution to the ever resisted higher density city. 
7.0 Typological Ties

Typology has been used in architecture since the age of enlightenment (first defined by de Quincy in Encyclopedie

1789) where analysis of built fabric first formalised a number of dwelling and morphology types. Since then the word has undergone two evolutions; post WWI during the European mass state funded housing era the concept suffered a loss of significance, reduced to 'stereotype'.

However, a re-emergence of the significance of type and typology is seen post 1950s, reflected especially Aldo Rossi's writings, mainly The Architecture of the City (1982) (Güney, p. 1).
This project can be positioned in the architecture discipline in relation to a number of built works. Discipline knowledge can be ordered through typology. This chapter starts by mapping established typologies that design test five relates to, then draws attention to developing typologies where relationships exist, showing each type to be rich in architectural and/or social history. 


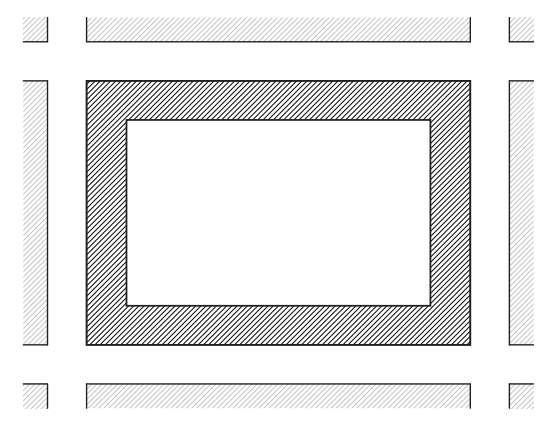

\section{Perimeter Block (established typology)}

In combination with the existing buildings of the block this scheme forms a perimeter block with internalised public space. a development of the typology that has become mo 1980s (Leup 1980s (Leupen, et al., p. 216). A typical significant issue of the perimeter block solving for reduced solar access and limited relationship with internal space at the corners (p. 216), was solved by breaking the block there simultaneously solving for this and public access to the central green.

This typology has much potential in Wellington because it can be included in the piecemeal development of the city. It may draw upon many European precedents for design solutions which can be successfully adapted to New Zealand conditions.

"[The perimeter block's] essential feature is a continuous line of buildings along every buildings therefore defines the streets and public spaces, while the open space inside the block is shielded from the activity of the city." (p. 216)
Figure 7.1.01

Perimeter block

ciagram

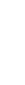

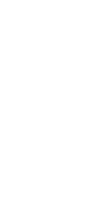

Figure 7.1.028

House, Bjarke

Ingels Group, 2009

$\longleftarrow$

Figure 7.1.03

Sanctum

Apartments,

Warren and
Mahoney, 2000

$\longleftarrow$

Figure 7.1.04 The

Whale, Frits van

-
Figure 7.2.01

Terrace house

diagram

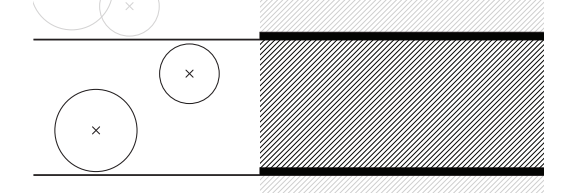

Figure 7.2.02

Atelier 5, 1960

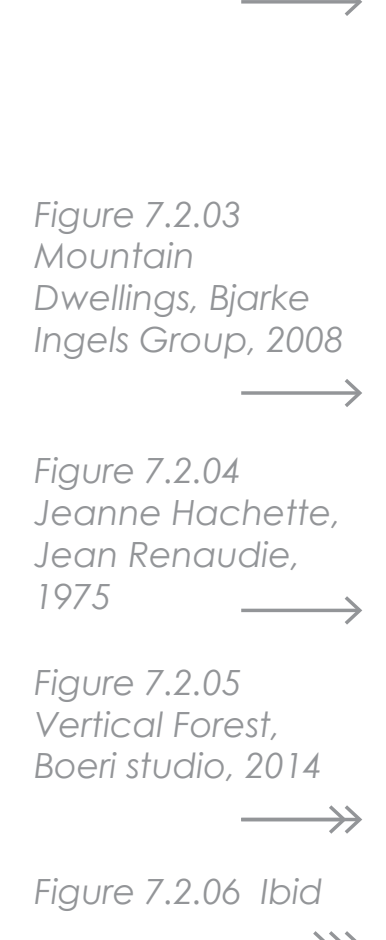

Figure 7.2.06 Ibid

$\ggg$
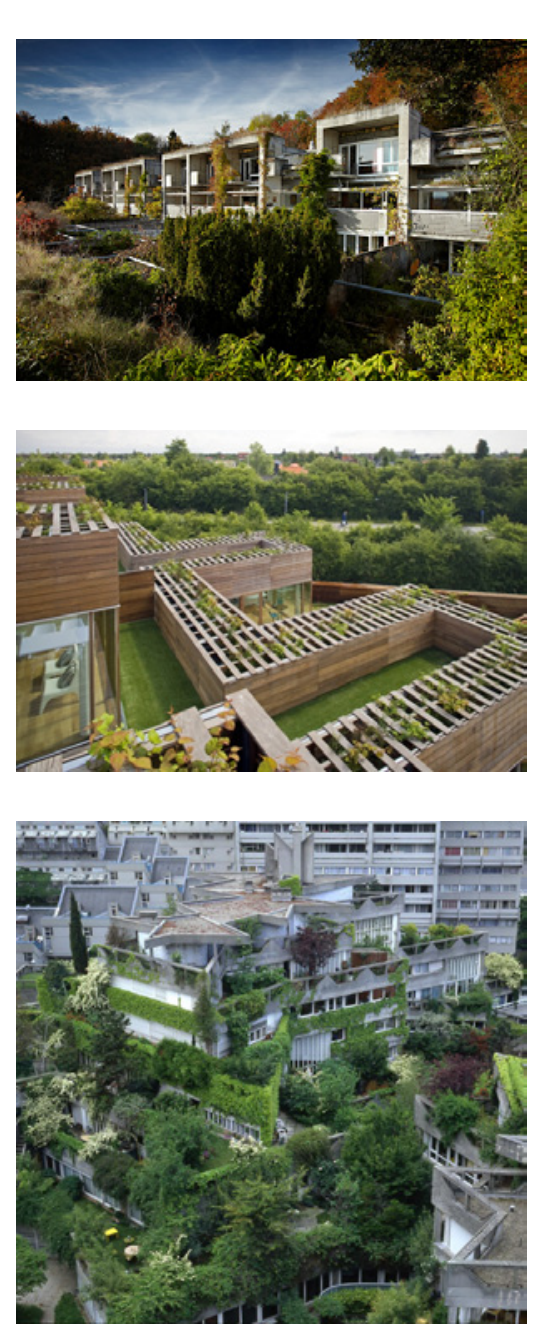

\section{Terrace House (established typology)}

In this scheme the terrace house is adapted so it appears the same in plan as a standard terrace house, but in section finds itself within a larger building, much like an apartment with a garden. Apartments with gardens imply a highrise attached external garden unit (not to be confused with the existing low-rise garden apartment typology).

In this scheme adapting the terrace typology provides a 'street' connection and garden for these units, and a borrowed garden for the common circulation areas.
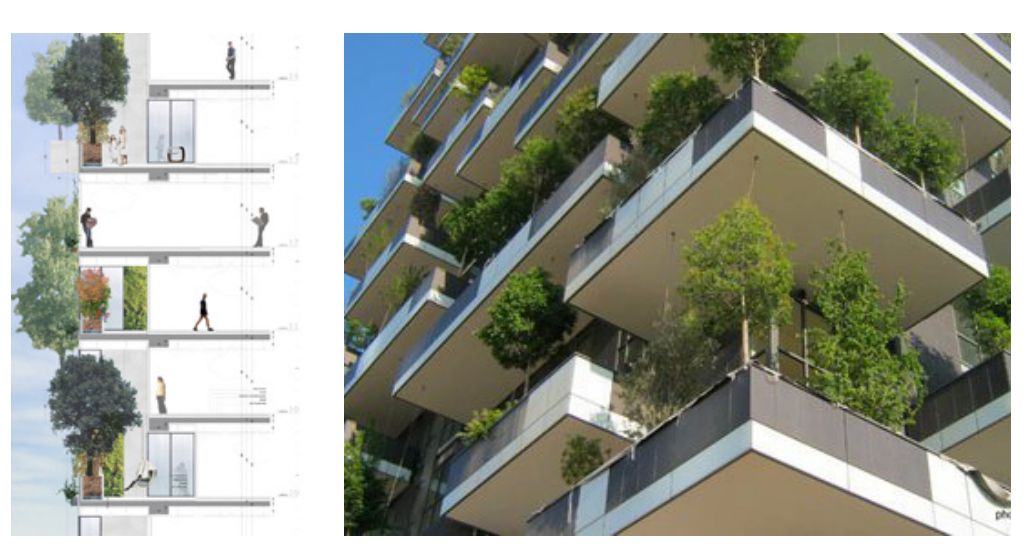


\section{Verte Maisonette (developing typology)}
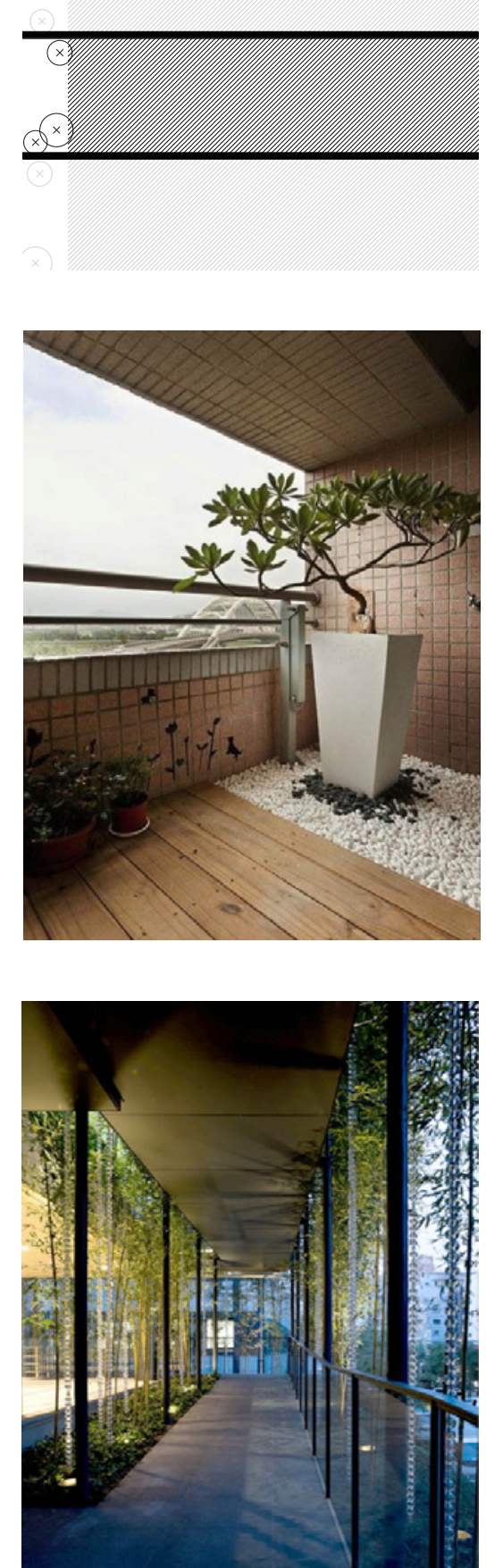

The verte maisonette typology is titled 'verte' after (feminine) green in French and the English word 'maisonette' taken from French 'little house'. In this scheme these units are typically accessed from the south and double storey with a marginally larger floor area than a terrace house. Although these units do not have private outdoor gardens, a the terrace houses do, they use private internalised garden typologies such as balconies, planted loggias, interna planter boxes and green screens as well as borrowed landscapes to maintain a desirable garden connection.

"The word maisonette means 'little house' in French, making its essential feature dwelling with multiple storeys, incorporated into a residential building."
Figure 7.2.07

Verte Maisonette
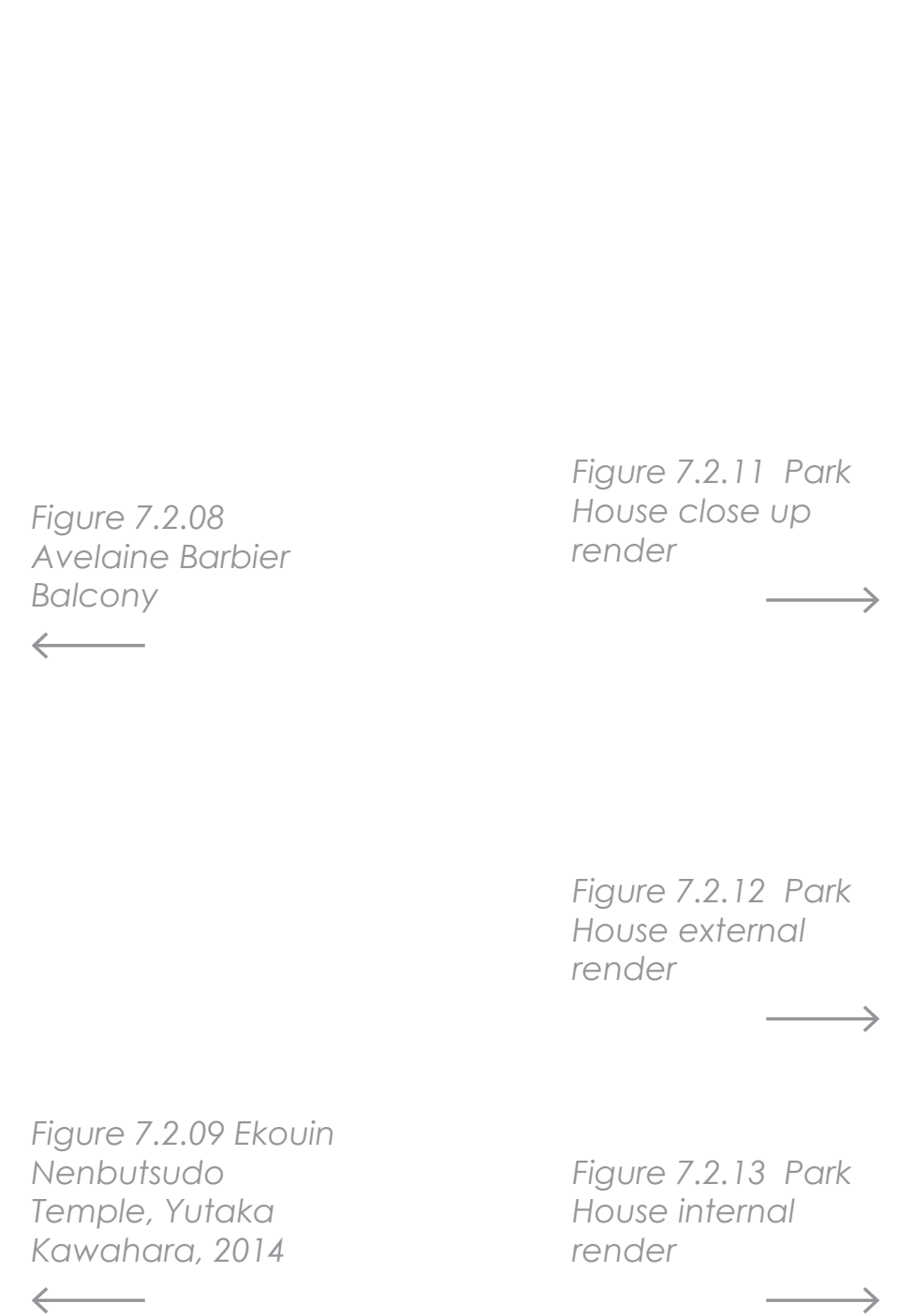
Figure 7.2.12 Park
House external
render

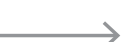

Figure 7.2.13 Park House internal

render

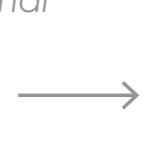

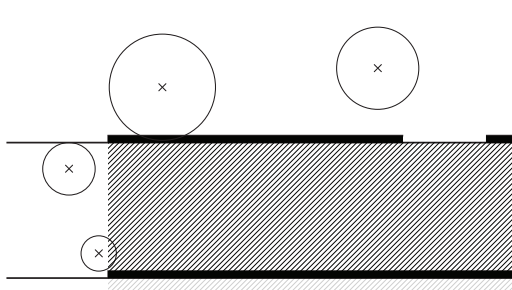
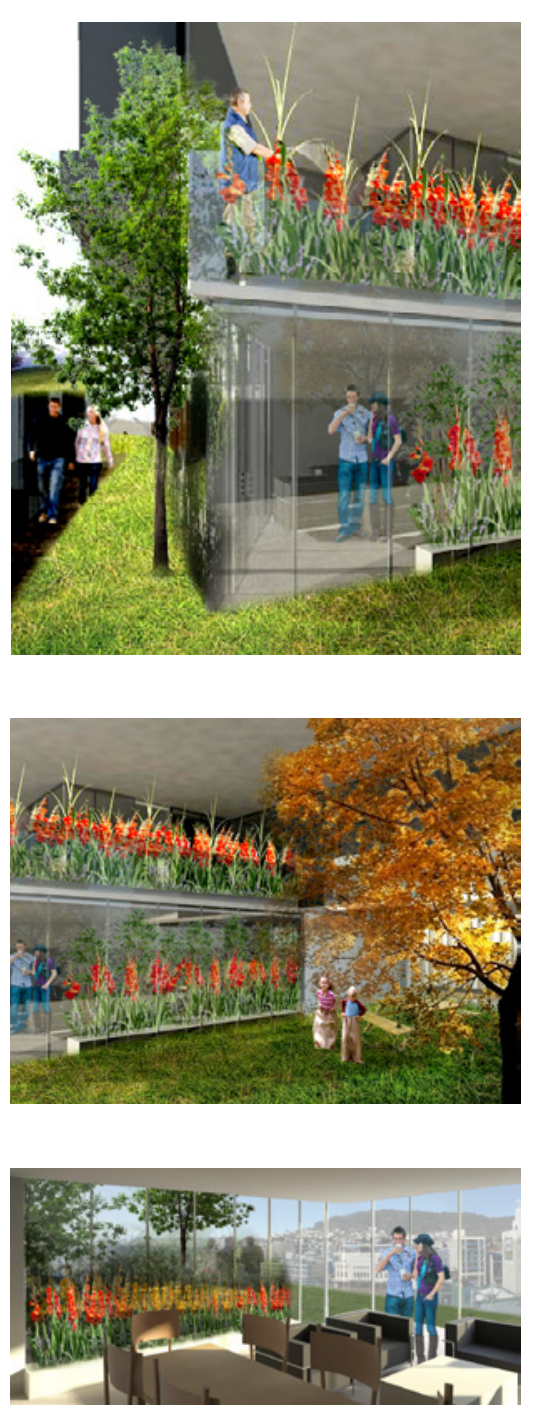

\section{Park House (developing typology)}

The park house is a typological invention. Defined by direct access onto a common pocket yard, these have to be specially designed to balance privacy of the unit with the comfort of pocket yard users. Often with secondary more private access options from the boardwalks, and superior solar access afforded by the adjacent common garden, these units have a generosity of garden and sunlight, which helps offset a perceived privacy loss due to the proximity of common space. 

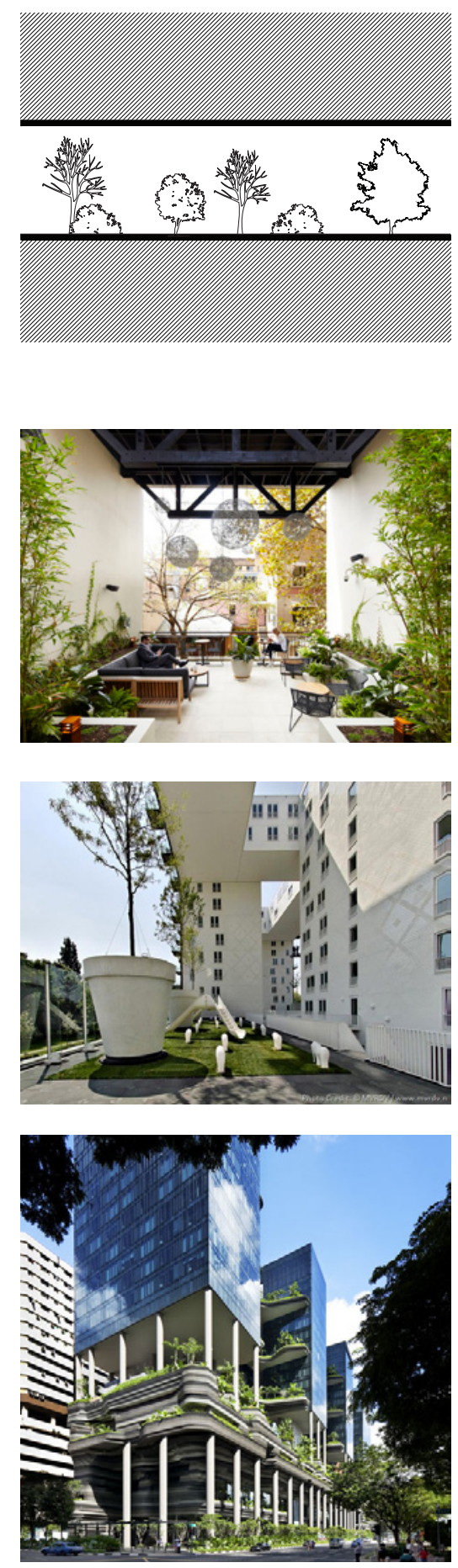

\section{Void Garden (developing typology)}

This developing typology has a large effect on the icon value of a development. Externally visible and

instantly desirable, these garden create an atmosphere of intermediate scaled intimacy especially suitable for common, or neighbourhood interaction a further desirable feature. When used in combination with circulation these spaces are catalysed by continual use. The costs of providing such large planted void space means they are rare, with each example either public or common thus optimising access to the iconic feature.

The design of the access creates condition degree to use it as a space for collective habitation. At the same time, how the collective area relates to the privacy of the individual dwelling is a vital consideration." Stacked/slic diagram
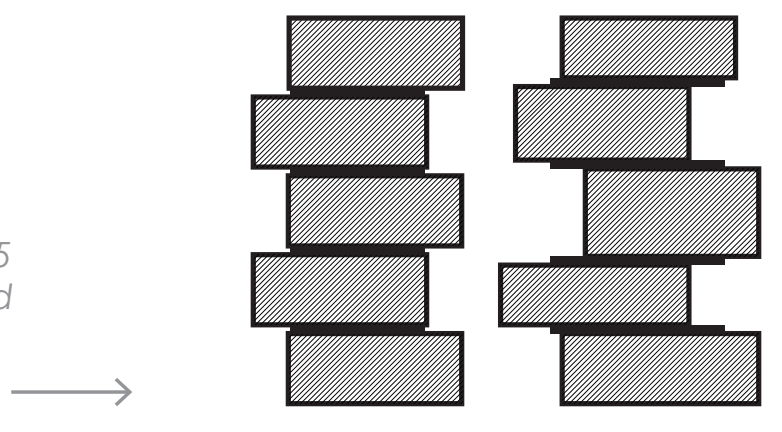

Figure 7.3.02

Harbour Rocks

$\longleftarrow$
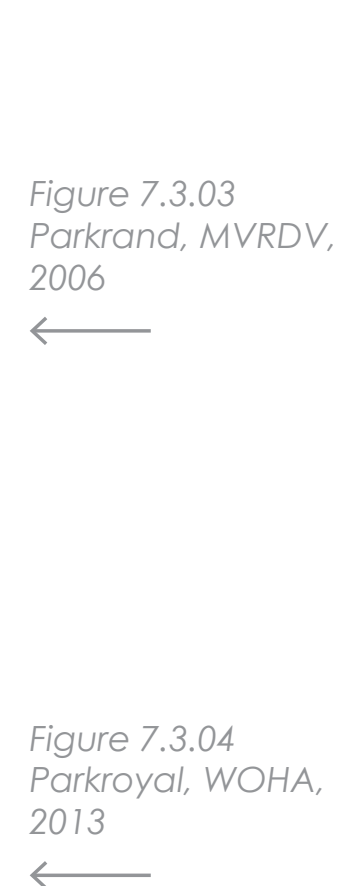

Figure 7.3.06 Axis

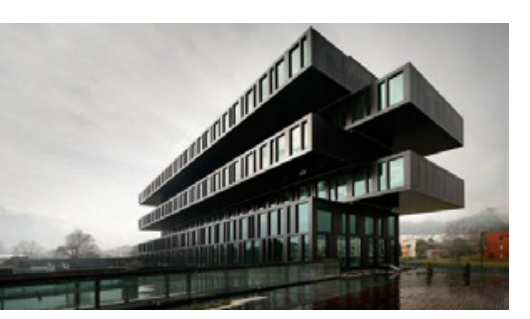

Figure 7.3.07 Habitat 67, Moshe Safdie, 1967

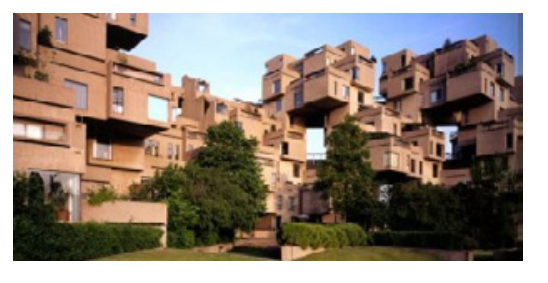
Figure 7.3.08
Edificio Palmas (office), Juan Sordo Madaleno,

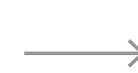

tacked/Slid Building (developing typology)

A stacking or slid architectonic is used in a number of projects to create an iconic look in conjunction with useful void spaces. Slid buildings have a striking look about them achieved through engineering innovation and well worked proportions. The resultant void spaces give the building texture and can, as in this scheme, be used as outdoor living or circulation areas. Used across multiple scales, down to furniture and joinery, the slid detail gives increased interest and associated icon potential. 


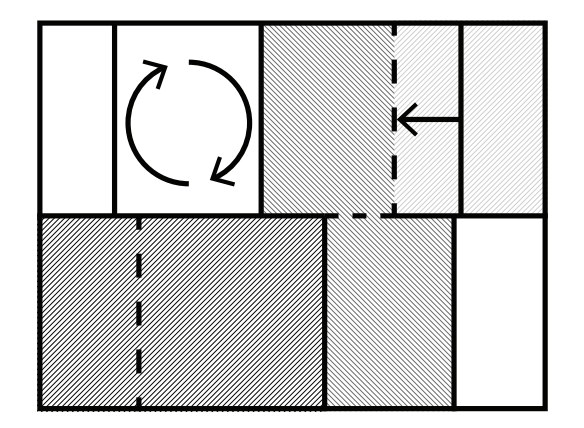

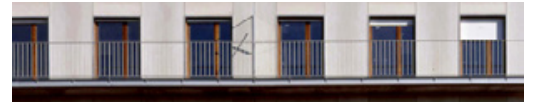

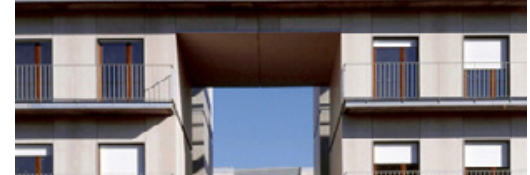

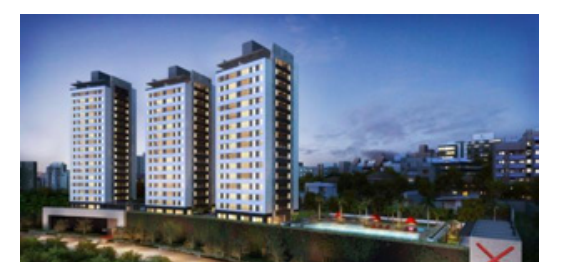

\section{Flexibility (developing typology)}

Designing for flexibility typically requires either uncommon ownership systems. to utilise all space at all times (as in this design proposall, or large units that are subdivided or rooms merged internally as required. Flexible buildings do not typically look any different externally, as in both situations the building envelope is fully formed. MaxHaus is purchased by the $70 \mathrm{~m}^{2}$ apartment, which can be merged into 140,210,280, or $560 \mathrm{~m}^{2}$ units that can be created and recreated as required (MaxHaus, 2013). Lakua Social Dwellings use the second method of flexibility, where a standard unit's room spaces can be subdivided or merged over time (French, p. 177). Design test five employs a hybrid system different to both, allowing for a flexible housing situation (Chapter 5.4). These design solutions look to the future to propose innovative and sustainable housing solutions for a changing society.

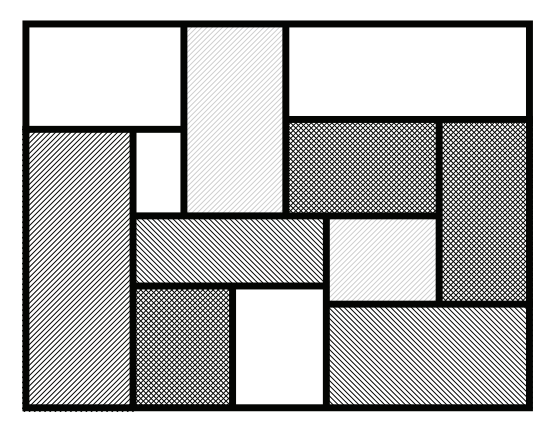

Figure 7.4.04 Salt

Figure 7.4.01

Flexibility diagram

$\leftarrow$
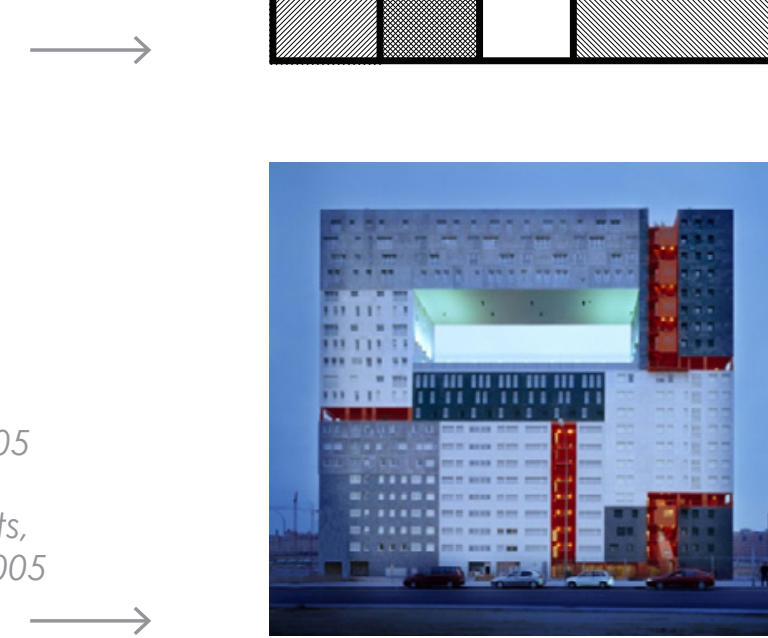

Social Dwellings.

Ercilla \& Campo

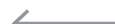

Figure 7.4.03

MaxHaus,

MaxHaus, not yet

completed

Figure 7.4.06 Chip building, Alsop
Architects, 2002

Figure 7.4.05

Apartments,

MVRDV, 2005
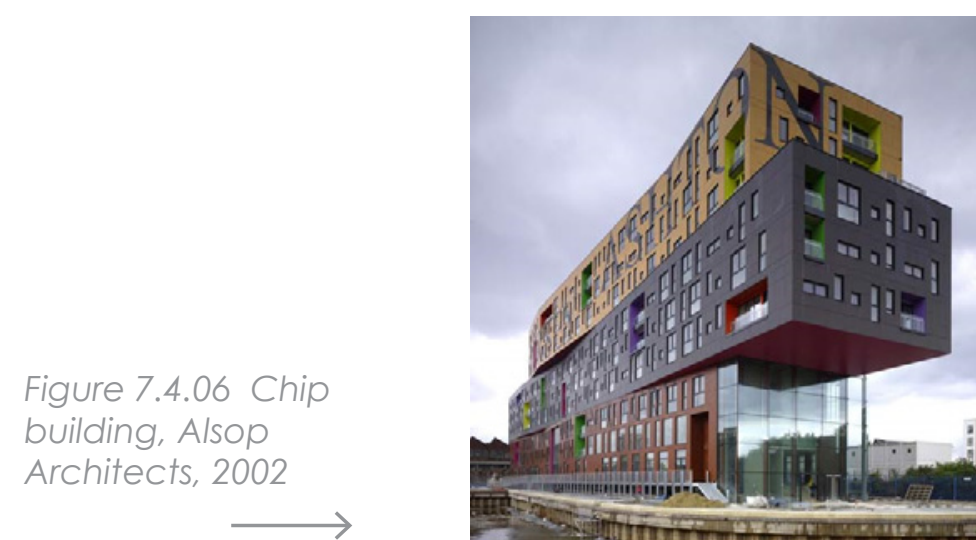

Figure 7.4.07

Silodam, MVRDV,
2003
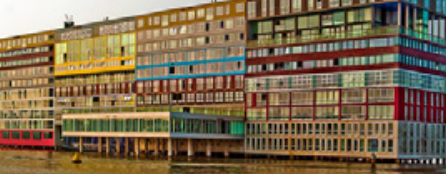

Salt and Peppering (developing typology)

Salt and peppered designs disperse type clusters throughout the building mass. In this case the terrace house and verte maisonette types were arranged in horizontal rows which were stacked. although initial experiments clustered them more randomly. As well as reading interestingly, with each unit type clearly articulated as a type (especially visible from the internal courtyard), this helps provide unit diversity while maintaining structural efficiencies. In each unit typology the different amenities that attract different occupants bringing diversity to the development community. These buildings often express their internal differences to create a further iconic look. 

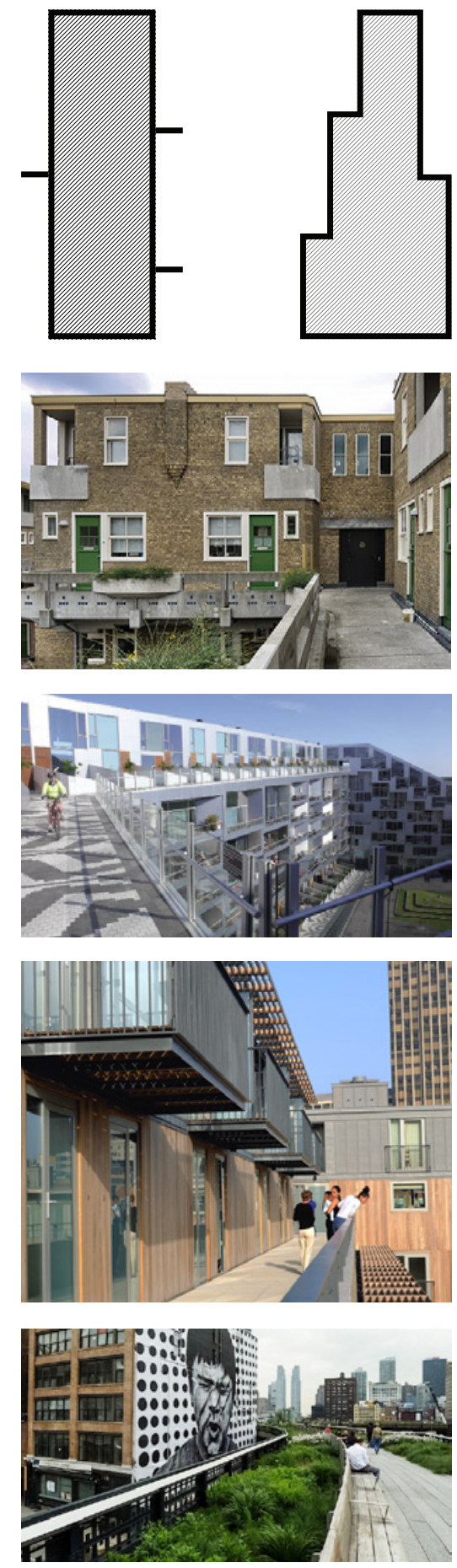

\section{Street in the Sky (redeveloping}

\section{typology)}

Following criticism of the Robin Hood Gardens (1961) and other modernist buildings for their ghetto-like externa circulation paths the profession has returned to an adapted form of gallery These new versions are flooded with light and offer passive surveillance, a community platform and an extension to the private dwelling. The earlier Justus van Effen Complex (1922) even had milk delivered on the upper street leve which helped to develop a community and proved its use in the neighbourhood (Fernández Per Mozas \& Ollero, 2013). This circulation typology is re-establishing itself with good design as a viable and community focussed alternative to internal circulation solutions. Housing, Haworth
Tompkins, 2004 $\longleftarrow$

Identified in relation to Justus van Effen Complex, the elevated external street is as element which links not onty the elo an built into the section but also collective living units and the residents of the housing complex." (Fernández Per, Mozas, \& Ollero p. 12)" (1)

Figure 7.4.09 Justus

van Effen

Complex,
Brinkman, 1922

$\longleftarrow$

Figure 7.4.108 House, Bjarke

Ingels

Egure 7.4.11 The

High Line, Jame

Corner Field

Operations, 2006
Figure 7.4.08 Street

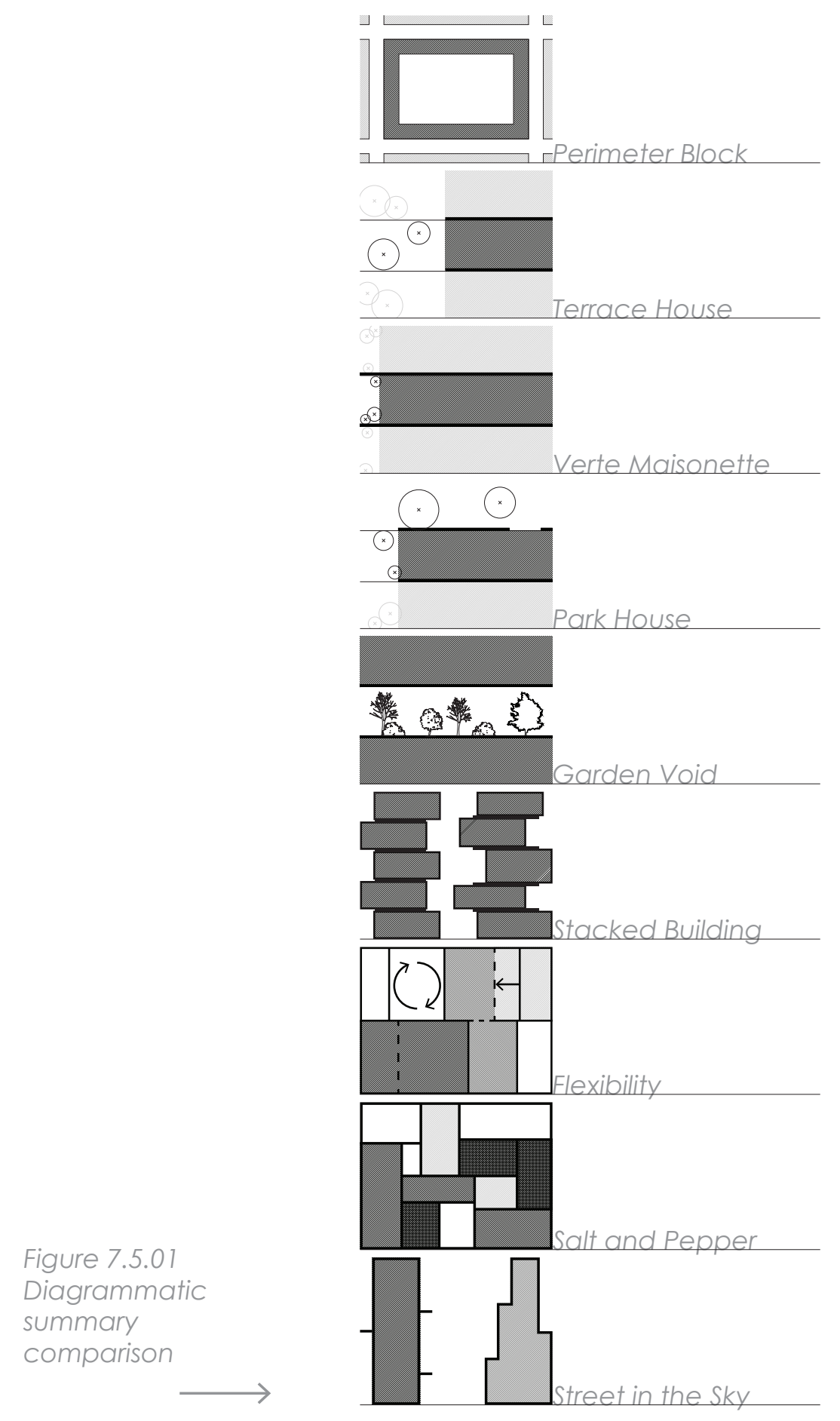

The use of 'type' as a tool in the design process led to new developments in the project which may be relevant to the residential design and development industry. The process of analysing types is especially valuable when types are understood and then adapted to different situations, as demonstrated in this thesis. When an understanding of the strengths and weaknesses of each typology is gained it is possible to apply and adapt them ad infinitum. In some instances typologies were the start point (as in unit and landscape types), and in others finding relationships with enough built examples spurred the identification of new types. Equally the project can be positioned in relationship to other ideas, processes or forms to order new knowledge in different ways. 


\subsection{Conclusion}

For reasons relating back to New Zealand's early settlement, New Zealanders have an on-going feel of entitlement to their 'own house, on their own land'. Generations of New Zealanders have grown up in suburban single detached houses, with childhoods spent in the prided front and back gardens of suburbia

Early attempts to encourage adoption of alternative higher density housing types were not successful, and then as now compounded by recent failures in the construction industry, are seen as inferior (CHRANZ p. iv).

This thesis commenced with a study of the Centre for Housing Research Aotearoa's 2011 study that highlights 29 disincentives needed to be overcome before New Zealander's consider adopting medium or higher density housing. These were set as design parameters and subsequently solved for.

Further to these, six additional design parameters were used as incentives to increase the desirability and acceptance of the higher density way of living.

This proposal is also an architectural study in density; targeting 250 DW/HA. While this is high by New Zealand standards the target was used to give the project an element of feasibility acknowledging the developer driven market in New Zealand. It also tests the application of concepts at a local extreme. 
Using garden, this project demonstrates how it is possible to incorporate substantia landscaped spaces into higher density developments. In this development a generous 'common green network' used as the primary circulation device. This study of an alternative circulation method allows for space appropriation and full utilisation of common ground and a symbolic and physical connection between residents.

A variety of landscape typologies are used to regulate people from the public to the private realm. The different mixes of public, common and private landscapes are of different scales and plantings - and provide screening from one zone to the next. Within this scheme private gardens are provided for in a substantial proportion of units, giving significant characteristics of suburban style living to vertical housing dwellings.
This propositional design suggests a new way to encourage New Zealand suburbanites to live in the city. The desire for space enough for a child to learn to ride a bike or roll around on a lawn is part of the reason why Kiwis retreat to the suburbs to have families. The scheme provides large common open spaces to offset the smaller, as compared with traditional suburban sections, private gardens attached to the units. The reduced 'section size' is balanced against substantially larger and more easily accessible common areas to create a delightful place to live and raise a family.

The scheme balances access to amenities provided by the city and supplements its missing elements by incorporating them into the public or common realm. It provides all of the private amenities afforded by suburban housing, as well as immediate access to those provided by the central city. It recognises the city as rich in amenities and housing as a city amenity whilst consciously giving something back to the city itself. The identified missin amenities, a crèche and green, ar used to help integrate and knit the development into the city. This helps to supplement the neighbourhood with additional amenities, ones identified as missing, and in turn aids in developing a community within and outside of the scheme.

The possible application of the common green network strategy extends wider than this site, amenity study or city.

This thesis project offers a model for residential development distinguished by an embedded extensive green infrastructure, that, when introduced into urban situations such as Wellington's, can deliver benefits not only to the occupants but also to the city.
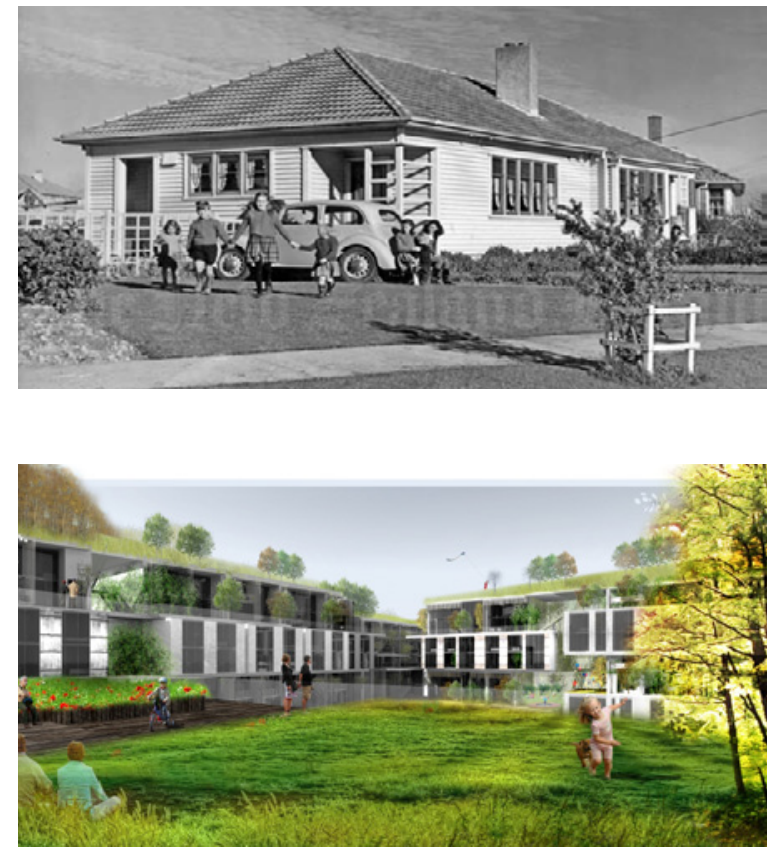
Auckland Regional Growth Forum. (2003). Auckland Metropolitan Growth Area: Capacity for Growth 2001. Auckland: Auckland City Council.

Bailey, R. (2012). Roof gardens: how citydwelling horticulturists are reaching new heights. London: The Telegraph.

Brookes, B. (Ed.). (2000). At Home in New Zealand: History Houses People. Wellington: Bridget Williams Books.

CHRANZ. (2011). Improving the Design Quality and Affordability of Residentia Intensification in New Zealand. Dunbar Richard: McDermott Philip Auckland: Centre for Housing Research, Aotearo New Zealand (CHRANZ).
Dekker, D. (2012, 08 26). Wellington Apartment Living An Aquired Taste. Dominion Post.

Downton, P. (2003). Design Research. Melbourne: RMIT Publishing.

Fernández Per, A., Mozas, J., \& Ollero, A. S. (2013). 10 stories of collective housing: graphical analysis of inspiring masterpieces. Vitoria-Gasteiz: $\quad a+\dagger$ architecture Publishers.

French, H. (2006). New Urban Housing New Haven: Yale University Press.

Güney, Y. I. (2007). Type and typology in architectural discourse. Ballkesir: Ballkesir University Faculty of Architecture and Engineering. 
Jencks, C. (2005). The Iconic Building; the power of enigma. London: Frances Lincoln Ltd.

Kebbell, S. (2013). BBSC, BArch (Hons), MDesS (Dist) Harvard. Desirable Icons. (A. Fraser, Interviewer)

Leupen, B., Mooij, H., Uytenhaak, R. Jürgenhake, B., Nottrot, R., Zondag, J.,

. Vroomen, L. (2011). Housing design: a manual. Rotterdam: NAi Publishers.

Lindstrom, M., \& Bartling, H. (Eds.). (2003). Suburban Sprawl: Culture, Theory, and Politics. Lanham-Seabrook, Maryland United States of America: Rowman \& Littlefield Publishers, Inc.

Malnar, J. M., \& Vodvarka, F. (2004). Sensory design. Minneapolis: University of Minnesota Press.

MaxHaus. (2013, June 21). MaxHaus Concept Retrieved from MaxHaus: http://www.maxhaus.com.br/conceito/
Mozas, J., \& Fernández, A. P. (2004). Density: New collective housing. VitoriaGasteiz: A+† Ediciones.

Ng, E. (Ed.). (2010). Designing High-Density Cities: For Social and Environmental Sustainability. New York: Earthscan.

Scalbert, I. (2004). The Right to Difference: the architecture of Jean Renaudie. London: Architectural Association.

SHoP. (2012). SHoP architects : out of practice. London: Thames \& Hudson.

Urban Task Force. (1999). Towards an Urban Renaissance: London Sustainable Settlement Guide. London: Department of Environment, Transport and the Regions. 
Figure Reference List

Figure 0.0.01 New Zealand Herald archive photography. Sourced from http://www. houses-1940s-state-house-family

Figure 0.0.02 Author's own image. Adapted from Table One: Desirable Attributes Identified

Figure 0.0.03 Author's own image. Adapted trom Table One.Desitable A Atribulestdenitied by Medium Density Housing Residents Figure 0.0.04 Author's own image Figure 0.1.01 Author's own image Figure 0.1.02 Author's own image Figure 0.1.03 Author's own image Figure 0.1.04 Author's own image Figure 0.1.05 Author's own image Figure 0.1.06 Author's own image Figure 0.1.07 Author's own image Figure 0.1.08 Author's own image
Figure 0.1.09 Author's own image Figure 0.2.01 Author's own image Figure 0.202 Author's own inac Figure 0.2.03 Author's own image amenities. Adapted from Urban Task Force ondon Sustainable Settlement Guide 39 Figure 0.2.05 Author's own image Figure 0.2.06 Author's own image Figure 0.2.07 Author's own image Figure 0.2.08 Author's own image Figure 0.2.09 Author's own image Figure 0.2.10 Author's own image Figure 0.4.01 Author's own image 31 Figure 0.4 .02 Perspective Chews Lane.
31 Sourced from http:///chewslane.co.nz/
images/flash/building-10-TB.jpg

32 
Figure 0.4.03 Author's own image Figure 0.4.04 Author's own image Figure 0.4.05 Author's own image Figure 0.4.06 Author's own image Figure 0.4.07 Author's own image Figure 0.4.08 Author's own image Figure 0.4.09 Author's own image Figure 0.4.10 Author's own image Figure 0.4.11 Author's own image Figure 1.0.01 Author's own image Figure 1.0.02 Perspective Porter House Sourced from http://www.e-architect.co.uk/ images/jpgs/architects/porter_house_new york_ch080509_sk.jpg

Figure 1.0.03 Author's own image Figure 1.0.04 Author's own image Figure 1.0.05 Author's own image Figure 1.0.06 Author's own image Figure 1.0.07 Author's own image Figure 1.0.08 Author's own image Figure 1.0.09 Author's own image Figure 1.0.10 Author's own image
46 Figure 1.0.11 Author's own image

47 Figure 1.0.12 Author's own image

47 Figure 1.1.01 Author's own image

48 Figure 1.1.02 Author's own image

48 Figure 1.1.03 Author's own image

49 Figure 1.1.04 Author's own image

49 Figure 1.1.05 Author's own image

49 Figure 1.1.06 Author's own image

49 Figure 1.1.07 Author's own image

53 Figure 1.1.08 Author's own image Figure 1.1.09 Author's own image Figure 1.1.10 Author's own image Figure 1.1.11 Author's own image

54 Figure 1.1.12 Author's own image

54 Figure 1.1.13 Author's own image

55 Figure 1.1.14 Author's own image

56 Figure 1.1.15 Author's own image

56 Figure 1.1.16 Author's own image

57 Figure 1.1.17 Author's own image

57 Figure 1.1.18 Author's own image

57 Figure 1.1.19 Author's own image
Figure 1.1.20 Author's own image Figure 1.1.21 Author's own image Figure 1.1.22 Author's own image Figure 1.1.23 Author's own image Figure 1.1.24 Author's own image Figure 1.1.25 Author's own image Figure 1.1.26 Author's own image Figure 1.1.27 Author's own image Figure 1.1.28 Author's own image Figure 1.1.29 Author's own image Figure 1.1.30 Author's own image Figure 2.0.01 Author's own image Figure 2.0.02 Author's own image Figure 2.0.03 Author's own image Figure 2.0.04 Author's own image Figure 2.0.05 Author's own image Figure 2.0.06 Author's own image Figure 2.0.07 Author's own image Figure 2.0.08 Author's own image Figure 2.0.09 Author's own image Figure 2.0.10 Author's own image
Figure 2.0.11 Author's own image

77 igure 2.1.02 Perspective Sanctum z.open2view.com/assets/property/XL/5/1/5 b555a77e7b7ld1227387642c5fle9e224c36 9f.branded.jpeg

Figure 2.1.03 Author's own image gure 2.1.04 Author's own image Figure 2.1.05 Author's own image igure 2.1.06 Author's own image Figure 2.1.07 Author's own image igure 2.1.08 Author's own image Figure 2.1.09 Author's own image figure 2.1.10 Author's own image figure 2.1.11 Author's own image Figure 2.1.12 Author's own image Figure 2.1.13 Author's own image figure 2.1.14 Author's own image Figure 3.0.01 Author's own image figure 3.0.02 Perspective, 8 House. ourced from http://www.camcycle.org. building_opt.jpeg 
Figure 3.0.03 Author's own image Figure 3.0.04 Author's own image Figure 3.0.05 Author's own image Figure 3.0.06 Author's own image Figure 3.0.07 Assembled Axonometric Figure 3.0.08 Author's own image Figure 3.0.09 Author's own image Figure 3.0.10 Author's own image Figure 3.0.11 Author's own image Figure 3.0.12 Author's own image Figure 3.0.13 Author's own image Figure 3.1.01 Author's own image Figure 3.1.02 Author's own image Figure 3.1.03 Author's own image Figure 3.1.04 Author's own image Figure 3.1.05 Author's own image Figure 3.1.06 Author's own image Figure 3.1.07 Author's own image Figure 3.1.08 Author's own image Figure 3.1.09 Author's own image Figure 3.1.10 Author's own image
96 Figure 3.1.11 Author's own image

97 Figure 3.2.01 Author's own image

.

97 Sourced from http://WwW.skyscrapercity com/showthread.php?t=1163565\&page $=8$

Figure 3.2.03 Author's own image

Figure 3.2.04 Author's own image

Figure 3.2.05 Author's own image

Figure 3.2.06 Author's own image

99 Figure 3.2.07 Author's own image

99 Figure 3.2.08 Author's own image

99 Figure 3.2.09 Author's own image

103 Figure 3.2.10 Author's own image

103 Figure 3.2.11 Author's own image

104 Figure 3.3.01 Author's own image

104 Figure 3.3.02 Perspective Mondria

104 Apartments. Sourced from http://stanisic.

104 com.au/projects/project/mondrian 115

105 Figure 3.3.03 Author's own image $\quad 116$

105 Figure 3.3.04 Author's own image $\quad 117$

107 Figure 3.3.05 Author's own image

107 Figure 3.3.06 Author's own image 118
Figure 3.3.07 Author's own image Figure 3.3.08 Author's own image Figure 3.3.09 Author's own image Figure 3.3.10 Author's own image Figure 3.4.01 Author's own image Figure 3.4.02 Author's own image Figure 3.4.03 Author's own image Figure 3.4.04 Author's own image Figure 3.4.05 Author's own image Figure 3.4.06 Author's own image Figure 3.4.07 Author's own image Figure 3.4.08 Author's own image Figure 3.4.09 Author's own image Figure 3.4.10 Author's own image Figure 4.0.01 Balcony examples. Left image
sourced from http:/ www zhila net/ Right sourced from htrp:// www.zhila.net/. Right com/design/small-balcony-garden 130 Figure 4.0.02 Conservatory examples. Left image sourced from hitp://Whw. decorating-ideas/conservatories. Right image sourced from http://thefhd.com/
Figure 4.0.03 Courtyard examples. gardenlandscapeideas. org/ideas/look/121/ modernzengardendesign.html. Right mage sourced from hitp.//Www.selectism. com/2013/05/01/optical-glass-house-byhigus Figure 4.0.04 Terrace garden examples. projects/great-barrier-house. Right image
sourced from http://guzarchitects.com/ 131 Figure 4.0.05 Garden void examples. Left image sourced from http://www. australiandesignreview.com/interiors/30336harbour-rocks-hotel. Right image sourced parkrand/ hitp.//WwW.mwalv.n/projects/ Figure 4.0.06 Rooftop garden examples. Left mage sourced from hitp://nydesignagenda. comage sourced from-int manhatlan/. Right rof-garden

Figure 4.0.07 Green examples. Left image sourced from http://Www.landezine.com/ pavilion-by-fondarius-architecture/ Right image sourced from http://tietgenkollegiet. $\mathrm{dk} / \mathrm{en} /$ the-building/the-architecture/ $\quad 132$ Figure 4.0.08 Plaza examples. Left image sourced trom www. Ihehighline.org/. Right Author's own. 
Figure 4.0.09 Pot plant example. Image Figure 4.1.16 Author's own image soured www.houzz.com/balcony-garden Figure 4.1.17 Author's own image

Figure 4.1.18 Author's own image $\begin{array}{lll}\text { Figure 4.0.10 Path example. Image } & \text { Pagurced } \\ \text { sourtp://carsonvision.wordpress. } & \text { Figure 4.1.19 Author's own image }\end{array}$ sourced htp:///carsonvision.wordplest.
com/2012/04/10/rosemary-beach-walkingpath/ 132

Figure 4.0.11 Author's own image Figure 4.1.01 Author's own image Figure 4.1.02 Author's own image Figure 4.1.03 Author's own image Figure 4.1.04 Author's own image Figure 4.1.05 Author's own image Figure 4.1.06 Author's own image Figure 4.1.07 Author's own image Figure 4.1.08 Author's own image Figure 4.1.09 Author's own image Figure 4.1.10 Author's own image Figure 4.1.11 Author's own image Figure 4.1.12 Author's own image Figure 4.1.13 Author's own image Figure 4.1.14 Author's own image Figure 4.1.15 Author's own image

143 Figure 5.1.08 Author's own image
141 Figure 5.1.05 Author's own image

141 Figure 5.1.06 Author's own image

141 Figure 5.1.07 Author's own image

143 Figure 5.1.09 Author's own image

145 Figure 5.2.01 Author's own image
Figure 5.2.02 Author's own image Figure 5.2.03 Author's own image Figure 5.3.01 Author's own image Figure 5.3.02 Author's own image Figure 5.3.03 Author's own image Figure 5.4.01 Author's own image Figure 5.4.02 Author's own image Figure 5.4.03 Author's own image Figure 5.4.04 Author's own image Figure 5.4.05 Author's own image Figure 5.4.06 Author's own image Figure 5.4.07 Author's own image Figure 5.4.08 Author's own image Figure 5.4.09 Author's own image Figure 5.4.12 Author's own image Figure 5.4.10 Author's own image Figure 5.4.11 Author's own image Figure 5.4.13 Author's own image Figure 5.4.14 Author's own image Figure 5.4.15 Author's own image Figure 5.4.16 Author's own image
163 Figure 5.4.17 Author's own image

163 Figure 5.4.18 Author's own image

166 Figure 5.4.19 Author's own image

167 Figure 5.4.20 Author's own image

169 Figure 5.4.21 Author's own image

172 Figure 5.4.22 Author's own image

172 Figure 5.4.23 Author's own image

173 Figure 5.4.24 Author's own image

175 Figure 5.4.25 Author's own image

175 Figure 5.5.01 Author's own image

175 Figure 5.5.02 Author's own image

175 Figure 5.5.03 Author's own image

176 Figure 5.5.04 Author's own image

177 Figure 5.5.05 Author's own image

178 Figure 5.5.06 Author's own image

178 Figure 5.5.07 Author's own image

178 Figure 5.5.08 Author's own image

180 Figure 5.5.09 Author's own image

180 Figure 5.5.10 Author's own image

180 Figure 5.5.11 Author's own image

181 Figure 6.0.01 Author's own image
181

182

184

185

185

188

189

191

192

194

201 
Figure 6.0.02 Author's own image

Figure 7.1.01 Author's own image

Figure 7.1.02 8 House, Bjarke Ingels Group. 2009. Image sourced http://www.arcspace.
com/features/big/8-house/

206

Figure 7.1.03 Sanctum Apartments, Warren and Mahoney, 2000 . Image sourced Source property/XL/5/1/1516555a77e7b71d 12273876 42c5fle9e224c369f.branded.jpeg Figure 7.1.04 The Whale, Frits van Dongen 200. Image sourced http://www. vd-k.e

Figure 7.2.01 Author's own image

Figure 7.2.02 Siedlung Halen, Atelier 5, 1960. Image sourced http://monocle.com/
magazine/issues/65/estate-of-the-art/ 207

Figure 7.2.03 Mountain Dwellings, Bjarke Ingels Group, 2008. Image sourced http:// www.big.dk/\#projects-mtn

Figure 7.2.04 Jeanne Hachette, Jean www skyscrapercity.com/showthread php?t=1163565\&page $=8$

Figure 7.205 Verlical Forest, Boeri 2014. 7.05 Vertical Forest, Boeri studio. 2014. Image sourced http://Www
stefanoboeriarchitetti.net/portfolios/boscoverticale/

Figure 7.2.06 Vertical Forest, Boeri studio.
2014. Image sourced http://www verticale/
valiarchitetti.net/portfolios/boscoFigure 7.2.07 Author's pwn image $\quad 208$ Figure 7.2.08 Avelaine Barbier Balcony. mage sourced http://www.home-designing. com/2012/1//modern-minimalist-decorwith-a-homey-flow/white-and-wood

do

7.2.09 Ekouin Nenbutsudo Temple, Yutaka Kawahara, 2014. Image architecture/yutaka-kawahnoom.com/ kaikouin-nenbutsudo-temple-withbambo0-01-30-2014/ Figure 7.2.10 Author's own image

Figure 7.2.11 Author's Own image 209 Figure 7.2.12 Author's own image $\quad 209$ Figure 7.2.13 Author's own image $\quad 209$ Figure 7.3.01 Author's own image $\quad 210$ Figure 7.3.02 Harbour Rocks Hotel, SJB, 2012. Image sourced. Image sourced http://www. australiandesignreview.com/interiors/30336harbour-rocks-hotel

Figure 7.3.03 Parkrand, MVRDV, 2006. Image sourced http://www.mvrdv.nl/projects/
parkrand/ Figure 7.3.04 Parkroyal, WOHA, 2013.
Mage sourced http://www.archdaily. com/363164/parkroyal-on-pickering-woha(151756295b3fc4b9bac000 $14 f$ parkroyal-onjpg/

Figure 7.3.05 Author's own image $\quad 21$ Figure 7.3.06 Axis Viana Hotel, VHM, 2008. mage sourced $h t t p: / / w w w$.archdaily

Figure 7.3.07 Habitat 67, Moshe Safdie, 1967. Image sourced hip./MWw.skyscrap 196 com/latin-bar/60073-los-50-edificios-mas-

Figure 7.3.08 Edificio Palmas (office), Juan Sordo Madaleno, 1975. Image sourced http://centreforthedestheticrevolution. blogspot.co.nz/2010/08/exhibitions-i-diant-

Figure 7.4.01 Author's own image

212

Figure 7.4.02 Lakua Social Dwellings, Ercilla \& Campo Arquitectura, 2002. Image sourced New collective housing Vitoria-Gasteiz: A Ediciones

Figure 7.403 MaxHaus MaxHauss not cigure 7.4.03 Maxhaus, Maxhaus, not yet maxhaus.com.br/conceito/ 1

Figure 7.4.04 Author's own image

213
2005. Image sourced http://www.mvrdv.nl/ projects/mirador/

Figure 7.4.06 Chip building, Alsop Architects, 2002. Image source $h t t p: / / w w w . t h e g u a r d i a n$. com/artanddesign/2009/jul//2/chips-willFigure 7.4.07 Silodam, MVRDV, 2003. Image sourced http://www.mvrdv.nl/projects/

Figure 7.4.08 Author's own image

214 Figure 7.4.09 Justus van Effen Complex, Brinkman, 1922. Image sourced Fernández I0 stories of collective housing: graphical analysis of inspining masterpieces. VitoriaGasteiz: $a+t$ archifecture Publishers. $\quad 214$ Figure 7.4.10 8 House, Bjarke Ingels Group, 2009. Image sourced http://www.camcycle.
org.uk/newsletters/103/article5.html 214 Figure 7.4.12 Iroko Housing, Haworth Tompkins, 2004. Image sourced htpp://www.
haworthtompkins.com/built/proj22/index.
html

Figure 7.4.11 The High Line, James Corner Field Operations, 2006. Image sourced http://

214
215 


\section{Appendix Figures}

Figure A.01 Author's own image Figure A.02 Author's own image Figure A.03 Author's own image Figure A.04 Author's own image Figure A.05 Author's own image Figure A.06 Author's own image Figure A.07 Author's own image Figure A.08 Author's own image Figure A.10 Author's own image Figure A.11 Author's own image Figure A.09 Author's own image Figure A. 14 Author's own image Figure A. 13 Author's own image Figure A. 12 Author's own image Figure A.15 Author's own image Figure A. 16 Author's own image Figure A. 17 Author's own image Figure A. 18 Author's own image Figure A.19 Author's own image Figure A.20 Author's own image
Figure A.22 Author's own image

241 Figure A.21 Author's own image

243 Figure $A$

245 Figure A.24 Author's own image

249 Figure A.25 Author's own image

251 Figure A.26 Author's own image

253 Figure A.28 Author's own image

257 Figure A.27 Author's own image

257 Figure A.29 Author's own image

258 Figure A.30 Author's own image

258 Figure A.31 Author's own image

258 Figure A.32 Author's own image

259 Figure A.33 Author's own image

259 Figure A.34 Author's own image

259 Figure A.35 Author's own image

262 Figure A.36 Author's own image

262 Figure A.37 Manhattan Loft Gardens by

263 SOM. Sourced from http://Www.archdaily.

com/248753/manhattan-loft-gardens-som/

264 Figure A.38 Author's own image 273

264 Figure A.39 Author's own image 274
Figure A.40 Author's own image Figure A.42 Author's own image Figure A.41 Author's own image Figure A.43 Author's own image Figure A.44 Author's own image Figure A.45 Author's own image Figure A.46 Author's own image Figure A.47 Author's own image Figure A.48 Author's own image Figure A.50 Author's own image Figure A.49 Author's own image Figure A.52 Author's own image Figure A.51 Author's own image Figure A.54 Author's own image Figure A.53 Author's own image Figure A.55 Author's own image Figure A.56 Author's own image Figure A.57 Author's own image Figure A.58 Author's own image Figure A.59 Author's own image Figure A.60 Author's own image
274 Figure A.61 Author's own image

275 Figure A.62 Author's own image

275 Figure A.63 Author's own image

276 Figure A.64 Author's own image

276 Figure A.65 Author's own image

277 Figure A.66 Author's own image

278 Figure A.67 Author's own image

280 Figure A.68 Author's own image

280 Figure A.69 Author's own image

281 Figure A.70 Author's own image

281 Figure A.71 Author's own image

282 Figure A.72 Author's own image

282 Figure A.73 Author's own image

283 Figure A.74 Author's own image

283 Figure A.75 Author's own image

284 Figure A.76 Author's own image

284 Figure A.77 Author's own image

285 Figure A.78 Author's own image

286

287
288

289

292

292

293

293

294

294

295

296

296

297

297

301

303 
A.1.1.i Design Test One Goldfoam Massings 

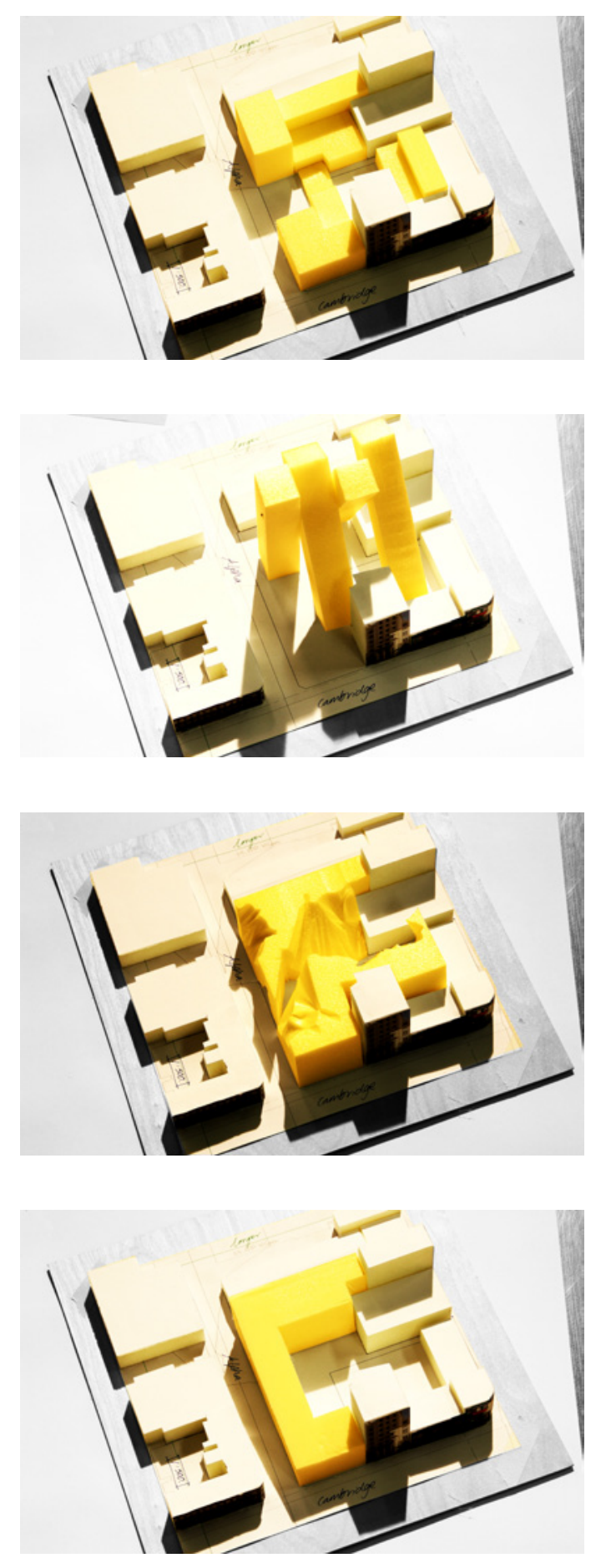
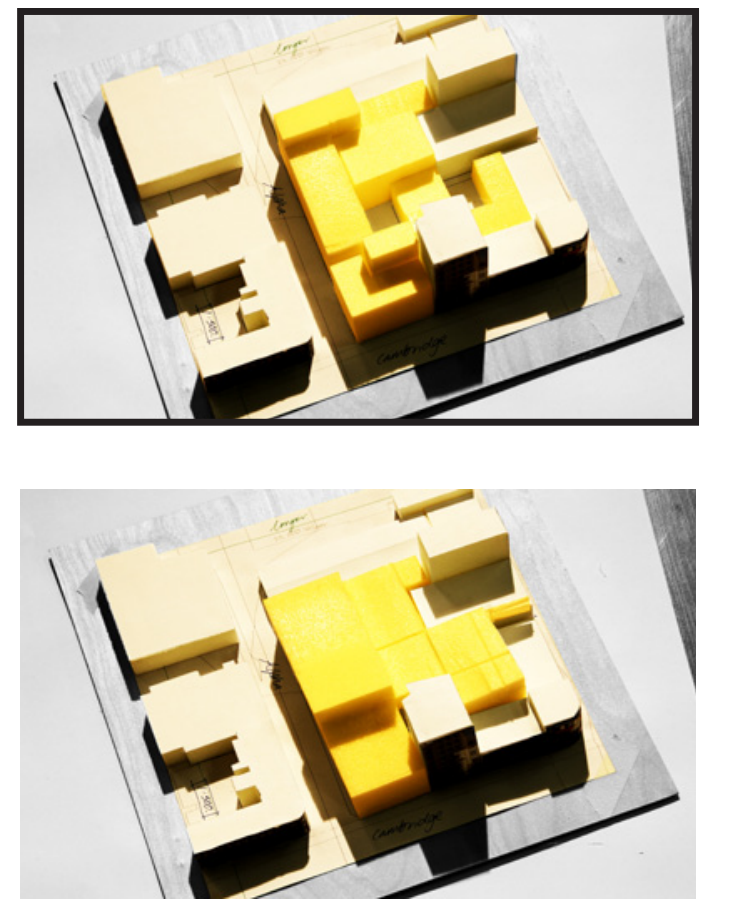

EARLY LIST OF

POTENTIAL FORM
DESIGN DRIVERS

Atmosphere Emotional

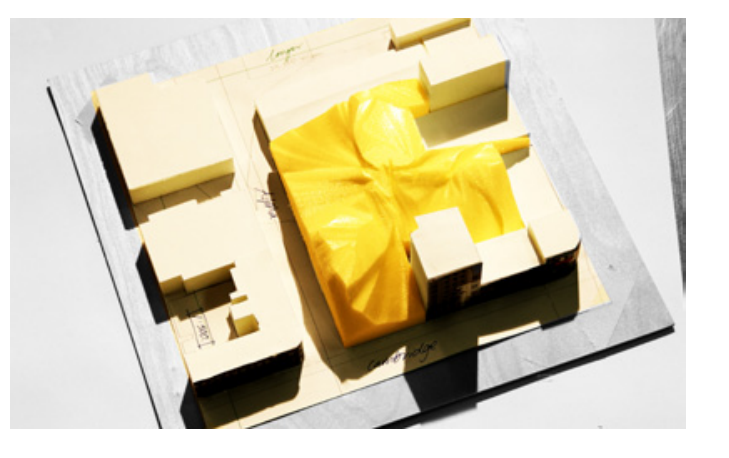

Perception

Symbolism

Philosophy

Structure

Proportion
Materials

Finances

Playfulness

Environment

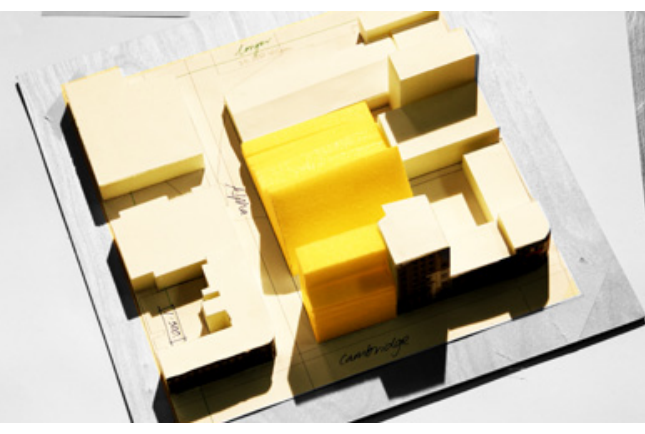

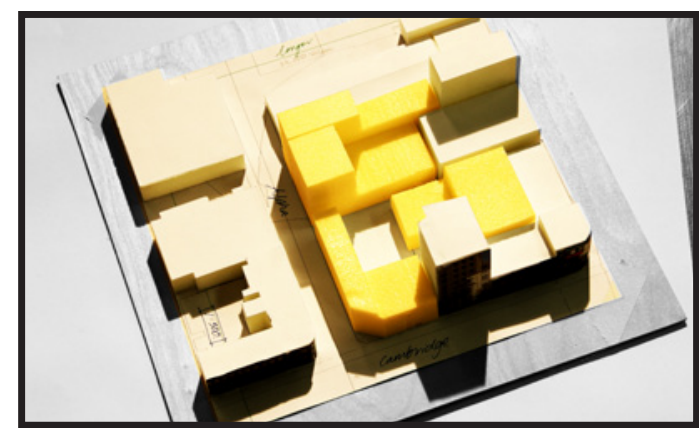

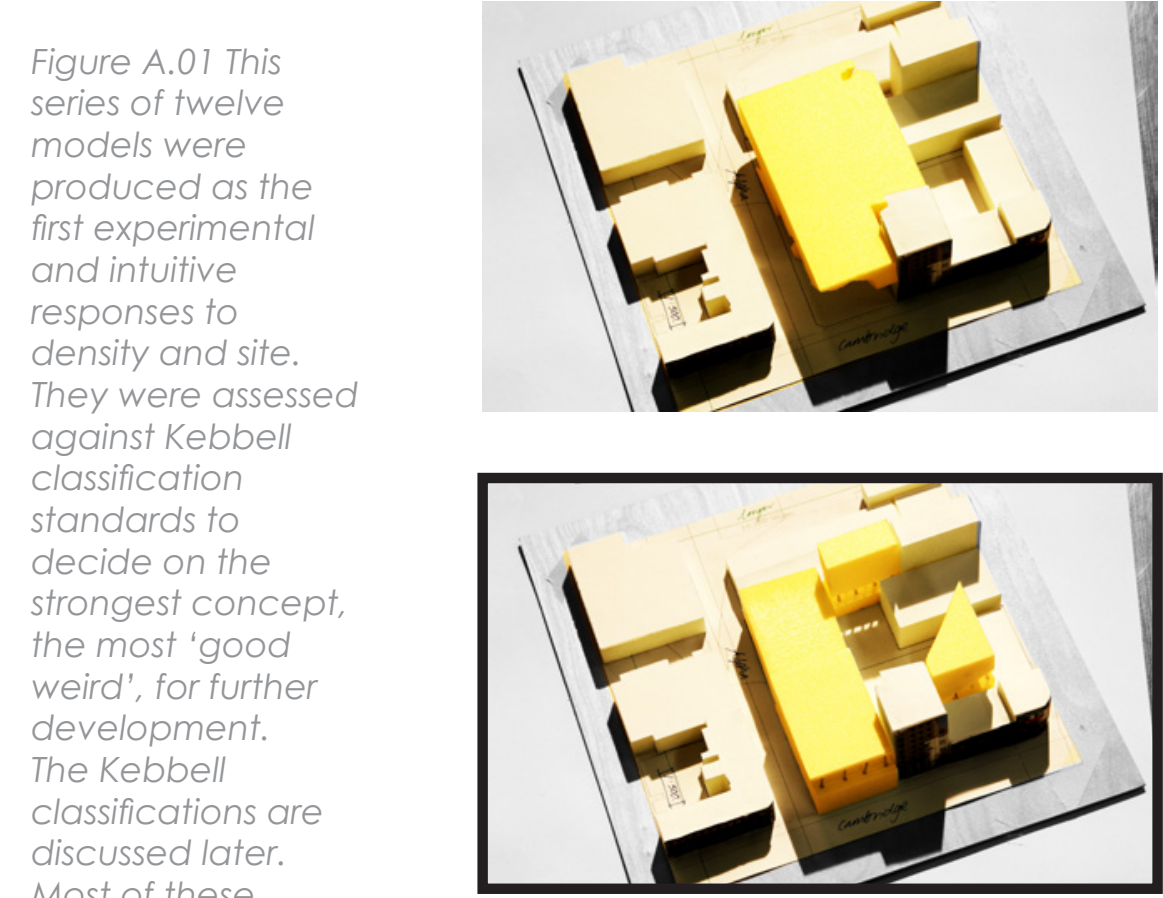

Most of these

fall into the 'bad

weird categary
although the

design highlighted
in bold, is 'good

weird' especially
compared with the

other highlighted

good name
solutions.

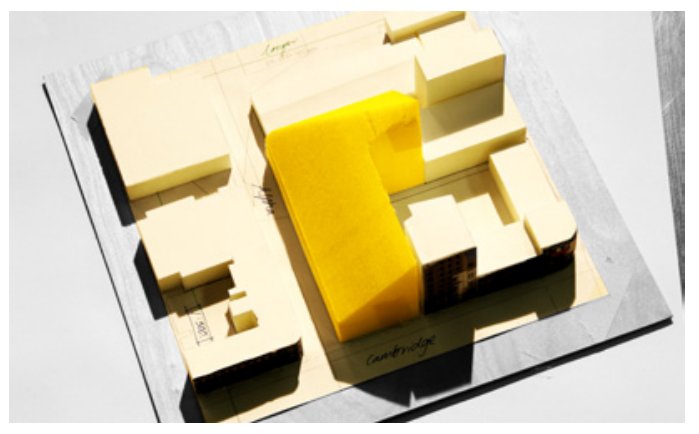


ALTERNATIVE MASSING DESIGNS

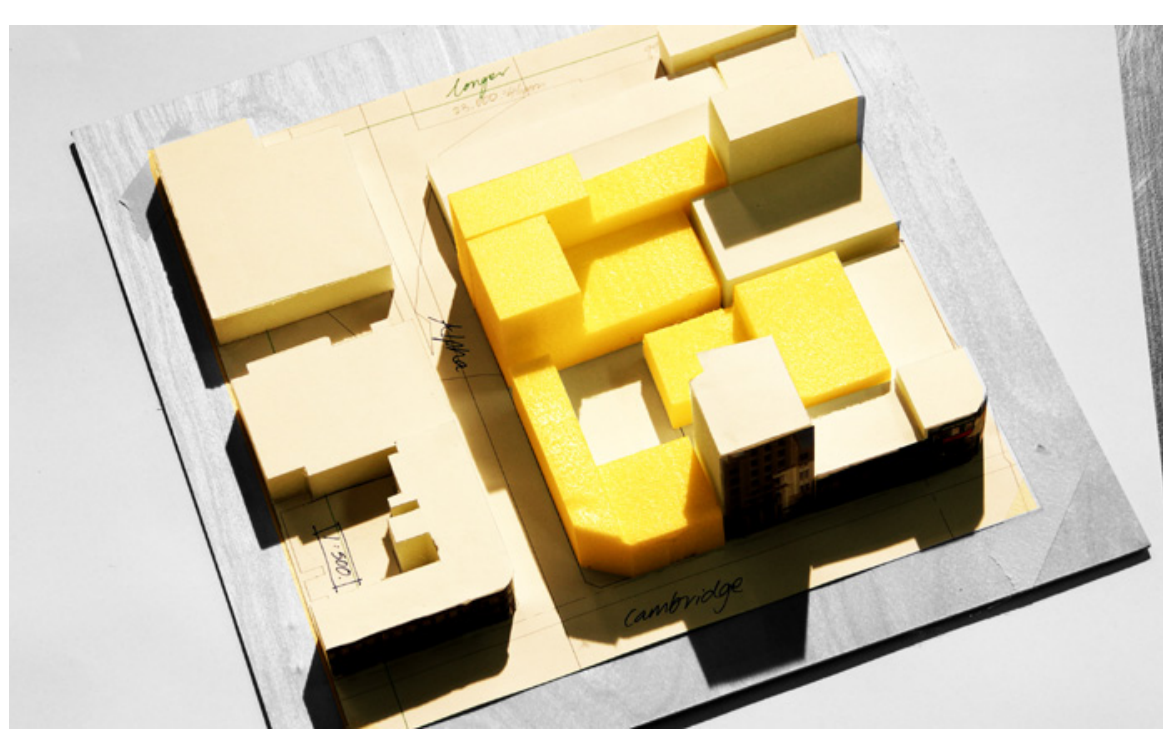

Fine Settlemen

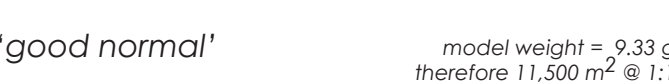

Critique \& Development Opportunities

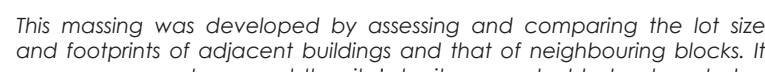

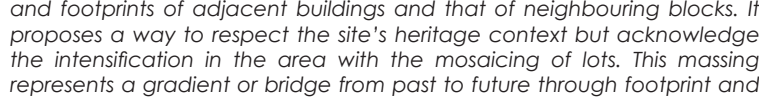

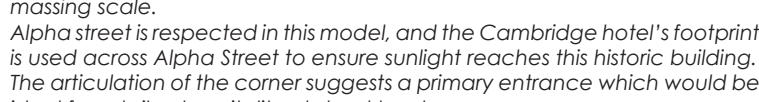

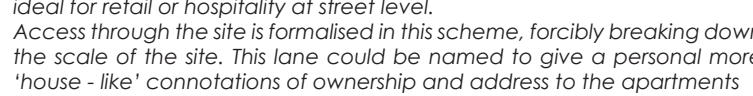

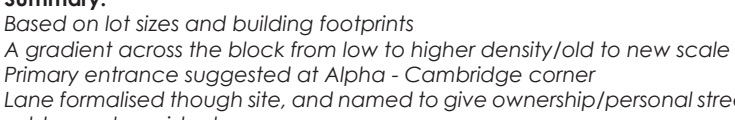

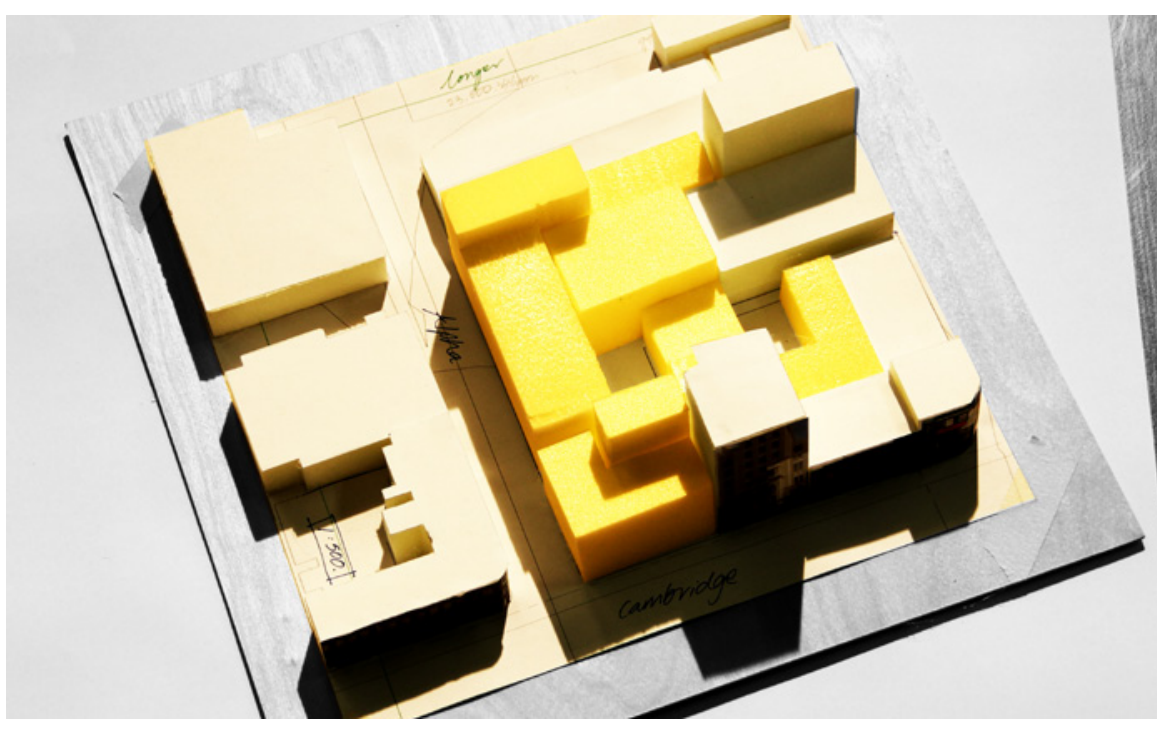

Journey Through

'good normal' $\quad \begin{gathered}\text { model weight }=12.119 \\ \text { therefore } 15.000 m^{2}\end{gathered}$

Critique \& Development Opportunities

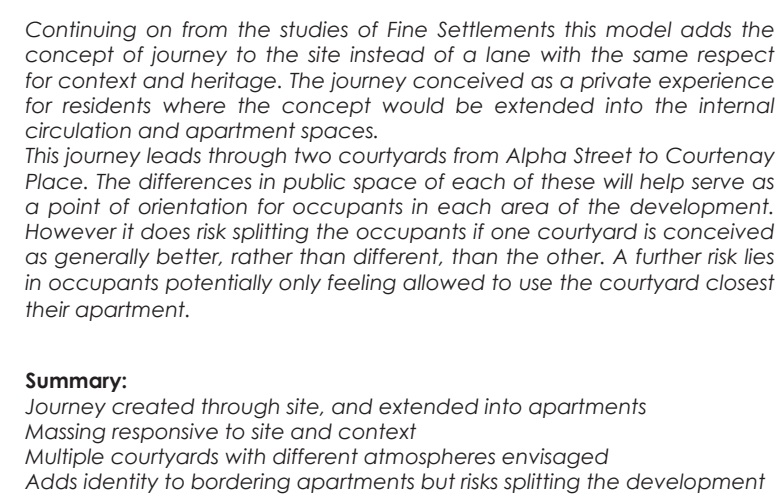




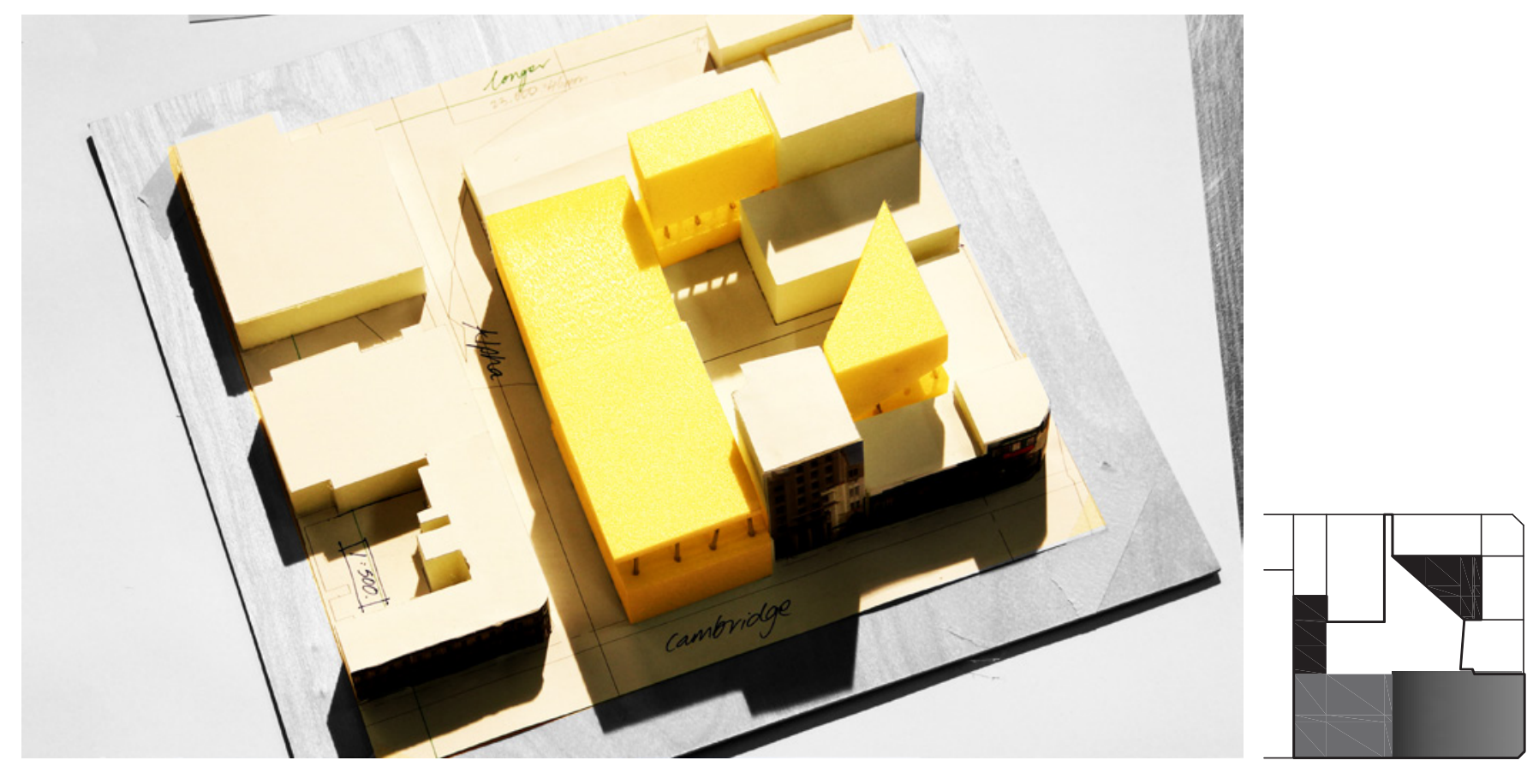

\section{TargetDensity 250
site area $=3230 \mathrm{~m}^{2}$}

1:5000 Plan Diagram Key 20-27 15-20 $05-15 \quad 00-05 \mathrm{~m}$

\section{SKETCH MODELS}

'Kebbell Classification' minimum area required for 250

Defining 'Kebbell Classification'
good weird
good normal

what people don't want; t too unique, rude or some
other failing

See appended massing models for full discussion
Dwelling possib
spaces

\section{LIGHTING AFFEC}

'good weird'

model weight $=10.60 \mathrm{~g}$
therefore $13.200 \mathrm{~m}^{2} @ 1: 1$

Critique \& Development Opportunities

Light and shadow were used to develop this dramatic form. It ains to get light into the height on the northern edge of the site. The courtyard is open to everyone so all residents can view the success of the development and enjoy the quality environment it creates.

The articulation of the void space, including angles of cut and structure density can allow the mass to be read as eilher solid or With different a void cuts deves or thes. different seasons sun angles it may even be possible to get more sunlight in winter the summer in the courtyard. Pictured aside, it from the north-west, is a representation of a afternoon summer sun.

The structural density may also offer wind protection to the central space in the harsh
Wellington climate.
This development also challenges the solid fill but reaching the 32-36meter heiehts of the existing context in a passive response heritage. This increased height also affords better views out to the harbour to the north, Mount Victoria to the west and to the CBD

This design has possible circulation issues the form.

There is potential to dwell in the void spaces, or plant it in deciduous trees, making a

The design also has a steeple like element to it as seen from Blair Street bringing iconic status to the building. 
A 1.1.ii Design Test One Site Solar Studies 

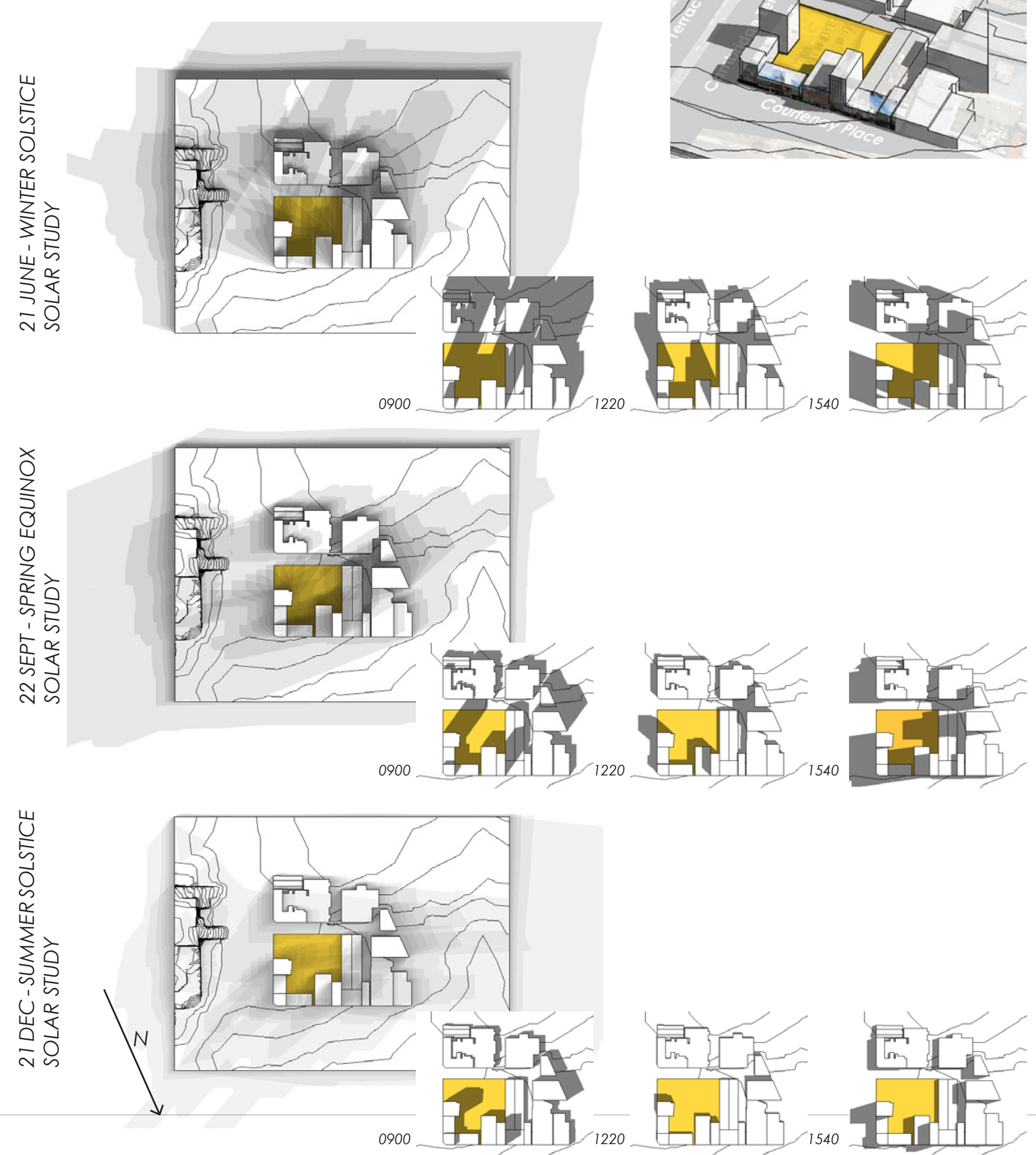

\section{SITE SUMMARY}

Winter morning sun is limited to the site with only one small patch falling on the southern edge of the site at the equinox. This is due to the tall historic registered post office building to the east of the site. To protect this sunlight to the ast of this chink which comes over the low historic buildings on Courtenay Place.

The northern edge of the site is bordered typically by the two to three
storey historic buildings of Courtenay Place. There is one tall and deep building, Adelphi Finance House, due north of the site's centre that casts a shadow that in winter is deep enough to divide the site at noon.

On winter afternoons the site is shaded by the Telecom development o the west. In summer shaded by the much lower Courtenay Muse on the adjacent site.

summer sun rises and sets well south of due east/ shadows in the northern direction. 


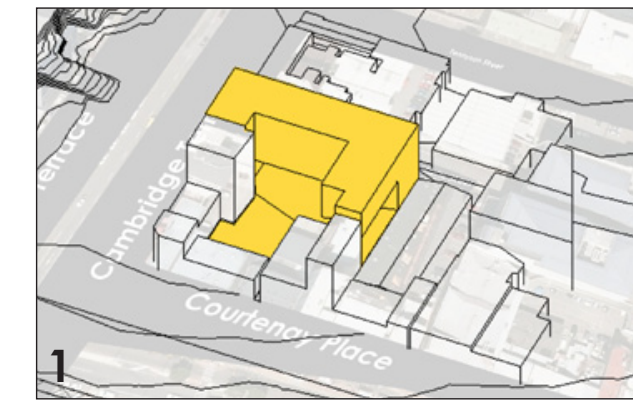

Cantilever to the west to allow low afternoon sun into a central common afternoor
area.

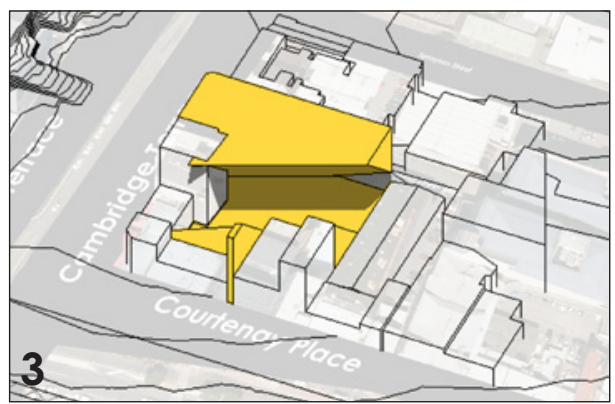

Maximum building envelope with a void extrusion cut based on the northern equinox sun angle.

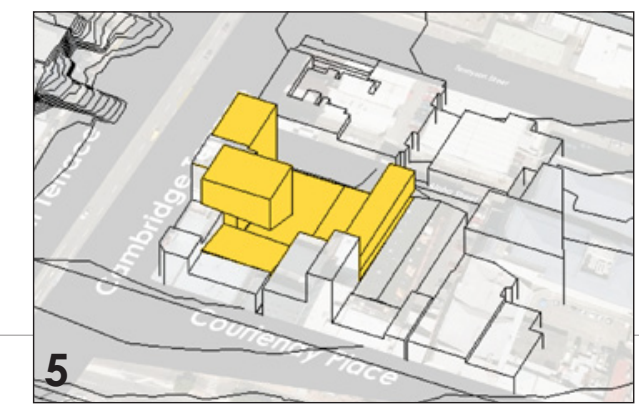

Experimenting with void cuts in buildings to the north and west that allow out sun.

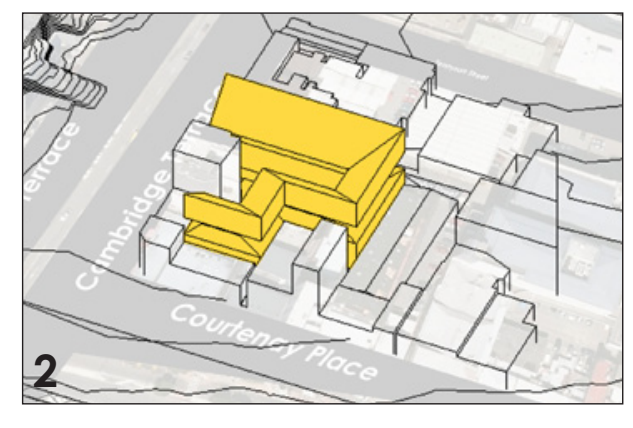

Swept profile around the perimeter designed based on mid morning sun

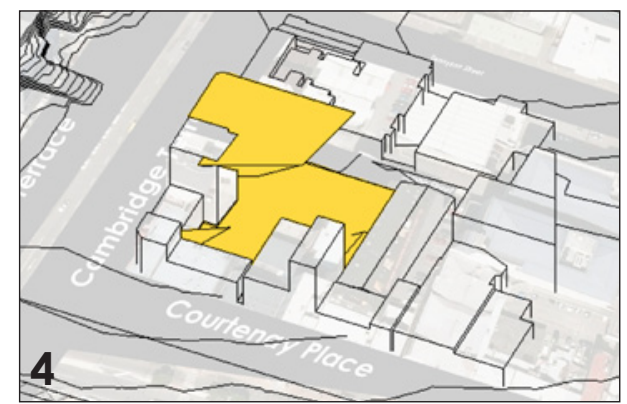

Continuing on from 3 a double cantilever designed to allow afternoon sun in too.

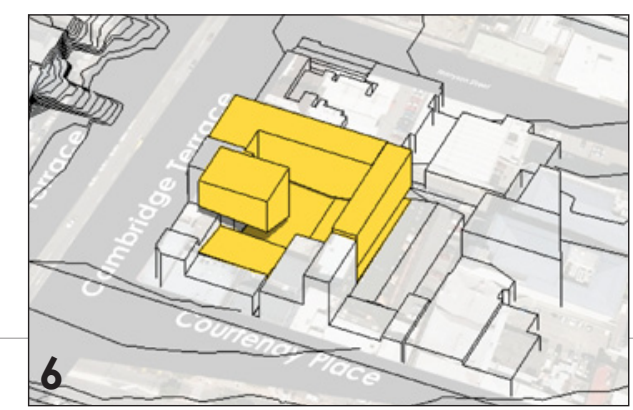

Raised building to the west and new building to the south to increase number of dwellings.

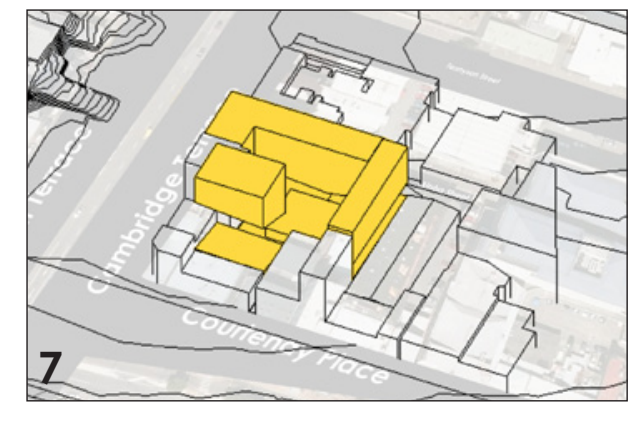

Raised internal platform in western corner to increase winter moming sunlight to increase witer moming sunlight

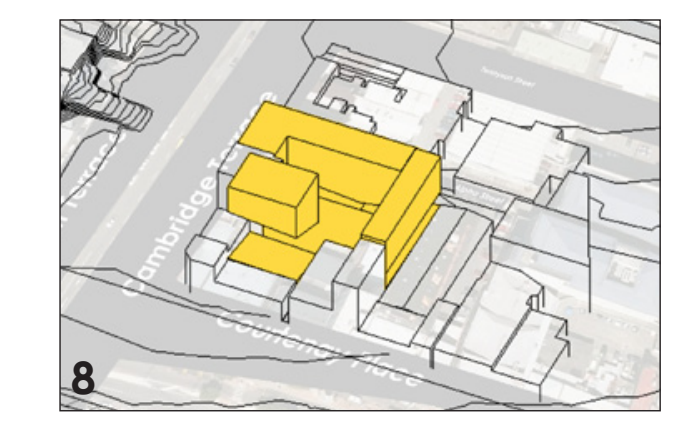

Raised internal platform over the entire area: does not increase the amount of sunlight to the area.

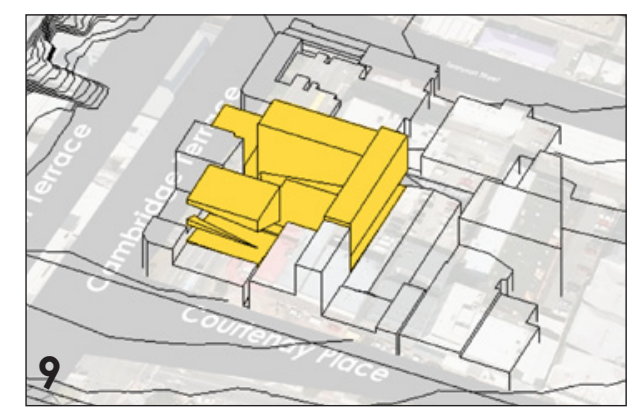

Figure A.05 Sequential massing design iteration
Lowering of perimeter buildings to properly respect the existing fabric. 

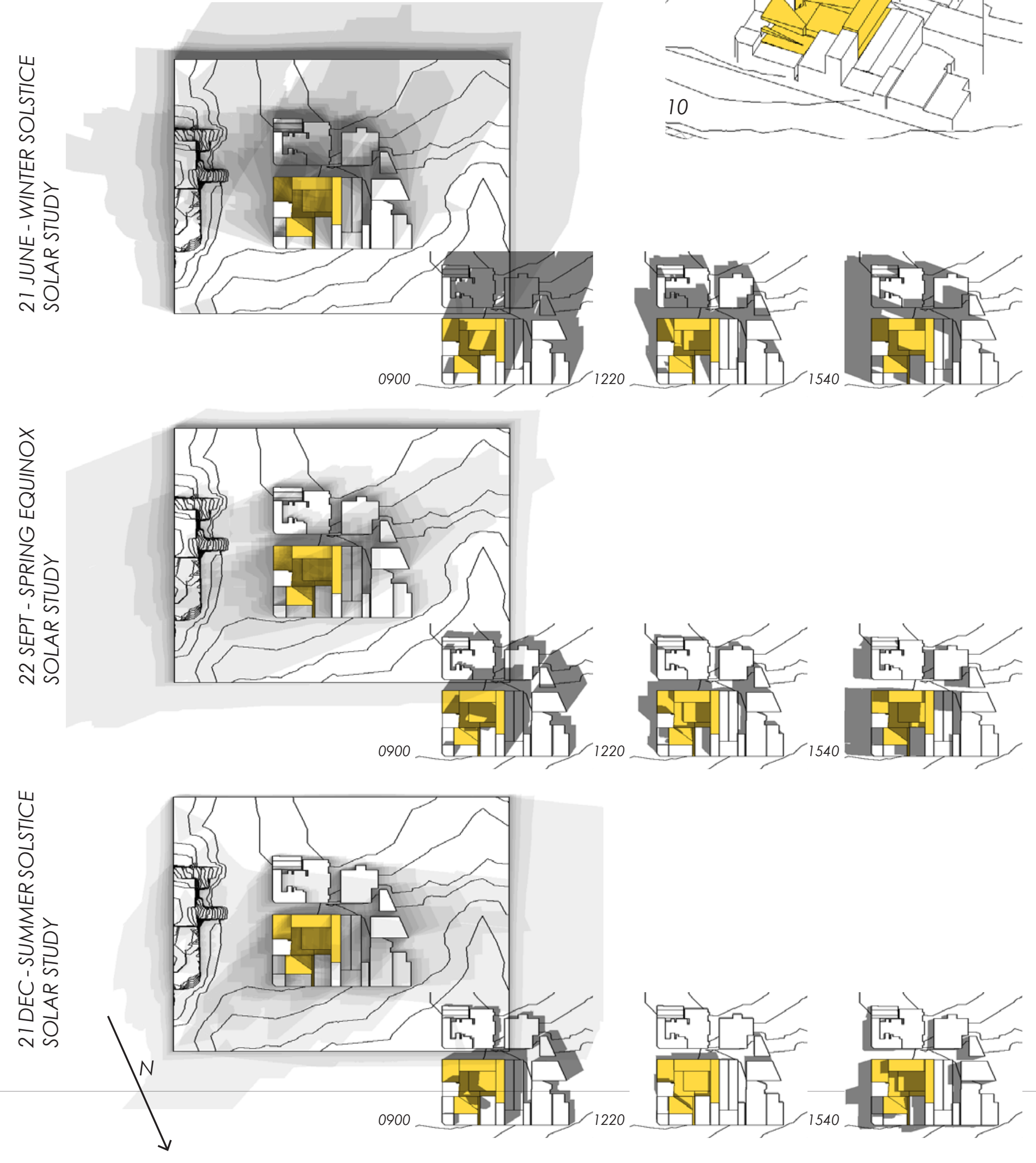

- PUMARacy addressed within the

develop

- Dramatic

- Staggered massing heights along

Alpha Street are respectful to the

existing context

- Lowered northern building, while still

maintaining year round sunshine into

the design, comple

Figure A.06 Fina context response

- Raised platform/park

Within correct volume range to

create high density housing

- Natural access points suggested from

Alpha Street and Courtenay Place

massing for

design iteration one tested year
and day round. achieved in apartments 
A.2.1 Design Test Two Additional Drawings 


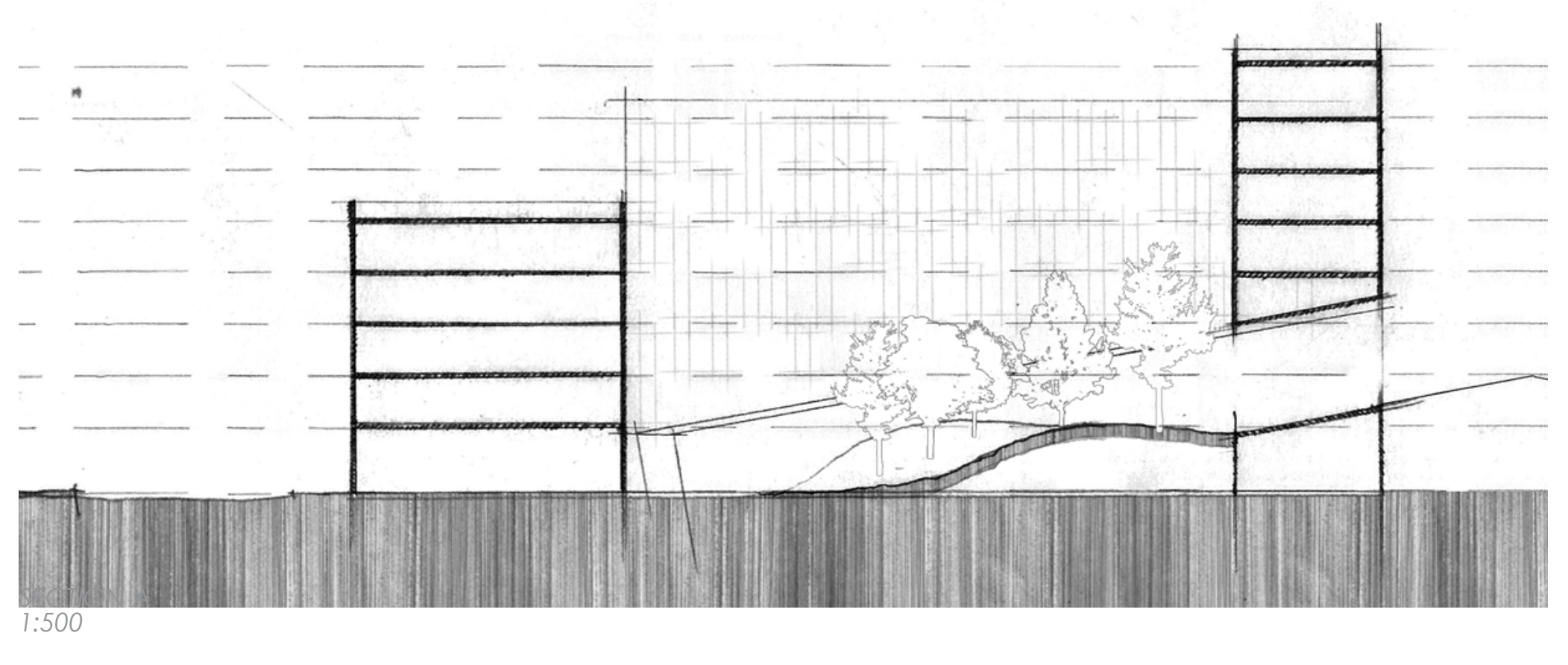

Figure A.07
Section cut EastWest through the site showing rising to increase solar access to the central planted
courtyard area

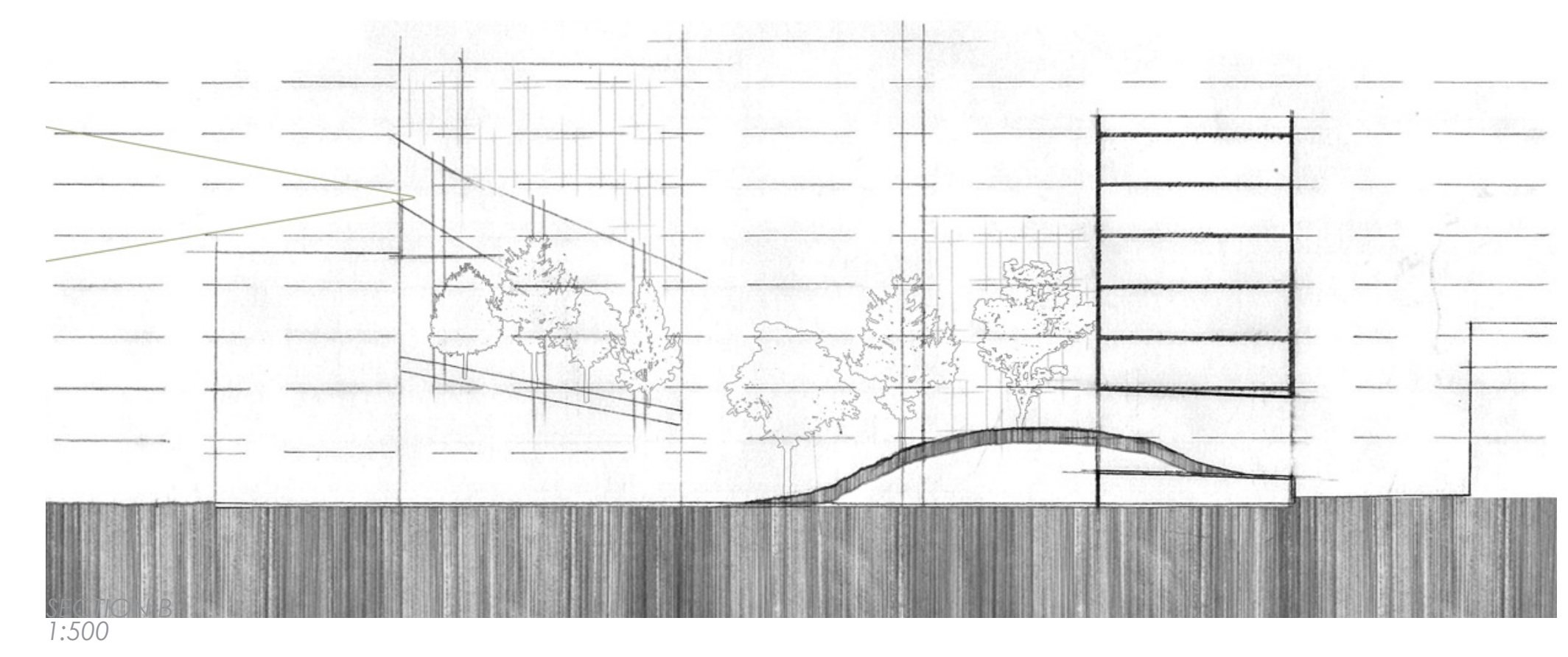



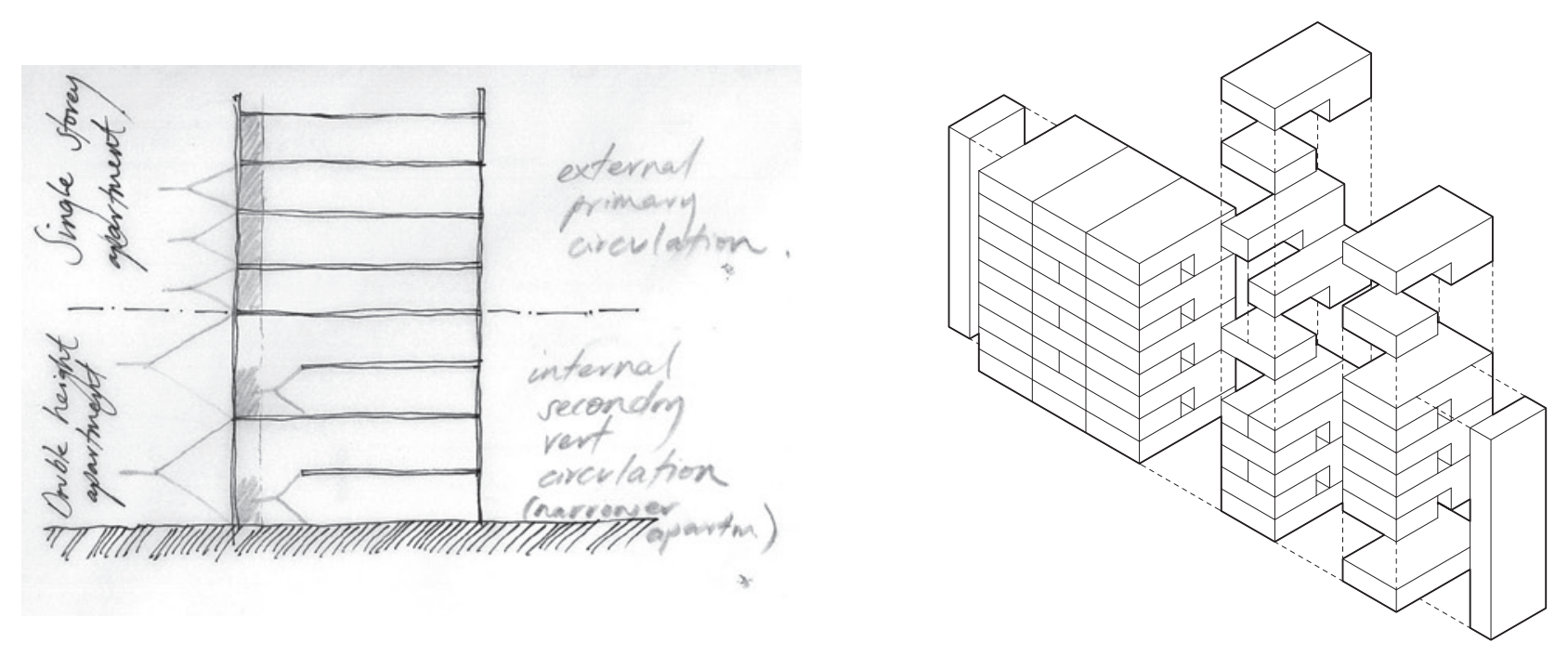

Figure A. 10

relation to unit

世

Figure A. 11

Exploded isometric

of circulation

system scheme
this

$\longleftarrow$

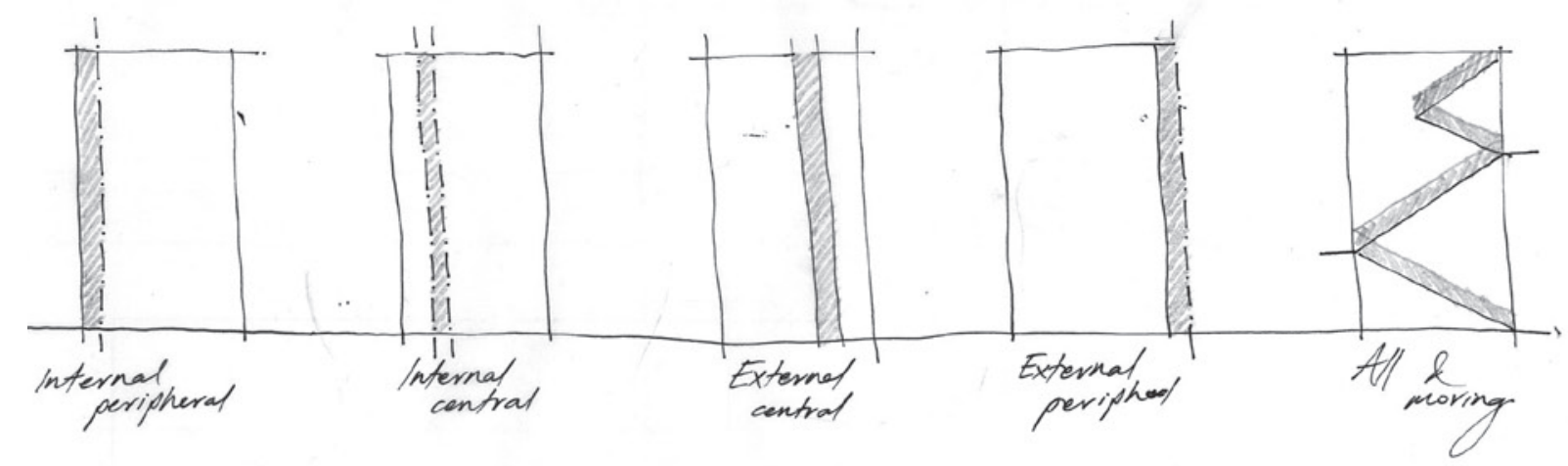

Figure A.09

Circulation studies

options

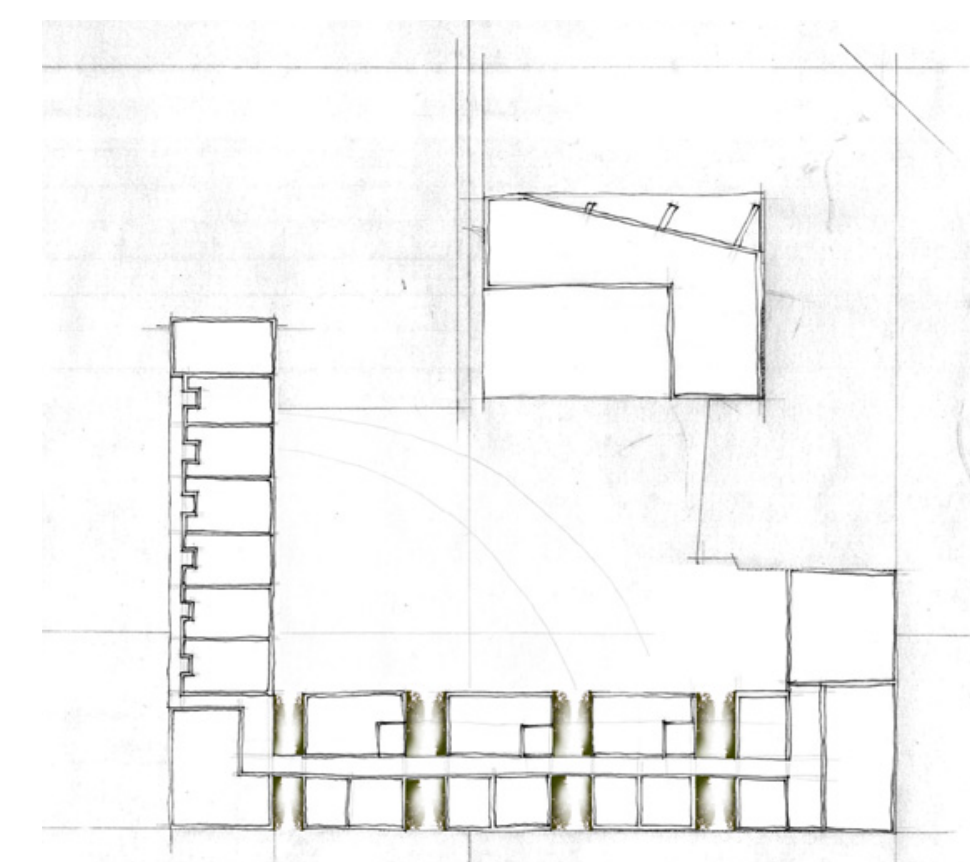

Figure A.13 Lower level plan showing vertical green vertical green
spaces in relation to units and circulation

Figure A. 12

Typical floor pla

study, testing

between unit and

circulation

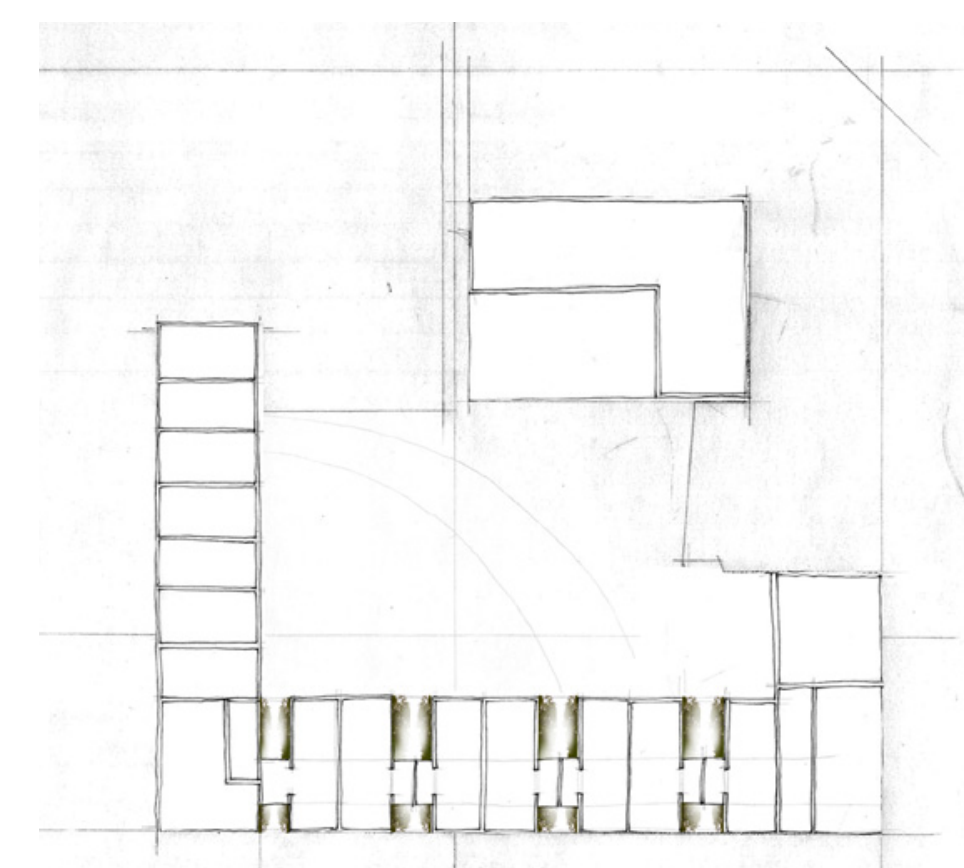

$=$

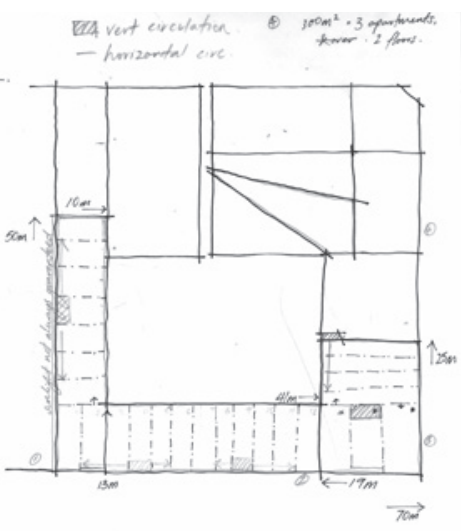

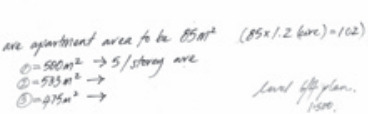

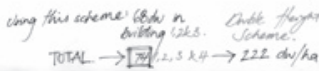


A.4.1 Design Test Four Butter Paper Design Development 

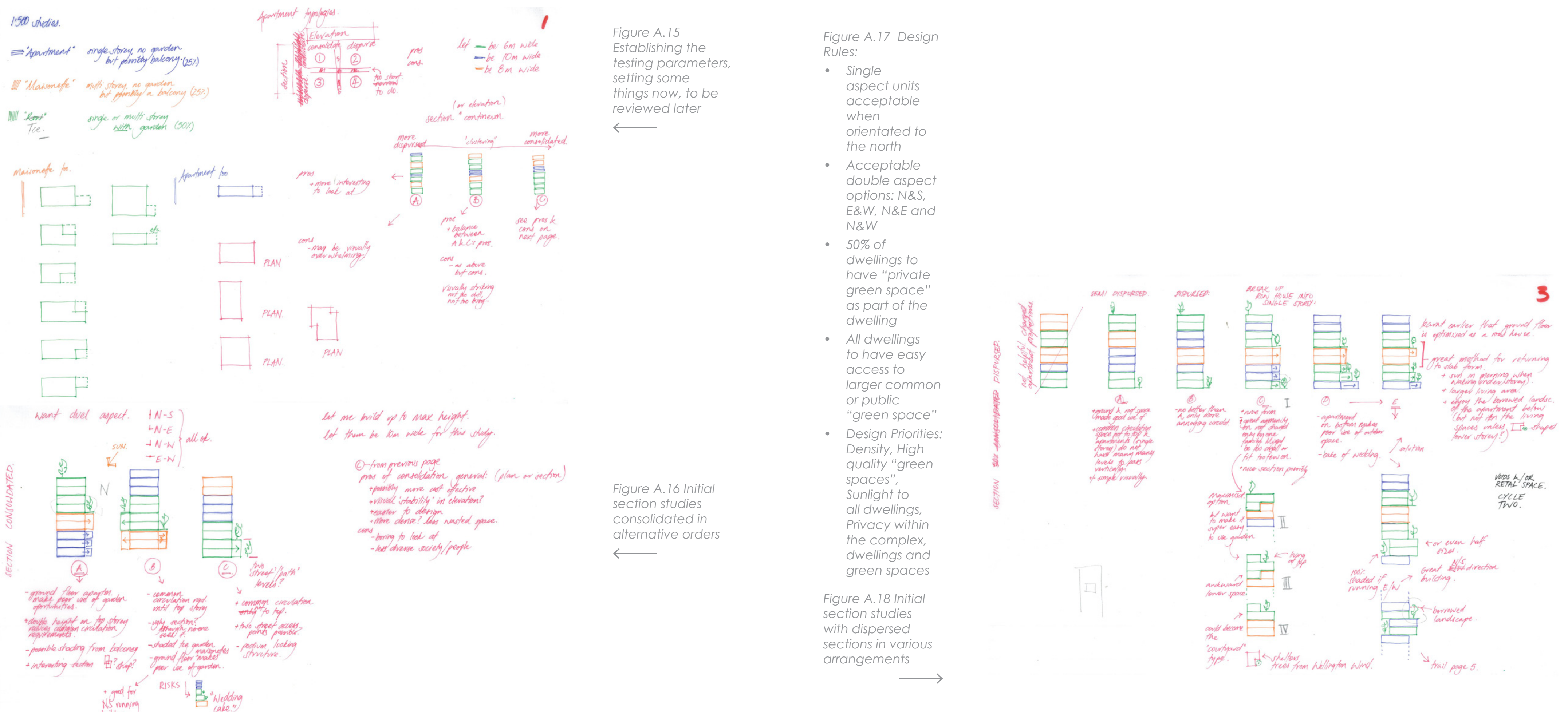

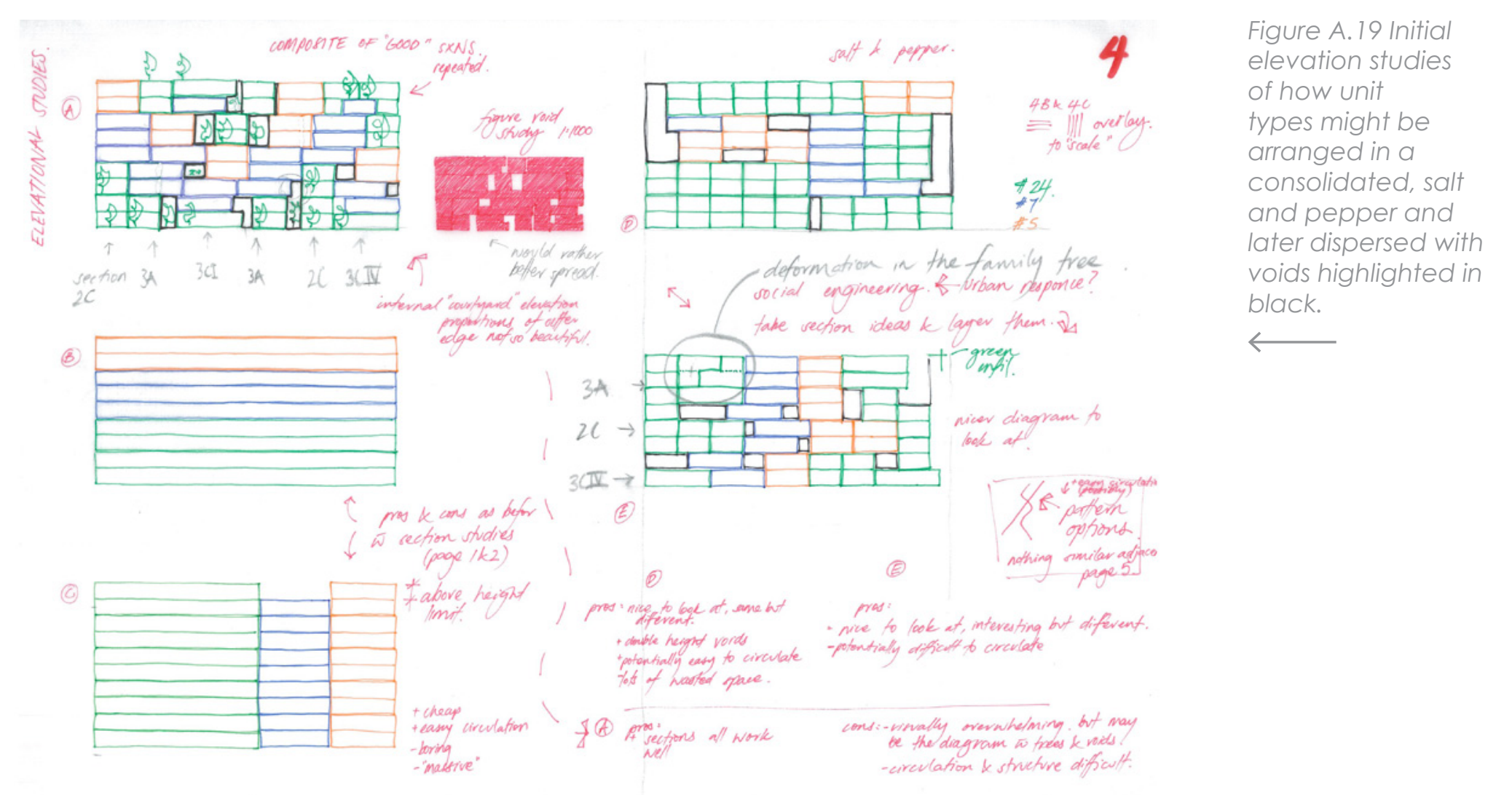

Figure A.22
Elevation studies
of how unit
types might be
arranged with
voids hightlighted
in black. Top right;
the development
of a $3 \mathrm{D}$ reading
system where
means an offset
towards, and -
means an offset
away to create the
sections below

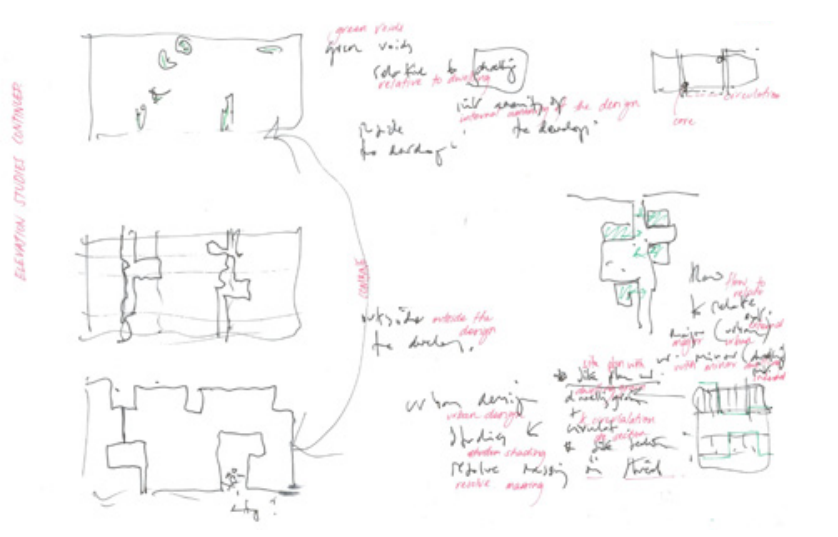

Figure A.20
Supervisor student
conversation
regarding
circulation in green
spaces
$\longleftarrow$

Figure A.21 Unit

ye observations regarding services. circulation and green space elationships
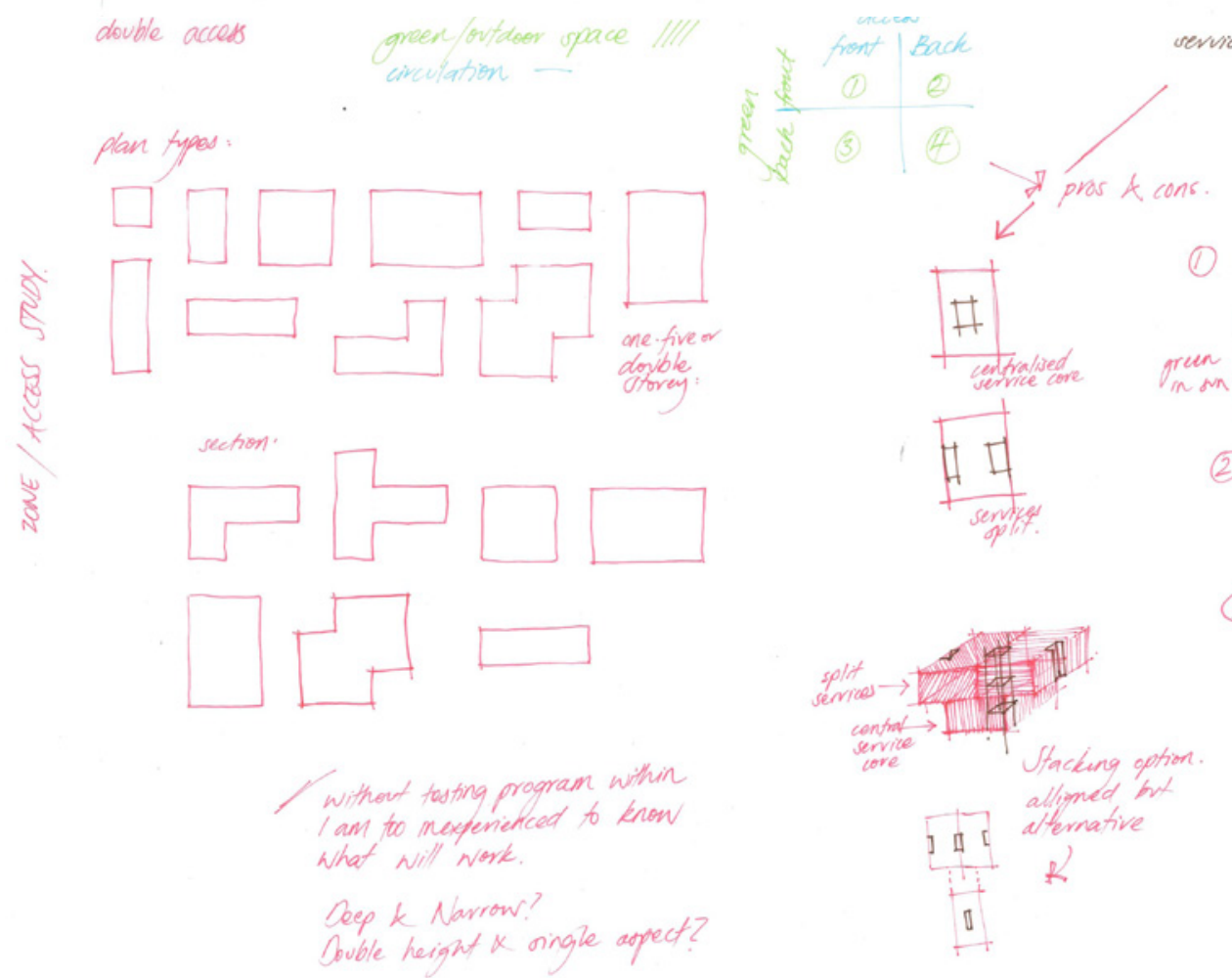
shaded areas.
+orod place for

- cun enrourage a

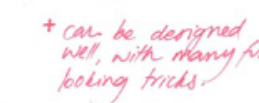

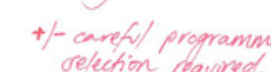

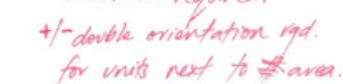

tomajor moveres read. to

造

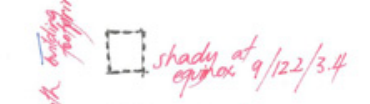

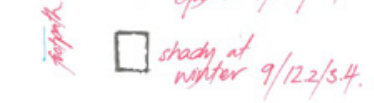

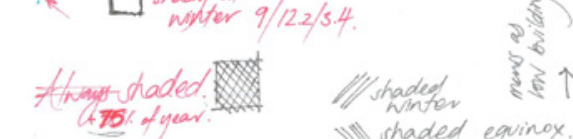

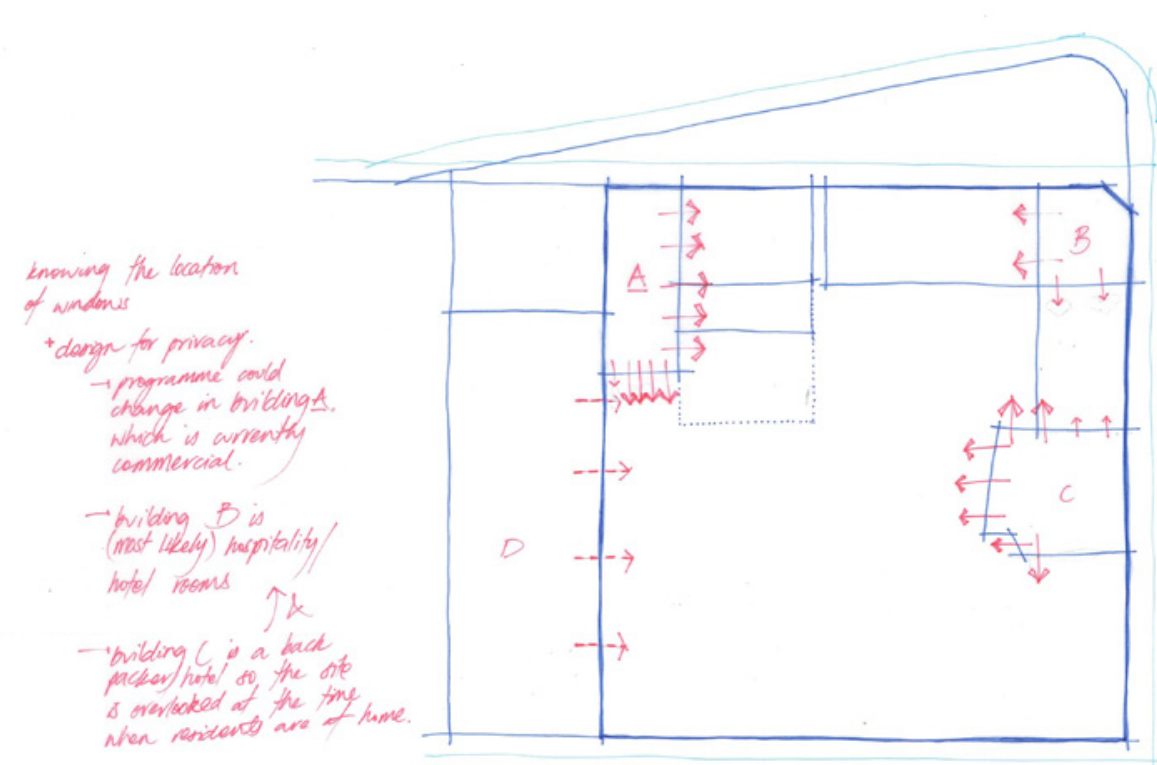

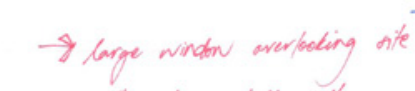

$\rightarrow \rightarrow$ mall Ninden werlating

D bribing O may be develiped (stad DIN
Figure A.23

existing site solar

study at 0900, 1220

and 1540 during

and winter solstice

$\longleftarrow$

8
Figure A.25 Site

arrangement

options plan

analysis

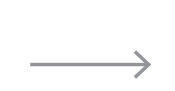

gure A.24 Site

privacy study
highlighting

views of site from

adjacent buildings.

include building $D$

as it may be bu

building away from

this edge will future

Figure A. 26

future site access
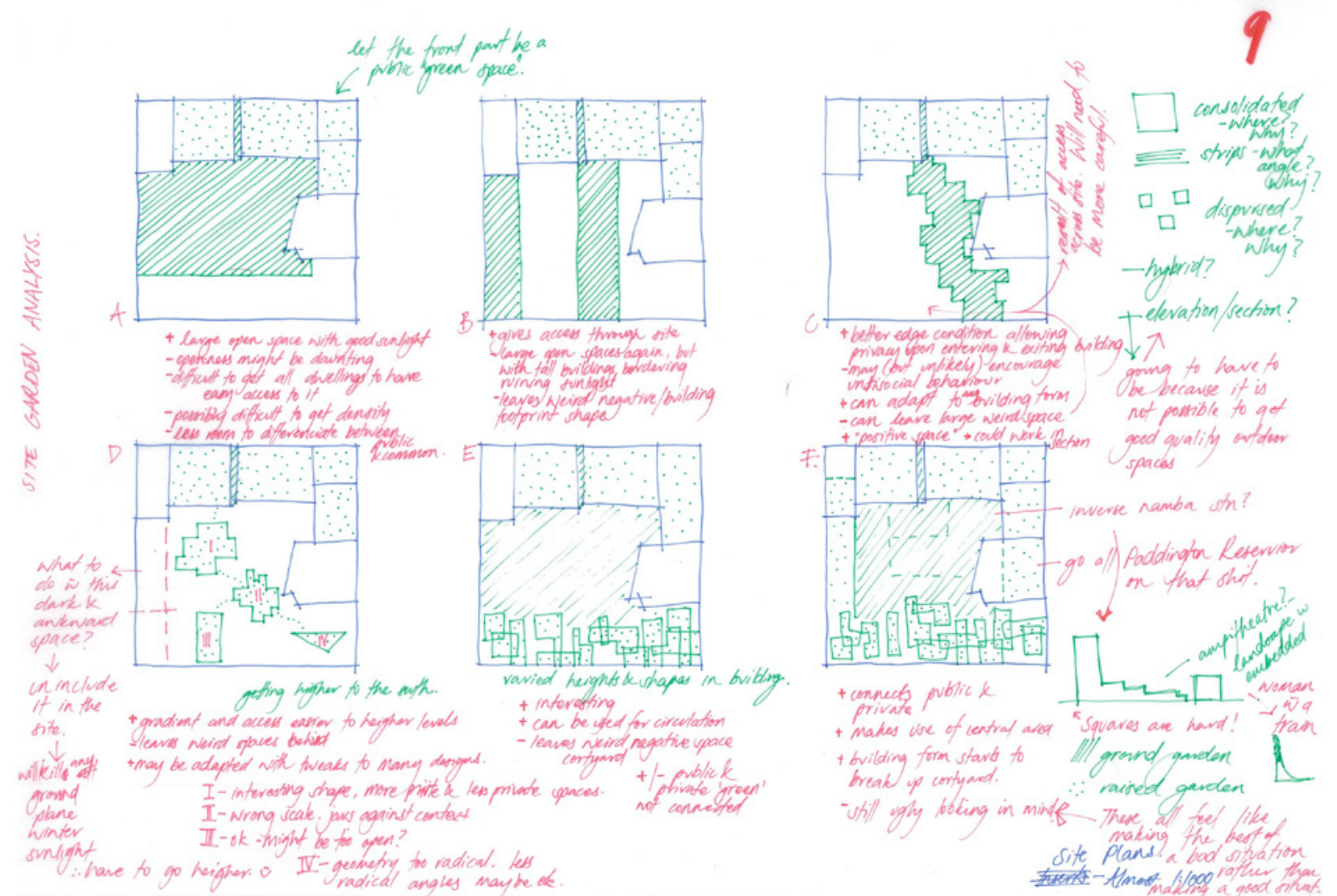

opportunities

$\longrightarrow$

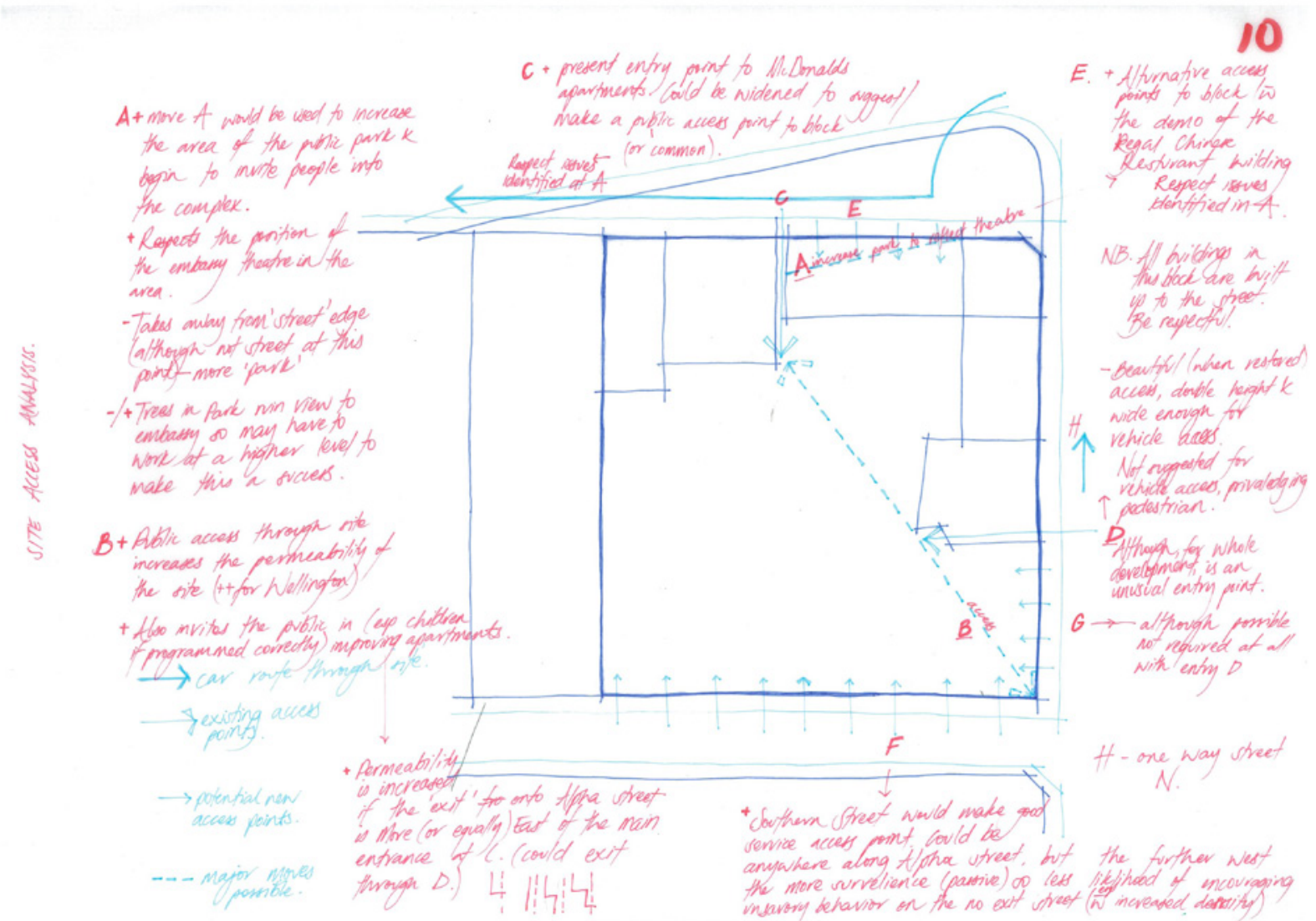



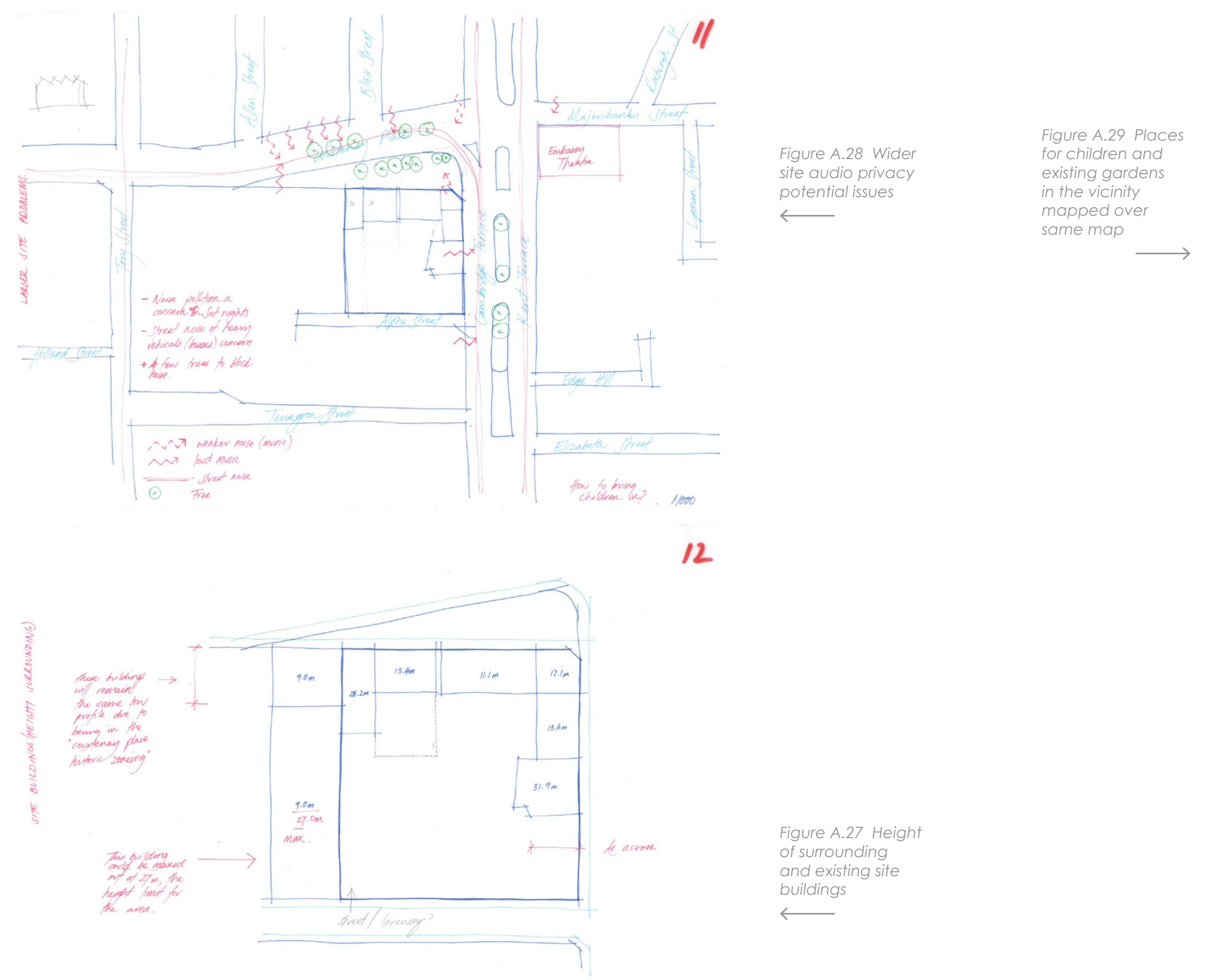

Figure A.27 Height

of surrounding

buildings

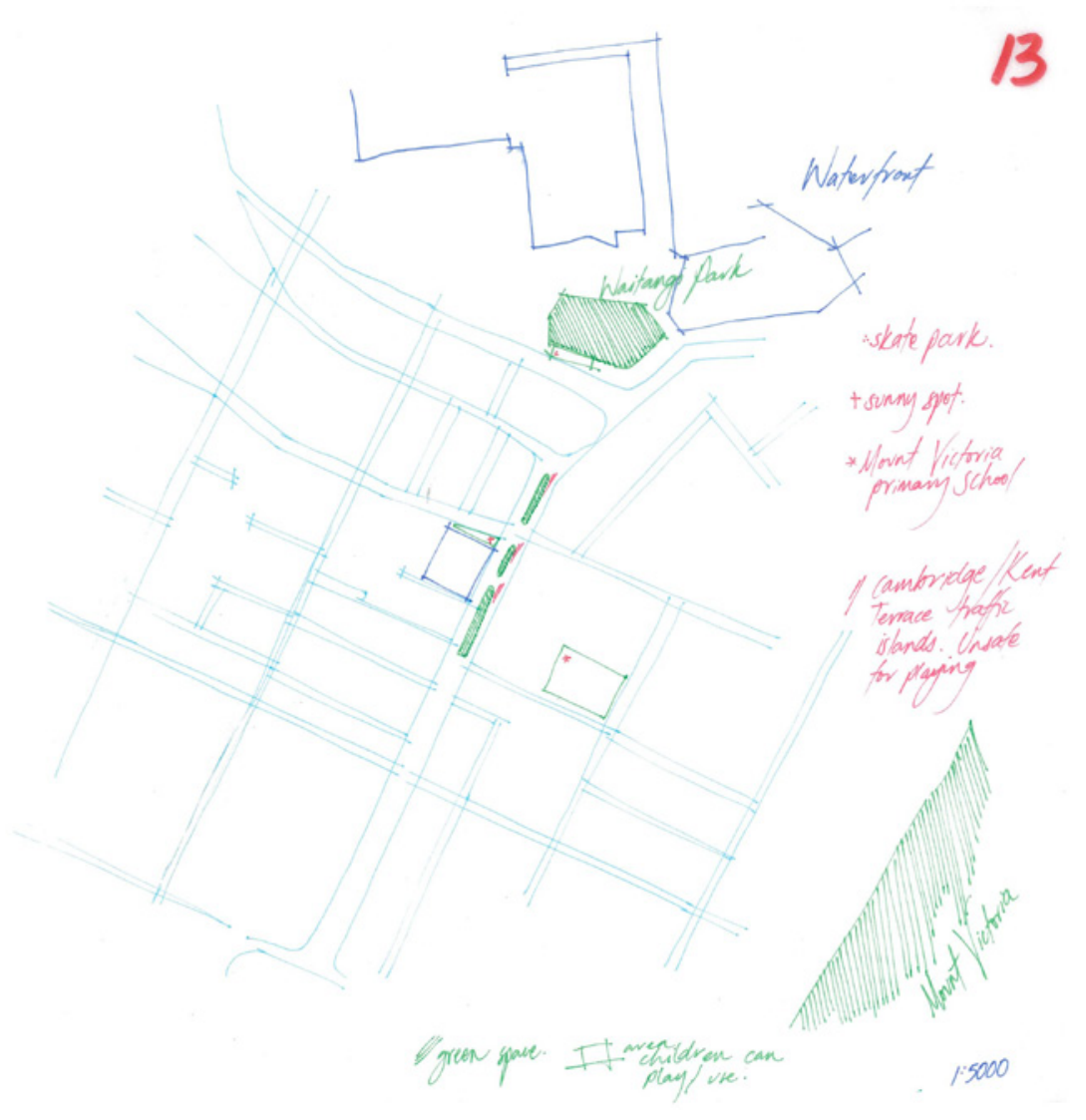



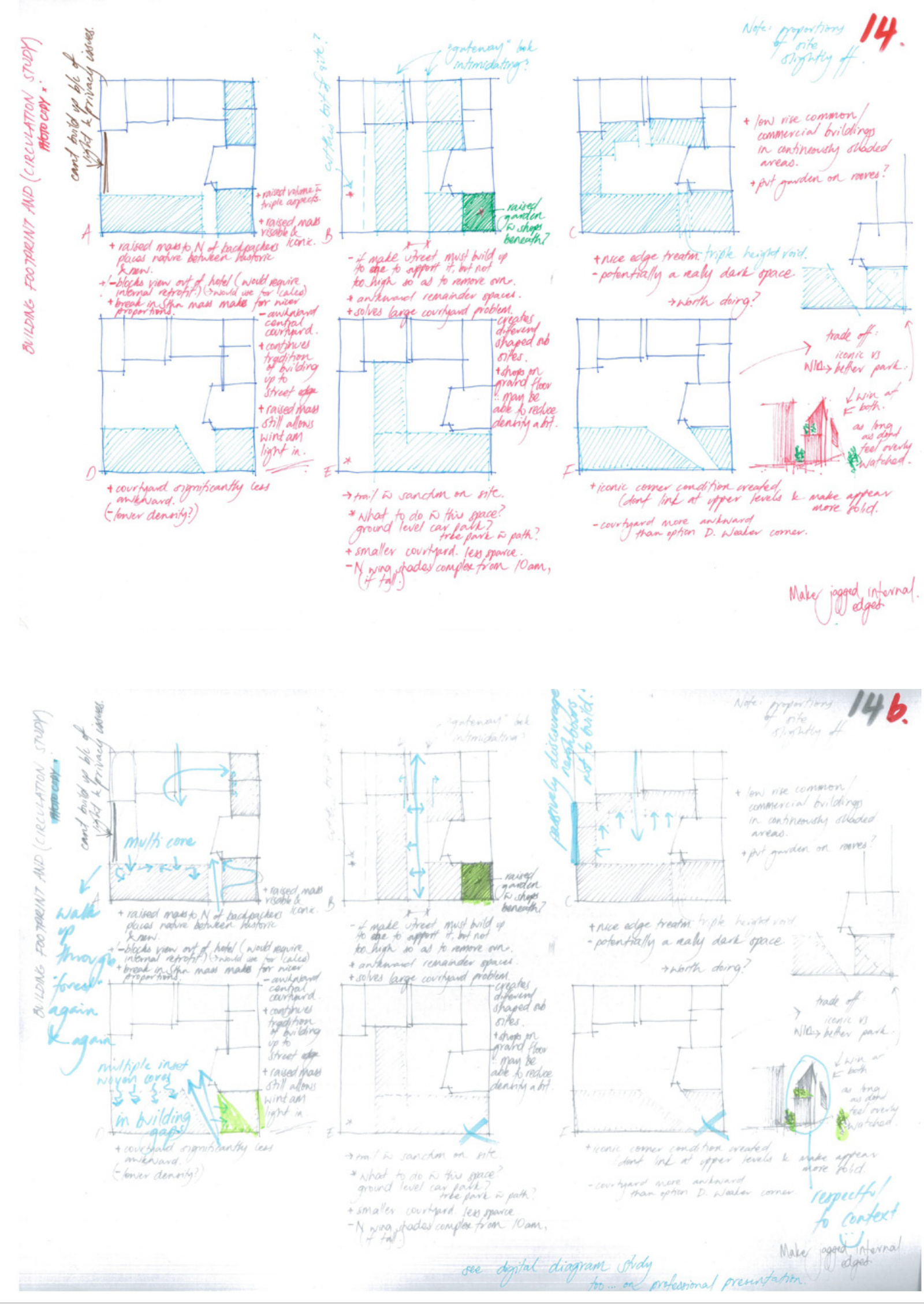

Figure A.30

study nestled within
the existing fabric

$\longleftarrow$
Figure A. 32 design (design on page 14)

Figure A.33

Designing for an

teonic moment

of context View

taken from
Cambridge

Figure A. 31
Building footprint

study in relation to

circulation

towards Courtenay

Place

$\longrightarrow$

$\longleftarrow$

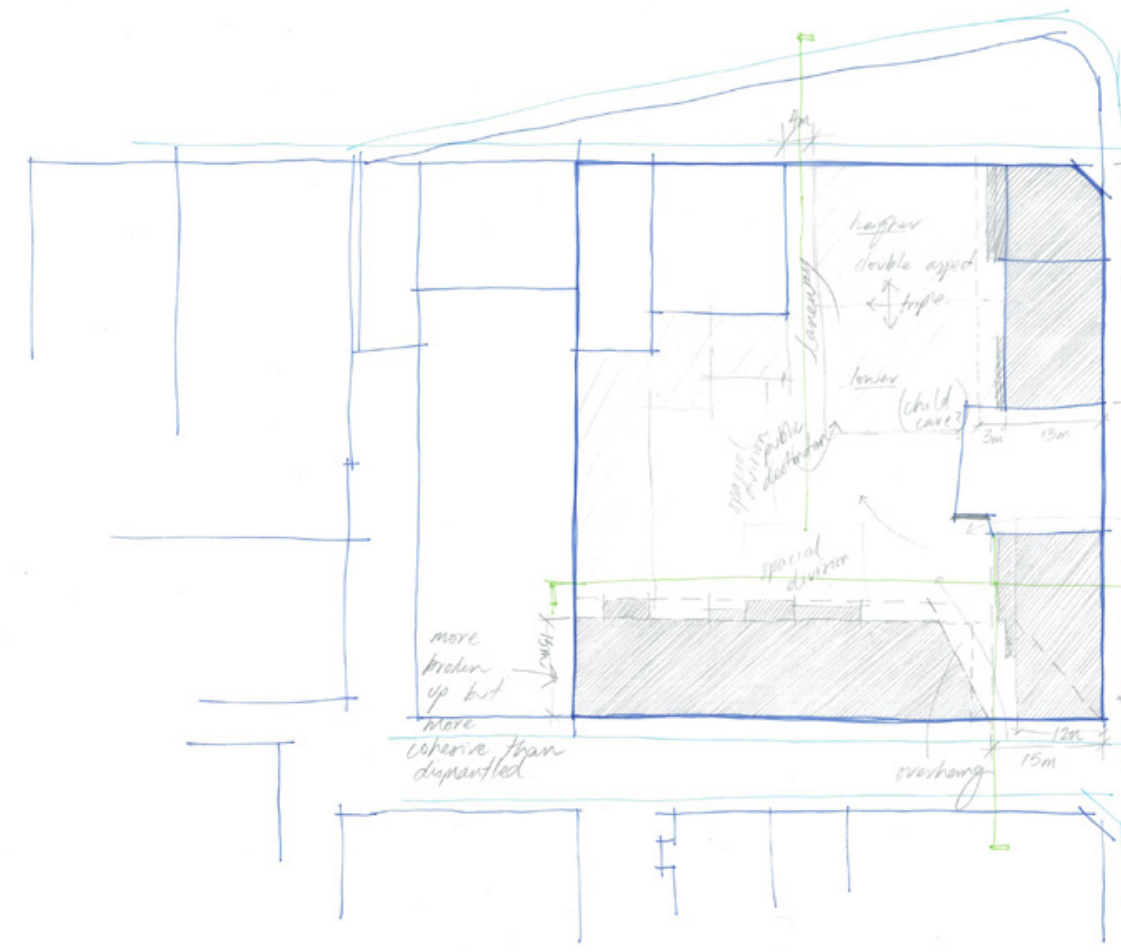

15.

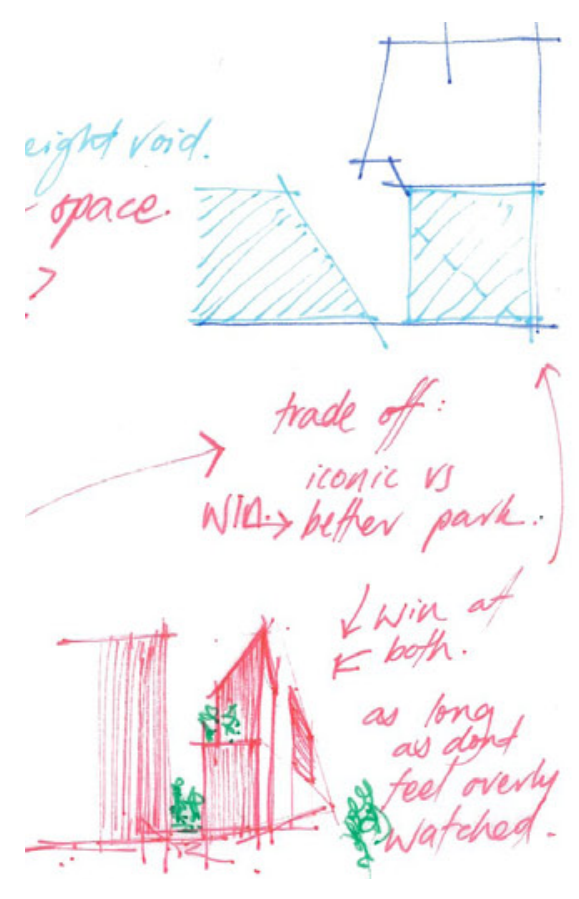



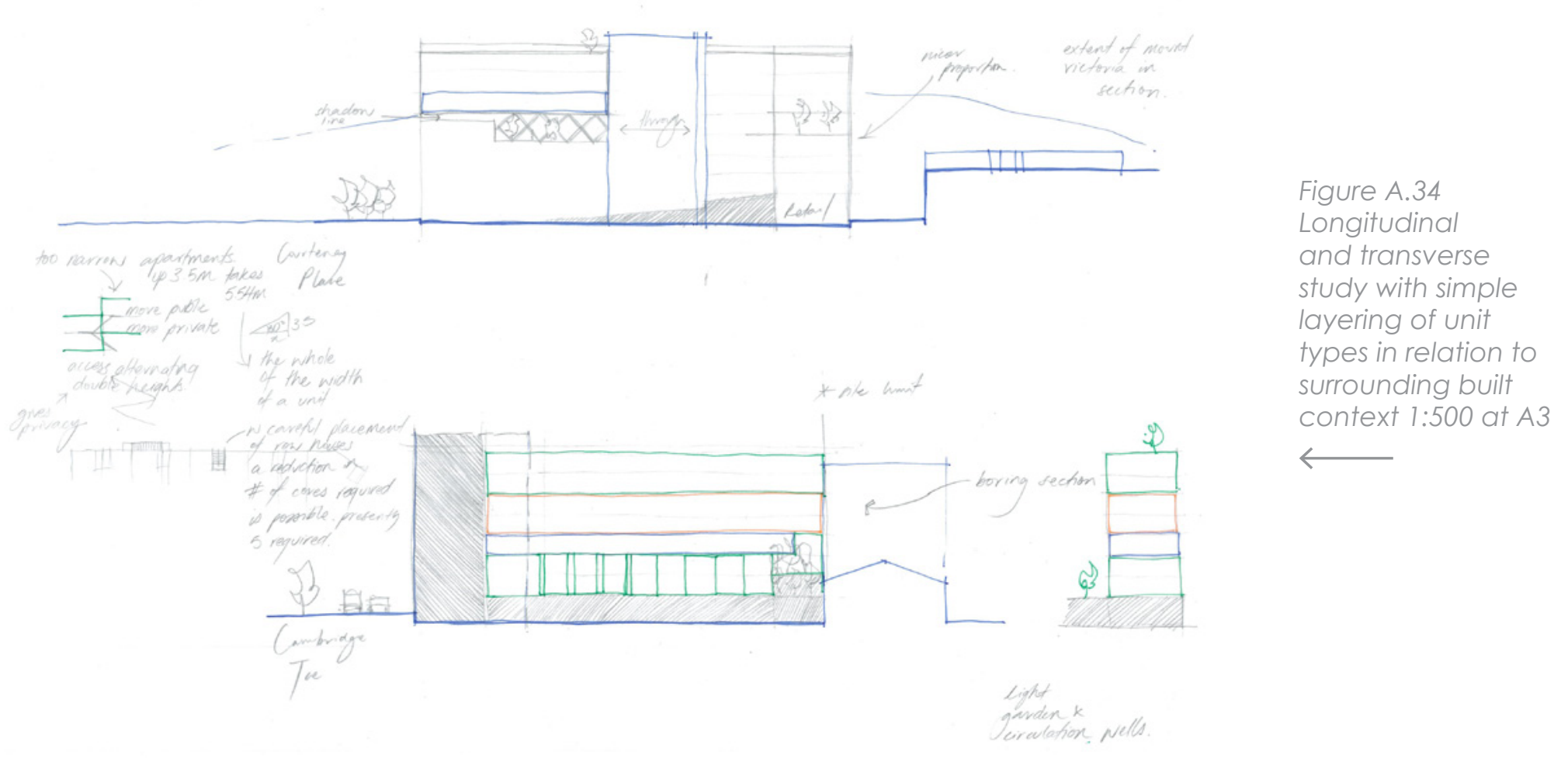

Figure A.36 Unit

external access

with multiple cores

and double heigh

Units. Circulation is

lots of it forming a

poor space ratio

compared with

1:100 at A3

Figure A.37 Inset

of Manhattan

Loft Gardens

source $h+t p \cdot 11$

.

com/248753/

ardens-som/
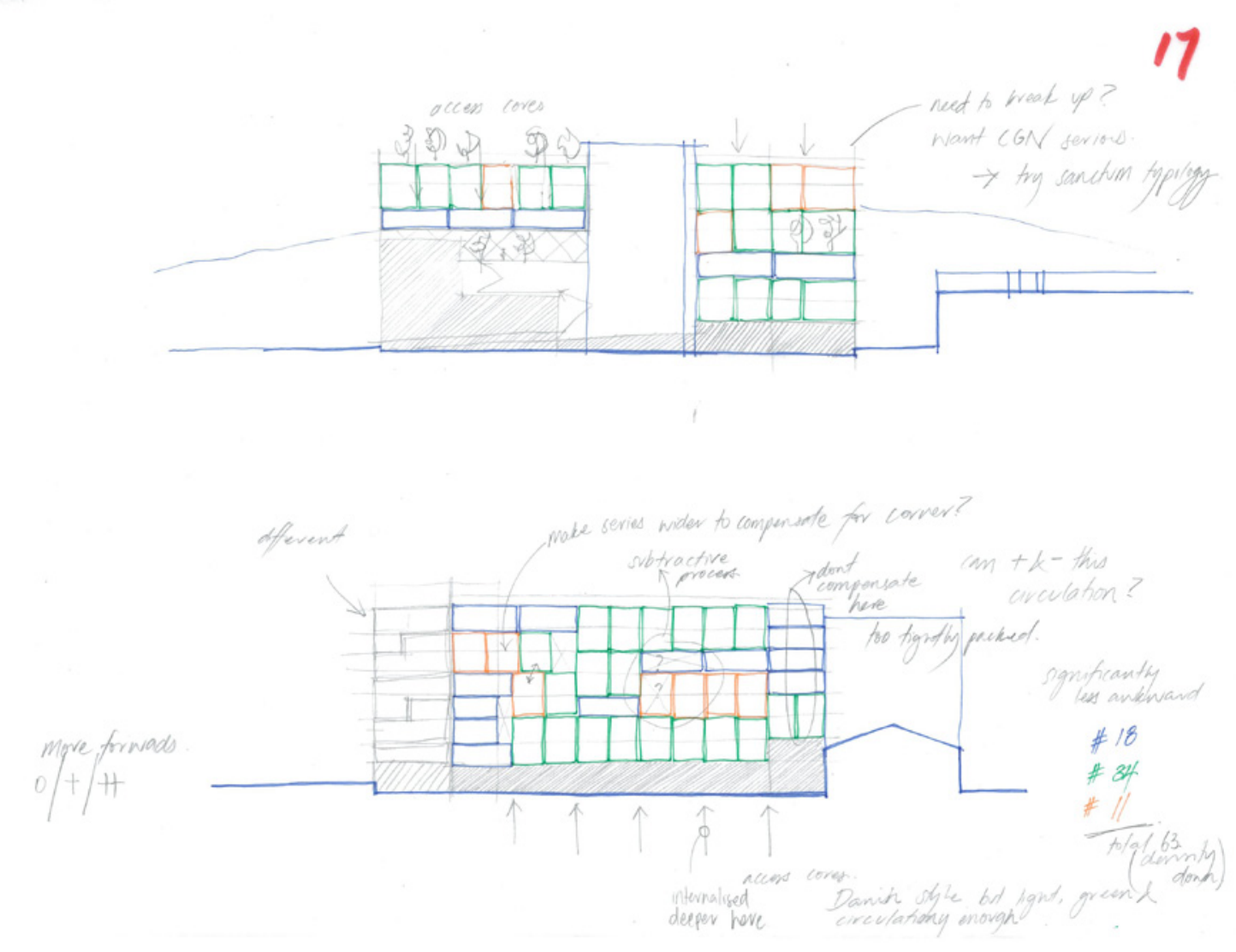

Figure A. 35

transverse study

with salt and

peppering of

types in relation to

surrounding built
context 1:500 at A3
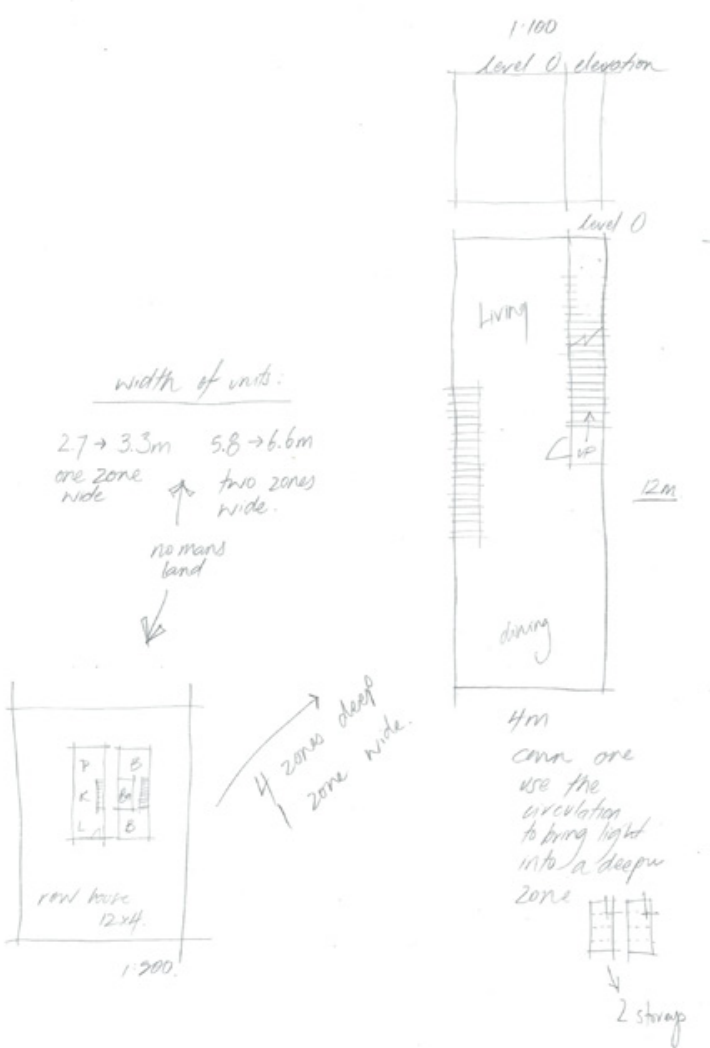

windmpotionity

gardens-som/

Figure A.38 Study

plan options to

provide interesting

suburban like

plans. Based off

Loft Gardens' by

OM. Knowledge

used to establish

expected $m^{2}$ of

each unit. This

typology takes up

fewer apartments

performing poorly

under the density

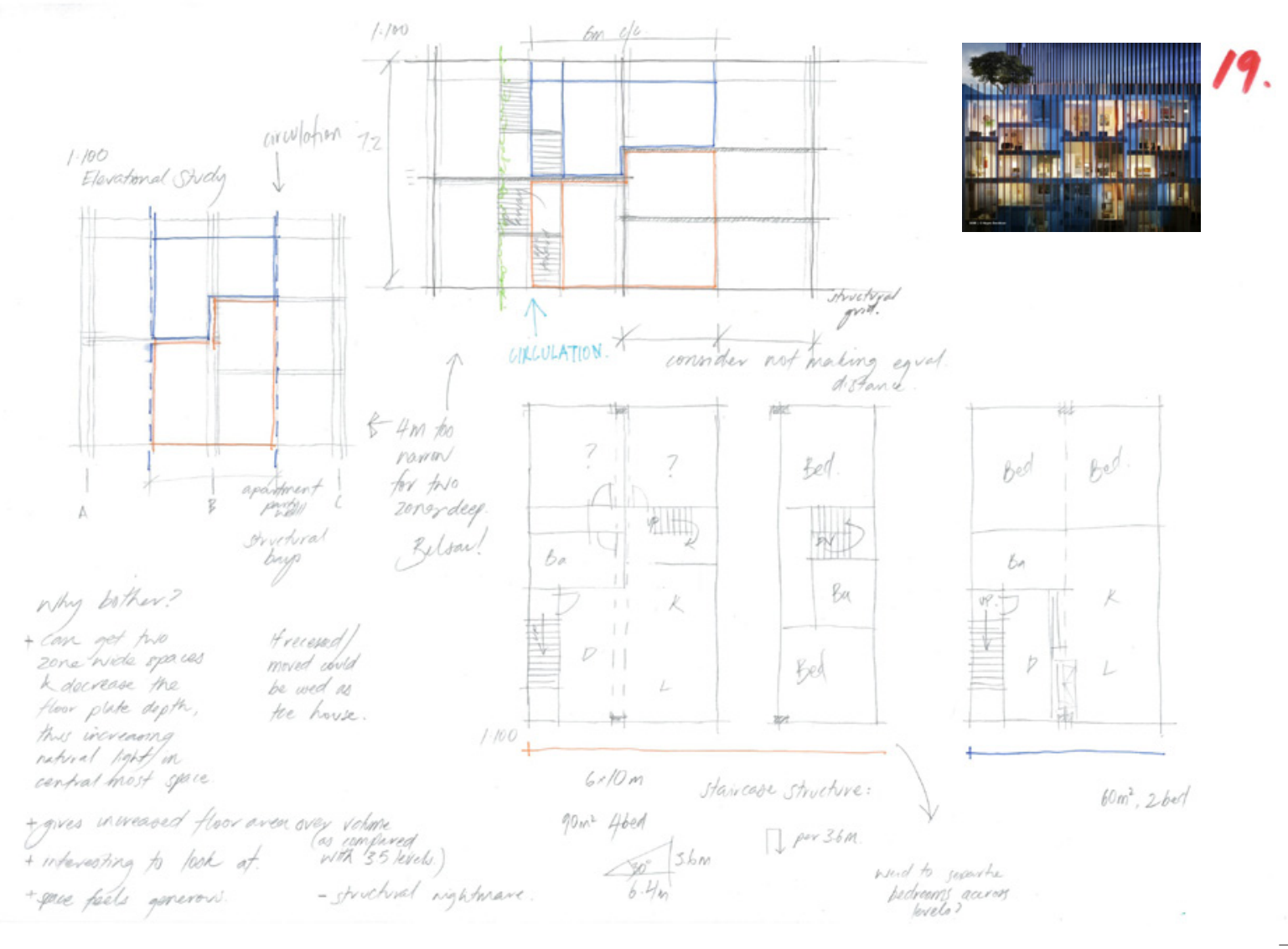



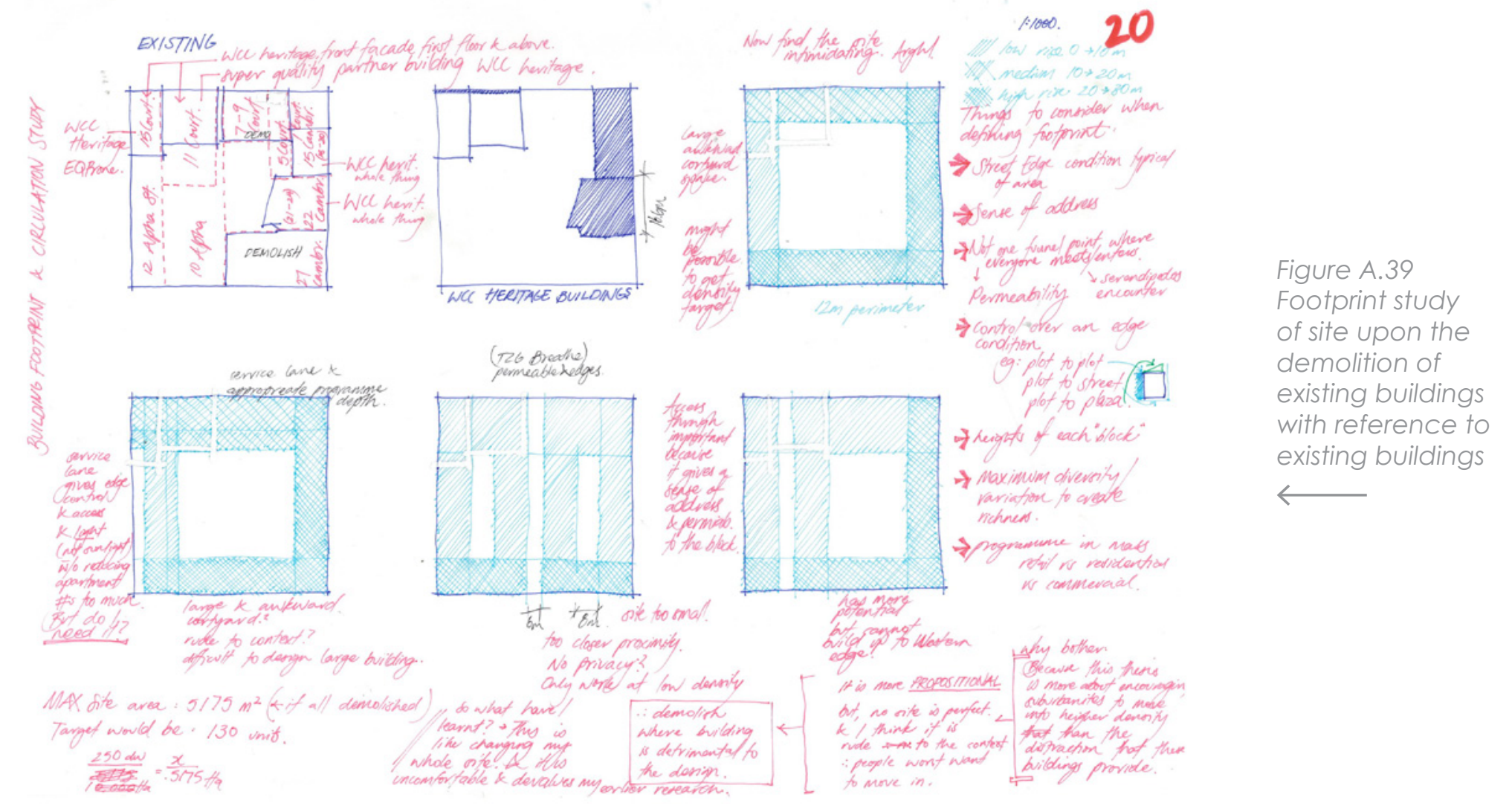

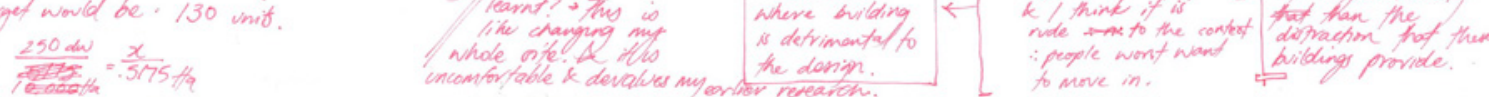

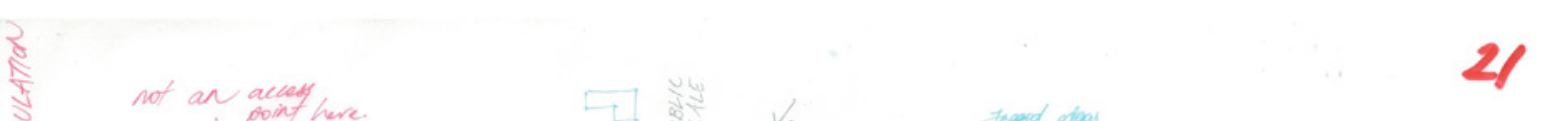

Figure A.40 Furthe building footprint studies

keep faceade or jos the musing.

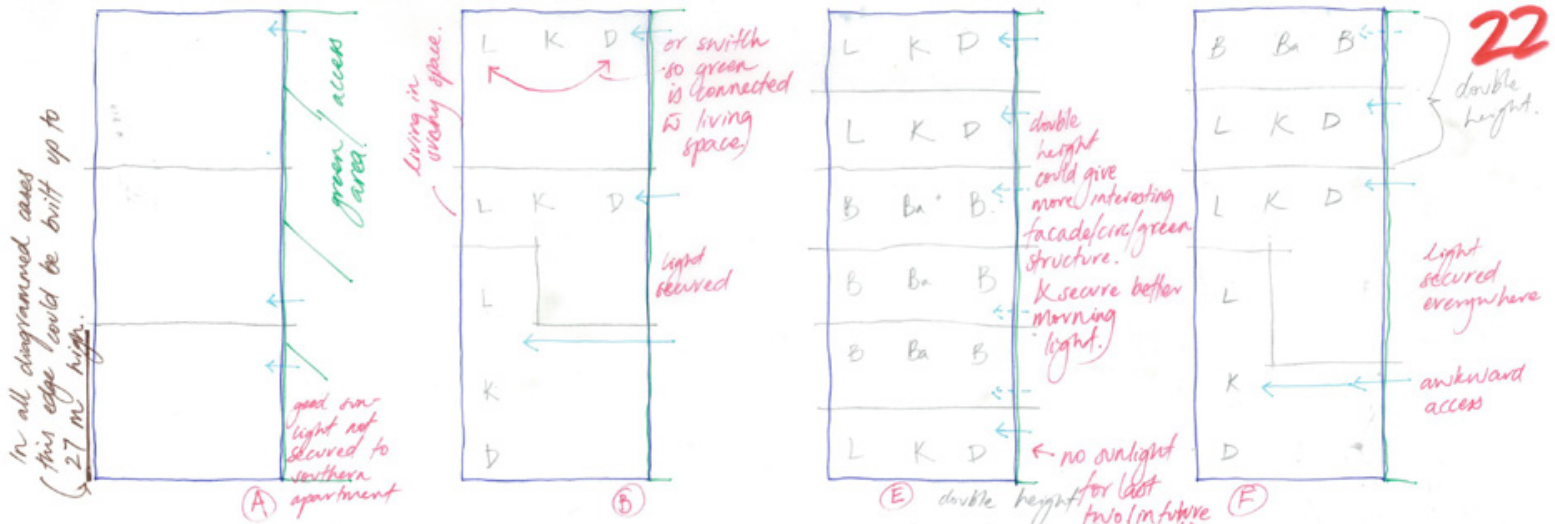

Figure A.42 Take Adelphi Finance building on north eastern most

Plan studies to establish different circulation/access arrangements $\longrightarrow$
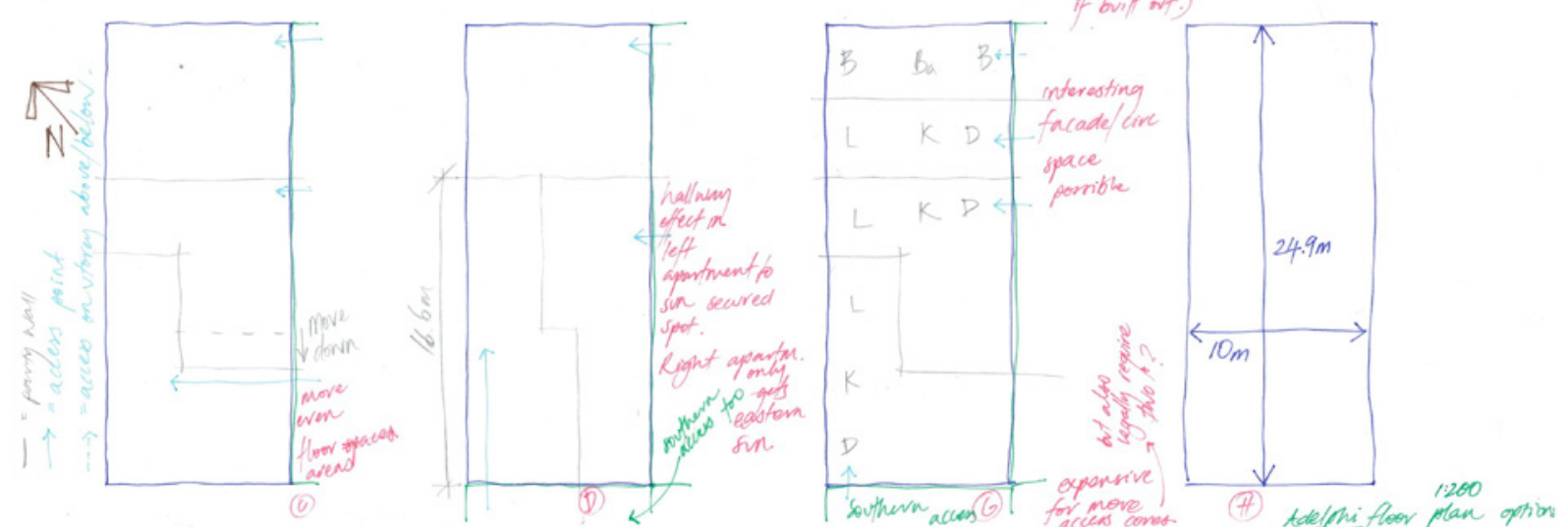
Adelphi Finance

Building 1:100 at A3

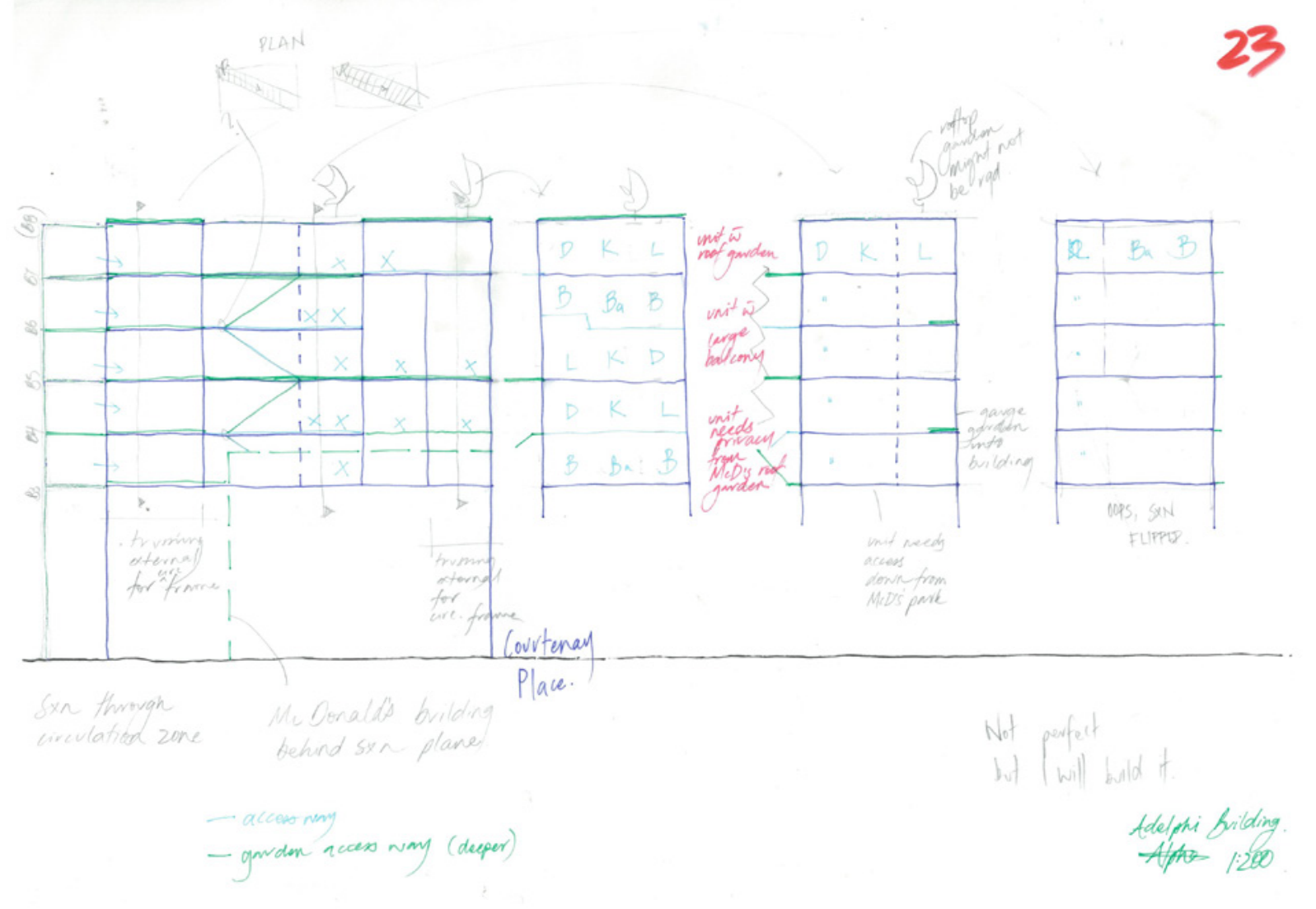



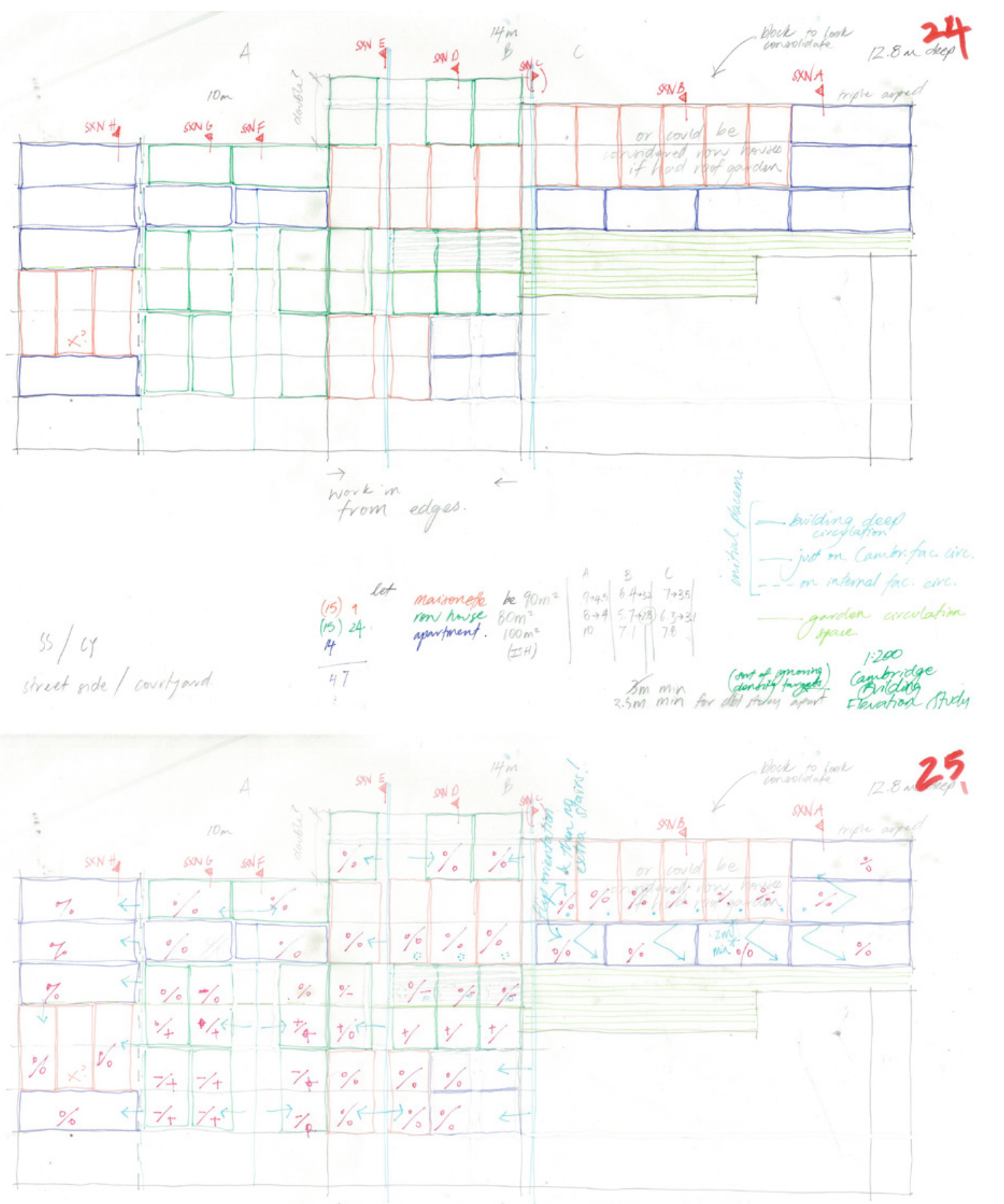

Figure A.43 Study
of Cambridge

Terrace block unit

types layout 1:200

$\longleftarrow$

Figure A.44
Extrusions of the

block in and out

of the page to

provide garden
and circulation

spaces to the salt

and peppered

$\longleftarrow$

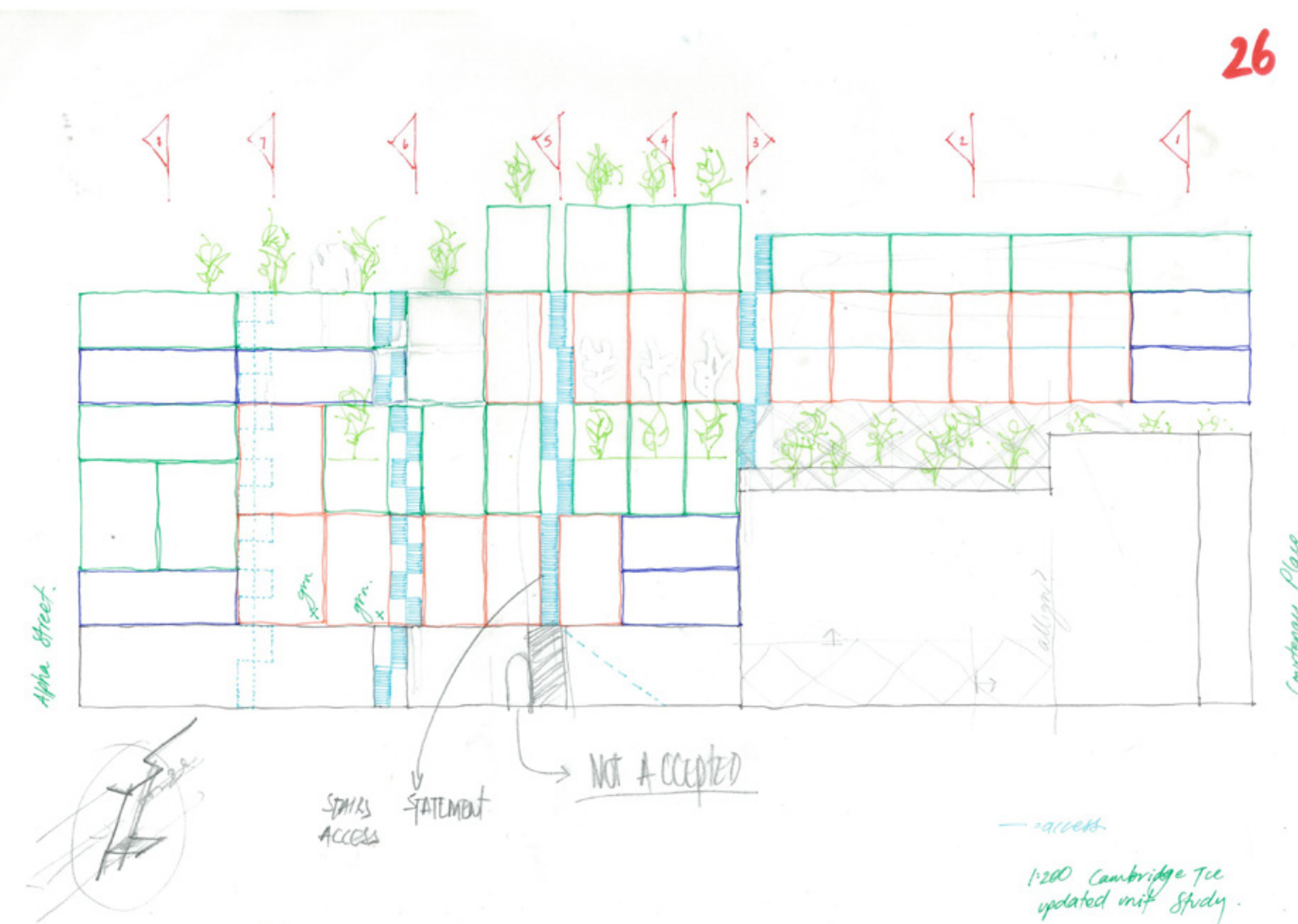

Figure A.45

Development

Terrace buildings to

establish location

where gardens

appear on the

facade 1:200 at A3

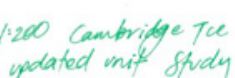




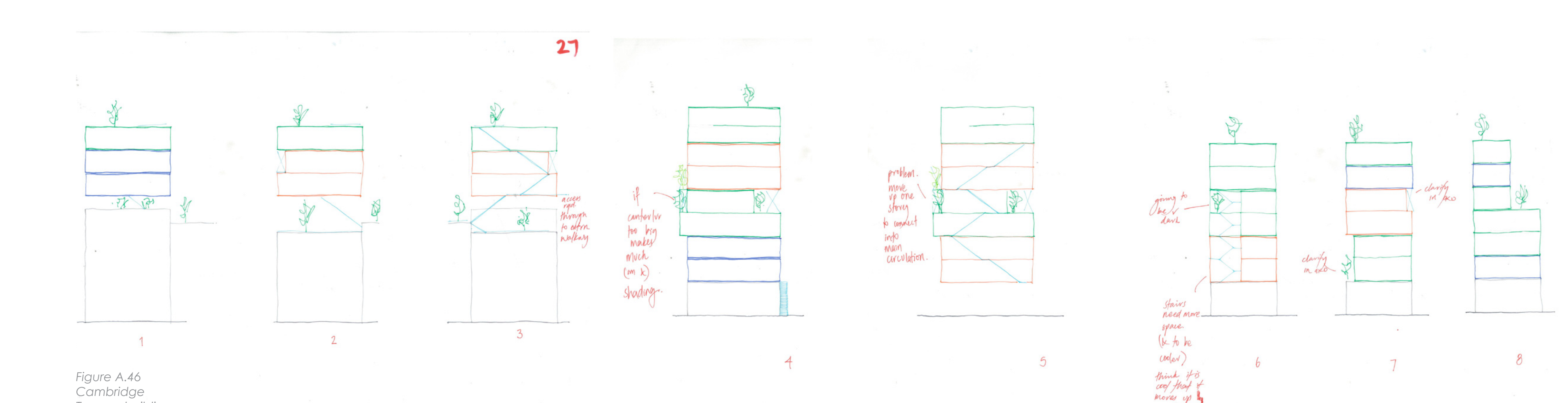



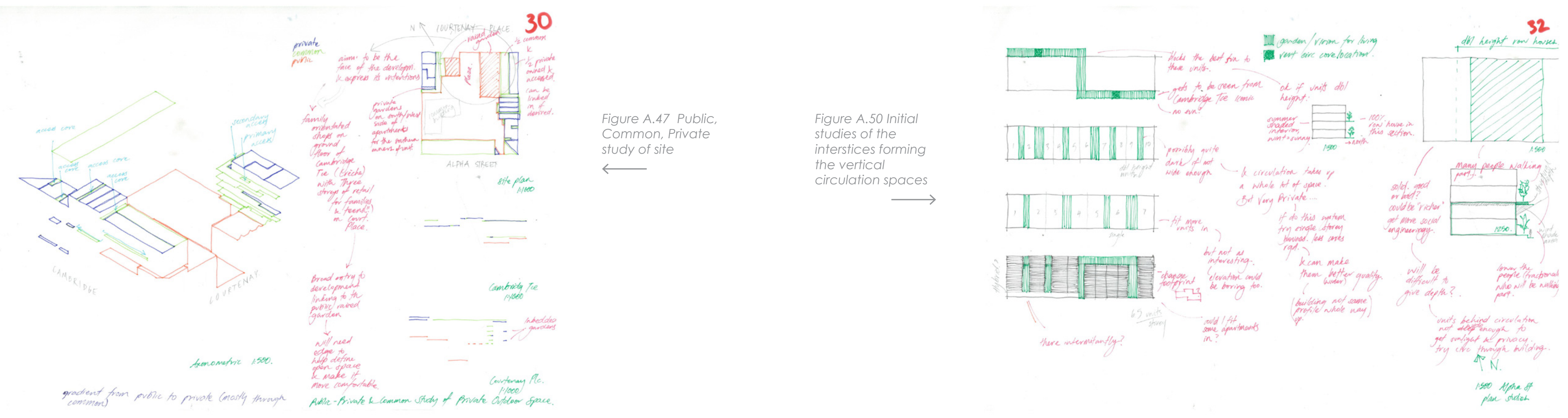

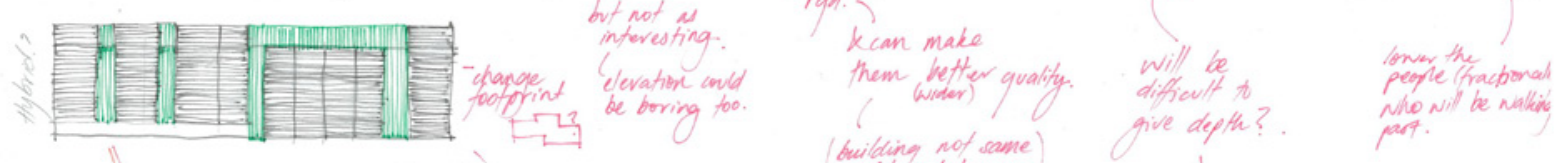

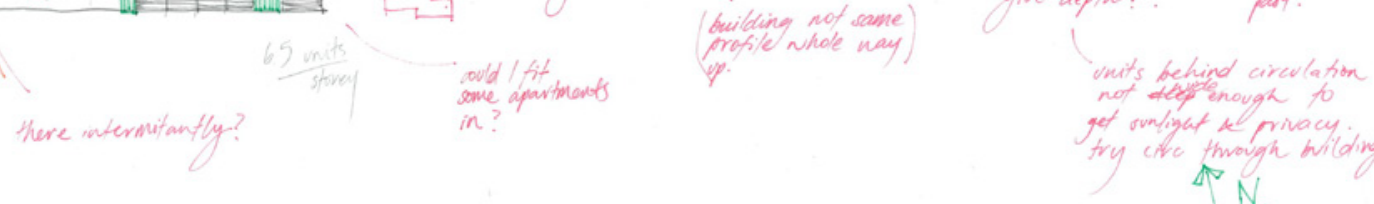

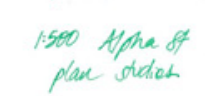

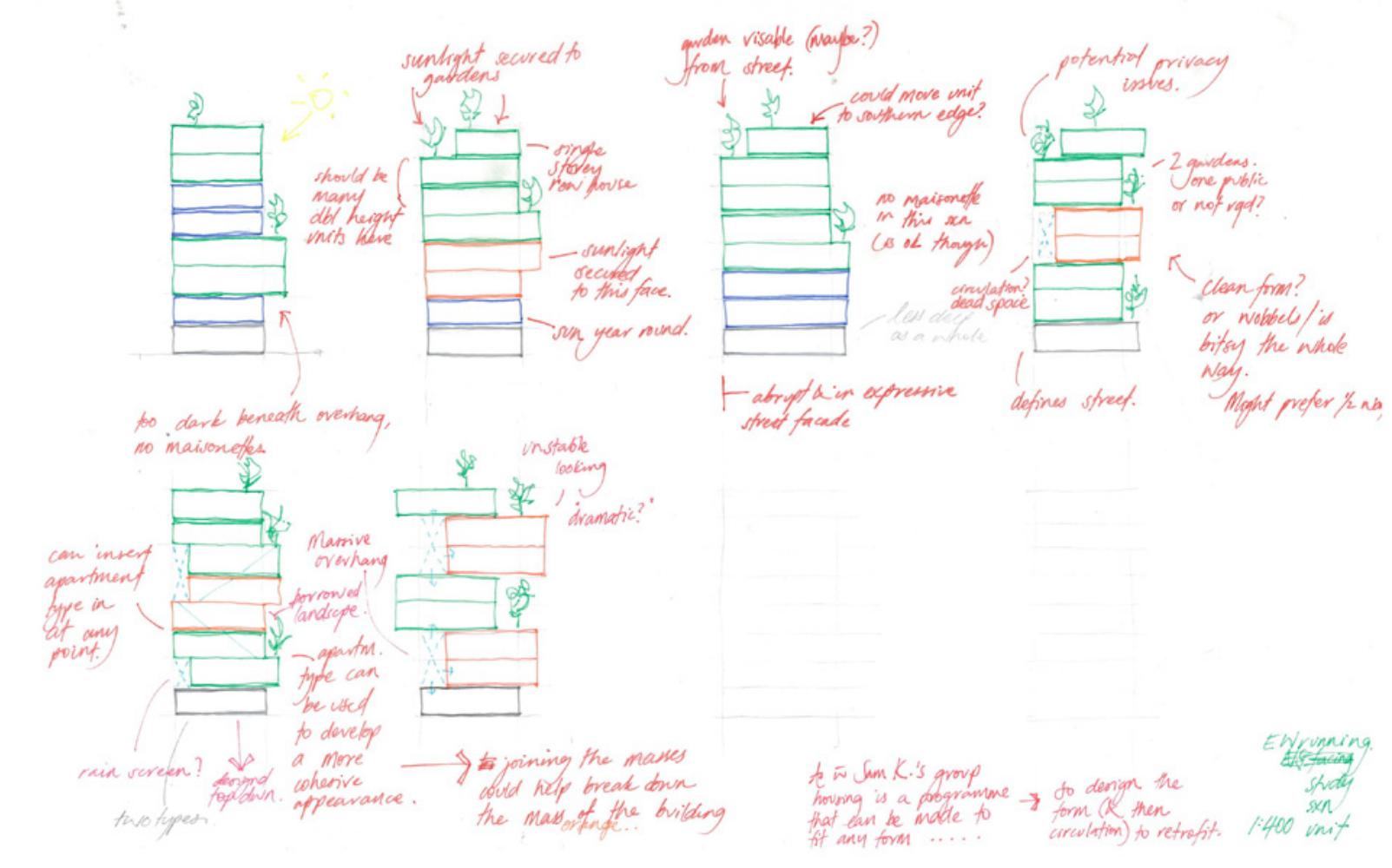

Figure A.48 Alpha Street buildings the north-south direction) unit $\longleftarrow$

Figure A.49 Study looking at the
articulation of circulation zones, with regard to solar access $\longrightarrow$

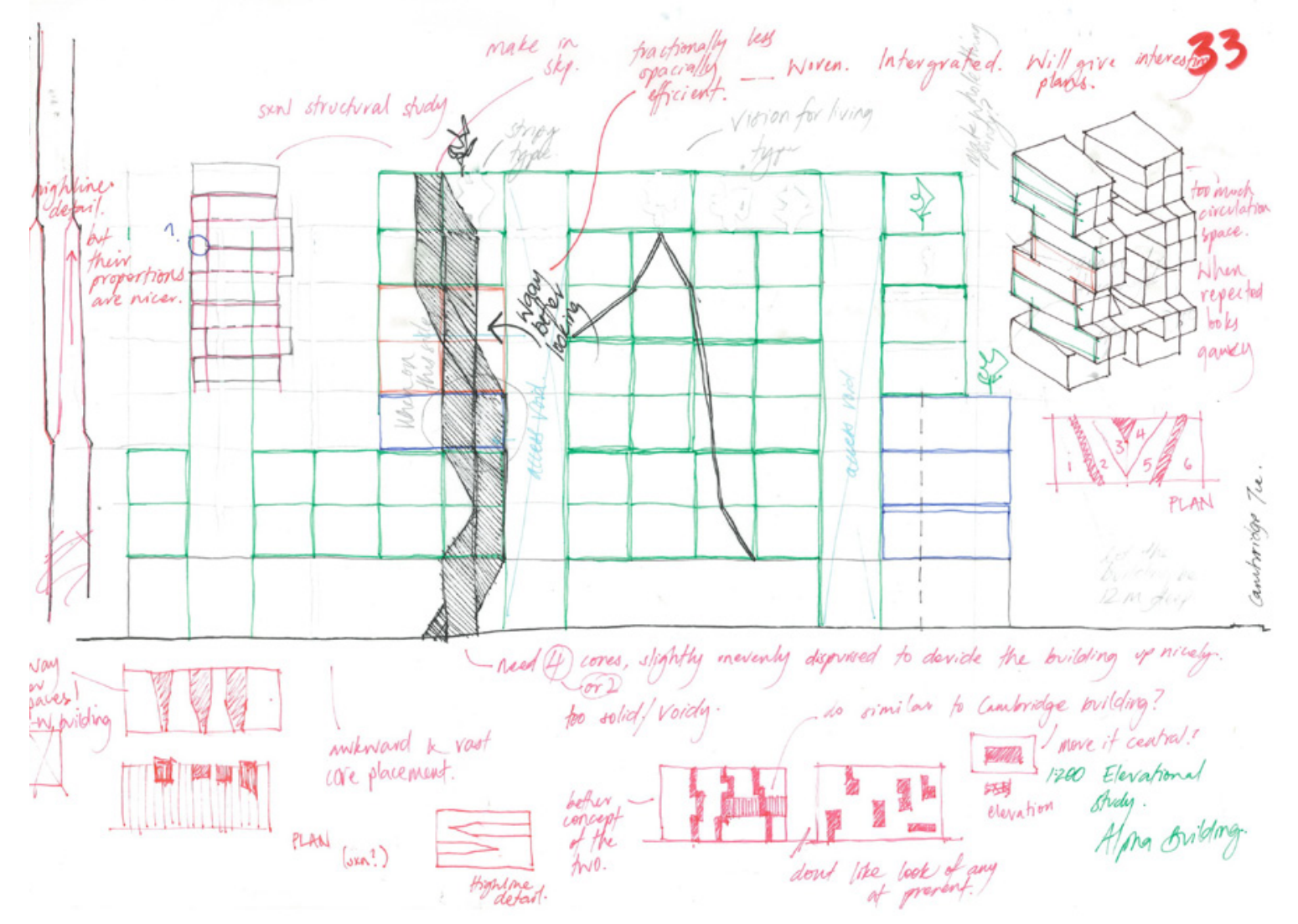


fire Rropramme Requirements.

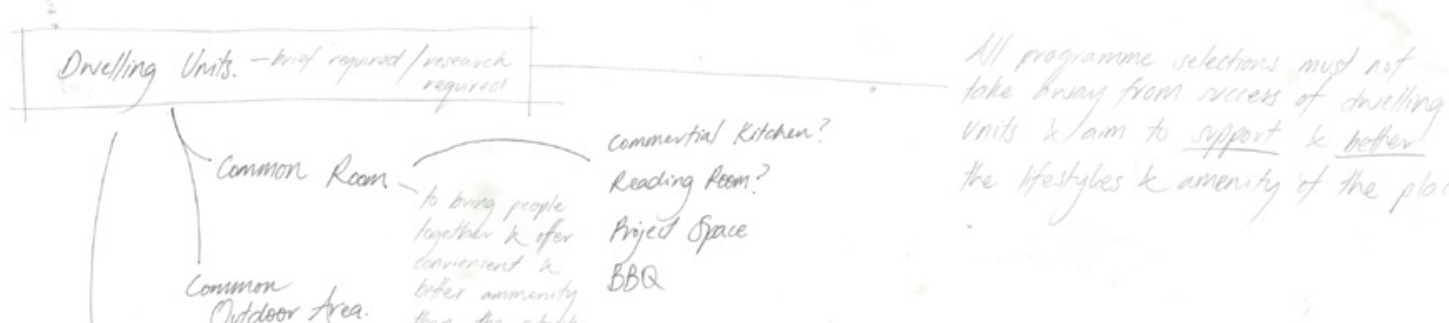

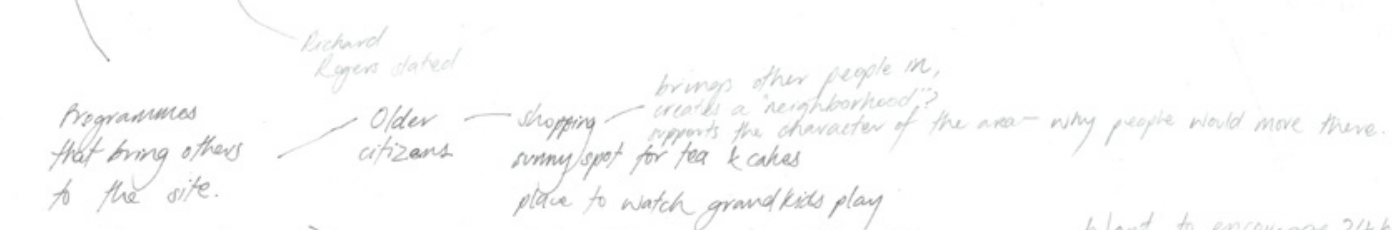

Nans to encourage 24 her prom

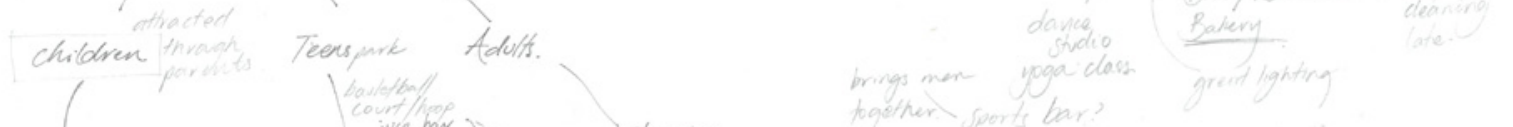

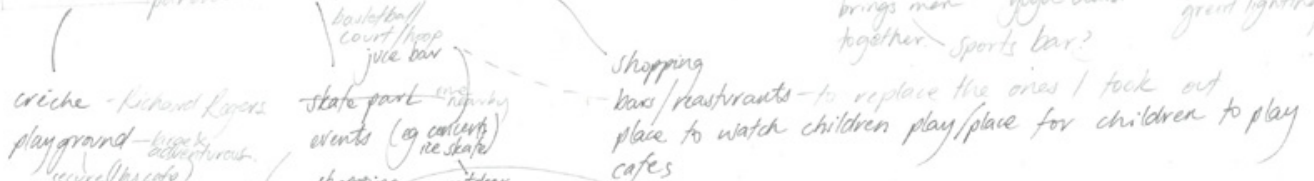

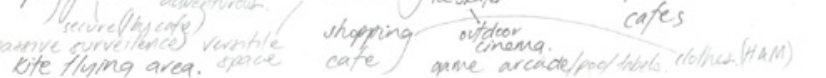

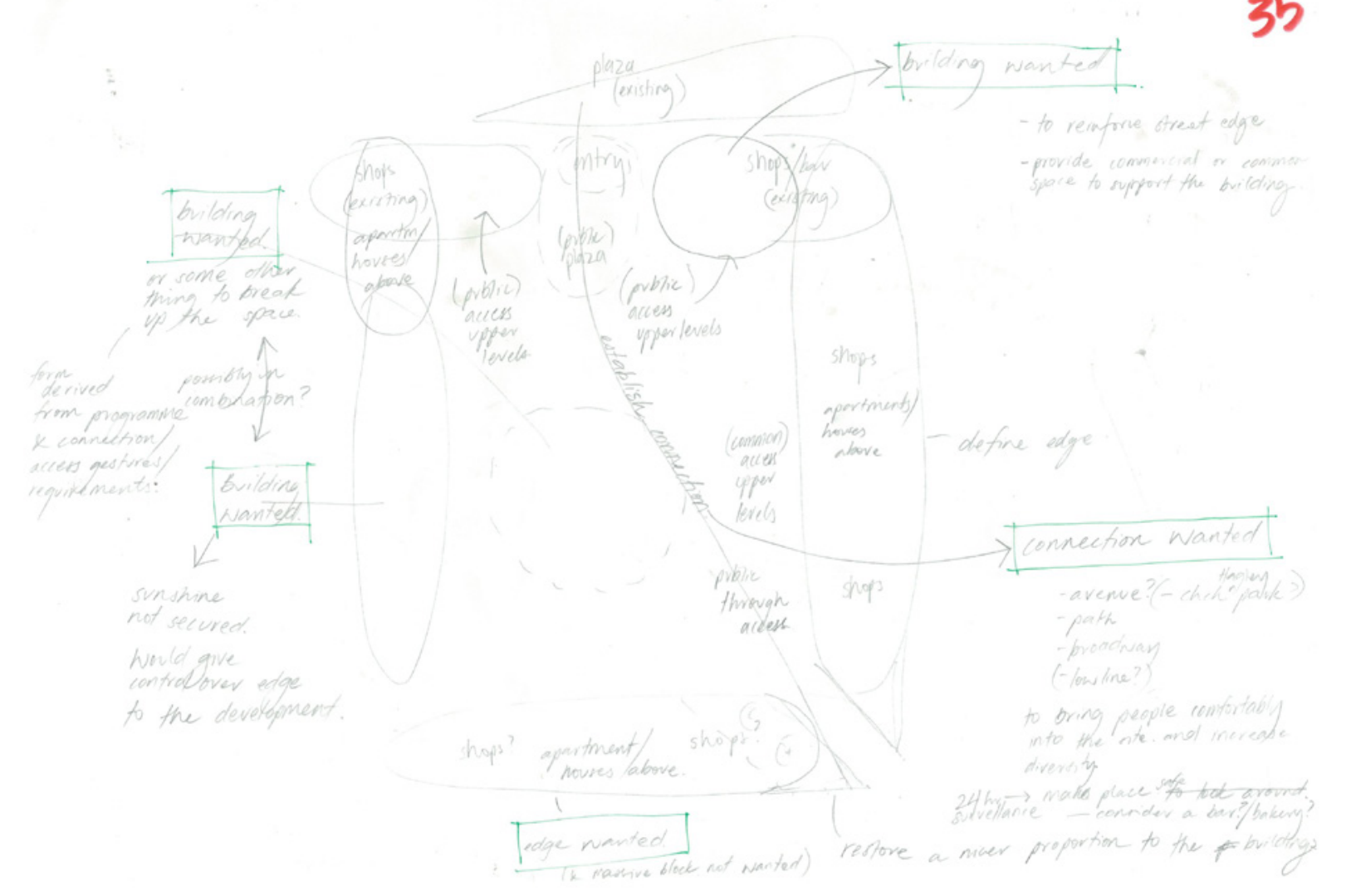

Figure A.52

Rogers' 'Towards

and Urban

Renaissance' and
looking to integrate

more site specific

programmatic
requirements

$\longleftarrow$

Figure A.51 Site

plan study looking
at the effect each

building/massing

move has on the
site master plan

$\longleftarrow$

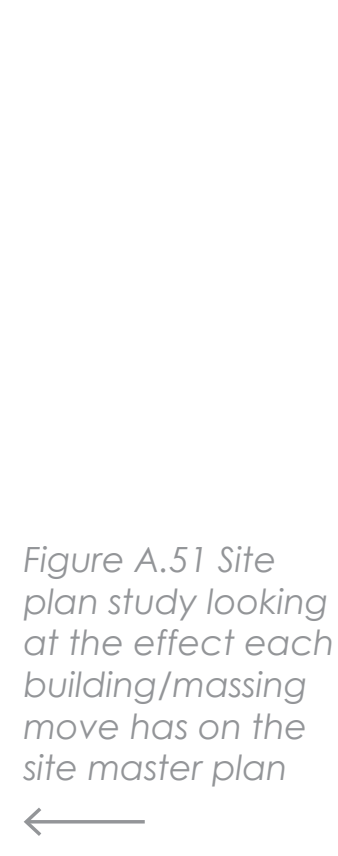

Figure A. 54
Breaking up

building masses'

site footprint to

make the site less

$\longrightarrow$

Figure A.53 A study to the site and

development

permeability
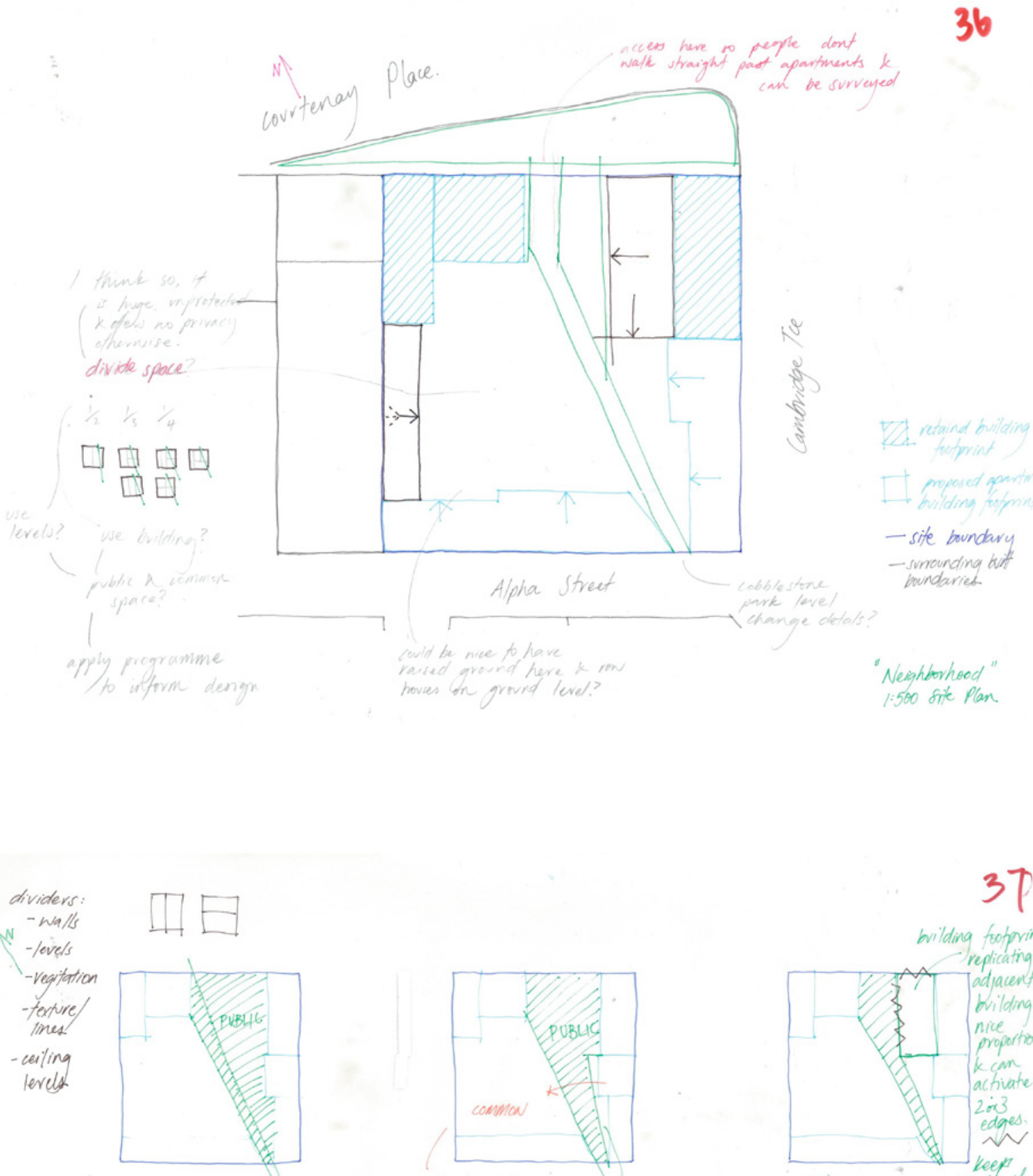

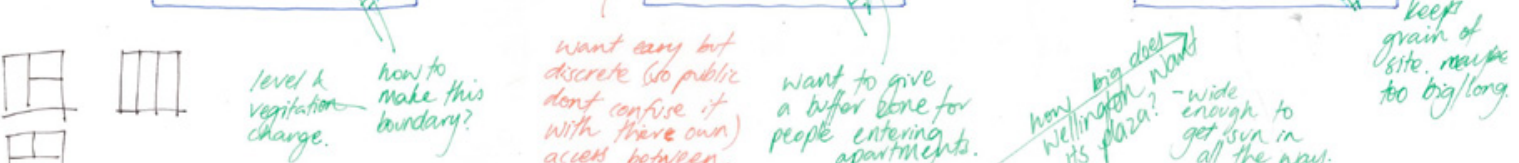
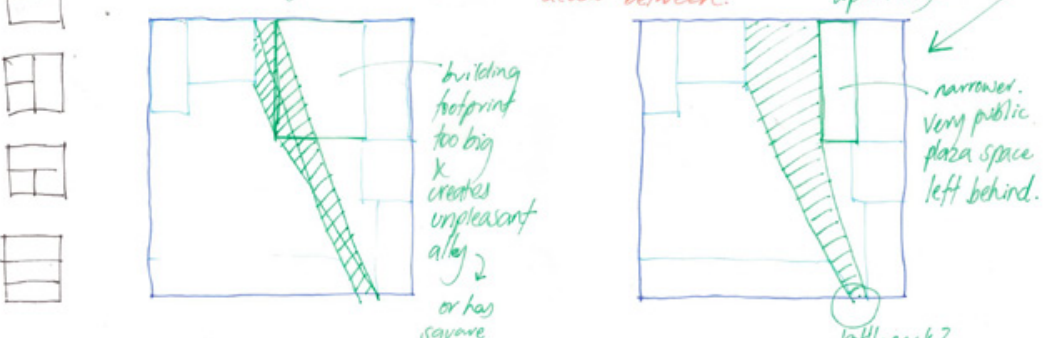

sovere

(a)

doe f hive this?

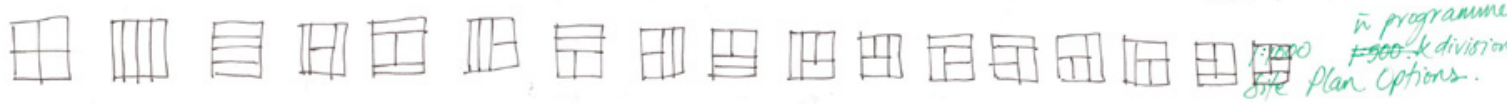



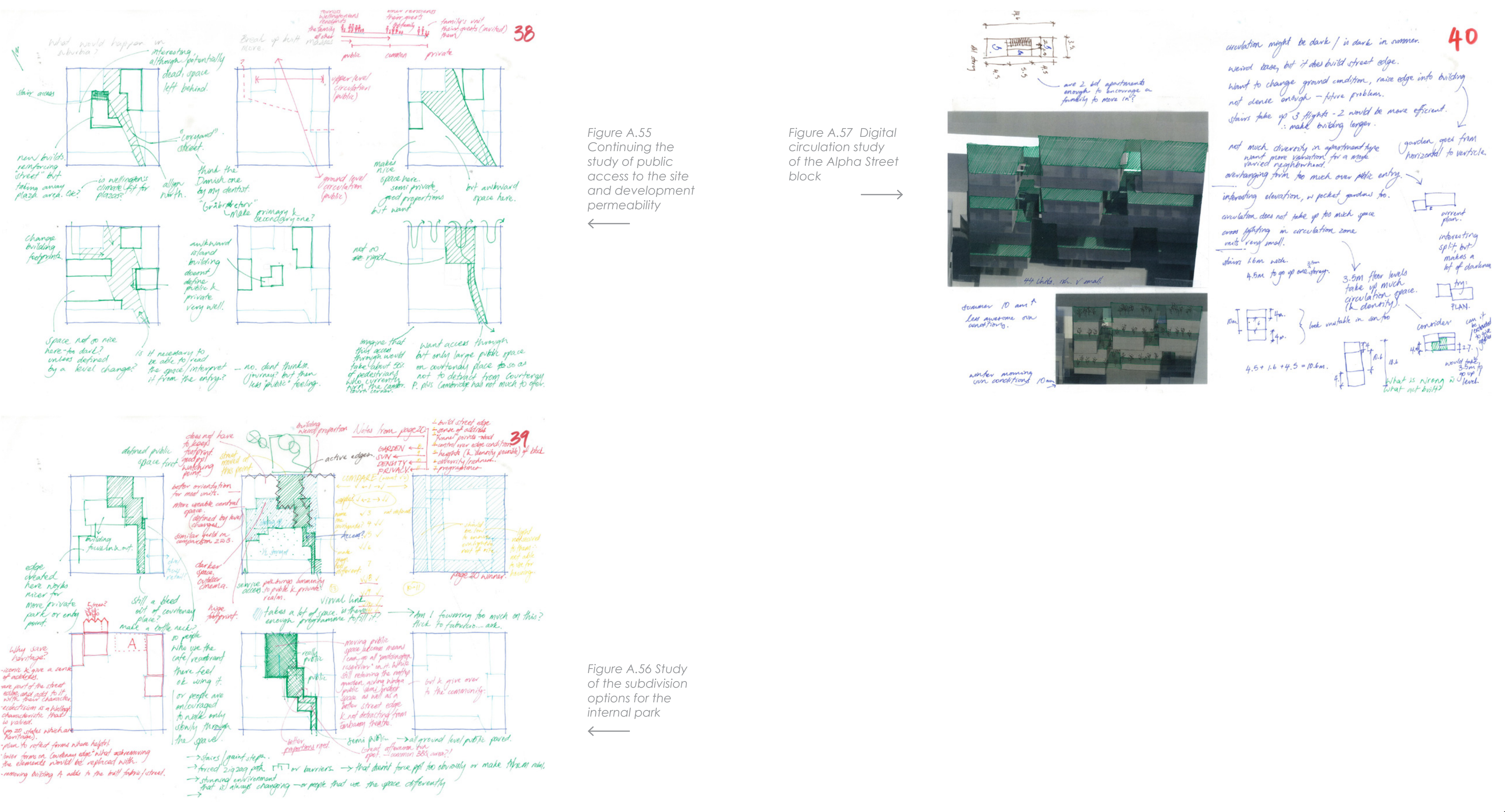


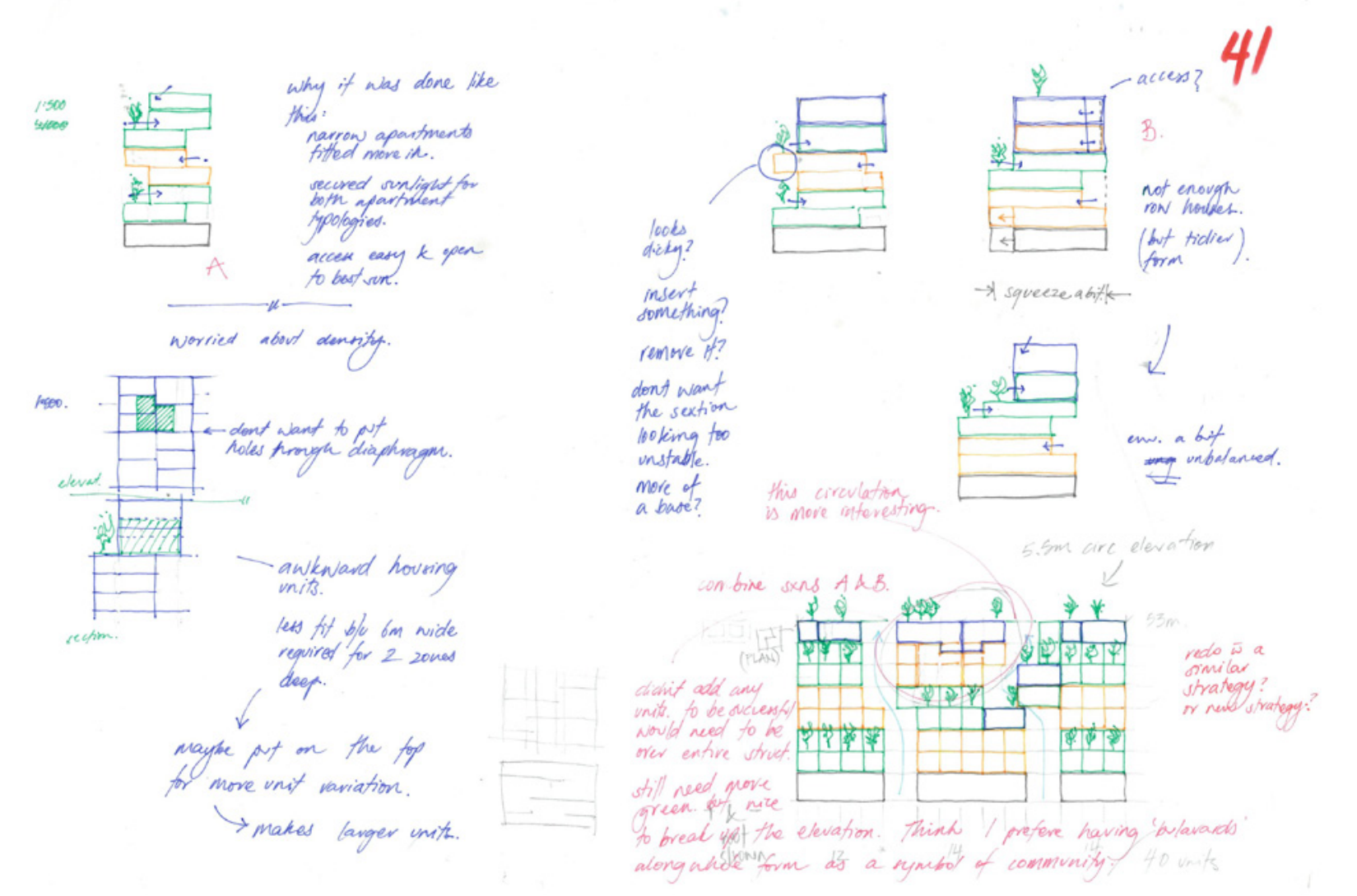

$\begin{array}{ll}\text { Figure A.58 Alpha } & \text { Figure A.60 } \\ \text { Street design } & \text { Cambridge } \\ \text { of vertical core } & \text { Terrace circulation } \\ \text { shapes } & \text { study and mass }\end{array}$

shapes

study and mass
model

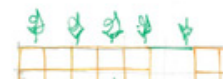

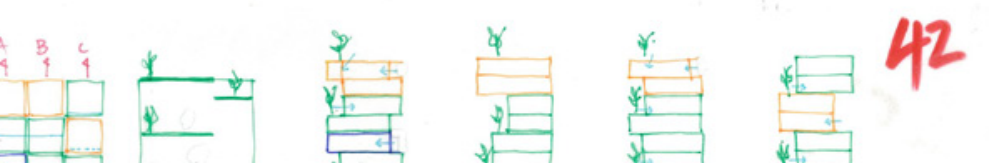

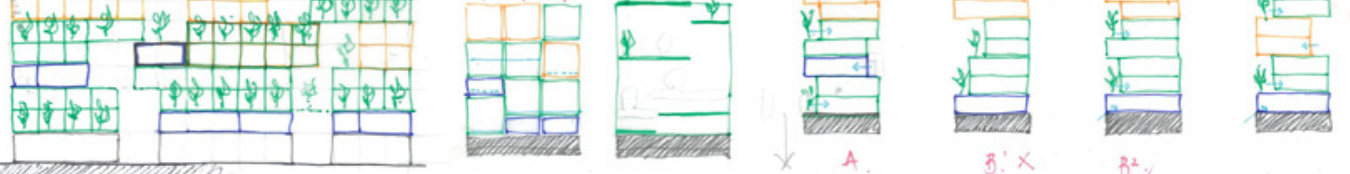

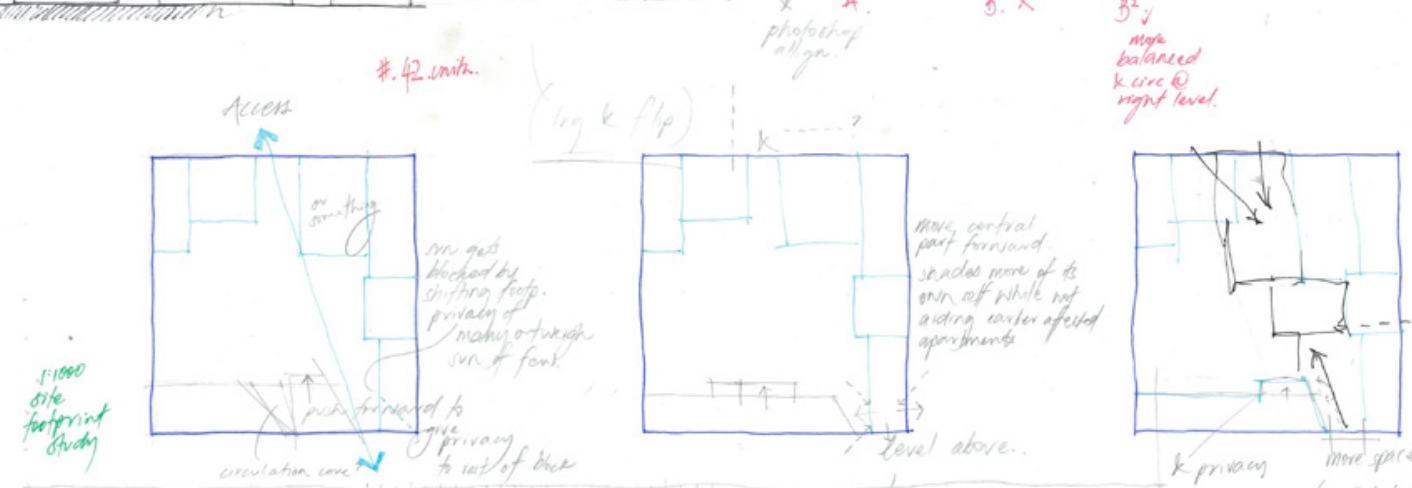

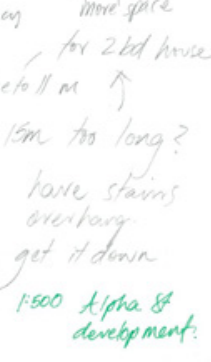

Figure A.59 Alpha Street building un
and site access $\stackrel{\text { study }}{\longleftarrow}$

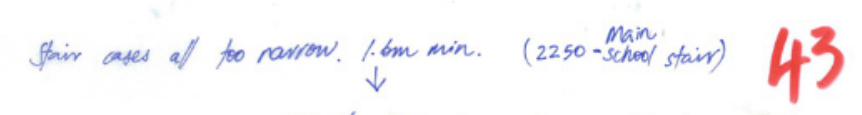

$$
\text { aim for } 2 m \text { so peope can stop a dicus/falle }
$$

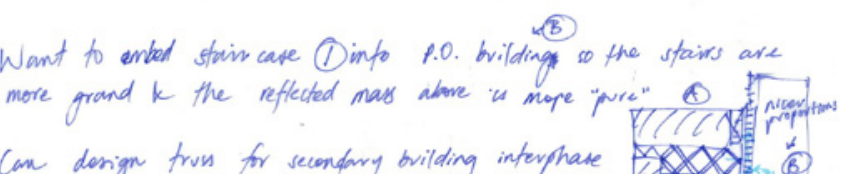

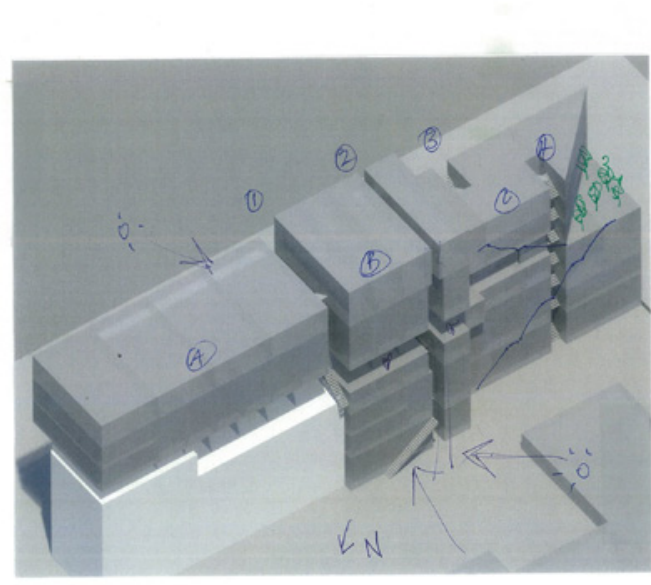

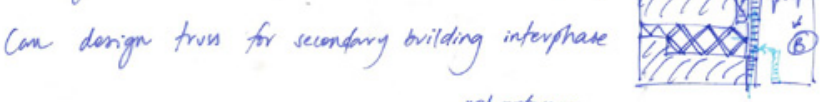

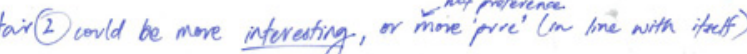

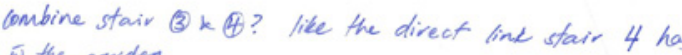

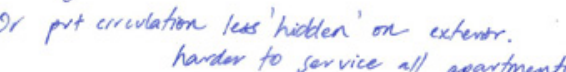

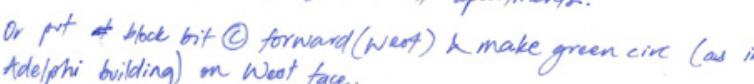

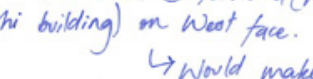

$$
\rightarrow \text { Wowld make less }
$$

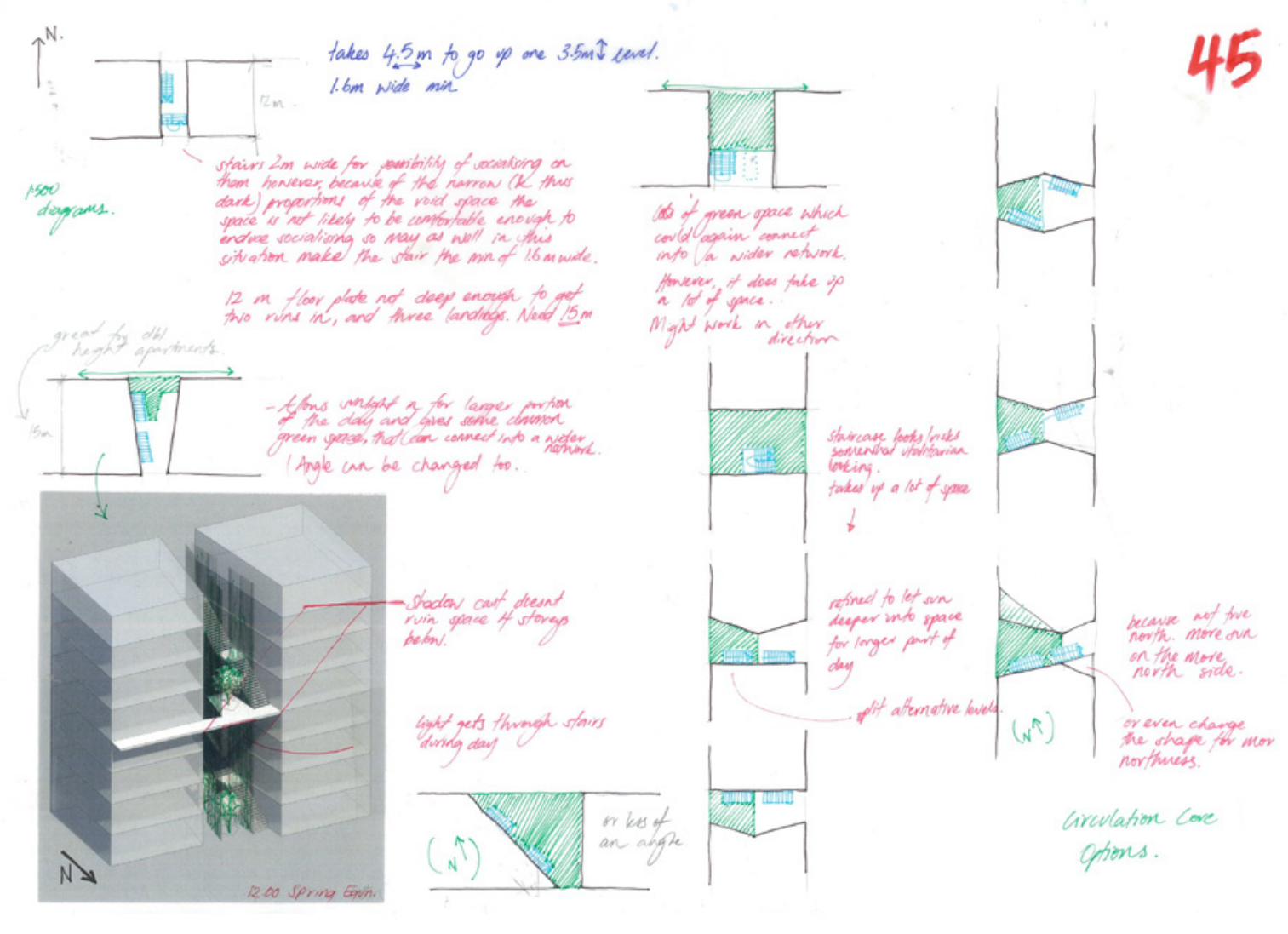




\section{4}

$$
\text { (2) }
$$

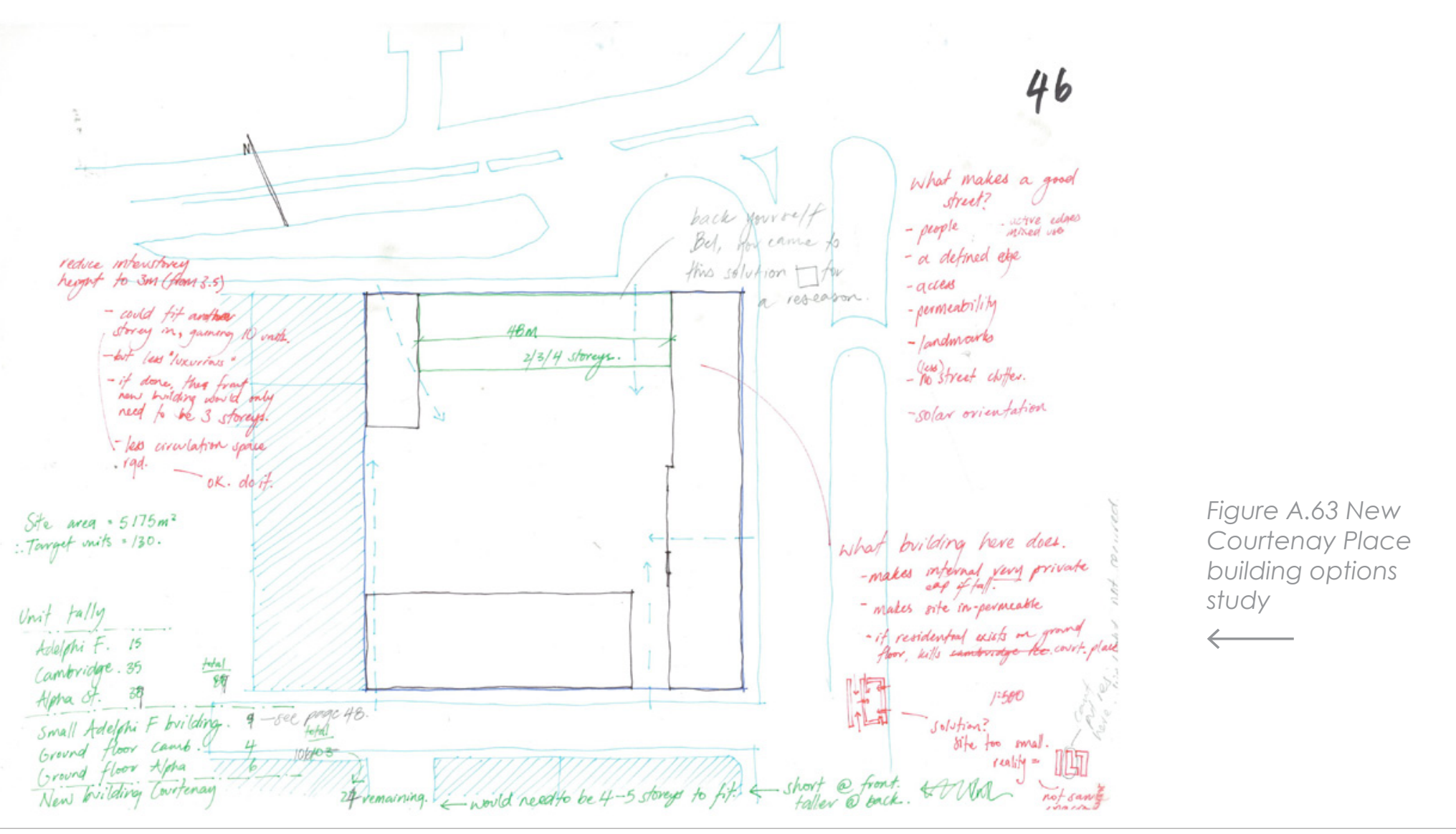

Figure A.62
Cambridge

Terrace individual

unit access studies

Figure A.64

Building tectonics

and unit stacking

$\longrightarrow$

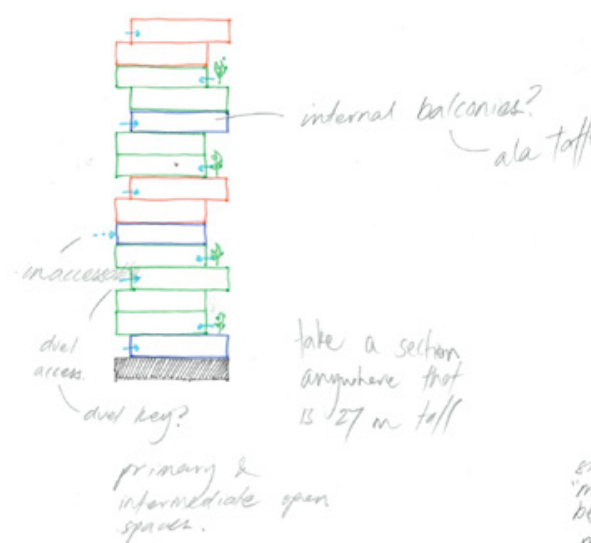

more bot

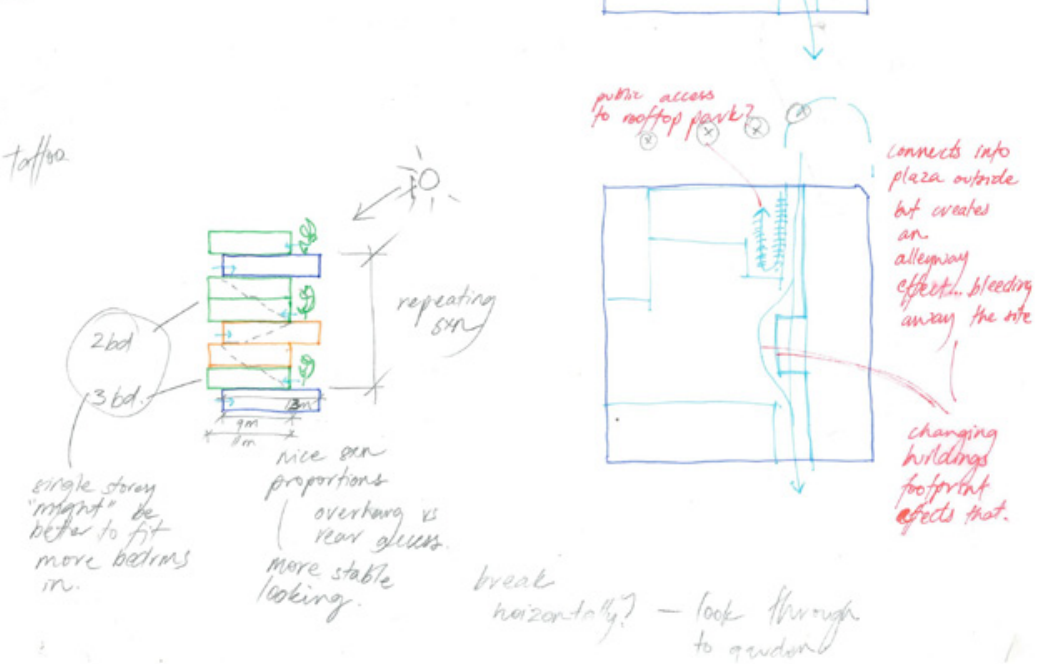


A.5.0 Design Test Five Research 


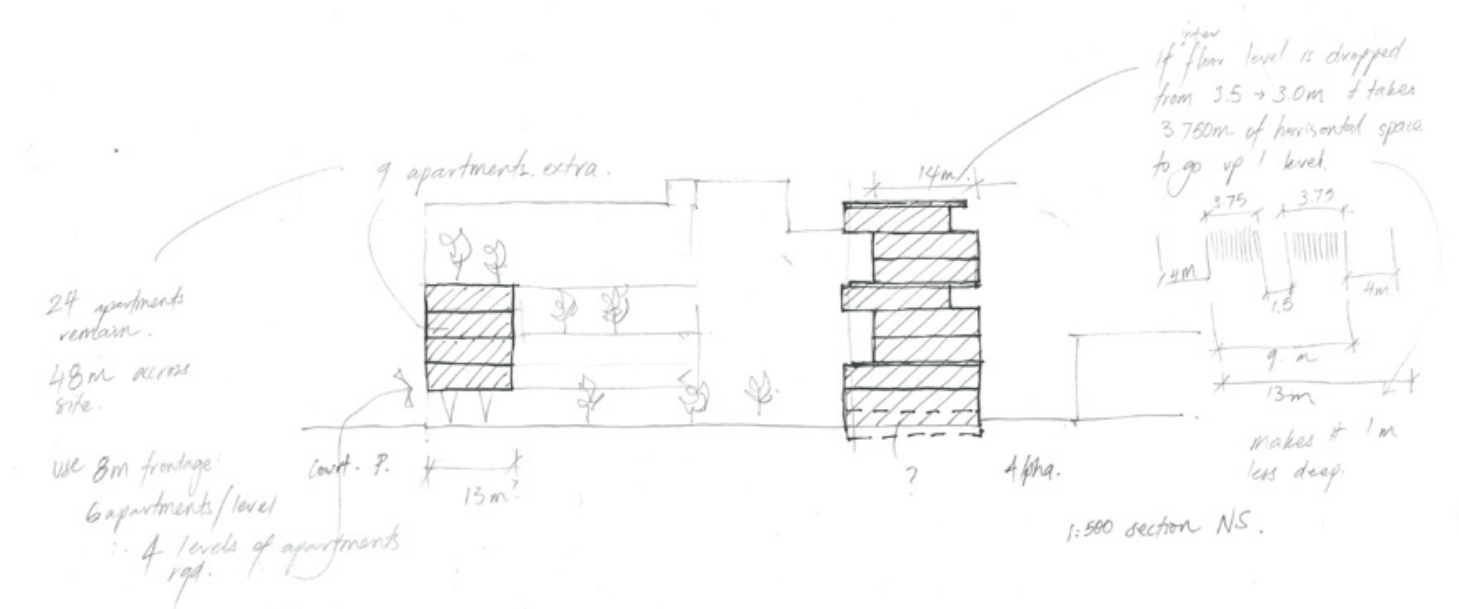

Figure A.65 Initial

new Courtenay

place building.

Discovered at this

point a shadow

plan will also be

the northern

intervention and

aid the decision

making process

Figure A.67 Option two; an elevated

building with visual

and physical

to internal public

courtyard public

$$
\longrightarrow
$$

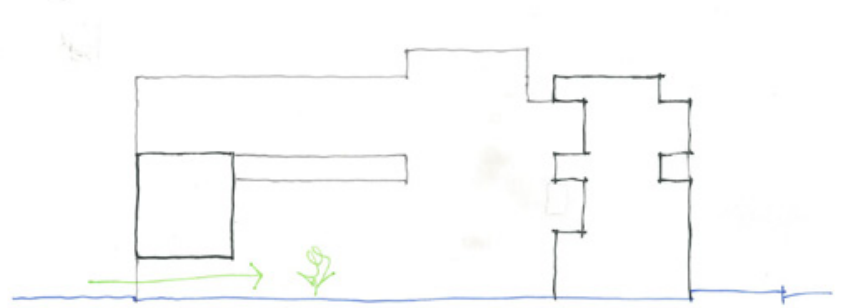

Slightly raised mast

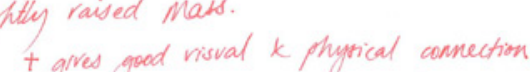

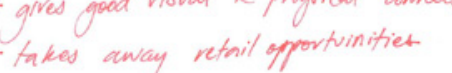

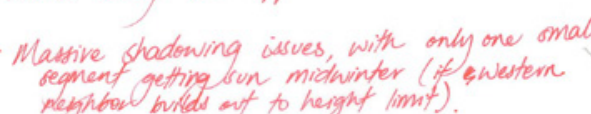

NoT Acetprate. - ether ground it (yq4)

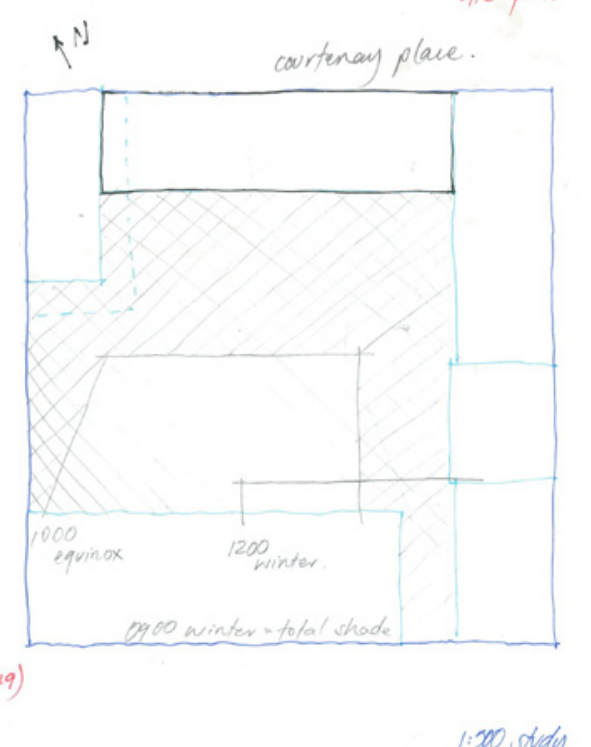

Figure A.68 Option

three; a split
building because

raising the mass by

one storey had a

significant negativ

effect on the

Figure A.66 Option

internal courtyard.

to bring more

winter sun into the

courtyard between

the building and

the ground plane

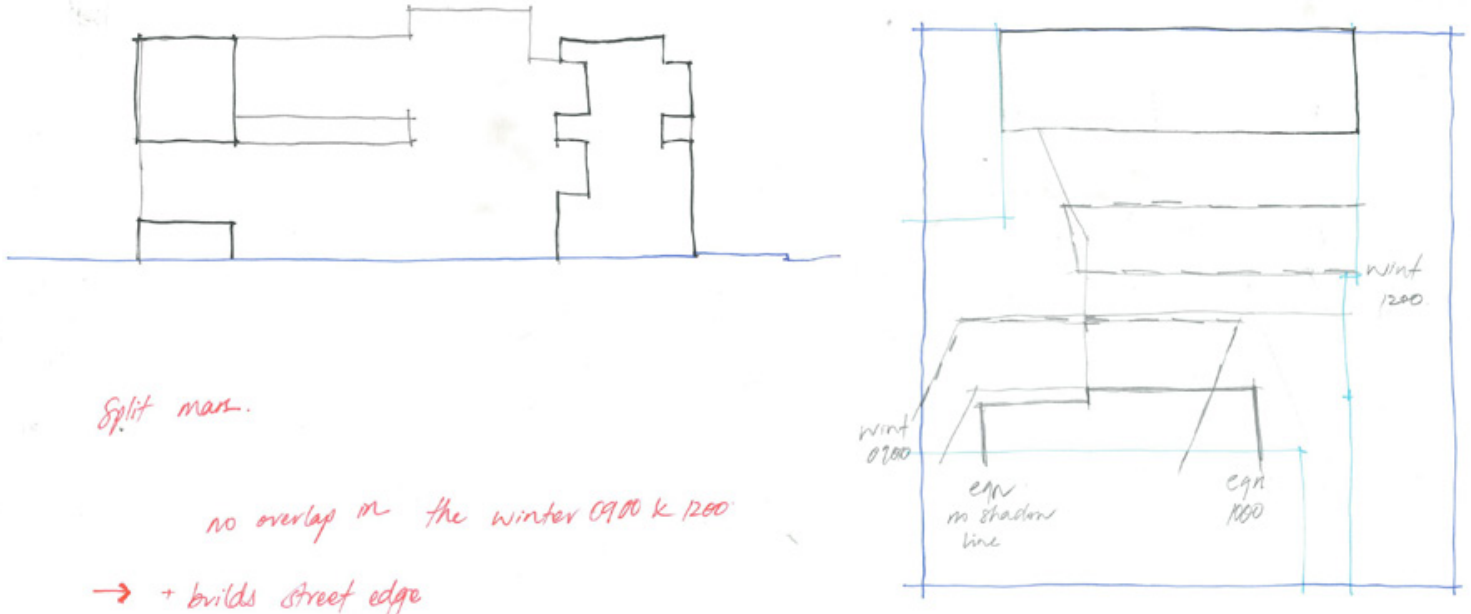

$\rightarrow+$ brilds struet edge

- loses aw weward

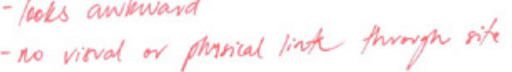

associated shado

$\longleftarrow$

$\longrightarrow$

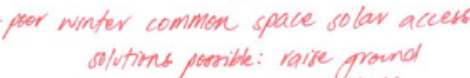




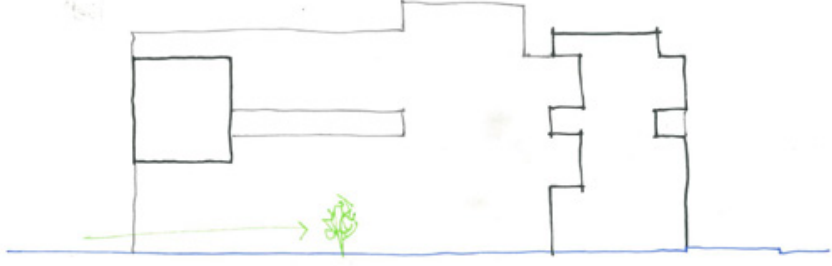

Mass Nell rased.

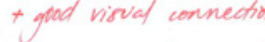

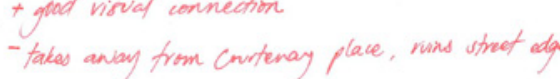

to very interating whadow pattorist

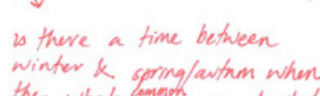

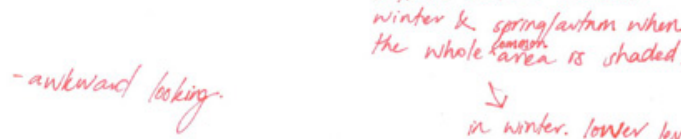

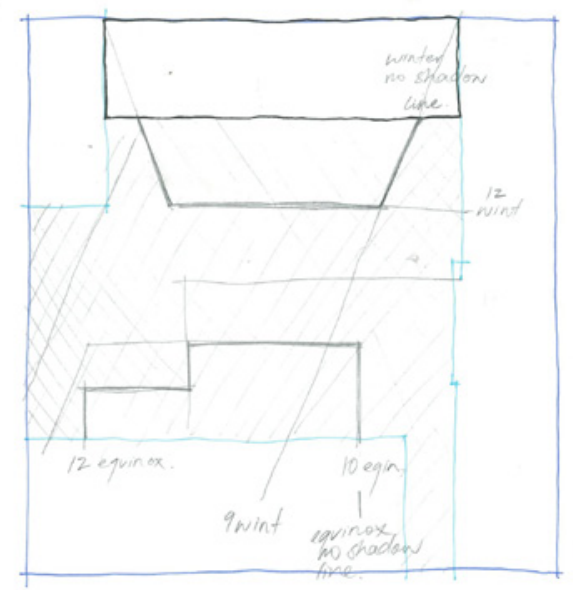

Conver level alphe apportiventis shadined al day:

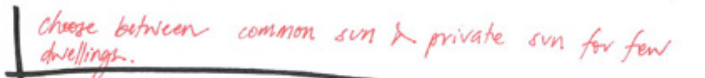

53

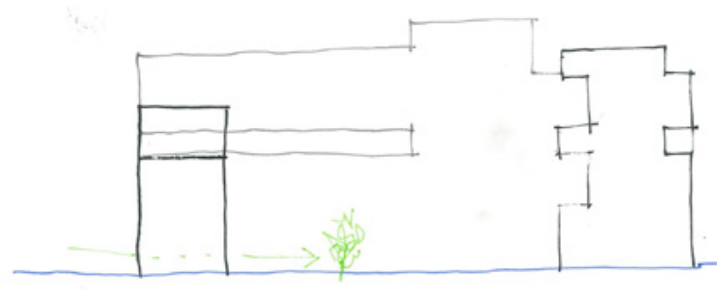

stepped Mass.

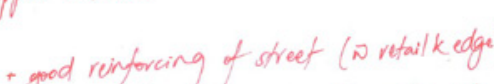

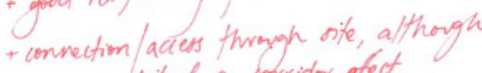

- Vern jor wintor sun performance.

$\rightarrow \rightarrow$ in refleding

- loots less suwhend.
Figure A.69 Option four; a raised four

to increase solar

coverage of

courtyard area in

winter
Figure A.70 Option five; a stepped mass, higher on

the eastern edge,

an area that has

the least effect on

the building's solar

$\longleftarrow$
Figure A.71 Studies on the building as

an object

$$
\text { What woubl make a grod front butlang: }
$$

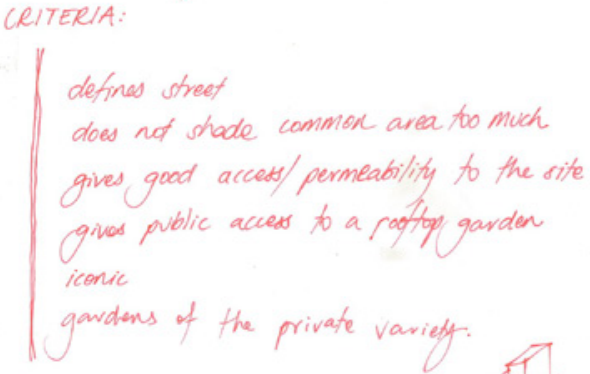

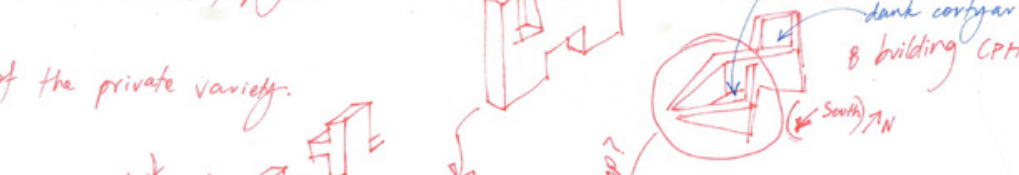

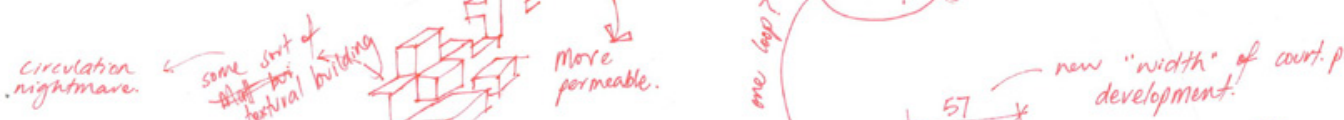

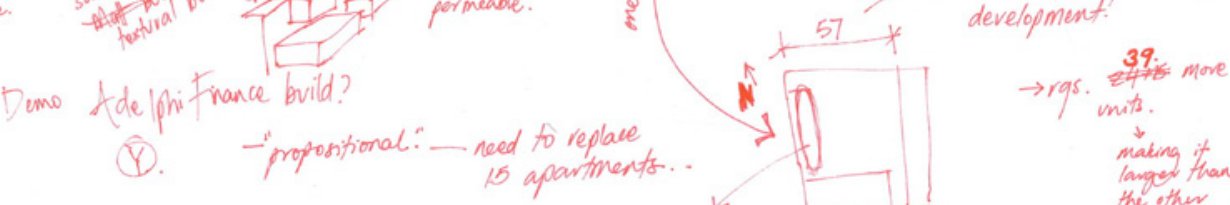

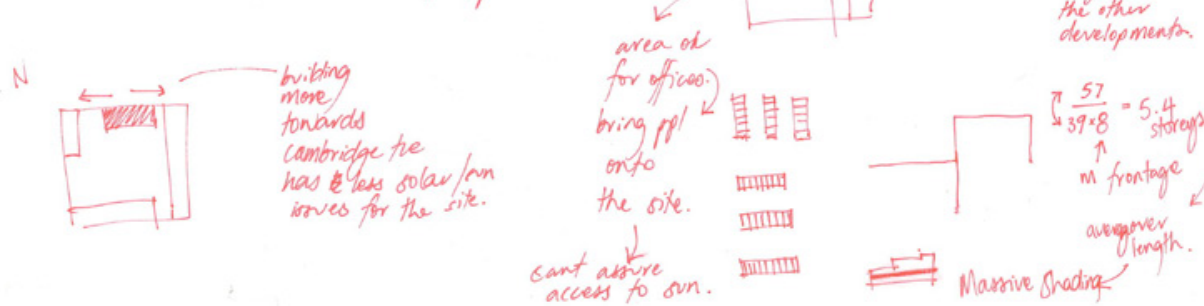

Figure A.72 Rough expect units to come from each targeted density will be met

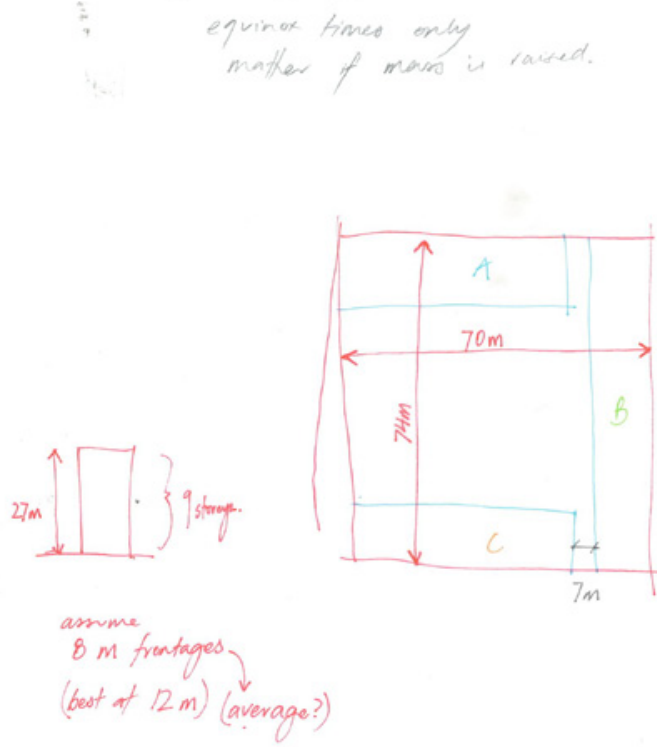

$A-18 \mathrm{~m} \mathrm{ded}$ (32) inits ored 5 im $30-45-55=30$ $\frac{3+30 \times 8 \times+2}{21}$ $($ bot ot $12 \mathrm{~m}$ ) (averag 

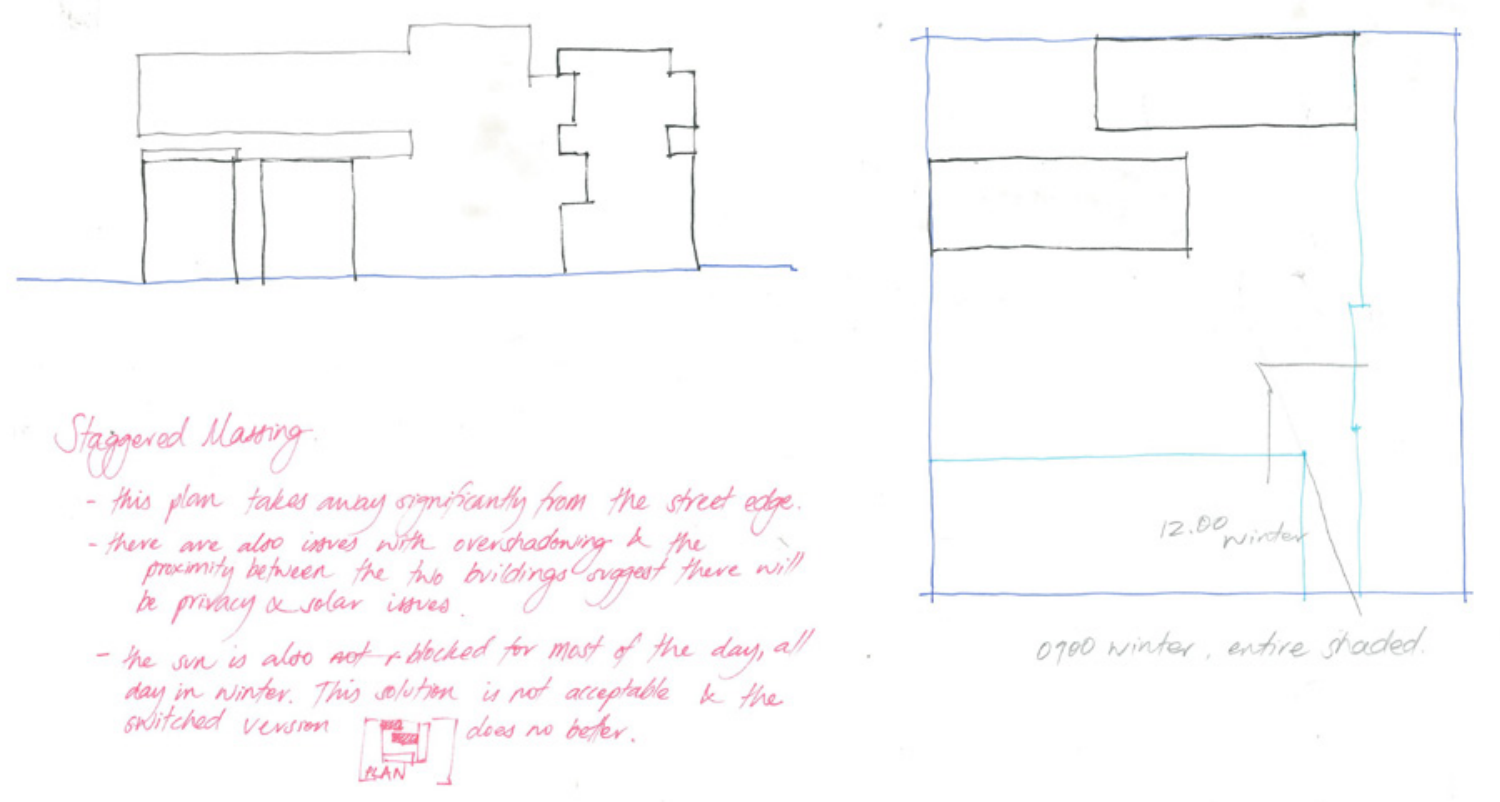

Detail Magazine, 2013 (nel/ow) "trampareent $5 \mathbf{8 0 .}$

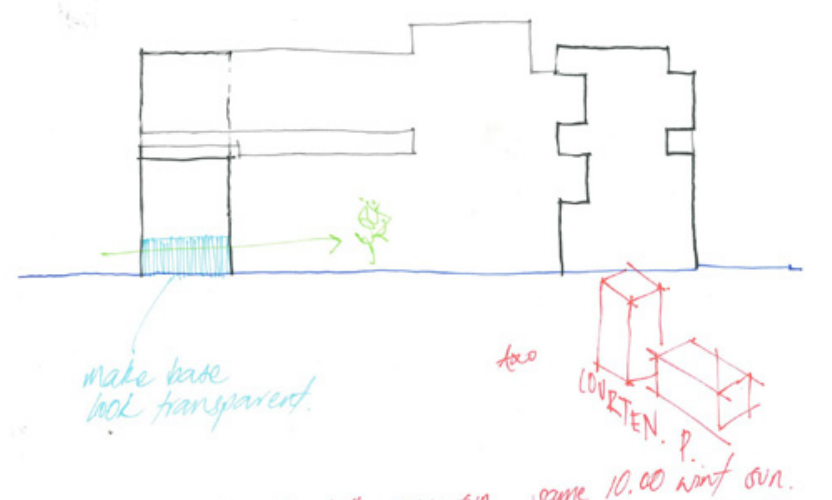

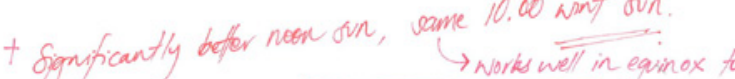

+ grod prinical a risual ank througa to intornal

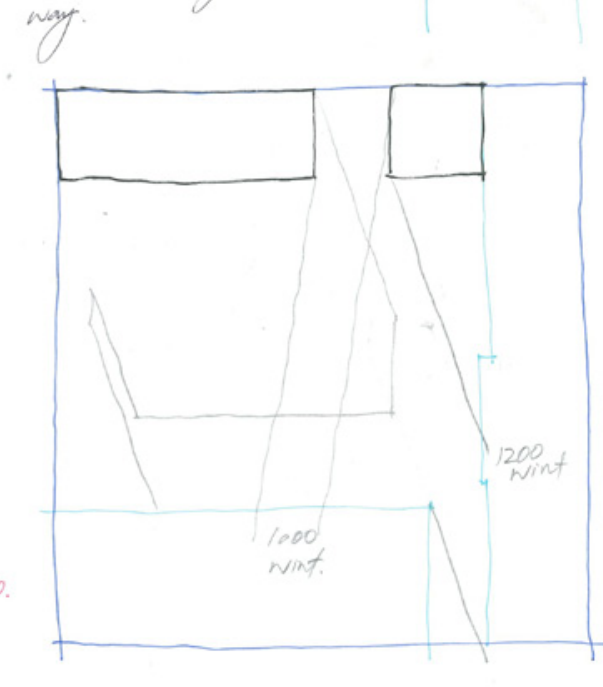

$$
\begin{aligned}
& \text { Ystill taper ages possitidy. } \\
& \text { follows b }
\end{aligned}
$$

Figure A.73

Option six;
staggered massing

experiment to

try and increase

building too high

$\longleftarrow$

Figure A.75 Option

seven, a four storey

visual and physical

access through

to internal public

couttyard

$\longrightarrow$

Figure A.74 Option

eight, a four storey

visual access

though to interna

courtyard with a

taller tower closer

to Cambridge

$\longleftarrow$

Figure A.76 Option

nine; building on
from option eight.

but altering the

articulation of the

corners to allow

more sunlight into

the courtyard

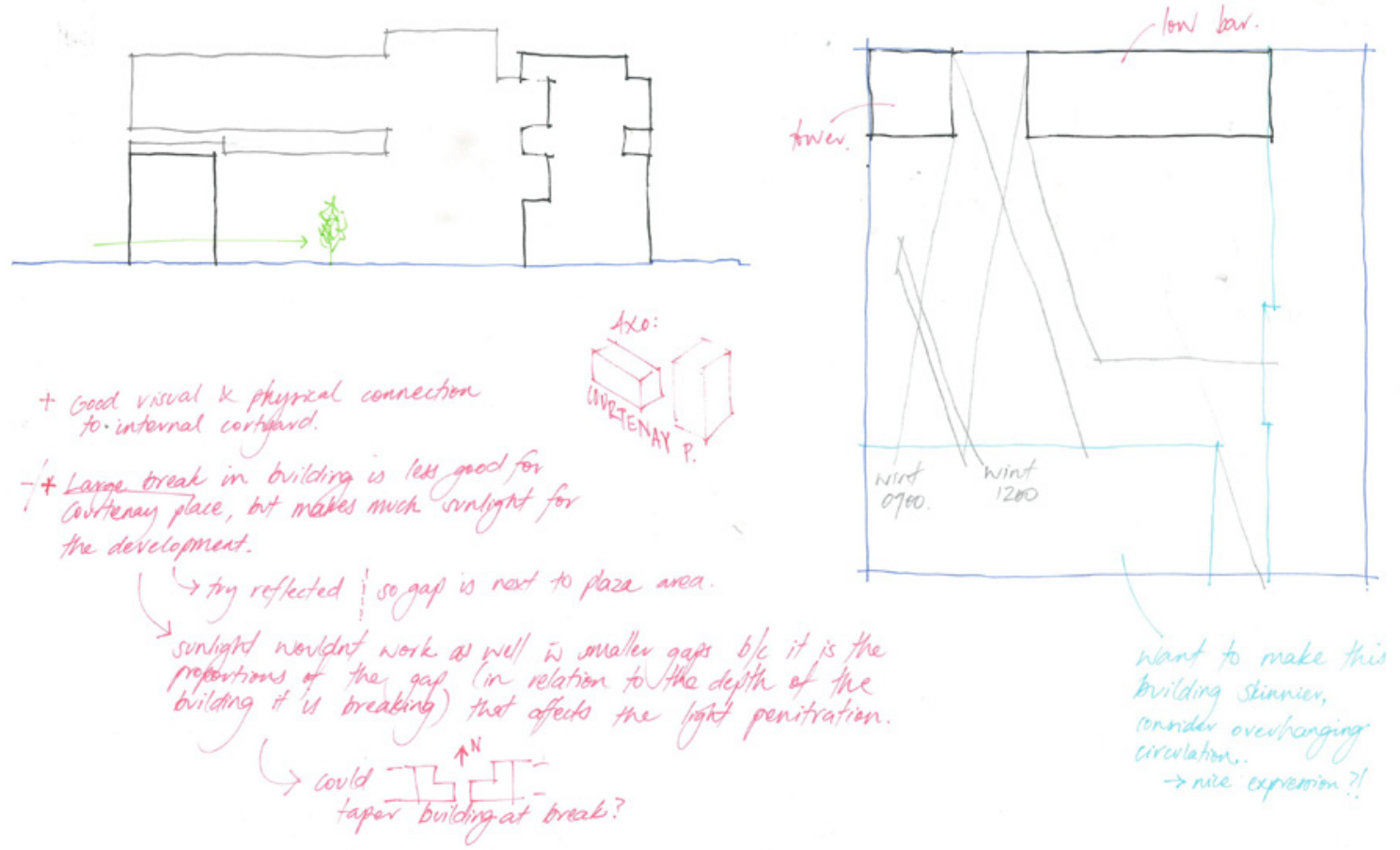

59.

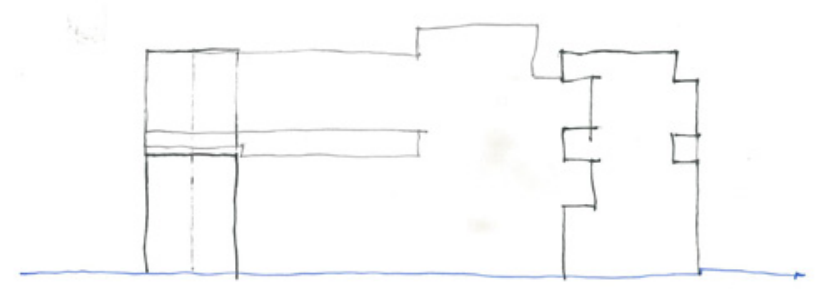




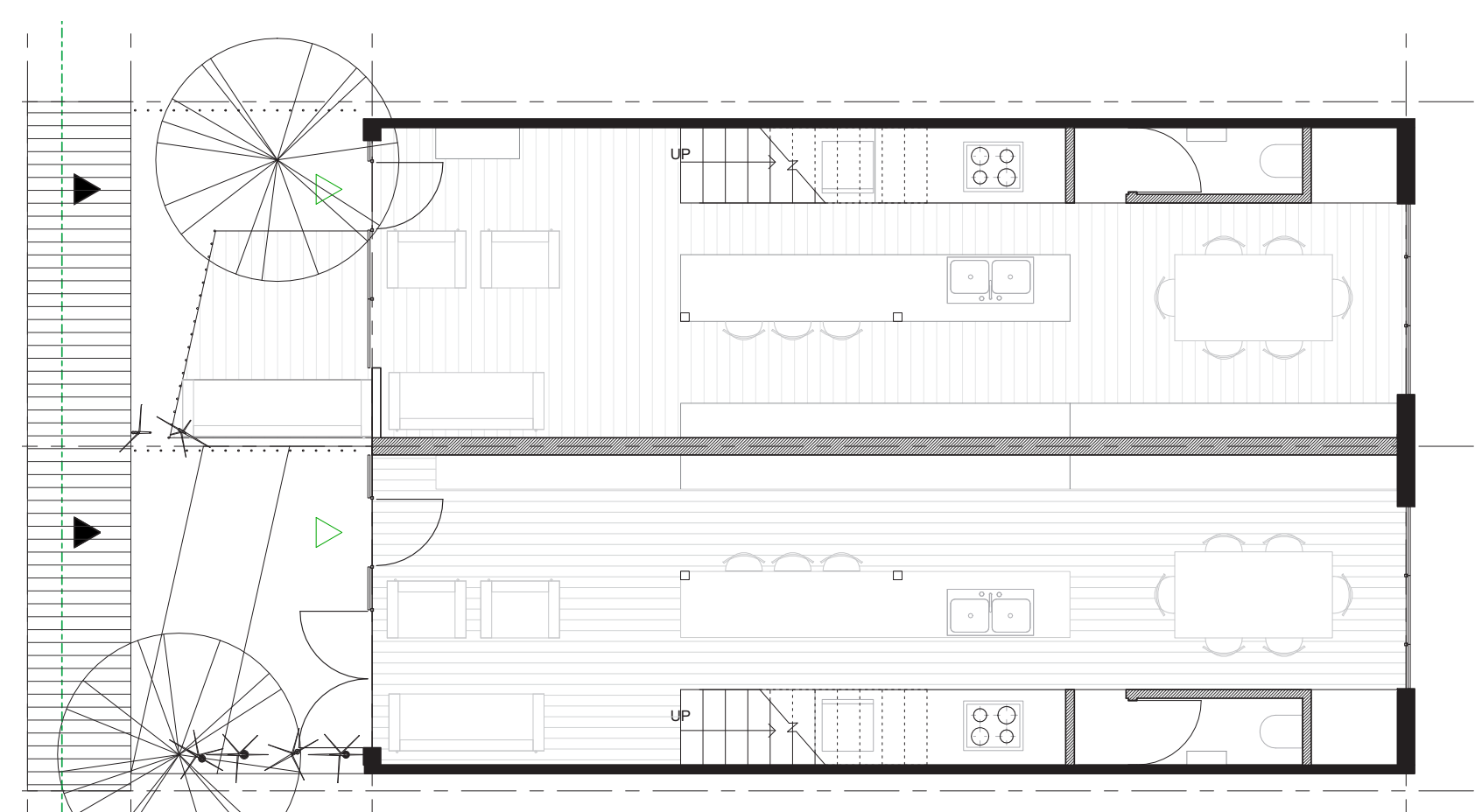

(1) $1: 00$

EAST WEST ASPECT ORIENTATION Terrace House Types
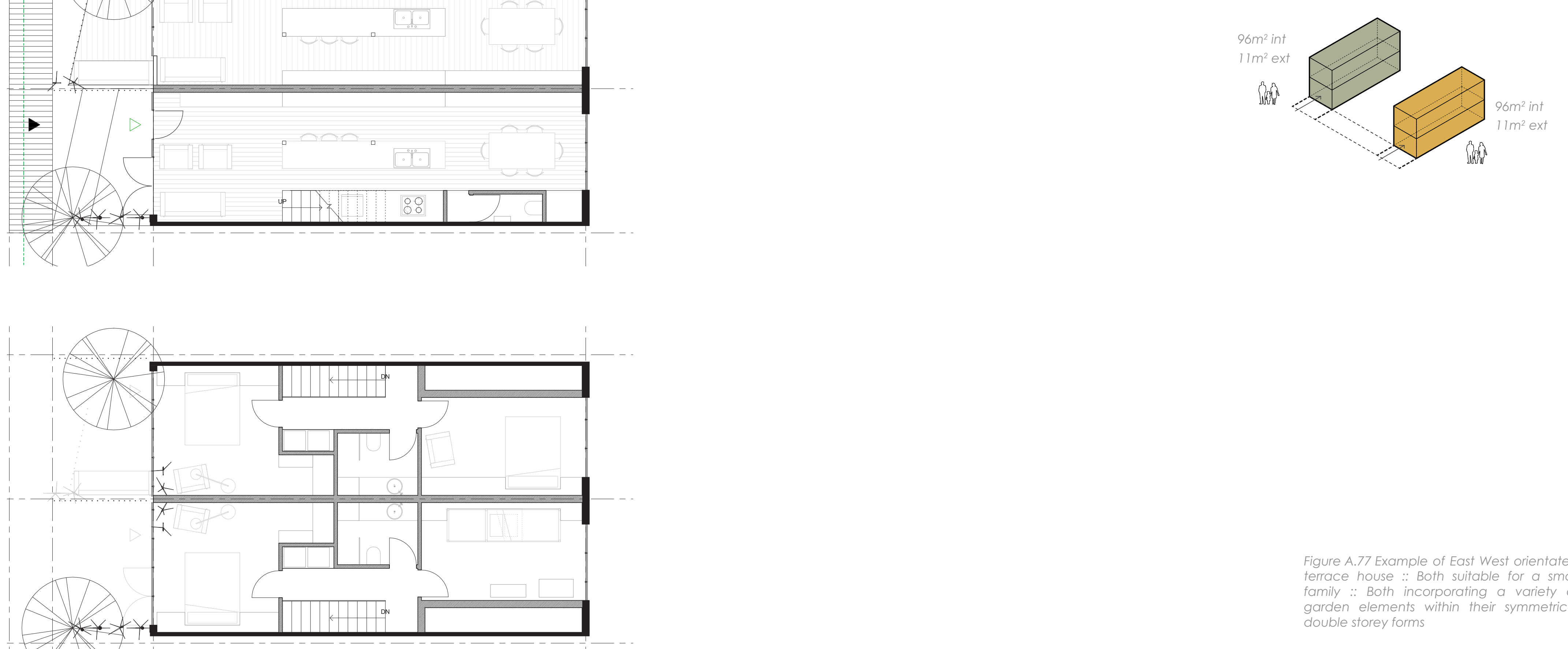

Figure A.77 Example of East West orientated terrace house ". Both suitable for a small amily :: Both incorporating a variety of double storey forms 

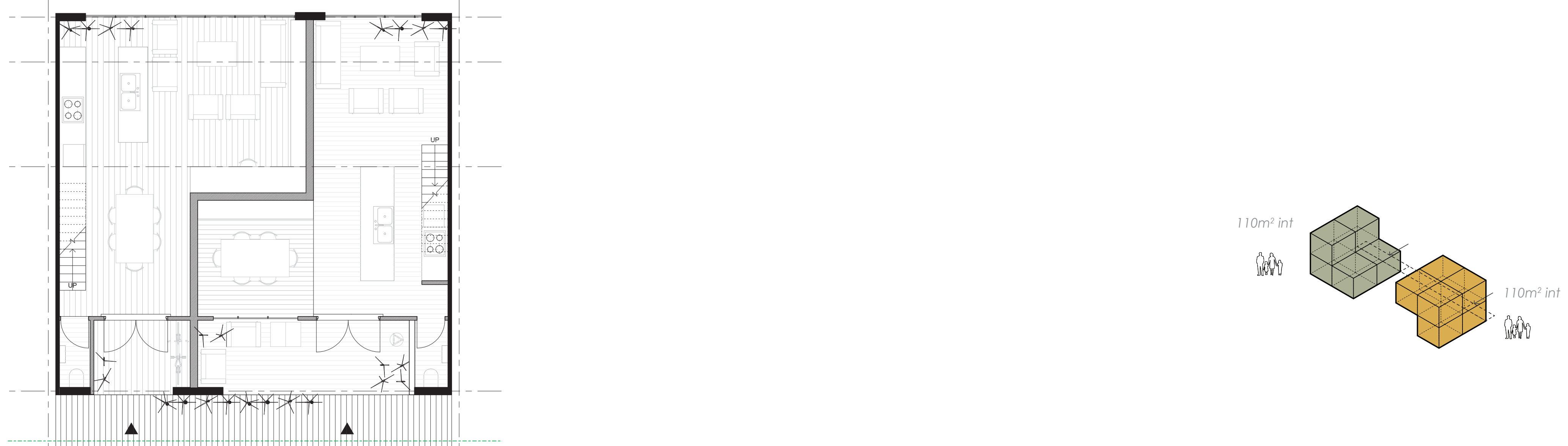

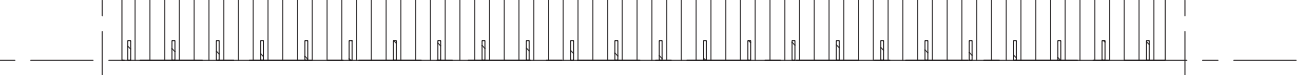

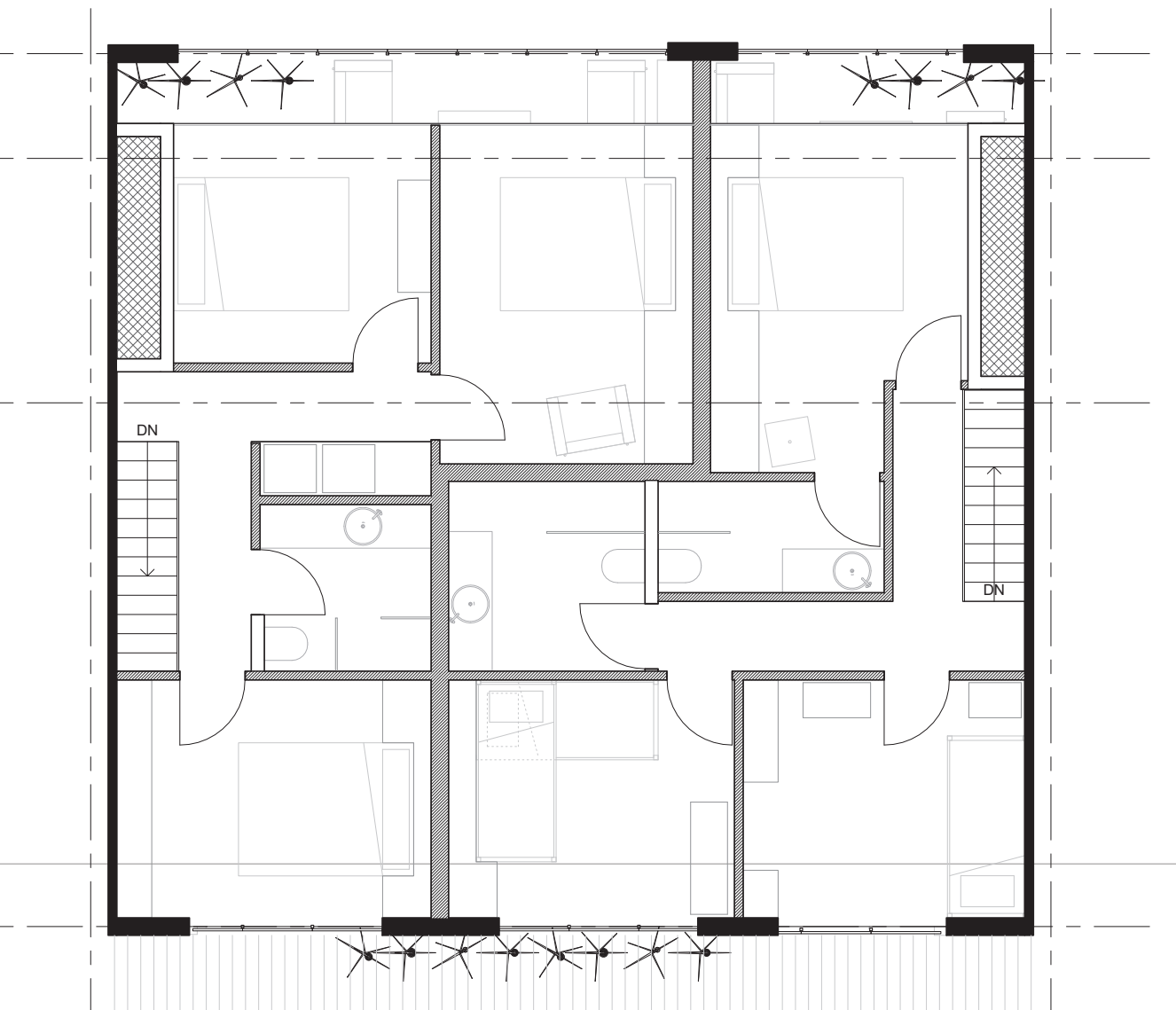

Figure A.78 Example of North South arge families :: Both incorporating garden within their interlocking forms 
Architecture is not so much a knowledge of form, but a form of knowledge

-Bernard Tschumi 